\title{
ESTUDIO DEL IMPACTO ECONOMICO DE DIVERSAS \\ SOLUCIONES AL PROBLEMA DEL LACTOSUERO \\ GENERADO POR LA INDUSTRIA QUESERA
}

\author{
TESIS QUE PRESENTA \\ RODOLFO TREJO VAZQUEZ \\ PARA LA OBTENCION DEL GRADO DE \\ DOCTOR EN CIENCIAS \\ Junio de 1996
}

UNIVERSIDAD AUTONOMA METROPOLITANA

DIVISION DE CIENCIAS BASICAS E INGENIERIA 


\section{AGRADECIMIENTOS}

Agradezco a mi Dios Todopoderoso, el haberme permitido vivir para alcanzar la meta de ser Doctor en Ingenieria Química, así como el haberme dado la fuerza. el coraje y la inteligencia necesarios para ello.

Agradezco y dedico este trabajo a mi esposa Ada Adela, por haberme apoyado ilimitadamente durante el tiempo que duró este proyecto. Igualmente a mis hijos, Alejandra y Rodolfo, para quienes deseo que sirva de testimonio en favor de la idea de que la perseverancia es un arma inuy poderosa para lograr lo que queremos en la vida

Agradezco muy sinceramente a mis asesores y amicos, los Doctores Sergio Revah Moiseev y Arturo Jiménez Gutiérrez, por todo lo que aportaron a este trabajo y a mi vida personal.

Dedico también este trabajo al MC. Francisco Pablo Ramirez Garcia, quien contribuyó de manera desinteresada y muy importante al mismo.

Por lo mucho que han significado en mi vida profesional dedico este trabajo al Grupo de Ingenieria Química del Instituto Tecnológico de Celaya.

Agradezco muy cuplidamente a los Doctores Felipe López y Tomás Viveros, el haber contribuido significativamente a mejorar la calidad de este trabajo.

Muchas gracias también a todos los expertos consultados, sin cuya guia no hubiera podido concluírse esta tesis.

RODOLFO TREJO V. 
INDICE

RESUMEN

pagina

CAPITULO 1. INTRODI CCION Y UBIEIIVO GENERAL

1

CAPITULO 2. PANORAMA GENERAL EN TORNO AL LACTOSUERO

CAPITULO 3. CONCEPTUALIZACION DEL PROBLEMA

32

CAPITULO 4. DESARROLLO DESDE EL PRIMER PUNTO DE VISTA

40

CAPITULO 5. DESARROLLO DESIDE LL SEGUNDO PUNTO DE VISTA

63

CAPITULO 6. CONCLUSIONES Y RECOMENDACIONES

85

CAPITHLO 7. BIBLIOGRAFIA

88

A MENDICE A. LISTADO DEL SIMULADOR DI PROCESOS EMPI EADO EN EL CAMTULO 4

101

APENDICE B. RESULTADOS DE LAS CORRIDAS DEL SIMULADOR DEL APENDICE A

127

APENDICE C. LIST ADO DEL SIMULADOR EMPLEADO EN

EL CAPIILUO 5

152

APINDICE D. ESTRUCTLRA DL LA LECHE Y DESCRIPCIUN

DEL PROCISOQUESEROTRADICIONAL

157

APENDICE E. ASIGNACION DE ALGUNOS COSTOS RELACIONADOS

CON LA OPERACION DE ULTRAFILTRACION

161

APENDICE F. RESULTADOS DE LAS CORRIDAS DEL SIMULADOR

DEL APENDICE C

177 


\section{RESUMEN}

Para no causar daño al medio ambiente, un desecho puede ser prevenido (procurando evitar su aparición), procesado hacia productos de valor o dispuesto mediante un tratamiento final. En la industria quesera esta última alternativa se ha adoptado con mucho mayor frecuencia que las otras dos, constituyendo un impacto nocivo importante para su economía y crecimiento. El presente estudio es un análisis referido al año 1993 de las posibilidades que la industria quesera mexicana tiene de recurrir competitivamente a las dos primeras alternativas mencionadas, con relación al lactosuero, que es la corriente principal de desecho de esta industria.

Considerando la primera opción (prevención) se realizó la evaluación económica de una tecnologia limpia para la industria quesera, obtenida por modificación del proceso quesero tradicional incluyendo en éste una etapa de concentración de leche por ultrafiltración y optativamente, adición de caseína. Se determinaron los límites y condiciones de aplicabilidad para esta tecnología limpia y se obtuvieron mediante un simulador desarrollado para el efecto, las ventajas o desventajas económicas de la reconversión en función de la escala (entre 5,000 y $100,000 \mathrm{~kg} /$ dia de leche fresca) para los casos con y sin adición de caseína. Los prospectos ensayados se jerarquizaron en orden de conveniencia económica para la reconversión y se identificó a los quesos crema, ricotta y queso fresco, como los más prometedores; cuyas condiciones de operación correspondientes también fueron determinadas para los casos con y sin adición de caseína. Las condiciones de rentabilidad de estos quesos selectos se ubicaron bastante arriba del criterio de rentabilidad mínima atractiva que se utilizó; especialmente a altas escalas de proceso.

Las inversiones requeridas calculadas fueron reducidas a un conjunto de ecuaciones empíricas sencillas y se estudió para el queso crema, tomado como caso ejemplo en esta metodología, la sensibilidad de la ventaja económica relativa del proceso reconvertido ante parámetros relevantes como precio del queso, precio del permeato, costo de disposición de efluentes y demanda de permeato y lactosuero, lo cual permitió establecer la importancia relativa entre estos parámetros. Este peso relativo se representó frente a la escala de proceso encontrándose que los mayores factores de peso corresponden a la demanda de lactosuero y el precio de productos, y que la adición de caseína tiene un efecto marginal sobre estos pesos relativos.

En cuanto a la segunda opción, se tomó como punto de partida que el lactosuero ya existia y se consideró como solución el procesamiento de éste hacia productos de valor en el mercado. 15 productos y 31 procesos diferentes que pueden incluír operaciones de deshidratación, desproteinado, hidrólisis, desmineralización y delactosado son estudiados mediante simulación, determinando las condiciones de costo mínimo de producción y a partir de éstas, la rentabilidad de cada proceso en términos de una tasa de retorno de la inversión. Por un análisis de los resultados obtenidos se localizaron los procesos más recomendables a escalas entre 10,000 y $1 ' 000,000 \mathrm{de} \mathrm{lb} /$ día de lactosuero fresco procesado.

Tres de los productos más prometedores fueron lactosuero seco, lactosuero desmineralizado seco y concentrado proteico seco de $92 \%$. Se estudió la rentabilidad en función de la escala para estos procesos, tomados como casos ejemplo en esta metodologia y se compararon sus características económicas. Se ajustaron los comportamientos económicos observados en los tres casos por una sola expresión empírica de dos parámetros, los cuales fueron puestos en función del precio de productos, la inversión y el costo de operación.

Se concluyó que existen rutas económicamente atractivas, tanto de prevención como de procesamiento de lactosuero, que pueden permitir a la industria quesera mexicana crecer sin perder competitividad y sin dañar al medio ambiente. 


\section{CAPITULO I}

INTRODUCCION Y OBJETIVO GENERAL

I a contaminación ambiental es hoy día un problema de primordial importancia para casi todos los países del mundo. De entre todas las fuentes de contaminación, se ha reconocido a la industria como una de las más importantes. En México, el impacto contaminante de la industria creció 20 veces de 1950 a 1989. Dos razones explican lo anterior: Por una parte, el crecimiento global de la industria en ese período fué de $1000 \%$; por la otra parte, el sector industrial que más se desarrolló fué el de las industrias más contaminantes. Hasta la década pasada, esta situación se veia como un dilema anarentemente sin solución, bajo el argumento de que los bienes y servicios que produce la industria están destinados a satisfacer las necesidades de la sociedad y son indispensables para su bienestar y subsistencia

Con el rápido deterioro del medio ambiente a nivel mundial, se ha confirmado de manera inequívoca que el enfoque adoptado implícitamente hasta hace poco, respecto de que era posible lograr bienestar y desarrollo por tiempo indefinido a expensas del medio ambiente, es falso. Fn sustitución del paradigma que ya no funciona, ha aparecido otro en los últimos años, que proclama la necesidad de establecer condiciones para un desarrollo sustentable de la sociedad; esto es, un desarrollo de magnitud y dirección tales que el bienestar obtenido de la satisfacción de necesidades no se revierta en el presente ni en el futuro por causa del deterioro ambiental involucrado, sin dejar de ser económicamente accesible a la sociedad

Este nuevo naradigma da paso a un concepto también nuevo en la producción de bienes y servicios: El concepto de tecnología limpia (372). Se entiende por tecnología limpia, a una manera de proporcionar a la sociedad la satisfacción de una necesidad en forma tal que globalmente se utilicen menos recursos y se causen menos daños al ambiente en comparación con las demás alternativas tecnológicas existentes; con las cuales deberá ser además económicamente competitiva.

De la definición anterior se desprenden dos implicaciones:

a) Fl concepto de tecnologia limpia es inseparable del concepto de rentabilidad económica.

b) La minimización de residuos y la prevención de la contaminación son componentes fundamentales en la filosofía de una tecnologia limpia.

En nuestro país, la industria quesera viene remontando una crisis que afecta a todo el sector alimentario en su conjunto. Fn el período 1988-1994 el déficit nacional de alimentos creció en más de $1000 \%$, entre otras razones, por el estímulo gubernamental hacia la importación de grandes cantidades de alimentos. E1 54\% de los alimentos importados fueron leche, azúcar, grasas y aceites. La nroducción nacional de leche, aunque desestimulada subsiste, y se dedica en buena parte a la producción de derivados lácteos. También subsiste una industria quesera nacional con presencia en el mercado interno y con potencial para crecer, de acuerdo a la demanda de ese mercado.

I a industria quesera mexicana no puede crecer adecuadamente entre otras razones, a causa de su proceso. Para elahorar queso se precisa remover desde la leche original entre otros, agua y lactosa 
en una gran proporción. En el proceso tradicional estos componentes forman parte de la corriente residual, denominada lactosuero. Esta corriente típicamente posee una baja demanda en el mercado, y por su elevado potencial contaminante requiere de un tratamiento previo a su disposición final. Los costos de este tratamiento afectan severamente a la economía del proceso.

El proceso quesero tradicional es un proceso delicado, como casi todos los procesos alimenticios, con fuertes bases empíricas y por lo mismo, la industria es conservadora respecto de la idea de modificarlo. A ello se debe que los estudios acerca de una tecnología limpia para la industria quesera nacional sean un tema escasamente estudiado a pesar de que existen en la literatura estudios previos que permiten visualizar las posibilidades técnicas de modilicación del proceso quesero en ese sentido.

La evaluación de la ventaja económica de un proceso quesero modificado respecto del tradicional es compleja, debido a que ésta depende de múltiples factores como el tipo de queso, la escala de proceso, los precios de productos, la demanda de éstos, etc., de modo que para saber si un proceso modificado, que garantice un mínimo de daño al medio ambiente resulta competitivo con el proceso tradicional, es preciso realizar un estudio comparativo bajo diferentes escenarios económicos y de operación. En el Capítulo 5 de esta tesis se realiza tal estudio y se identifican las oportunidades de reconversión del proceso quesero, así como las mejores condiciones del proceso reconvertido, para distintos tipos de quesos. También se dan a conocer los parámetros con mayor influencia sobre la ventaja económica de la reconversión.

Para los caso en que no es posible o deseable modificar el proceso quesero tradicional, la alternativa de la industria parece ser procesar el lactosuero generado para obtener de él productos de valor en el mercado. Una revisión del panorama de opciones de proceso o destinos para el lactosuero reportados en la literatura, se presenta en el Capítulo 2 de esta tesis. Aparentemente, muy poco se ha reportado respecto del impacto económico del procesamiento de lactosuero. En el Capítulo 4 de esta tesis se localizan las mejores oportunidades económicas de procesamiento de lactosuero en función de la escala de proceso y otros parámetros relevantes con ayuda de técnicas de Diseño, Sintesis, Optimización y Simulación de Procesos. Se estudia también la diferente sensibilidad de las opciones más prometedoras ante posibles perturbaciones del escenario económico y se representa el comportamiento económico de algunos casos mediante expresiones empíricas sencillas.

Dada la gran cantidad de parámetros y situaciones consideradas, fué preciso definir previamente el marco y las condiciones del problema abordado, a fin de precisar el o los puntos de vista desde los que se desarrollaron soluciones al mismo. Esta fase se presenta en el Capítulo 3 de esta tesis.

Las conclusiones derivadas de los desarrollos realizados constituyen el Capítulo 6 de este trabajo.

El objetivo general de esta tesis es explorar de manera original las posibilidades de una tecnología limpia para la industria quesera nacional, así como las alternativas de solución a la problemática de dar el mejor destino posible al lactosuero una vez generado, para identificar de acuerdo a economía, las mejores opciones y la influencia de parámetros relevantes sobre los resultados de estas opciones elegidas. 
CAPITULO 2:

PANORAMA GENERAL EN TORNO AL LAC'TOSUERO

El queso es uno de los alimentos más antiguos que se conocen. La fecha en que el hombre encontró la manera de obtenerlo, tal vez por accidente, se pierde en la historia; sin embargo, se cree que desde el año 5000 A.C. ya se producia en Mesopotamia (184). Por casi 7000 años la manufactura de queso se ha conservado como un arte en el cual la consistencia, el aroma y el sabor del producto dependen de las materias primas, de las condiciones de operación del proceso y de complicados mecanismos no totalmente entendidos, creando una gran dificultad para modificar el proceso $\sin$ alterar las caracteristicas del producto.

Entre la enorme variedad de quesos conocidos en la actualidad puede hacerse una clasificación en dos grupos: los quesos maduros (como el Suizo, Cheddar, Blue Mold, Brick, Edam, Mozzarella, etcétera) y los quesos frescos o no madurados (como el Ricotta, Crema, Cottage, etcétera).

En la fabricación del queso se distinguen alrededor de ocho etapas principales. Las caracteristicas particulares de un queso provienen de la forma y el énfasis con que se dan estas etapas en un proceso dado, asi como de las condiciones ambientales y los microorganismos que intervienen en el mismo.

El conocimiento científico y tecnológico del proceso para producir queso data de los últimos $100 \mathrm{o}$ 200 años. En ese lapso, la demanda mundial del producto ha aumentado vertiginosamente, al mismo tiempo que se han estandarizado las texturas, composiciones y sabores de muchas variedades, cuyos nombres los identifican mundialmente.

El proceso general para producir queso incluye en sus primeras etapas la descomposición de la leche en un componente sólido que evoluciona hasta convertirse en queso propiamente dicho, y un líquido amarillo verdoso denominado suero lácteo o lactosuero que se desecha.

Empleando el balance de masa, podría decirse que el proceso es casi 10 veces más eficaz para producir lactosuero. Sin embargo, muy poca atención se prestó al lactosuero hasta hace unos decenios, cuando su presencia ya no pudo ser soslayada debido al número de fuentes productoras, a su cantidad y a sus efectos.

\subsection{Producción.}

La participación de los países en la producción de lactosuero en el mundo a principios de los años ochenta era como sigue: $50 \%$ para Europa, $10 \%$ para Norteamérica, $2.5 \%$ Australia y Nueva Zelanda, $15 \%$ para otros paises desarrollados y $14.5 \%$ para los paises no desarrollados. Los principales productores europeos fueron en ese período Francia, Alemania e Italia, en tanto que India fue el principal productor de los paises no desarrollados (220).

La magnitud del problema que la industria quesera mundial enfrenta tiene que ver con la cantidad de lactosuero que se produce, la cual ha alcanzado niveles fuera de proporción; en 1990, por ejemplo, se produjeron alrededor de 125 millones de toneladas. Esta producción tan abundante, distribuida en focos de generación asociados con cuencas lecheras, además de los problemas ecológicos que presenta, debe examinarse en función de las posibilidades y los retos derivados de su existencia.

Factores dados durante este siglo, tales como el incremento poblacional, la industrialización y tecnificación del agro, así como el desarrollo de la tecnología de alimentos, han provocado en algunos países un crecimiento explosivo en la producción de queso, y por lo tanto de lactosuero. 
En 1984, el crecimiento anual mundial en la producción quesera fue de 3\% (249), en tanto que en 1988 Norteamérica registraba un crecimiento anual promedio, en los 12 años anteriores, de $6.4 \%$ (43).

Junto a estos casos hay otros, principalmente en países no desarrollados, en donde la producción de leche es insuficiente aún para el consumo interno como leche fresca. Esta situación se refleja en una industria quesera contraida, y por tanto con volúmenes de lactosuero inferiores en varios órdenes de magnitud a los de los países desarrollados.

En el caso de México, el déficit lechero por más de un decenio ha ido en aumento(70). La permanencia de sistemas de explotación inadecuados y obsoletos, la falta de estímulos a la inversión, la escasa introducción de tecnología, la deficiente organización de los productores y la falta de capital de los mismos, entre otros factores, han determinado que la explotación lechera nacional se caracterice por niveles insuficientes de producción, escasa productividad, costos elevados y una oferta heterogénea en cuanto a precio y calidad (11).

Se estima que la producción nacional de lactosuero en 1991 fué de alrededor de un millón de toneladas, lo cual es congruente con los datos sobre producción de queso en México que reportó la FAO para fechas ccrcanas a ese año (13), (14)

\subsection{Composición.}

De los procesos utilizados para obtener quesos madurados y caseína enzimática, se obtiene un tipo de lactosuero denominado "dulce", con pH entre 5.9 y 6.3 , en tanto que de los procesos para quesos no madurados y caseína láctica o mineral, se obtiene lactosuero "ácido", con pH entre 4.4 y 4.6 Las Tablas 2-1 a la 2-9 presentan algunas composiciones de lactosuero fresco y en polvo consignadas en la bibliografia. Como se puede ver, una importante proporción de los nutrientes de la leche se encuentra en el lactosuero, tales como proteínas, lactosa, vitaminas y elementos minerales. El ácido cítrico también está presente entre 0.26 y $1.3 \mathrm{~g} / 1$. El lactosuero tipo ácido contiene más ácido láctico, calcio, fósforo y lactosa que el de tipo dulce.

TABLA 2 -1

PRINCIPALES COMPONENTES DE LACTOSUEROS TIPICOS Y LECHE (184)

\begin{tabular}{|l|c|c|c|}
\hline COMPONENTE & $\begin{array}{c}\% \text { EN LS } \\
\text { DULCE }\end{array}$ & $\begin{array}{c}\% \text { EN LS } \\
\text { ACIDO }\end{array}$ & $\begin{array}{c}\% \text { EN } \\
\text { LECHE }\end{array}$ \\
\hline Solidos tot. & 6.25 & 6.5 & 12.5 \\
\hline Agua & 93.7 & 93.5 & 87.5 \\
Grasa & 0.5 & 0.04 & 3.5 \\
\hline Proteina tot. & 0.8 & 0.75 & 3.3 \\
\hline Lactasa & 4.85 & 4.9 & 5 \\
\hline Cenizas & 0.5 & 0.8 & 0.7 \\
\hline Ac. láctica & 0.05 & 0.4 & -- \\
\hline
\end{tabular}

TABL $\wedge 2-2$

COMPOSICION TIPICA PROMEDIO DE LA PROTEINA DEL L.ACTOSUERO (247)

\begin{tabular}{|c|c|}
\hline GRUPO & PORC I ENTO \\
\hline Beta-lactoglobulina & 46 \\
\hline Alfa-lactalbúmina & 21 \\
\hline Seroalbúmina & 5 \\
\hline Proteosa-peptona & 19 \\
\hline Inmunoglobulina & 9 \\
\hline
\end{tabular}


TABLA 2-3

CONTENIDO VITAMINICO TIPICO

DEL LACTOSUERO DULCE (43)

\begin{tabular}{|c|c|}
\hline VITAMINA & $\mathrm{mg} / 1$ \\
\hline Tiamina & 4000 \\
Riboflavina & 17600 \\
Niacina & 10000 \\
Ac. Pantoténico & 40900 \\
Vitamina B-12 & 22100 \\
Piridoxina & $\mathrm{N} / \mathrm{A}$ \\
Inositol & $\mathrm{N} / \mathrm{A}$ \\
Colina & $\mathrm{N} / \mathrm{A}$ \\
\hline
\end{tabular}

TABLA $2-5$

CONTENIDO VITAMINICO

DEL LACTOSUERO SECO (249)

\begin{tabular}{|c|c|}
\hline VITAMINA & $\begin{array}{c}\mathrm{mg} / / 100 \mathrm{~g} \mathrm{de} \\
\text { lactosuero seco }\end{array}$ \\
\hline Tiamina & $4.0-6.0$ \\
Piridoxina & $0.0-10.0$ \\
Riboflavina & $7.0-30.0$ \\
Pantotenato de calcio & $30-70$ \\
& $0.2-0.3$ \\
Biotina & $0.01-0.05$ \\
Cobalamina & $30-50$ \\
Vitamina C & \\
\hline
\end{tabular}

TABLA 2-7

CONTENIDO DE ALGUNOS METALES EN EL LACTOSUERO

SECO (249)

\begin{tabular}{|c|c|}
\hline METAL & $\begin{array}{c}\text { mg./100 g } \\
\text { de suero }\end{array}$ \\
\hline Fierro & $1.0-7.0$ \\
Cobre & $0.5-5.0$ \\
Zinc & $5.0-9.0$ \\
Manganeso & $0.01-0.04$ \\
\hline
\end{tabular}

TABLA 2-4

AMINOACIDOS ESENCIALES CONTENIDOS EN LAS PROTEINAS DEL LACTOSUERO (358) V.S. NORMA FAO PARA NUTRICION HUMANA

\begin{tabular}{|c|c|c|}
\hline AMINOACIDO & Norma FAO & Contenido LS \\
\hline Metionina & $4.2^{*}$ & $4.3^{*}$ \\
Leucina & 9 & 15.5 \\
Lisina & 4.2 & 8.2 \\
Fenilalanina & 2.8 & 4 \\
Treonina & 2.8 & 5.5 \\
Valina & 42.5 \\
Tirosina & 2.8 & 5.7 \\
Triptofano & 1.4 & 2.5 \\
\hline
\end{tabular}

* g/100 g de proteina

TABLA 2-6

ALGUNOS OTROS COMPONENTES MINERALES CONTENIDOS

EN EL LACTOSUERO (37)

\begin{tabular}{|c|c|}
\hline ELEMENTO & $\mathrm{g} / \mathrm{Kg}$. de LS \\
\hline Fósforo inorgánico & 0.33 \\
Fosforo total & 0.39 \\
Potasio & 1.48 \\
Azufic & 0.14 \\
Sodio & 0.56 \\
& \\
Magnesio & 0.09 \\
Cloro & 1.19 \\
\hline
\end{tabular}

$T A B L \wedge 2-8$

FRACCION DE NUTRIENTES DE LA LECHE QUE PASAN AL LACTOSUERO

(247)

\begin{tabular}{|c|c|}
\hline COMPONENTE & $\%$ DEL CONTENIDO \\
& EN LECHE ENTERA \\
\hline Grasa & 14 \\
Proteina & 22 \\
Cenizas & 74 \\
Lactosa & 98 \\
\hline
\end{tabular}


TABLA 2-9

MICRO EI.EMENTOS CONTENIDOS EN

LL LACTO SUERO (37)

\begin{tabular}{|c|c|c|}
\hline ELEMENTO & CONTENIDO & $\begin{array}{l}\text { UNIDADES DE } \\
\text { CONCENTRACION }\end{array}$ \\
\hline Boro & 0.11 & $\begin{array}{c}\text { micro- gramos/g } \\
\text { de lactosuero }\end{array}$ \\
\hline Cobre & 0.07 & $"$ \\
\hline Fierro & 0.36 & " \\
\hline Manganeso & $<0.01$ & " \\
\hline Molibdeno & $<0.03$ & $"$ \\
\hline Zinc & 0.14 & " \\
\hline Cobalto & $<4.00$ & nano-gramos/g \\
\hline Selenio & 1.3 & $\begin{array}{c}\text { de lactosuero } \\
"\end{array}$ \\
\hline
\end{tabular}

2.3 Riesgos por inadecuada disposición del lactosuero.

La necesidad de deshacerse sin tardanza del lactosuero en una quesería proviene del peligro de contaminación del queso, debido a que el lactosuero constituye un medio de cultivo muy rico para un gran número de microorganismos que se implantan rápidamente en él, multiplicandose y extendiendo su presencia hasta el aire ambiente. Algunos de estos microorganismos son patógenos, como Brucellus abortus, Mycobacterium tuberculosis, Coxiella burnetli, Staphylococcus Aureus, Sireptococcus agalactiae y varias especies de Salmonella, entre otros (244).

Los problemas de fagos en queserias, que se reflejan en mal funcionamiento de los iniciadores de la coagulación, también se relacionan a menudo con la forma de manejar el lactosuero en la planta.

Cada kilogramo de queso producido significa unos $0.4 \mathrm{~kg}$. de DBO5 que pueden dañar el ambiente si no se les da un tratamiento. Algunos autores han comparado el efecto de la descarga de una pequeña instalación quesera, que produzca por ejemplo unos 4000 litros de lactosuero por día, con las aguas negras municipales producidas por 1800 personas (220). La Tabla 2-10 presenta una comparación del potencial contaminante de los efluentes típicos de diversos procesos, en función de su DBO5 (demanda bioquímica de oxigeno durante los primeros 5 días). Además, el lactosuero tiene una DQO (demanda química de oxígeno) muy elevada, del orden de $68000 \mathrm{mg} . / 1$. 
TABLA 2-10

POTENCIAL CONTAMINANTE DE DIVERSOS EFLUENTES

INDUSTRIALES EN TERMINOS DE SU DBO5 (144)

PROCESO

DBO5/LITRO DE EFLUENTE,

NORMALIZADO RESPECTO A UN EFLUENTE DE AGUAS NEGRAS MUNICIPALES

A) Procesadores de lácteos

A 1) Pasteurizadoras de leche

3.33

A2) Productoras de nieve (Ice cream)

13) Otros procesadores de alimentos

B.1) Pastelillos industrializados

B.2) Enlatadoras de carne

B 3) Dulceras

B.4) Procesadores de pescado fresco

C) Lactosuero

C. 1) Lactosuero dulce

C.2) Lactosuero ácido

D) Aguas negras municipales

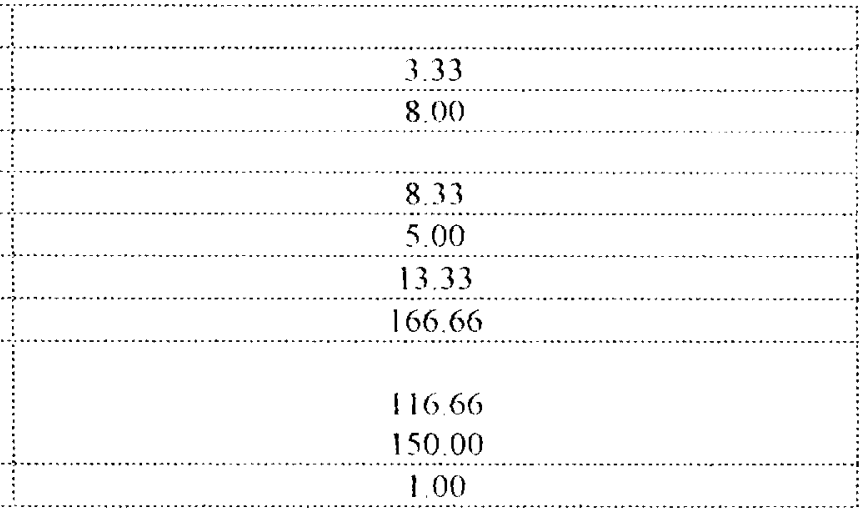

2.4 Opciones elementales de disposición de lactosuero.

Pese a que contiene sustancias de reconocido valor, en pocas ocasiones el lactosuero ha constituido un producto de interés para la industria quesera debido principalmente a su alto contenido acuoso. En este capítulo se entiende por opciones tecnológicas simples, aquellas que solo requieren de equipos sencillos y de bajo costo, y en donde las operaciones realizadas no requieren en lo general de personal especializado. Entre estas opciones se encuentran las aplicaciones del lactosuero como nutriente de plantas y como complemento alimenticio para el ganado.

Una antigua práctica que llega hasta nuestros días para disponer en forma económica el suero lácteo sin dañar cuerpos de agua consiste en usarlo para rociar los cultivos. Algunas limitaciones económicas y de uso restringen este método. La práctica de rociar la tierra con lactosuero reporta en algunos casos buenos resultados para el crecimiento de las plantas en una etapa inicial. Sin embargo, la sobredosis de nutrientes por sucesivas aplicaciones de suero provoca acumulaciones de sales minerales y nitrógeno, lo cual dificulta el crecimiento posterior de las plantas. Es necesario por tanto, mantener un equilibrio entre la cantidad de nutrientes que las plantas absorben y la suministrada por la aspersión del suero. Rociar un espesor de $2.5 \mathrm{~cm}$. de lactosuero equivale a adicionar a la tierra $145 \mathrm{Kg}$. por hectárea de nitrógeno, $45 \mathrm{Kg}$. por hectárea de fósforo y 181 por hectárea de potasio, además de considerables cantidades de sales minerales y carbohidratos (220). Por otro lado, es importante tomar en cuenta los costos derivados del transporte y manejo del suero, que varían ampliamente de un caso a otro. Otro problema que se ha observado estriba en que la grasa residual presente en el lactosuero se acumula paulatinamente en el suelo y forma una capa impermeable, capaz de impedir la posterior infiltración de líquido al suelo, así como de propiciar la implantación de condiciones anaerobias en las raices de las plantas, con los consecuentes efectos adversos en éstas.

Tal vez una forma de controlar estos inconvenientes sea usar el suero lácteo en el proceso de fabricación de la composta en lugar de aplicarlo directamente al suelo. Como se sabe, la composta es un producto de la degradación bioquímica de la materia orgánica fermentable, proveniente de 
desechos sólidos urbanos. Se usa en agricultura para mejorar suelos e inhibir la erosión, en virtud de su capacidad de reponer en el suelo la materia orgánica y los micronutrientes perdidos a causa del cultivo exhaustivo. Sin embargo, la composta elaborada al modo tradicional está muy lejos de ser un fertilizante, ya que típicamente contiene alrededor de $1 \%$ de nitrógeno, $0.25 \%$ de fósforo y $0.25 \%$ de potasio (333). En virtud de lo anterior, parece posible la existencia de compatibilidad entre el suero lácteo y la materia orgánica fermentable de la basura urbana para producir una composta más rica en nutrientes. Sin embargo, el autor de esta tesis no tiene conocimiento de aplicaciones de este tipo para el suero lácteo.

Otra vieja práctica para disponer del lactosuero consiste en reciclarlo a la alimentación del ganado vacuno. Mezclar el lactosuero fresco con la pastura, o como sustituto de leche en el destete de becerros tiene varias limitantes, entre ellas los costos de manejo y transporte del suero con la rapidez y la limpieza necesarias para que sea aceptado por los animales y no les cause daños. Existen algunas medidas para preservar en buen estado el suero y recomendaciones prácticas para la implantación de este sistema (244). Otra modalidad del método es el uso del lactosuero como sustituto parcial del agua para abrevar el ganado. Si esta práctica se inicia desde que el ganado es muy joven, la mayoría de las reses se acostumbran a beberlo (especialmente el lactosuero dulce). En algunos casos se han obtenido resultados muy positivos en cuanto al aumento de peso y producción de leche; sin embargo, la excesiva ingestión de sales por una dosificación inadecuada o la ingestión de producto en estado avanzado de fermentación puede producir diarrea y en algunos casos llegar hasta la muerte de los animales. La práctica se ha extendido con resultados similares a la alimentación de cerdos.

Aunque los ahorros en alimentación y bebida pueden ser significativos, no siempre es recomendable este recurso. Se necesita un acceso fácil y rápido entre la quesería y la granja, así como mucha cooperación entre el personal de ambas y mucha limpieza y supervisión en el manejo del lactosuero para evitar daños al ganado.

Los recursos que se acaban de mencionar son de aplicación limitada a queserias pequeñas, cuando la economía, las condiciones locales y las regulaciones lo permitan. En la tabla 2-11 se citan algunos estudios relacionados con el uso o disposición de lactosuero a este nivel.

TABLA 2-11

ALGUNOS ESTUDIOS SOBRE LA UTILIZACION DIRECTA DEL LACTOSUERO EN AREAS DIVERSAS

\begin{tabular}{|c|c|}
\hline $\begin{array}{l}\text { REFEREN- } \\
\text { CIAS }\end{array}$ & CONTENIDO \\
\hline 37 & $\begin{array}{l}\text { Experiencia de utilización de lactosuero en sustitución de fertilizantes convencionales en Nueva } \\
\text { Zelandia }\end{array}$ \\
\hline $343,246,297$ & $\begin{array}{l}\text { Estudio experimental de uso del lactosuero en su forma fresca y en forma concentrada para la } \\
\text { alimentación de cerdos }\end{array}$ \\
\hline 165,47 & $\begin{array}{l}\text { Desarrollo de un complemento alimenticio para ganado bovino a base de suero lácteo y sus } \\
\text { resultados }\end{array}$ \\
\hline 244 & Análisis del potencial del lactosuero como fertilizante y como alimento de cerdos y bovinos \\
\hline 162 & $\begin{array}{l}\text { Desarrollo experimental de un combustible sólido y un suplemento alimenticio para ganado, a partir } \\
\text { de suero lácteo }\end{array}$ \\
\hline 112 & $\begin{array}{l}\text { Estudio de la producción y el consumo de formulaciones a base de lactosuero para uso como } \\
\text { sustituto de leche en becerros lactantes }\end{array}$ \\
\hline 128 & Discusión sobre los posibles usos del lactosuero en forma de sólido moldeado \\
\hline 123 & Descripción de usos culinarios de un lactosuero ácido en Islandia \\
\hline
\end{tabular}


2.5 Opciones tecnológicas de mediana complejidad.

Se consideran aquí acuellos métodos de disposición o aprovechamiento de lactosuero que requieren de equipo y personal de cierta especialización, cuyo uso es corriente en paises desarrollados. Las tecnologias de estas opciones provienen típicamente de la Ingenieria Quimica y de la lngeniería Bioquímica y reflejan el grado de avance de estas disciplinas. Los métodos de disposición en general fueron adaptados de sistemas conocidos de tratamiento de efluentes industriales. Estos incluyen disposición en lagunas de estabilización, sedimentación, flotación, coagulación, procesos con lodos activados, filtros con empaques activos, digestores aerobios o anaerobios, sistemas biológicos de multietapa, etcétera. Ciertas prácticas son más populares en unos países que en otros, en virtud de factores económicos locales, infraestructura tecnológica disponible e incluso preferencias personales de los diseñadores. La tabla 2-12 describe algunos estudio al respecto.

TABLA $2-12$

\begin{tabular}{|c|c|}
\hline $\begin{array}{l}\text { REFEREN- } \\
\text { CIAS }\end{array}$ & $\begin{array}{l}\text { TRATAMIENTO DE EFLUENTES EN LA INDUSTRIA DE LACTEOS } \\
\text { CONTENIDO }\end{array}$ \\
\hline 127 & $\begin{array}{l}\text { Tratamiento de las aguas de desecho de la industria de lácteos por flotación con el proceso } A P V \\
\text { Pasilac }\end{array}$ \\
\hline 94 & Estudio del tratamiento aerobio de las aguas de desecho en la industria de lácteos \\
\hline 223 & $\begin{array}{l}\text { Aplicación de la tecnologia de levaduras libres e immovilizadas para el tratamiento de aguas de } \\
\text { desecho en la industria de lácteos. Se incluye la caracterización de dichas aguas de desecho }\end{array}$ \\
\hline 36 & $\begin{array}{l}\text { Estudio de la fermentación anaerobia de lactosuero utilizando un digestor senvicontinuo con adición } \\
\text { de floculante quimico para aumentar la concentración de biomasa }\end{array}$ \\
\hline
\end{tabular}

Hay testimonios indicadores de que a partir de cierta escala es económicamente mas conveniente procesar el lactosuero que disponerlo, y siendo este un fluido de valor alimenticio, sus primeras aplicaciones se han dado en el sector de alimentos. El atractivo puede ser mayor cuando dentro de un grupo industrial donde se produce lactosuero, también se puede consumir para formar algún producto derivado (291). A nivel mundial, el proceso más extendido para el lactosuero es la deshidratación, la cual puede ser total o parcial por medio de ósmosis inversa, evaporación y subsecuente secado por aspersión. En la tabla 2-13 se describen algunos estudios al respecto.

TABLA 2-13

ALGUNOŚS ESTUDIOS SOBRE LA DESHIDRATACION DE LACTOSUERO

$\begin{array}{ll}\text { REFEREN- } & \text { CONTENIDO } \\ \text { C1AS } & \text { Discusión de las condiciones de proceso, equipos y costos del secado de lactosuero } \\ 156 & \text { Revisión de principios básicos del secado por aspersión y su aplicación a productos biocuuimicos } \\ 224 & \text { Presentación de desarrollos tecnologicos recientes en equipos para secado de lactosuero } \\ 181 & \text { Presentación de avances recientes en la tecnologia de concentración de lactosuero por evaporación } \\ 295 & \text { Situación del mercado para el lactosuero seco y sus productos } \\ 3398 & \text { Descripción de equipos de remoción de agua para leche y suero } \\ 285 \text { (Cap. 4) } & \text { a }\end{array}$

Aunque el proceso es costoso por la energía requerida, es muy conveniente por la facilidad de manejo y conservación del suero en polvo. Una vez en forma sólida, el lactosuero puede usarse en formulaciones de alimentos balanceados para animales o como ingrediente en diversos alimentos de consumo humano, o bien puede ser subsecuentemente fraccionado. Entre las posibilidades de procesamiento ulterior (que requiere de tecnología más desarrollada) está la producción de concentrados proteicos, formulaciones alimenticias maternizadas, ingredientes de uso en farmacia, panadería, confitería, postres, vinagre, requesón, bebidas fermentadas de consumo humano, 
etcétera. La demanda de lactosuero en polvo en el sector alimenticio ha ocasionado el desplome del mercado de la leche en polvo descremada en Estados Unidos desde hace más de 25 años (368).

Dentro del sector de derivados lácteos, el uso mas extenso del lactosuero en polvo es en la manufactura de helados, donde la reglamentación oficial estadounidense limita a $25 \%$ el reemplazo de leche descremada en polvo por lactosuero. Otra aplicación es la incorporación de suero en polvo durante la manufactura del queso Ricotta y otros tipos de quesos untables o sucedáneos de quesos, también en la elaboración de formulaciones que imitan la crema ácida y en la producción de botanas ("snacks") con o sin sabor a queso. El lactosuero en polvo se usa también como ingrediente en cremas batidas, yoghurt, etcétera.

En Islandia es común el uso de un suero lácteo proveniente de un producto parecido al yoghurt, llamado skyr, para preparar en forma casera sopa de pescado (123).

Por su bajo contenido en calorías y alto valor nutricional, el lactosuero se ha usado como base para preparar bebidas refrescantes, bebidas alcohólicas y sustitutos lácteos de diversos tipos, al mezclarse con otros ingredientes como azúcar, jugos de frutas o verduras, aceites vegetales, infusiones de hierbas, sabores artificiales, etcétera (185).

La Tabla 2.14 muestra algunas de las bebidas conocidas en el mundo, cuya formulación incluye lactosuero. La mayoría de ellas tienen la desventaja de poseer una vida de anaquel de pocos días, 10 que ha impedido su producción masiva. También como sustituto de la malta se ha usado el lactosuero experimentalmente en el proceso de cervecería con buenos resultados (185).

TABLA 2-14

ALGUNAS BEBIDAS DE CONSUMO HUMANO ELABORADAS CON BASE EN LACTOSUERO (185)

\begin{tabular}{|c|c|c|c|}
\hline PAIS & NOMBRE DE LA BEBIDA & PAIS & $\begin{array}{c}\text { NOMBRE DE LA } \\
\text { BEBIDA }\end{array}$ \\
\hline Alemania & $\begin{array}{c}\text { Mango } \\
\text { Big-M } \\
\text { Plus }\end{array}$ & Ex-Unión Sovietica & $\begin{array}{c}\text { Kumys } \\
\text { Victoria } \\
\text { Olympia } \\
\text { Letniy } \\
\text { Senetate } \\
\text { Lubiytelskii } \\
\text { Berezka } \\
\text { Prokhlada } \\
\text { Atlant } \\
\text { Choc-it } \\
\text { Salomat } \\
\text { Rusanowskii }\end{array}$ \\
\hline Estados Unidos & $\begin{array}{c}\text { Samson } \\
\text { Pure D'Lite }\end{array}$ & Suecia & Natures wonder \\
\hline Lituania & Bochu & Suiza & $\begin{array}{l}\text { Lactofruit } \\
\text { Rivella rot } \\
\text { Rivella Blau }\end{array}$ \\
\hline Polonia & $\begin{array}{c}\text { Lactovat } \\
\text { Rewit }\end{array}$ & & \\
\hline
\end{tabular}


2.6 Opciones tecnológicas modernas.

En esta parte se mencionan procesos de tecnología reciente, orientados hacia la obtención de productos con alto valor agregado, sin analizar de momento su viabilidad económica. La presencia de procesos biotecnológicos es sobresaliente, ya que utilizan condiciones moderadas de temperatura y presión sobre recursos renovables y las transformaciones que logran son muy específicas. No obstante, estos procesos presentan inconvenientes importantes, como los altos costos y dificultades para concentrar los productos a partir de soluciones muy diluidas, la necesidad de cofactores expansivos (nutrientes adicionales y condiciones especiales) para mantener constantes los niveles de conversión y serios problemas de escalamiento de procesos para producción de gran volumen. También representa una dificultad el hecho de que el lactosuero sea un sustrato poco versátil, debido a que el único carbohidrato que contiene es la lactosa.

Más de una vez en el pasado, la biotecnología ha sido considerada como alternativa importante para el aprovisionamiento de suministros químicos en la industria y en otras tantas ocasiones la aparente abundancia de petróleo barato ha frenado su desarrollo por incosteabilidad. Fste comportamiento cíclico tendrá que romperse alguna vez, cuando el agotamiento de las reservas de hidrocarburos, el avance de las ciencias biotecnológicas o ambos, hagan económicamente viables algunos bioprocesos para producir especies químicas.

Las tendencias mundiales de reducir las tasas de consumo de energía y la dependencia del petróleo, además de los desarrollos en Ingenieria Genética, parecen indicar que la Biotecnología puede incrementar aún más su importancia en el futuro.

En esta línea se ubican muchos esfuerzos de investigación hacia la obtención de productos químicos de amplia demanda que permitan utilizar los grandes volúmenes de lactosuero por medio de fermentación, hidrólisis o por purificación de lactosa.

\subsection{Fraccionamiento del lactosuero.}

Desde el punto de vista nutricional, se puede objetar al lactosuero su alto contenido de minerales y de lactosa; esta última no fácilmente asimilable y a veces no tolerada por algunos individuos. En cambio, se puede decir que su contenido proteico es su mejor atributo, por lo que separando el lactosuero en sus componentes se amplían las posibilidades de su aprovechamiento.

\subsubsection{Proteínas}

La técnica desarrollada por Maubois, Mocquot y Vassal conocida como ultrafiltración, patentada en Francia en 1969, superó ampliamente todos los métodos anteriores de separación de proteinas del lactosuero.

La ultrafiltración es una operación de separación de solutos de alto peso molecular contenidos en un fluído por medios mecánicos. En principio, el método se encuentra entre la filtración convencional y la ósmosis inversa, difiriendo los tres casos en el tamaño de las partículas que se van a separar, en la magnitud de la presión aplicada y en la estructura de la barrera física usada como medio filtrante (véase Figura 2-1). 


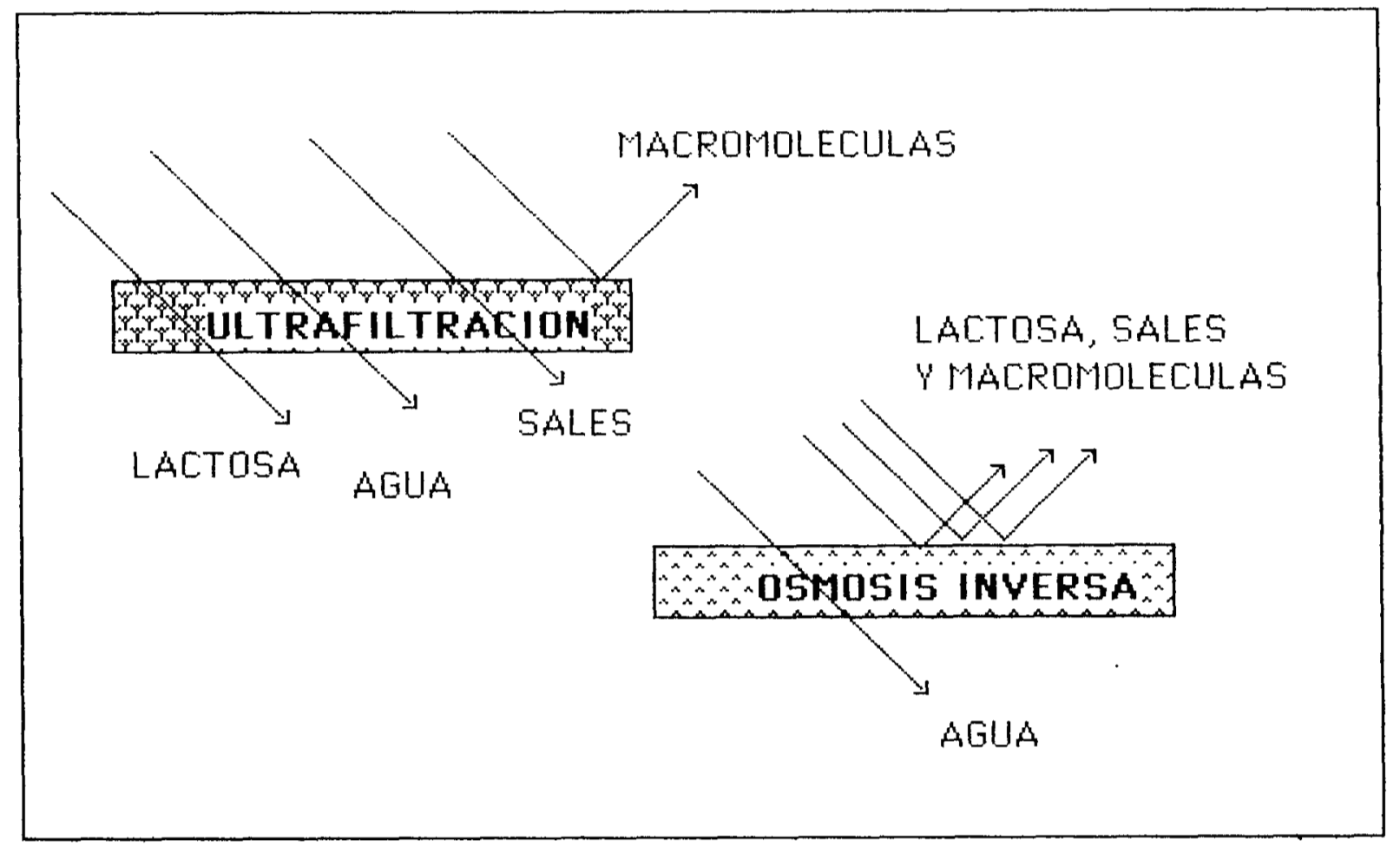

FIGURA 2-1

\section{COMPORTAMIENTO DE LAS MEMBRANAS DE ULTRAFILTRACION Y DSMOSIS INVERSA AL PROCESAR LECHE O SUERO LACTEO}

Las primeras membranas de ultrafiltración estaban hechas de acetato de celulosa. Sólo se les podía usar a temperaturas menores a $35 \mathrm{C}$ y $\mathrm{pH}$ entre 3 y 7 . Tratando de superar estas limitaciones, aparecieron las membranas de poliamida y posteriormente las de polisulfonatos, cuya tolerancia llega a los $80 \mathrm{C}$ de temperatura y pH entre 2 y 12 , mostrando buena resistencia mecánica. Recientemente se han desarrollado para usos especiales membranas de óxido de circonio soportado en grafito (285). Estas poseen una gran resistencia al desgaste mecánico y a la presión, y pueden trabajar a cualquier $\mathrm{pH}$ y a temperaturas hasta de $400 \mathrm{C}$.

En el caso del lactosuero, la fracción retenida por la membrana (retentato) contiene principalmente proteínas, en tanto que la fracción ultrafiltrada (permeato), carece de proteínas y grasa, y su contenido de lactosa y sales minerales es semejante al del suero original. Además del tainaño y perfil de las moléculas que se van a separar, existen otros efectos que dificultan la ultrafiltración, los cuales son motivo de estudio en la actualidad, ya que pueden ser significativos y aún dominantes durante la operación. Se trata de efectos asociados con interacciones químicas entre la membrana y 
los componentes del sistema que se pretende filtrar. Estos efectos son capaces de producir serias obstrucciones en las membranas y, en consecuencia, una disminución del flujo de permeato respecto al esperado.

Como contraparte a estos problemas, la separación por membranas ofrece un enorme potencial de ahorro de energía comparado con otras técnicas de separación, particularmente con la evaporación Una ventaja más sobre la evaporación es la preservación de propiedades sensibles a la temperatura como el valor nutricional y las propiedades funcionales de las proteinas.

El empuje de esta tecnología de separación se puede percibir al considerar que sólo en 1985, se solicitaron 1200 patentes de aplicación de la tecnología de membranas en el mundo (98)

Las buenas propiedades funcionales de las proteínas del suero lácteo como solubilidad, viscosidad, capacidad de retención de agua, poder emulsificante y poder espumante, les han permitido ingresar como aditivos y como fuentes proteicas en muy diversos procesos alimenticios. Por la diversidad de proteínas presentes en el suero se pueden obtener concentrados con distintas propiedades funcionales mediante el fraccionamiento de grupos de peso molecular definido (220). Algunos estudios de interés sobre aplicación de membranas a la separación de proteínas del lactosuero y sobre la caracterización de fracciones proteicas se muestran en las tablas 2.15 y 2.16.

TABLA 2-15

ALGUNOS ESTUDIOS RECIENTES SOBRE TECNOLOGIA DE MEMBRANAS PARA PROCESAMIENTO DE I $\triangle$ CTOSUIERO

\begin{tabular}{|c|c|}
\hline Referencias & Contenido \\
\hline 337,139 & $\begin{array}{l}\text { Experimentación, estudios de diseño y estimación de costos para un sistema de } \\
\text { hiperfilitación de suero dulce }\end{array}$ \\
\hline $\begin{array}{l}331,327,325 \\
105\end{array}$ & $\begin{array}{l}\text { Estudios de la influencia de parámetros de operación en el flujo de permeato } \\
\text { durante la ultrafiltración de lactosa }\end{array}$ \\
\hline 167 & $\begin{array}{l}\text { Estudio del comportamiento de lactosueros dulces y ácidos durante su } \\
\text { ultrafiltración. se reportan los resultados de algunas medidas tomadas para reducir } \\
\text { los efectos de polarización de la concentración y oclusión de membrana }\end{array}$ \\
\hline 369,129 & Ultrafiltración aplicada a la leche \\
\hline 264 & Peculiaridades de la concentración de lactosuero por ósmosis inversa \\
\hline 125,231 & Estudios sobre los procesos de manufactura de queso con ultrafiltración \\
\hline 202,201 & $\begin{array}{l}\text { La electrodiálisis y su aplicación al procesamiento de alimentos. Incluye un estudio } \\
\text { de caso de lactosuero }\end{array}$ \\
\hline 314 & Estudio experimental de ultrafiltración de leche en el establo \\
\hline 332 & $\begin{array}{l}\text { Caracterización de las oclusiones proteinicas en membranas de ultrafiltración de } \\
\text { lactosuero }\end{array}$ \\
\hline
\end{tabular}


BIBLIOGRAFIA RECIENTE SOBRE PROTEINAS DE LACTOSUERO

\begin{tabular}{|c|c|}
\hline Referencias & Contenido \\
\hline 80 & $\begin{array}{l}\text { Estudio de la desnaturalización térmica y agregación de proteinas de lactosuero en función } \\
\text { de temperatura, tiempo de exposición, pH y concentración de iones calcio }\end{array}$ \\
\hline 5 & $\begin{array}{l}\text { Estudio de diversos métodos para aislamiento de inmunoglobulinas y lactoferrina de suero } \\
\text { lácteo }\end{array}$ \\
\hline 214 & $\begin{array}{l}\text { Comparación de tres métodos para deteminar la desnaturalización de proténas de suero } \\
\text { lácteo de leche procesada témicamente }\end{array}$ \\
\hline 79 & $\begin{array}{l}\text { Estudio de la terno estabilidad de proténas en suero de caséna por la presencia de } \\
\text { dodecilsulfato de sodio, yodato de potasio y Nivetilmaleimida }\end{array}$ \\
\hline 218,252 & Revisión de literatura reciente sobre proteínas de lactosuero y su desnaturalización \\
\hline $\begin{array}{l}263,270,316, \\
229,248\end{array}$ & $\begin{array}{l}\text { Descripción de procesos propuestos para fraccionamiento (en alfa y beta) de las proteinas } \\
\text { del suero lácteo y de las propiedades de ambas fracciones }\end{array}$ \\
\hline 148 & Descripción de los mercados potenciales para proteinas de lactosuero \\
\hline 107 & $\begin{array}{l}\text { Efceto de los azúcares en la desnaturalización térmica y coagulación de proténas de } \\
\text { lactosucro }\end{array}$ \\
\hline 177 & $\begin{array}{l}\text { Estudio del efecto de la ultrafiltración y el uso de secado por congelación o secado por } \\
\text { aspersión, sobre la composición y funcionalidad de concentrados proteicos de lactosuero }\end{array}$ \\
\hline 21,313 & $\begin{array}{l}\text { Esludio de separación de proteinas de lactosuero usando diferentes resinas de intercambio } \\
\text { iónico }\end{array}$ \\
\hline 212 & $\begin{array}{l}\text { Proposición de un método para predecir la funcionalidad de concentrados proteicos de } \\
\text { lactosuero }\end{array}$ \\
\hline $\begin{array}{l}315,317,318 \\
211,74\end{array}$ & Estudio de las propiedades funcionales de fracciones proteicas de lactosuero \\
\hline 24 & Análisis de concentrados proteicos de lactosuero por cromatografia de líquidos (HPLC) \\
\hline $\begin{array}{l}20,368,227 \\
236\end{array}$ & Perspectivas globales en el fraccionamiento de proteinas de suero lácteo y en su uso \\
\hline 155 & Revisión de procesos industriales de separación de proteinas de lactosuero \\
\hline 207 (CAP. & Técnicas más comunes para separación de proteinas de lactosuero \\
\hline $299,75,213$ & Estudio del efecto del procesamiento sobre la funcionalidad de las proteinas del lactosuero \\
\hline 341 & Aplicaciones de las proténas del lactosuero en la industria procesadora de cereales \\
\hline 131 & $\begin{array}{l}\text { Evaluación de propiedades funcionales de las proteinas de lactosuero dentro de un sistema } \\
\text { alimenticio, por oposición al método de evaluación en sistemas aislados estándar }\end{array}$ \\
\hline 173 & $\begin{array}{l}\text { Estudio de las modificaciones fisicas, químicas y enzimáticas que se pueden efectuar sobre } \\
\text { las proteinas de lactosuero para mejorar sus propiedades funcionales }\end{array}$ \\
\hline 196,143 & $\begin{array}{l}\text { Estudio de la estabilidad de algunas proteinas de lactosuero durante su almacenamiento } \\
\text { seco }\end{array}$ \\
\hline 176 & Proposición de una estandarización a la metodología para evaluar proteínas de lactosuero \\
\hline 186 & $\begin{array}{l}\text { Estudio de la desnaturalización témica de beta-lactoglobulina y su efecto sobre la } \\
\text { transferencia térmica en un intercambiador de calor de placas }\end{array}$ \\
\hline
\end{tabular}


TABLA 2-16

(CONTINUACION)

\begin{tabular}{|l|l|}
\hline 254 & $\begin{array}{l}\text { Estudio experimental de la recuperación de proteinas de una mezcla de leche } \\
\text { descremada y lactosuero ácido, por calentamiento a pl } 1 \text { alcalino }\end{array}$ \\
\hline 175 & $\begin{array}{l}\text { Proceso propuesto para obtener altos concentrados proteicos a partir de lactosuero } \\
\text { sin necesidad de diafiltración, utilizando células inmovilizadas de } K \text {. frágilis }\end{array}$ \\
\hline 115 & $\begin{array}{l}\text { Recuperación de proteínas de suero dulce en crudo mediante sulfitólisis en estado } \\
\text { sólido }\end{array}$ \\
\hline
\end{tabular}

\subsubsection{Minerales.}

El lactosuero en polvo contiene alrededor de $7 \%$ de minerales, los cuales se deben abatir en 90 a 95\% para la mayoría de aplicaciones de consumo humano. El contenido mineral del lactosuero varía en función del pH existente al momento de su separación del coágulo. Entre mas bajo sea el $\mathrm{pH}$, habrá mayor cantidad de fosfato de calcio.

La desmineralización por intercambio iónico es un método desarrollado inicialmente para el tratamiento de aguas que también puede ser usado con el lactosuero. En su forma tradicional es una técnica que contempla el uso de resinas en un lecho fijo, las cuales tienen la capacidad de captar iones de una solución que fluye a través del lecho, liberando a cambio iones hidrógeno y iones hidroxilo hasta un punto en el cual se agotan, debiendo ser regeneradas.

La remoción de iones sigue un orden general de selectividad, conforme al cual los iones multivalentes tienen preferencia sobre los monovalentes. Para iones de la misma valencia, la selectividad es conforme al tamaño iónico. Así, para los líquidos típicos manejados en la industria de lácteos, se tiene el siguiente orden de selectividad:

Cationes: calcio $>$ magnesio $>$ potasio $>$ sodio

Aniones: citrato $>$ fosfato $>$ nitrato $>$ cloruro

Durante la desmineralización se puede dar también una pérdida significativa de proteinas por precipitación si estas están presentes, debido a las variaciones de $\mathrm{pH}$ que el fluido complejo experimenta al pasar por las columnas de intercambio aniónico y catiónico. Esta pérdida de proteínas puede reducirse mediante un enfriamiento del suero hasta 5 o $10 \mathrm{C}$ antes de la operación (163). Para regenerar las resinas de intercambio se utilizan soluciones diluidas de ácido clorhídrico e hidróxido de sodio. Algunos otros inconvenientes importantes de este tipo de desmineralización son el alto consumo de productos químicos para la regeneración de resinas y el uso de grandes cantidades de agua de lavado.

Se ha desarrollado un proceso modificado de desmineralización, conocido como proceso del bicarbonato de amonio o proceso SMR (163), (272), el cual reduce el consumo de agua y productos de regeneración.

El creciente conocimiento en el campo de las membranas permitió que recientemente se desarrollaran otros métodos para la desinineralización del suero lácteo, basados en el uso de membranas selectivas a través de las cuales los iones pueden viajar bajo la influencia de un campo eléctrico. El proceso comercial se denomina electrodiálisis y se están perfeccionando algunos 
aspectos de su operación, como la polarización de la concentración, el bloqueo frecuente de las membranas, etcétera.

La tabla 2-17 describen algunos estudios interesantes acerca de la desmineralización del lactosuero.

TABLA 2-17

ALGUNOS ESTUDIOS RLCIENTES SOBRE DESMINERALIZACION DIE LACIOSULRO

\begin{tabular}{|c|c|}
\hline Referencias & Contenido \\
\hline 202,25 & $\begin{array}{l}\text { Revisión de las aplicaciones prácticas de la electrodiálisis, incluyendo la } \\
\text { desmineralización de lactosuero y otros fluidos lácteos }\end{array}$ \\
\hline 163 & $\begin{array}{l}\text { Descripción de principios generales del intercambio iónico y comparación del } \\
\text { proceso convencional para desmineralización de suero con el proceso SMR (o del } \\
\text { bicarbonato de amonio) }\end{array}$ \\
\hline 117 & $\begin{array}{l}\text { Descripción de un proceso de ósmosis inversa modificado, denominado de ultra- } \\
\text { ósmosis y su aplicación en la separación de cloruro de sodio de lactosuero salado }\end{array}$ \\
\hline 272 & $\begin{array}{l}\text { Estudio del comportamiento de cuatro resinas diferentes de intercambio aniónico y } \\
\text { cinco de intercambio catiónico en la desmineralización de lactosuero por el } \\
\text { proceso del bicarbonato de amonio }\end{array}$ \\
\hline
\end{tabular}

\subsubsection{Lactosa.}

El potencial contaminante del lactosuero se debe principalmente a la lactosa, por lo que su remoción es indispensable a fin de abatir dicho potencial. Esto se puede lograr usando evaporación, cristalización y secado por aspersión. La lactosa existe en dos formas isoméricas, alfa y hela, que difieren entre sí por la configuración de un grupo hidroxilo en la posición 1 del lado glucosado del disacárido (278). La forma alfa se prefiere para la mayoría de las aplicaciones actuales.

En solución, los isómeros de lactosa coexisten en equilibrio, con $63 \%$ para la forma beta. Al secar por aspersión, la lactosa obtenida es predominantemente $a l f a$, mientras que al secar por tambor rotatorio (con mayor exposición al calor) se obtiene con preponderancia la forma beta (279), (39). Como sucede con otras ęspecialidades químicas, el mercado de la lactosa es pequeño, pero de alto valor agregado. Se estima que 5\% del lactosuero que se produce en el mundo contiene suficiente lactosa para abastecer la demanda mundial de este producto, cuyas aplicaciones principales son en alimentos maternizados e infantiles, chocolates y productos derivados, conservas de frutas, panadería, embutidos, sopas, cremas, etcétera. Se están estudiando nuevas aplicaciones, con base en sus propiedades de absorción de sabores y como agente inhibidor de iones metálicos (249). En farmacia se usa como facilitador del empastillado, acarreador y relleno (39). Existen varios derivados de la lactosa con aplicaciones también en alimentos y farmacia, tales como el lactato de amonio, la lactulosa, el lactitol y el ácido lactobiónico (249).

En la tabla 2-18 se presentan algunos estudios relacionados con la purificación y usos de lactosa de lactosuero. 
TABL $\wedge 2-18$

ALGUNAS REFERENCIAS RECIENTES SOBRE PURIFICACION Y USOS DF LACIOSA DI: LACTOSUERO

\begin{tabular}{|c|c|}
\hline Referencias & Contenido \\
\hline $\begin{array}{l}348,141,279 \\
103(\text { Cap. } 1 \\
Y 2)\end{array}$ & $\begin{array}{l}\text { Revisión sobre alternativas de procesamiento de lactosa, incluyendo estructura, } \\
\text { propiedades, hidrólisis, modificación hacia lactitol, laclulosa, lactosil urea, ácicio } \\
\text { lactobiónico y ácido glucónico }\end{array}$ \\
\hline 365 & Relevancia nutricional y aspectos digestivos de la lactosa y sus derivados \\
\hline 336 & $\begin{array}{l}\text { Comparación de procesos por lotes y continuo para recuperación de lactosa de } \\
\text { lactosuero }\end{array}$ \\
\hline 242 & $\begin{array}{l}\text { Revisión de los aspectos generales: preparación, fisiologia, hidrólisis por la } \\
\text { microflora intestinal, actividad como Factor Bifidus, aspectos favorables a la salud, } \\
\text { toxicología y aplicaciones de la lactulosa, un azúcar derivado de la lactosa }\end{array}$ \\
\hline 32 & $\begin{array}{l}\text { Revisión de la estructura, preparación, propiedades y usos del lactitol, un agente } \\
\text { endulzante derivado de la lactosa con aplicaciones a la dieta de diabéticos }\end{array}$ \\
\hline 245 & $\begin{array}{l}\text { Estudio de la factibilidad técnica para producir lactosa grado alimenticio y grado } \\
\text { farmacéutico. Estándares de calidad de ambos grados }\end{array}$ \\
\hline 257 & $\begin{array}{l}\text { Estudio de las propiedades de complejación con iones metálicos y adsorción de } \\
\text { compuestos volátiles por la lactosa. Estudio del proceso de cristalización de la } \\
\text { misma desde soluciones acuosas }\end{array}$ \\
\hline 259,275 & $\begin{array}{l}\text { Estudio del efecto de diversos agentes precipitadores en la precipitación de lactosa } \\
\text { desde soluciones acuosas }\end{array}$ \\
\hline 322 & $\begin{array}{l}\text { Estudio de laboratorio por lotes del crecimiento aerobio de Klehsiella oxy foca } \\
\text { sobre lactosa con sustrato simple y con varios substratos dobles, analizando } \\
\text { oscilaciones resultantes en la densidad celular }\end{array}$ \\
\hline 278 & Aplicaciones de la lactosa en la industria panadera \\
\hline
\end{tabular}

\subsubsection{4 lactosuero desproteinado (permeato)}

Las tecnologías orientadas hacia productos de alto valor agregado, requieren complementarse con aplicaciones de gran escala del permeato desproteinado remanente, el cual contiene 35-50 g/ de lactosa, sales, vitaminas y algo de ácido láctico. La falta de aplicaciones de este permeato constituye hoy en día un obstáculo importante para el aprovechamiento de mayores cantidades de lactosuero. Diversas posibles soluciones se vienen estudiando con gran intensidad desde los años ochenta, buscando una forma económica de obtener productos cuyo mercado potencial sea de gran escala para poder procesar las enormes cantidades de lactosuero producido. Entre las operaciones biotecnológicas mas estudiadas para el procesamiento de lactosa de lactosuero se encuentran la fermentación y la hidrólisis.

I) Fermentación. 
El término "fermentación" significa la transformación ordenada de materiales por la acción de microorganismos. Los microorganismos empleados en la fermentación pueden ser levaduras, bacterias, hongos, etcétera (88). Algunos procesos de fermentación se usan en la industria desde hace un siglo (266). En los siguientes párrafos se presentan algunos aspectos de los procesos fermentativos aplicables al permeato desproteinado de lactosuero.

a) Las generalidades de los procesos.

En primera instancia, lo que todo microorganismo tiende a hacer espontáneamente es alimentarse y reproducirse. Manipulando estas tendencias naturales mediante la selección del microorganismo deseado y su colocación en estado puro y apto para reproducirse en un medio provisto de alimento, donde se mantengan constantes los parámetros ambientales (temperatura, $\mathrm{pH}$, oxígeno, etcétera.) de modo que su desarrollo sea óptimo, los biotecnólogos obtienen productos de interés, ya sea una cosecha aumentada de los propios microorganismos o algunos productos sintetizados por estos como parte de su actividad vital.

La necesidad de controlar con precisión las condiciones ambientales de la fermentación implica usualmente la no existencia de otros microorganismos en el medio, así como la adición o remoción de calor, nutrientes, agua, acondicionamiento de un ambiente oxigenado o anaeróbico, agitación, remoción de productos, etcétera, todo lo cual plantea dificultades muy serias durante el escalamiento del proceso a nivel industrial.

Tratándose de fermentaciones de lactosuero, la lactosa contenida es la única fuente de carbono disponible para el desarrollo microbiano. En ocasiones se requiere enriquecerla con otros micronutrientes para formar un sustrato adecuado al microorganismo empleado. La concentración inicial de lactosa puede ser un factor limitante para ciertas fermentaciones, lo que supone en esos casos la necesidad de concentrar o diluír el permeato antes de iniciar el proceso de fermentación. En general existen dos tendencias en los procesos: transformar la lactosa en especies químicas accesibles al microorganismo por medio de la hidrólisis, o usarla directamente con microorganismos capaces de metabolizar ese sustrato. En ambas tendencias también se puede optar por centrar el interés en hacer crecer el microorganismo en el medio, obteniendo así un material (biomasa) de mayor contenido proteico o interesarse principalmente en los productos metabolizados por él (249).

\section{b) Los productos:}

Existe una diversidad de productos que se pueden obtener del permeato desproteinado por la vía de la fermentación, al menos a nivel de laboratorio. Entre ellos se pueden mencionar algunos de alto consumo en la industria química, como el etanol, butanol, acetona, metano, etcétera.

También es factible producir especialidades químicas con alto valor agregado como ácido láctico, levadura de panadería, biomasa, lactasa, goma de xantina y otros.

El etanol es uno de los productos de fermentación del lactosuero con mayores posibilidades de viabilidad económica según diversos estudios y se puede obtener usando diferentes microorganismos. Se le puede producir en concentraciones hasta de $12 \%(\mathrm{v} / \mathrm{v})$ usando $\mathrm{K}$. fragilis sobre lactosuero desproteinado concentrado ( $40 \mathrm{~g} / \mathrm{l}$ de lactosa) por 40 horas $(250)$. También mediante (. pseudotropicalis sobre suero desproteinado concentrado ( $20.1 \%$ de lactosa), se puede obtener $9.7 \%(\mathrm{w} / \mathrm{v})$ de etanol sin necesidad de nutrientes adicionales (209)

Una mezcla de solventes (acetona, butanol y etanol) se puede lograr de (: acetohutylicum al fermentar lactosuero. La concentración normal de lactosa en el suero concuerda con la necesidades 
de este microorganismo. las condiciones de operación incluyen reposo por 120 horas a un pl de 6 y temperatura de $37 \mathrm{C}(354)$. El producto final contendrá alrededor de $0.6 \%$ en peso de acetona, $1.5 \%$ de butanol y $0.2 \%$ de etanol (57).

La producción de levadura de panadería se basa en la fermentación de ácido láctico y galactosa como substratos. El proceso a partir de lactosuero se puede iniciar con $S$. thermophilus, el cual transforma una parte de la lactosa en ácido láctico, al mismo tiempo que excreta galactosa en el medio. Algunos estudios estiman una eficiencia máxima de conversión de lactosa en levadura de panadería de $31 \%(249)$.

$K$. fragilis es una de las mejores opciones para producir biomasa de lactosuero. En algunos casos, es conveniente iniciar la fermentación con otros microorganismos, como K. lactis o

propionibacterium sp. El proceso requiere un intenso suministro de oxígeno (367).

La producción de ácido láctico por medio de bacterias lácticas es uno de los procesos de mayor eficiencia de conversión del sustrato ya que no se produce $\mathrm{CO}_{2}$. Se logran conversiones de hasta 0.9 g de ácido láctico por cada gramo de lactosa empleada, frente a rendimientos del orden de la mitad para el caso del etanol por levaduras (233). Entre las aplicaciones de interés para el ácido láctico se puede mencionar la producción de lactato de amonio, el cual es una fuente de nitrógeno tan buena como la soya en la alimentación de bovinos (249). Otra aplicación de interés es la producción de copolímeros de ácido láctico para la fabricación de materiales biodegradables con características de termoplásticos. Esto es posible gracias a que el ácido láctico contiene en su estructura los grupos hidroxilo y carboxilo, por lo que se puede convertir en poliésteres con relativa facilidad (199). La producción de lactasa (que es la enzima beta-D-galactosidasa) por fermentación de permeatos de suero, es otro ejemplo de procesos de alta tecnología. La lactasa es una enzima de gran importancia para reducir por hidrólisis el contenido de lactosa en la leche y otros productos lácteos. Las primeras preparaciones comerciales aparecieron a principios de los años setenta (130). La enzima se puede obtener de diversos microorganismos, como Aspergillus niger, A. oryzae, Kluyveromyces fragilis, K. Lactis, Lactobacillus thermophilus, Leuconostoc citrovortm e incluso Escherichia coli (293), siendo el origen de las enzimas un factor con influencia en el resultado de la hidrólisis.

En la producción de polisacáridos que contienen galactosa, como la goma de xantina, parece ser especialmente adecuada la utilización de lactosuero, pues como la lactosa es un disacárido de glucosa-galactosa, es posible sintetizar metabólicamente polisacáridos de galactosa directamente de los monosacáridos, sin emplear pasos metabólicos intermedios de glucosa (43). La concentración original de lactosa en el suero también es apropiada para alcanzar al final del proceso una concentración de alrededor de $3 \%$ del polisacárido, con conversiones de 50 a $60 \%$ del sustrato, lo que es típico en la producción de otros polisacáridos (43).

Aunque existen diversos organismos potencialmente viables para esta fermentación, el mas usual es $X$. campestris. Este, en su estado natural, es mucho más apto para fermentar glucosa que lactosa, por lo que una opción para este proceso consiste en descomponer la lactosa previamente por hidrólisis. En un enfoque diferente, se ha consignado el desarrollo en laboratorio de una cepa capaz de fermentar lactosuero sin ultrafiltración ni hidrólisis previas (307).

Las aplicaciones de la goma de xantina están concentradas actualmente en las áreas de alimentos y explotación petrolera, por lo que algunos autores consideran que su demanda mundial es moderada y en consecuencia no constituye un destino masivo para el permeato de suero lácteo (330). No obstante, se desarrollan activamente diversas investigaciones que podrían ampliar enormemente los mercados potenciales del producto (43), (339). 


\section{c) Las separaciones.}

Una gran parte de la energía requerida en los bioprocesos se usa para concentrar el producto de la solución acuosa en que se encuentra. El método convencional para esta concentración es la destilación. Se han propuesto algunas alternativas de menor consumo de energía, tales como la extracción por solvente, lavado por arrastre con $\mathrm{CO}_{2}$ en condiciones supercríticas, separación con ayuda de vacío, pervaporación (una combinación de difusión y evaporación utilizando membranas), perstracción, ultrafiltración, absorción preferencial en línea, absorción en dos etapas, etcétera. (269). Entre los procesos de separación por membrana, la ósmosis inversa tiene aplicación limitada, debido a la elevada presión osmótica de las mezclas que se van a separar, de modo que la concentración del producto obtenido dificilmente supera 30\%. Esta limitación no existe en el método de pervaporación cuando se mantiene el permeato por debajo de su presión de vapor de saturación.

La fracción del permeato en la fase de vapor se remueve con una bomba de vacío, con un gas de arrastre o por la condensación en pared fría. Desafortunadamente, la eficiencia energética de la pervaporación es menor que la de la ósmosis inversa.

Aunque la investigación con membranas sólidas continúa, las membranas líquidas parecen ser mas prometedoras para lograr la separación de los productos de la fermentación. Un atractivo adicional de las membranas líquidas es la facilidad para cambiar sus características, eligiendo entre diversos alcoholes y ésteres de alto punto de ebullición no se presentan problemas de estabilidad de estas membranas debido al vacío empleado en el proceso.

\section{d) La disposición de efluentes.}

Con muy pocas excepciones los métodos de aprovechamiento de lactosuero o sus componentes generan efluentes contaminantes, que pueden requerir un tratamiento final antes de ser descartados. Existen tratamientos biológicos anaerobios, aerobios o una combinación de ambos.

El proceso de lodos activados ampliamente usado para tratar efluentes industriales, resulta poco adecuado para un desecho de tan alto potencial contaminante como el lactosuero fresco, a causa de las grandes cantidades de energía requeridas para la aereación y el mezclado.

En cambio, los sistemas anaerobios tienen menor costo de operación y producen metano. Las principales objeciones a estos sistemas son su poca estabilidad de operación y baja capacidad de procesamiento. Cuando la fermentación se realiza en lagunas y no en digestores, se requieren grandes extensiones de terreno y se presentan problemas de mal olor e imposibilidad práctica de recuperar el metano (36).

Los sistemas mixtos anaerobio-aerobio para tratamiento de lactosuero son mucho más eficientes en conjunto que cualquiera de ellos en forma independiente.

Son raras las aplicaciones de fermentación anaerobia hacia metano con el propósito de aprovechamiento. Mas bien se usan como tratamiento final y sólo cuando es posible se recupera el producto (una mezcla de 50 a $60 \%$ de metano en $\mathrm{CO}_{2}$ llamado biogas) para reemplazar parcialmente el combustible utilizado en el propio proceso y en procesos colaterales. El uso de floculantes químicos durante el arranque y la operación de digestores en semicontinuo ha mejorado considerablemente la capacidad y confiabilidad de estos equipos. El desarrollo de digestores mas eficientes y confiables es un área que se investiga en la actualidad (36). De cualquier forma, la producción de especies químicas con fines combustibles es menos atractiva que como suministros químicos. Algunos autores estiman que los precios de estos suministros son unas tres veces más altos que su valor como combustibles (260). 
e) Ia economia.

La problemática económica de los bioprocesos de lactosuero se debe principalmente a las altas diluciones de sustratos y productos impuestas por las características de los microorganismos y del propio lactosuero, así como a la fuerte competencia del petróleo y de otras materias primas alternas para producir los mismos productos. Lo anterior se puede ilustrar con dos ejemplos: en la bioproducción de etanol, los precios de otros sustratos alternos como el azúcar impiden en algunos países la factibilidad económica del uso de lactosuero, el cual resulta comparativamente más costoso a causa de su requerido acondicionamiento, manejo y transporte. Lo mismo se puede decir de la producción de biomasa, en la que el principal obstáculo a la competitividad económica proviene del bajo costo de la proteína de soya.

Hasta el momento, ninguno de los productos que se pueden obtener por fermentación de lactosuero y que podrian consumir grandes cantidades de este, ha logrado llegar con rentabilidad económica, a la escala industrial.

En las tablas 2-19 a 2-27 se describen algunos estudios relacionados con la fermentación de lactosa, lactosuero o permeato.

TABLA 2-19

\begin{tabular}{|c|c|c|}
\hline \multicolumn{3}{|c|}{ ETANOL UTLLIZANDO LAC TOSA COMO FUENTE DE CARBONO } \\
\hline Referencias & Contenido & Microorganismo \\
\hline 234 & $\begin{array}{l}\text { Estudio de fermentación de permeato hidrolizado de lactosuero en } \\
\text { reactor de reciclo con membrana }\end{array}$ & $\begin{array}{l}\text { Saccharomyces } \\
\text { cerevisiae }\end{array}$ \\
\hline 152 & $\begin{array}{l}\text { Comparación experimental y selección de }(\therefore \text { pseudotropicalis } \\
\text { ATCC } 8619 \text { de entre nueve alternativas para fermentar lactosuero } \\
\text { concentrado hacia etanol }\end{array}$ & diversos \\
\hline 109 & $\begin{array}{l}\text { Estudio de fermentación continua en dos reactores tubulares en serie, } \\
\text { usando células inmovilizadas y lactosa obtenida de un lactosuero } \\
\text { desproteinado y desmineralizado }\end{array}$ & $\begin{array}{l}\text { Kluyveromyces } \\
\text { frágilis }\end{array}$ \\
\hline 133 & $\begin{array}{l}\text { Uso de células de bacterias y levaduras co-inmovilizadas con lactasa } \\
\text { para producción de etanol de lactosa }\end{array}$ & $\begin{array}{l}\text { S. cercevisiac' } \\
\text { Z. móbilis }\end{array}$ \\
\hline 277 & $\begin{array}{l}\text { Proceso para producir etanol a base de lactosuero reconstituido, } \\
\text { ultrafiltrado y desmineralizado. Se incluye análisis de costos }\end{array}$ & $\begin{array}{l}\text { Khuveromyces } \\
\text { frágilis }\end{array}$ \\
\hline 221 & $\begin{array}{l}\text { Estudios comparativos de fermentación por lotes de lactosa para } \\
\text { producir etanol usando } K \text {. marxiamus libre e inmovilizada y } S \\
\text { cerevisiae }\end{array}$ & diversos \\
\hline 370 & $\begin{array}{l}\text { Ajuste experimental de parámetros para óptima fermentación de } \\
\text { permeato de lactosuero hacia etanol con } K \text { frógilis y } K \text {. lactis }\end{array}$ & diversos \\
\hline 206,71 & $\begin{array}{l}\text { Descripción de algunos procesos desarrollados en los años setenta } \\
\text { para producción de etanol de lactosuero (procesos Milbrew, } \\
\text { Carberry Denmark y Lacto-Whey) }\end{array}$ & $\begin{array}{l}\text { K. frógilis, } \\
\text { T. crémoris }\end{array}$ \\
\hline 342 & $\begin{array}{l}\text { Estudio de los efectos de inhibición del etanol y otras limitaciones } \\
\text { durante la fermentación de permeato concentrado de lactosuero }\end{array}$ & $\begin{array}{l}\text { K. frágilis } \\
\text { NRRL } 665\end{array}$ \\
\hline
\end{tabular}


TABILA 2-20

ALGUNOS ESTUDIOS SOBRE FERMENTACIONES PARA PRODUCCION DE BIOGAS UTILIZANDO LACTOSA O LACTOSUERO

\begin{tabular}{|c|c|c|}
\hline Referencias & Contenido & Microorganismo \\
\hline 200,360 & $\begin{array}{l}\text { Estudio de un sistema integrado anaerobio/aerobio de una } \\
\text { mezcla de laclosuero y estiércol de ganado. Se estudió la } \\
\text { producción de metano a diferentes cargas orgánicas y la } \\
\text { eficiencia del tratamiento integrado. Se estudió adeinás el caso } \\
\text { anaerobio con reactor de lodos de flujo ascendente }\end{array}$ & Diversos \\
\hline 54 & $\begin{array}{l}\text { Estudio del tratamiento por filtrado anaeróbico de las aguas de } \\
\text { desecho en la industria de lácteos y de la producción de biogas }\end{array}$ & Diversos \\
\hline 306 & $\begin{array}{l}\text { Estudio del efecto de iones calcio respecto a la floculación de } \\
\text { lodos y producción de biogas en un reactor de lodos de flujo } \\
\text { ascendente }\end{array}$ & Diversos \\
\hline 178 & $\begin{array}{l}\text { Estudio sobre la cinética de crecimiento microbiano para la } \\
\text { fase acidogénica de lactosa a pl l de } 4.5 \text { y } 6\end{array}$ & Diversos \\
\hline 180 & $\begin{array}{l}\text { Estudio de la etapa acidogénica de fermentación de lactosa a } \\
\text { diferentes valores de } \mathrm{pH}\end{array}$ & Diversos \\
\hline 64,63 & $\begin{array}{l}\text { Estudio del efecto del contenido proteico, de la relación } \mathrm{C} / \mathrm{N} \text { y } \\
\text { del uso de diversos tratamientos neutralizantes alternos en la } \\
\text { metanogénesis de lactosuero en reactor estacionario de lecho } \\
\text { fijo y flujo ascendente }\end{array}$ & Diversos \\
\hline 179 & $\begin{array}{l}\text { Estudio del efecto de la dilución en la distribución de } \\
\text { productos de la fase acidogénica durante la fermentación } \\
\text { anaerobia de lactosa en dos fases }\end{array}$ & Diversos \\
\hline
\end{tabular}

TABLA 2-21

ALGUNOS ESTUDIOS SOBRE FERMENTACIONES PARA PRODUCCION DE GLICEROL, UTILIZANDO LACTOSA O GLUCOSA/GALACTOSA

\begin{tabular}{|l|l:l|} 
Referencias & Contenido & Microorganismo \\
346 & $\begin{array}{l}\text { Revisión de literatura reciente sobre la producción de glicerol } \\
\text { por fermentación a partir de diversos azúcares como sustratos }\end{array}$ & Diversos \\
347,345 & $\begin{array}{l}\text { Fermentación aerobia de glucosa y pérdida de especificidad } \\
\text { hacia glicerol en función de la concentración de oxigeno } \\
\text { disuelto y agitación }\end{array}$ & Pichia farinosa \\
\hdashline 344 & Fermentación aerobia de glucosa & \\
& & PTChia farinosa \\
& &
\end{tabular}


TABLA 2-22

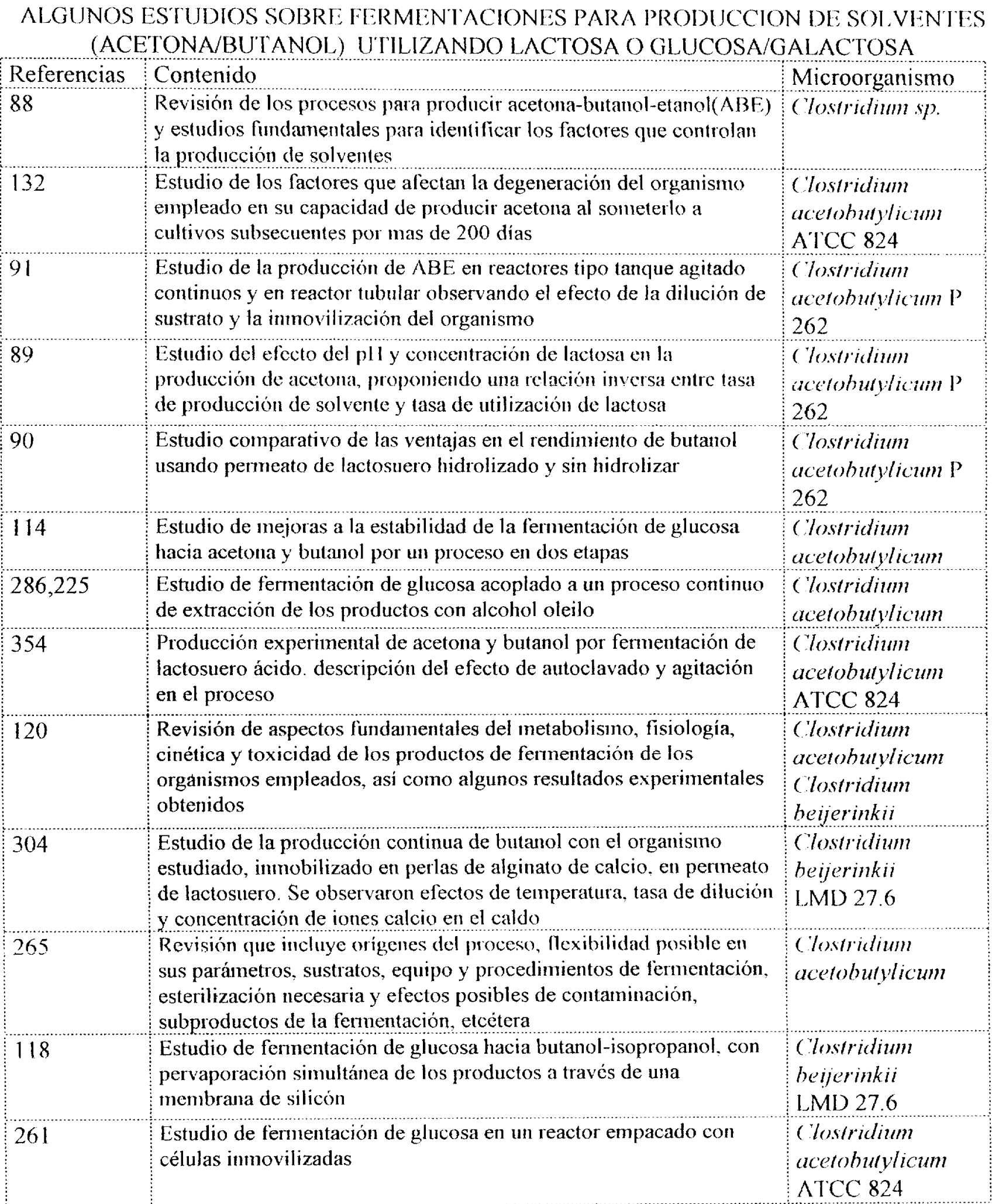


TABLA 2-22

(CONTINUACION)

\begin{tabular}{|c|c|c|}
\hline 57 & $\begin{array}{l}\text { Fstudio de la recuperación de acetona y butanol mediante un } \\
\text { sistema de extracción acoplado. Incluye la selección del mejor } \\
\text { solvente }\end{array}$ & \\
\hline 281 & $\begin{array}{l}\text { Estudio del mejoramiento en la selectividad hacia butanol en } \\
\text { fermentaciones continuas de glucosa }\end{array}$ & $\begin{array}{l}\text { Clostridium } \\
\text { acetobutylicum }\end{array}$ \\
\hline 100,99 & $\begin{array}{l}\text { Estudio comparativo de la cinética de fermentación hacia } \\
\text { acetona/butanol usando como sustratos glucosa, xilosa y una } \\
\text { mezcla de ambas. Se compararon además cultivos por lotes } \\
\text { simples y por lotes en cascada }\end{array}$ & $\begin{array}{l}\text { Clostridium } \\
\text { acelobufylicum }\end{array}$ \\
\hline 271 & $\begin{array}{l}\text { Fermentación continua con un ultrafiltro de fibra hueca } \\
\text { acoplado para separar y reciclar células }\end{array}$ & $\begin{array}{l}\text { Clostridium } \\
\text { acetobutylicum }\end{array}$ \\
\hline 355 & $\begin{array}{l}\text { Estudio del efecto de la concentración de lactosa y el grado de } \\
\text { agitación en una fermentación por lotes }\end{array}$ & $\begin{array}{l}\text { Closiridium } \\
\text { acetobuylicum } \\
\text { ATCC } 824\end{array}$ \\
\hline 81 & $\begin{array}{l}\text { Estudio del efecto de la agitación y la presión sobre la } \\
\text { producción fermentativa de acetona/butanol }\end{array}$ & \\
\hline 3,298 & $\begin{array}{l}\text { Estudio del incremento en la producción de solventes } \\
\text { mediante cultivo continuo con reciclo de células durante la } \\
\text { fermentación de glucosa }\end{array}$ & $\begin{array}{l}\text { Clostridium } \\
\text { acetobutylicum }\end{array}$ \\
\hline 216 & $\begin{array}{l}\text { Optimización a nivel de planta piloto de la fermentación hacia } \\
\text { acetona/butanol utilizando alcachofa Jerusalén como sustrato }\end{array}$ & $\begin{array}{l}\text { Clostridium } \\
\text { acetobutylicum }\end{array}$ \\
\hline 97 & $\begin{array}{l}\text { Estudio de la estabilidad a largo plazo del microorganismo en } \\
\text { la fermentación continua de glucosa a acetonabutanol }\end{array}$ & $\begin{array}{l}\text { Clostridium } \\
\text { acetobutylicum }\end{array}$ \\
\hline 321 & $\begin{array}{l}\text { Estudios de fermentación por lotes y continua sobre glucosa y } \\
\text { xilosa para producir acetona y butanol }\end{array}$ & $\begin{array}{l}\text { C. saccharoper- } \\
\text { butylacetoni-cum }\end{array}$ \\
\hline 23 & $\begin{array}{l}\text { Estudio de la toxicidad de los productos finales del } \\
\text { metabolismo en el crecimiento microbiano distinguiéndose el } \\
\text { efecto de las especies en fase gaseosa }\end{array}$ & $\begin{array}{l}\text { Clostridium } \\
\text { acetobutylicum }\end{array}$ \\
\hline 166 & $\begin{array}{l}\text { Metodología para seleccionar mutantes con mayor resistencia } \\
\text { a inhibición debida a los productos de fermentación }\end{array}$ & $\begin{array}{l}\text { Clostridium } \\
\text { acetobutylicum }\end{array}$ \\
\hline 96 & $\begin{array}{l}\text { Estudio del comportamiento de un ensamble con reciclo total } \\
\text { de biomasa por ultrafiltración y fermentación continuas para } \\
\text { estudios de fenómenos de inhibición y cultivos con alta } \\
\text { densidad celular }\end{array}$ & $\begin{array}{l}\text { Clostridium } \\
\text { acetobutylicum } \\
\text { ATCC } 824\end{array}$ \\
\hline
\end{tabular}


TABL $\triangle 2-23$

ALGUNOS ESTUDIOS SOBRE FERMENTACIONES PARA PRODUCCION DE PROTEINA UNICELULAR UTILIZANDO LACTOSA O GLUCOSA/GALACTOSA

\begin{tabular}{|c|c|c|}
\hline Referencias & Contenido & Microorganismo \\
\hline 238 & $\begin{array}{l}\text { Estudio de producción fermentativa de biomasa utilizando } \\
\text { lactosuero dulce, crudo }\end{array}$ & (ándida L Y 496 \\
\hline 85 & $\begin{array}{l}\text { Cultivo de diversos microorganismos en permeato de } \\
\text { lactosuero de queso Cheddar para producir biomasa con } \\
\text { distintos perfiles proteico y mineral }\end{array}$ & diversos \\
\hline 59 & $\begin{array}{l}\text { Estudio del lactosucro como posible fuente de productos } \\
\text { sustitutos de suero fetal de becerros en su aplicación al cultivo } \\
\text { de células eucariótidas }\end{array}$ & \\
\hline 326 & $\begin{array}{l}\text { Estudio de producción de biomasa y aceite unicelular (SCO) } \\
\text { por fermentación de lactosa o lactosuero y efecto del } \\
\text { envejecimiento del organismo }\end{array}$ & $\begin{array}{l}\text { Trichosporum } \\
\text { beigelii }\end{array}$ \\
\hline 357 & $\begin{array}{l}\text { Comparación de eficiencia de diversos organismos y } \\
\text { correlación entre la conversión a biomasa y disponibilidad de } \\
\text { oxígeno en el medio }\end{array}$ & Diversos \\
\hline 20 & $\begin{array}{l}\text { Revisión de procesos recientes para producción de proteina } \\
\text { unicelular de lactosuero }\end{array}$ & Diversos \\
\hline 230 & $\begin{array}{l}\text { Estudio de efectos de velocidad de agitación, concentración de } \\
\text { lactosa, suplementación nutricional y concentración de etanol } \\
\text { en la producción por lotes de biomasa }\end{array}$ & $\begin{array}{l}\text { Klayveromyces } \\
\text { marxianus } \\
\text { Y } 113\end{array}$ \\
\hline 86 & $\begin{array}{l}\text { Estudio sobre la influencia de la concentración de cloruro de } \\
\text { sodio en el crecimiento y productividad de distintos } \\
\text { organismos estudiados, fermentando permeato de lactosuero } \\
\text { de queso Cheddar para producir proténa unicelular }\end{array}$ & diversos \\
\hline
\end{tabular}

TABLA 2-24

ALGUNOS ESTUDIOS SOBRE FERMENTACIONES PARA PRODUCCION DE GOMA XANTINA UTILIZANDO LACTOSA O GLUCOSA/GALACTOSA

\begin{tabular}{|c|c|c|}
\hline Referencias & Contenido & Microorganismo \\
\hline 284 & $\begin{array}{l}\text { Estudio de la producción y simultánea concentración de goma } \\
\text { xantina utilizando un bio-reactor de transporte controlado }\end{array}$ & $\begin{array}{l}\text { Xanthomonas } \\
\text { campestris } \\
\text { NRRL B } 1459\end{array}$ \\
\hline 330 & $\begin{array}{l}\text { Construcción genética de un derivado de Xanthomonas } \\
\text { campestris que utiliza directamente la lactosa de lactosuero } \\
\text { clarificado para producir goma xantina }\end{array}$ & $\begin{array}{l}\text { Xanthomonas } \\
\text { campestris } \\
\text { B } 1459\end{array}$ \\
\hline
\end{tabular}


TABI,A 2-25

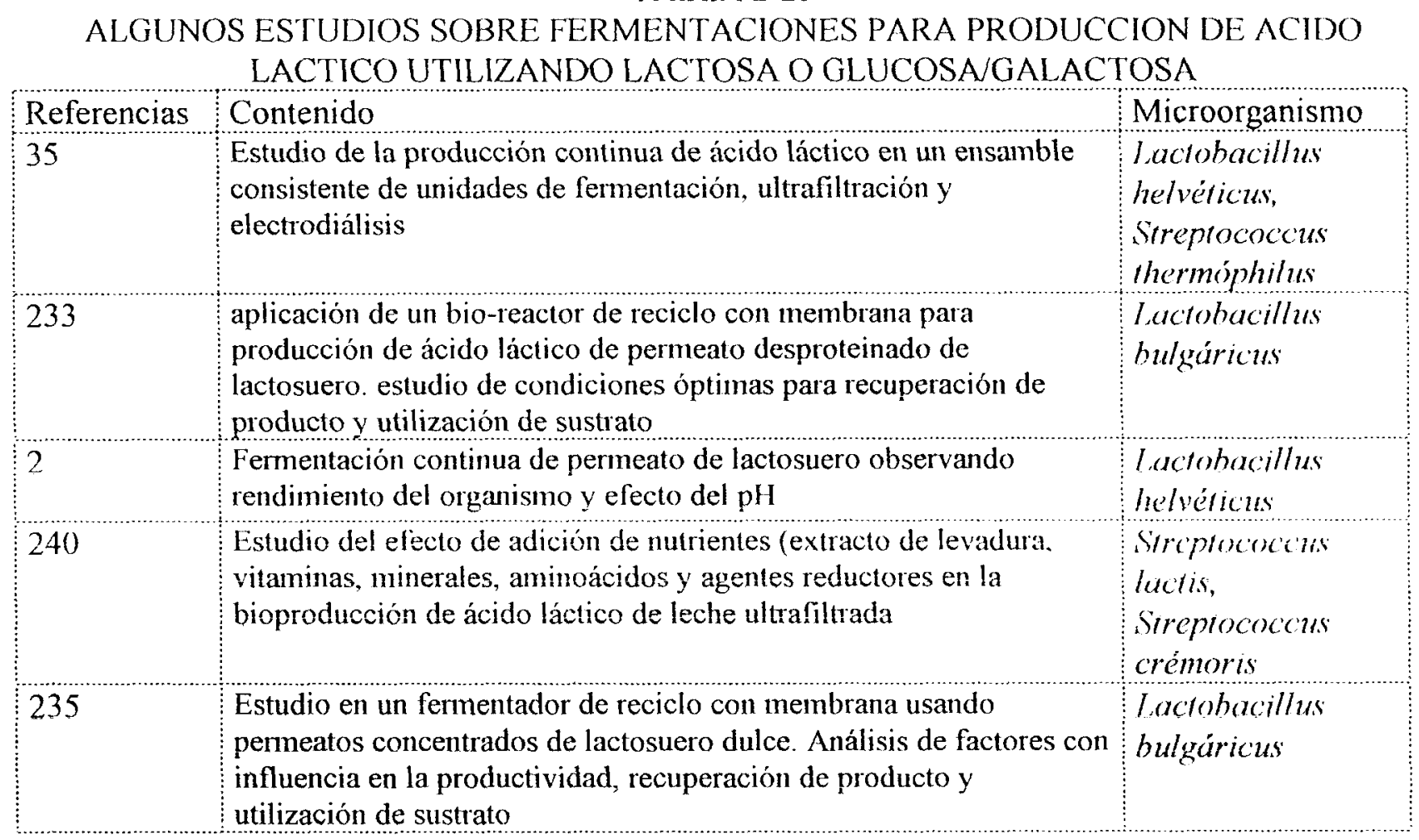

TABLA 2-26

\section{ALGUNOS ESTUDIOS SOBRE FERMENTACIONES PARA PRODUCCION DE LACTASA UTILIZANDO LACTOSA O GLUCOSAGGALACTOSA}

\begin{tabular}{|c|c|c|}
\hline Referencias & Contenido & Microorganismo \\
\hline 267 & $\begin{array}{l}\text { Revisión de literatura sobre procesos para obtener lactasa, } \\
\text { inmovilizarla y medir su actividad en función del pH, temperatura, } \\
\text { agentes inhibitorios, etcétera }\end{array}$ & Diversos \\
\hline 44 & $\begin{array}{l}\text { Estudio de fermentación sobre lactosa para producir lactasa } \\
\text { extracelular y caracterización preliminar de la enzima }\end{array}$ & $\begin{array}{l}\text { Trichoderma } \\
\text { reesei RUT C30 }\end{array}$ \\
\hline 319 & $\begin{array}{l}\text { Producción y caracterización de lactasa a partir de una cepa alta } \\
\text { productora, aprovechando sus propiedades autoliticas después del } \\
\text { crecimiento en un medio a base de permeato de suero lácteo }\end{array}$ & $\begin{array}{l}\text { Streptococcus } \\
\text { thermóphilus } \\
11 \mathrm{~F}\end{array}$ \\
\hline 219 & $\begin{array}{l}\text { Comparación de la actividad enzimática de lactasa producida por } \\
\text { cultivos en estado estable y por cultivos en estado transitorio }\end{array}$ & \\
\hline 108 & $\begin{array}{l}\text { Resumen de las principales fuentes posibles de la enzima, de sus } \\
\text { propiedades y de algunos procesos comerciales existentes }\end{array}$ & Diversos \\
\hline 209 & $\begin{array}{l}\text { Descripción del proceso por lotes y su comparación económica con } \\
\text { los procesos de fermentación hacia etanol y biomasa }\end{array}$ & $\begin{array}{l}\text { ('ándida } \\
\text { pseudoiropicalis } \\
\text { NCYC } 744\end{array}$ \\
\hline
\end{tabular}


TABLAA 2-27

ALGUNOS OTROS PRODUCTOS DE FERMENTACION UTILIZANDO LACTOSAO GLUCOSA/GALACTOSA

\begin{tabular}{|c|c|c|}
\hline Referencias & Contenido & Microorganismo \\
\hline 249 & $\begin{array}{l}\text { Revisión de los proceso mas conocidos para obtención de: } \\
\text { levaduras alimenticias }\end{array}$ & diversos \\
\hline 42 & Antocianina & Ajuga reprams \\
\hline 352 & Acetaldehido & Timomona móbilis \\
\hline 53 & ^cidos acético y propiónico & $\begin{array}{l}\text { Propionibacteriu } \\
\text { macidi-propionici }\end{array}$ \\
\hline 33 & Acido propiónico & $\begin{array}{l}\text { Propionibacteria } \\
\text { macidi-propinnici }\end{array}$ \\
\hline 30 & Acido propiónico y biomasa & $\begin{array}{l}\text { Propionibactoriu } \\
\text { macidi-propionici }\end{array}$ \\
\hline 340 & ^cido glucónico & $\begin{array}{l}\text { Siluconobacter } \\
\text { orydans }\end{array}$ \\
\hline 6 & Acido butírico & $\begin{array}{l}\text { (lostridium } \\
\text { beijerinckii }\end{array}$ \\
\hline 190 & 2,3 butanodiol & $\begin{array}{l}\text { Klebsiclla } \\
\text { pneumoniae }\end{array}$ \\
\hline 363 & Lípidos & $\begin{array}{l}\text { Apiotrichum } \\
\text { curvatum }\end{array}$ \\
\hline 288 & Energía eléctrica & $\begin{array}{l}\text { Excherichia coli } \\
\text { ML } 308\end{array}$ \\
\hline
\end{tabular}

II) Hidrólisis

La lactosa es un disacárido compuesto de una molécula de glucosa y otra de galactosa. Su disociación con adición de una molécula de agua por cada molécula de lactosa se denomina hidrólisis, y constituye una excelente opción para aumentar los usos posibles del permeato y del mismo lactosuero. Asimismo, la hidrólisis de lactosa mejora sus propiedades como constituyente de alimentos en tres aspectos: incrementa su solubilidad, aumenta su poder edulcorante y elimina el inconveniente de la intolerancia a la lactosa que pudieran tener algunos de los consumidores. A continuación se detallan dichos aspectos.

a) La solubilidad.

La solubilidad en agua de varios azúcares puros se muestra en la Tabla 2.28. En mezclas de azúcares, las solubilidades individuales se modifican por la presencia de los demás. Existen algunas correlaciones consignadas por Nickerson (293) para estimar solubilidades en mezclas de lactosa, glucosa y galactosa. 
TABLA $2-28$

SOLUBILIDAD DE DIVERSOS AZUCARES EN AGUA

\begin{tabular}{|l|c|c|c|c|}
\hline $\begin{array}{l}\text { CARBOH II- } \\
\text { DRATO }\end{array}$ & Sacarosa & Glucosa & Galactosa & Lactosa \\
\hline $\begin{array}{l}\% \text { SOLUBILI- } \\
\text { DAD }\end{array}$ & 67.9 & 45.4 & 40.6 & 18.0 \\
\hline
\end{tabular}

b) El poder edulcorante.

La medición del poder edulcorante es una determinación apreciativa; algunos autores establecen que, asignando un valor de 100 al poder edulcorante de la sacarosa, la lactosa tendria 15, en tanto que una mezcla de glucosa y galactosa en partes iguales (es decir, lactosa hidrolizada) tendría 70 (249).

Estimar el poder edulcorante de un carbohidrato es un asunto mas complicado de lo que parece, ya que en él intervienen entre otros los siguientes factores (293):

1. Temperatura. Se percibe distinto grado de endulzamiento en una solución a diferentes temperaturas.

2. Configuración química. La lactosa beta es mucho mas dulce que la lactosa alfa.

3. Concentración. El poder edulcorante no es una función lineal de la concentración del carbohidrato en la solución.

4. Efectos sinergéticos debidos a otros azúcares. Una mezcla de dos o mas azúcares distintos puede dar una percepción diferente de dulzura debido a efectos sinergéticos de los componentes.

5. Efectos sinergéticos no debidos a otros azúcares. Las dulzuras relativas se determinan normalmente en soluciones estándar y no en alimentos preparados. Existen efectos que no se consideran en las soluciones estándar debidos a las sales, ácidos y saborizantes de los alimentos, que modifican la dulzura advertida en ellos. Incluso existen efectos de sabor debidos al orden en que se adicionan los componentes, a la forma de mezclarlos y a los procesos térmicos a que se sujete la mezcla.

Los tipos de hidrólisis.

La literatura establece dos tipos de hidrólisis de lactosa: enzimática y ácida. La primera de ellas es la más común y estudiada.

a) Hidrólisis enzimática.

Esta se puede clasificar conforme al modo de operación de la enzima en libre o inmovilizada. Dado que la hidrólisis de lactosa produce dos azúcares (glucosa y galactosa), esta tecnología es una buena alternativa en situaciones de escasez o altos precios del azúcar. Las primeras aplicaciones de hidrólisis enzimáticas de lactosa en productos lácteos datan de los años cincuenta. Durante los sesenta, se reconoció que la intolerancia a la lactosa es una situación muy extendida en el mundo; se presenta en el 95\% de los habitantes de paises asiáticos y africanos. En Norteamérica, 70\% de la población no blanca es intolerante a la lactosa (249). 
Para hidrolizar lactosa proveniente de lactosueros ácidos son mas apropiadas las enzimas procedentes de $A$. niger, por su pH ácido y temperatura de operación relativamente alta. No requieren iones metálicos para su estabilidad, aunque son inhibidas fuertemente por la D-galactosa producida, retardando la conversión

Para hidrolizar lactosuero dulce son recomendables las enzimas provenientes de $K$. frágilis, las que operan en un pH neutro, temperaturas moderadas y son menos inhibidas por la D-galactosa formada, aunque no son muy estables. Dentro de cierto intervalo de valores, los factores tiempo y temperatura son recíprocos en una hidrólisis, de modo que un grado de conversión determinado se alcanza en menos tiempo a mayor temperatura, y viceversa

La modalidad de inmovilizar a la enzima permitió su reutilización, con lo que se redujeron significativamente los costos de proceso. Existen diversas técnicas de inmovilización, basadas generalmente en adsorción, atrapamiento o enlace covalente (293). Un problema de los sistemas inmovilizados es que se requieren tiempos de operación del ciclo muy reducidos para evitar la contaminación microbiana $(220)$

b) Hidrólisis ácida.

La hidrólisis ácida se puede lograr con ácidos minerales; sin embargo, casi siempre se prefiere usar resinas de intercambio catiónico, ya que se elimina el paso de la desmineralización previa. Existen dos tipos de procesos con resinas catiónicas; en el primero, la columna empacada con resina sirve como reactor operando entre 90 y $100 \mathrm{C}$. En el segundo, la resina se utiliza para reducir el pH del permeato a 1.2 , en un paso previo a la hidrólisis (130)

Los mayores problemas de la hidrólisis ácida son las fuertes reacciones que ocurren, dando tonos café oscuro al producto cuando la carga tiene algo de proteínas o péptidos. Incluso la hidrólisis de permeatos ultrafiltrados requiere de complicadas etapas de remoción de color. La hidrólisis ácida sólo se ha empleado industrialmente con soluciones de lactosa pura, no con lactosuero (130).

La hidrólisis de lactosa ha recibido gran atención de los especialistas, como puede verse en la tabla $2-29$

TABLA 2-29

ALGUNAS REFERENCIAS RECIENTES SOBRE HIDROLISIS DE LACTOSA

\begin{tabular}{|c|c|}
\hline Referencias & CONTENIDO \\
\hline 267 & $\begin{array}{l}\text { Estudio teórico-experimental de caracterización de la hidrólisis de lactosa en } \\
\text { reactor enzimático de lecho capilar y modelo matemático para describir la cinética } \\
\text { de la reacción y los flujos dentro del reactor }\end{array}$ \\
\hline 274 & $\begin{array}{l}\text { Detalles técnicos del proceso LACTOHYD a escala piloto para hidrólisis } \\
\text { enzimática inmovilizada de lactosuero }\end{array}$ \\
\hline 171 & $\begin{array}{l}\text { Estudio de la inmovilización de lactasa en una preparación a base de huevo de } \\
\text { gallina en polvo, como medio de reducir costos en el proceso de hidrólisis de } \\
\text { lactosa }\end{array}$ \\
\hline 141 & Revisión del proceso de hidrólisis de lactosa \\
\hline 338 & $\begin{array}{l}\text { Estudio de hidrólisis de lactosa en un suero parcialmente desproteinado usando un } \\
\text { reactor de lecho fluidizado con deflectores }\end{array}$ \\
\hline
\end{tabular}


TABLA 2-29

(CONTINUACION)

\begin{tabular}{|c|c|}
\hline 256 & Análisis comparativo de diversos métodos de hidrólisis de lactosa de lactosuero \\
\hline 146 & $\begin{array}{l}\text { Estudio de la influencia de diversos parámetros ( } \mathrm{pH} \text {, temperatura, concentración de lactosa, } \\
\text { fuente de procedencia de la lactosa, concentración de la enzima, tipo de membrana del } \\
\text { reactor y presión de operación) en la hidrólisis de lactosa }\end{array}$ \\
\hline 319 & $\begin{array}{l}\text { Estudio del uso de una lactasa proveniente de Sireptococcus thermophilus para hidrolizar } \\
\text { leche y diversos lactosueros }\end{array}$ \\
\hline 60 & Descripción del proceso piloto de hidrólisis enzimática inmovilizada BC\&M para lactosa \\
\hline 50 & $\begin{array}{l}\text { Estudio de recuperación de los principales componentes de lactosuero dulce } \\
\text { desmineralizado, asi como de la velocidad de hidrólisis de lactosa de permeatos } \\
\text { desmineralizados de lactosuero dulce con lactasa proveniente de hongos o levaduras a } \\
\text { temperaturas optimas y menores. Estudio de la calidad del concentrado hidrolizado } \\
\text { producido }\end{array}$ \\
\hline 268,262 & $\begin{array}{l}\text { Estudio de hidrólisis de lactosa con lactasa inmovilizada en un reactor continuo de lecho } \\
\text { capilar empacado a diferentes concentraciones de lactosa y diferentes temperaturas. Se } \\
\text { realizó una modelación del proceso, incluyendo la desactivación térmica }\end{array}$ \\
\hline 22 & $\begin{array}{l}\text { Estudio de hidrólisis de lactosa de leche descremada mediante lactasa inmovilizada usando } \\
\text { un reactor continuo de flujo espiral }\end{array}$ \\
\hline 294 & Estudio de hidrólisis de lactosa por lactasas derivadas de hongos \\
\hline 215 & $\begin{array}{l}\text { Estudio de las condiciones óptimas para hidrólisis de lactosa de lactosuero usando lactasa } \\
\text { obtenida de } K \text { frágilis inmovilizada en una resina de intercambio aniónico }\end{array}$ \\
\hline 203 & $\begin{array}{l}\text { Estudio de hidrólisis de lactosa en suero entero con un reactor enzimático de flujo } \\
\text { transversal y lactasa de } A \text {. oryzae inmovilizada en una membrana microporosa }\end{array}$ \\
\hline 68 & Hidrólisis de lactosa y lactosueros usando células enteras de $K$. bulgaricus \\
\hline 289 & Cuadro-resumen de diversos sistemas de inmovilización de lactasa \\
\hline 220 & Descripción del proceso piloto CORNING para hidrólisis enzimática de lactosa \\
\hline 338 & $\begin{array}{l}\text { Estudio de hidrólisis de lactosa en suero lácteo por lactasa immovilizada de } A \text {. oryzae en un } \\
\text { reactor de lecho fluidizado }\end{array}$ \\
\hline 26 & $\begin{array}{l}\text { Estudio de la capacidad de hidrólisis en lactosa de una lactasa inmovilizada en un gel de } \\
\text { alcohol polivinílico fonnado en los poros de una malla de algodón }\end{array}$ \\
\hline 310 & $\begin{array}{l}\text { Estudio del efecto de la concentración proteica en lactosuero durante su hidrólisis con } \\
\text { lactasa de } A \text {. oryzae }\end{array}$ \\
\hline 130,293 & $\begin{array}{l}\text { Revisión de la tecnología reciente, productos y aplicaciones de hidrolizados de lactosuero y } \\
\text { lactosa }\end{array}$ \\
\hline 273 & $\begin{array}{l}\text { Estudio comparativo de hidrólisis de lactosa usando lactasas de varios orígenes (fungales y } \\
\text { de levaduras) }\end{array}$ \\
\hline 361 & $\begin{array}{l}\text { Método gráfico para determinar los parámetros cinéticos de la hidrólisis enzimática de } \\
\text { lactosa }\end{array}$ \\
\hline 280 & $\begin{array}{l}\text { Estudio experimental con } S \text { frágilis inmovilizada para remoción de lactosa en leche en } \\
\text { proceso por lotes }\end{array}$ \\
\hline
\end{tabular}


CAPITULO 3

CONCEPTUALIZACION DEL PROBLEMA.

La temática de interés de este trabajo, parte del siguiente enunciado:

"La industria quesera mexicana produce a través de su proceso tradicional, queso y una corriente de material residual denominado lactosuero. Este lactosuero se genera en cantidades que sobrepasan excesivamente a su demanda y posee un alto potencial contaminante para suelos y aguas. Dar tratamiento a la corriente no demandada deteriora gravemente la economía de la industria, por lo que es preciso buscar soluciones de modo que las afectaciónes al medio ambiente y a la economía del proceso global sean las mínimas posibles".

A lo largo de esta tesis se replantea el enunciado del problema desde la perspectiva personal del autor y se exploran opciones atractivas, con un enfoque original, aplicando técnicas de diseño de procesos a la solución de la problemática propuesta y obteniendo soluciones nuevas, o por lo menos estudiando esta temática desde ángulos no abordados hasta ahora en la literatura. En cuanto a tiempo, el estudio se basa en las condiciones del año 1993.

La industria quesera mexicana está formada por una gran cantidad de factorias de muy diversos tamaños, que producen quesos de distintos tipos a partir de leche mediante un proceso semiempírico, cuyas etapas principales se describen de manera somera en el $A$ péndice $D$ (una descripción detallada de este proceso se puede encontrar en la literatura (83), (184)).

Los precios de los quesos son diversos, lo mismo que sus rendimientos; las escalas de cada instalación lo son también y las posibilidades de procesamiento del lactosuero son muchas (Capítulo 2). Así pues, la dificultad para conceptualizar el problema estriba en encontrar una manera de manejar el conjunto de variabilidades mencionadas, y que sin embargo sea posible determinar cuales son las mejores alternativas de solución.

Siguiendo la escuela de diseño y estrategia de procesos del Dr. Dale F. Rudd, de la Universidad de Wisconsin, se aborda el problema de una manera flexible, de modo que permita separar por conjuntos las soluciones peores de las mejores, y caracterizar a estas últimas de modo que se conozcan las principales relaciones de tipo causa-efecto entre variables. No se trata pues de encontrar a la manera ortodoxa la solución óptima a un problema definido matemáticamente y cuyas variables de entrada tienen valores precisos. Se trata más bien de "sobrevolar" entre escenarios técnicos y económicos, obteniendo un mapa de respuestas a la pregunta "Qué pasaría si...".

Este tipo de aproximación utiliza en la solución de los problemas una combinación entre métodos algorítmicos y heurísticas. El beneficio de esta manera de tratar el problema es que permite explorar una diversidad de situaciones que los métodos ortodoxos no exploran. Esta manera llexible con que se elije abordar el problema, permite el uso de una técnica de generación de ideas, llamada del pensamiento lateral.

En el pensamiento lateral se busca producir una idea nueva; un nuevo concepto a partir de una realidad quizá ya estudiada por el pensamiento ortodoxo (o pensamiento vertical). El pensamiento vertical sigue la línea más obvia: la línea recta. Cuando se está buscando la solución de un problema, el pensamiento vertical elije un sitio por decirlo asi, para la búsqueda, y profundiza más y más en el mismo sitio. El pensamiento lateral en cambio, explora las diferentes formas de ver un problema en lugar de tomar directamente las opciones que la lógica ofrece y actuar de acuerdo con ellas. Desde el punto de vista del pensamiento vertical la lógica rige en todo momento. El diseñador de procesos busca obtener con toda precisión las condiciones del problema para plantearlo 
rigurosamente y obtener una solución impecable. Desde el punto de vista industrial, en muchos casos no se puede definir con precisión a qué condiciones debe buscarse la solución óptima de un problema, porque están involucradas situaciones de incertidumbre a mediano plazo en cuanto a normatividad, abasto de materia prima, liquidez económica, inflación, oportunidades de ingreso a nuevos mercados, competencia en el mercado actual, etc.

El pensamiento lateral se apoya en la intuición y busca alejarse de los patrones que llevan hacia una dirección definida (y quizás ya explorada antes). Trata de moverse hacia los lados, reformulando los patrones, reformulando las preguntas, reformulando el problema.

Con frecuencia, los elementos básicos de una idea nueva ya están a mano, y lo único que falta es encontrar esta manera correcta de abordar el problema para obtener soluciones nuevas. Una de las características del pensamiento lateral es que cuando se genera por medio de él una idea nueva, ésta parece sumamente obvia una vez que se descubre, pero habría sido dificil de encontrar por medio del pensamiento vertical.

El pensamiento lateral no sustituye al pensamiento vertical, sino lo complementa.

Conceptualización del problema desde un primer punto de vista.

Analizando el enunciado del problema mediante el pensamiento vertical se obtendria una estrategia de solución como se muestra en la figura 3-1; cuyas limitaciones se detallan a continuación.

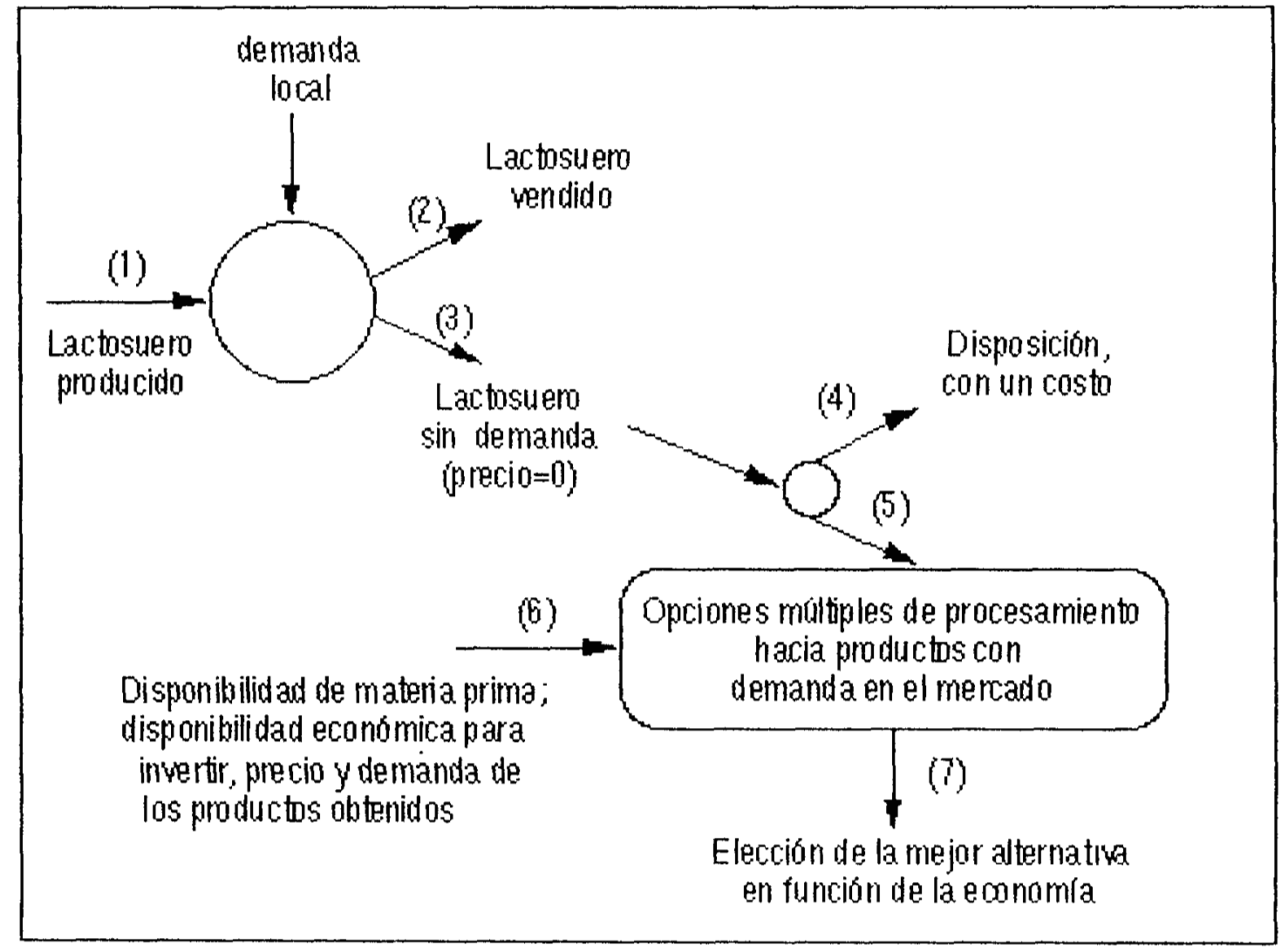

FIGURA 3-1. REPRESENTACION ESQUEMATICA DE LA PROBLEMATICA A RESOLVER, DE ACUERDO CON EL PENSAMIENTO VERTICAL. 
Cuando una corriente se vende (como la corriente 2 de la ligura 3-1), se obtiene un beneficio derivado de ello. Cuando una corriente se dispone (como la corriente 4), se paga un costo por ello. Cuando una corriente se procesa y los productos son vendidos (como la corriente 5) se paga un costo y se obtiene al mismo tiempo un ingreso. Generalmente las rutas 4 y 5 son excluyentes entre sí. La diferencia neta entre el costo y el ingreso después de impuestos asociada al tratamiento de la corriente 5 , comparada con el costo de disponer la corriente 4, permite determinar la mejor ruta a seguir para la corriente 3 . Sin embargo, para decidir por la 5 no basta con que el balance económico arroje costos iguales a los de la ruta 4 . Dado que se invierte dinero en el procesamiento, se desea que esta inversión produzca una rentabilidad aceptable, comparada con otras opciones de inversión. Esto significa que después de invertir en el procesamiento de la corriente 5 , no es bastante con lograr una situación de pérdida como la de la corriente 4 , sino que se desea obtener utilidades comparables con otras inversiones disponibles para el dinero. Comúnmente se utiliza como referencia la rentabilidad bancaria. La corriente de información 6 en la figura 3-1 puede ser altamente variable de un caso particular a otro y fácilmente cambiante dentro de una empresa, y este hecho dificulta grandemente el poder obtener resultados aplicables a la realidad que la industria está viviendo, ya que muchos de estos datos dependen del tamaño de industria y de situaciones fuera de control para ésta, o bien de decisiones tomadas dentro de la industria o dentro del sector industrial.

Un esquema más abierto se presenta en la figura 3-2, en la cual con ayuda del pensamiento lateral se replanteó el problema de la figura 3-1. Se van a encontrar un conjunto de soluciones que permitan saber dónde se ubicaría la mejor rentabilidad si la cantidad de lactosuero tomase distintos valores, dentro de un intervalo de posibilidades. Del mismo modo, se va a estudiar qué pasaría con esta rentabilidad en un entorno de condiciones próximas a los valores base de las inversiones, los costos de operación y los precios de los productos, y con toda esta información se podrá saber cuales son las mejores alternativas de proceso en función de la escala, el monto de inversión o el producto a producir 


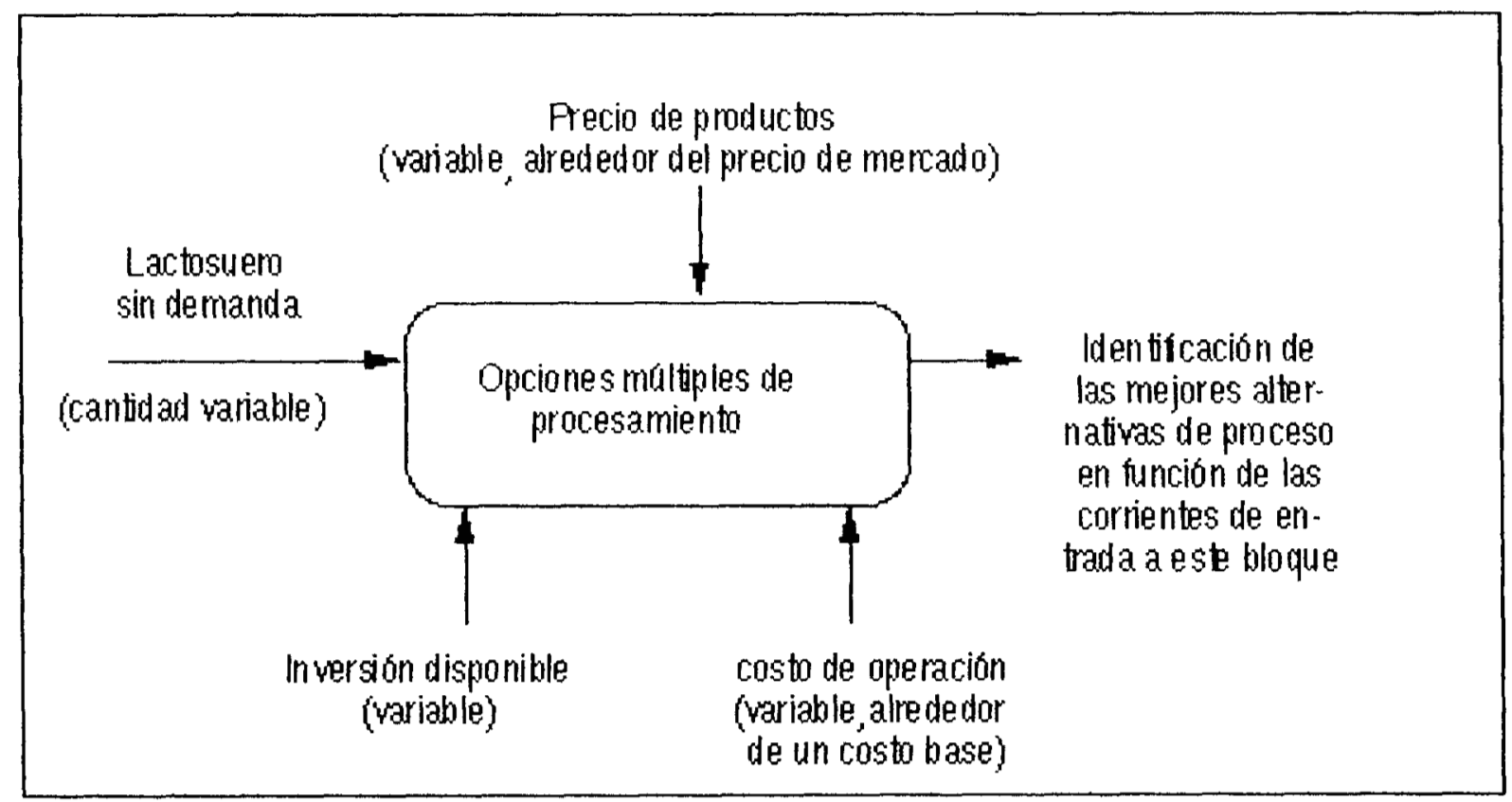

FIGURA 3-2

REPLANTEAMIENTO DEL PROBLEMA ORIGINAL MEDIANTE EL PENSAMIENTO
LATERAL

Una vez localizado el conjunto de las mejores opciones de procesamiento mediante simulación detallada de los procesos y su economía, conviene disponer de formas que permitan estimar su inversión y rentabilidad dentro de una región de condiciones congruente con el esquema de la figura 3-2, con el mínimo esfuerzo de cálculo posible y dentro de una precisión aceptable (que para este trabajo se tomó de alrededor de 10\%). El enfoque anterior constituye el planteamiento del problema desde un primer punto de vista, que parte de considerar que existe una corriente de lactosuero $\sin$ demanda. El desarrollo de soluciones para este primer punto de vista, se presenta en el Capitulo 4.

Conceptualización del problema desde un segundo punto de vista.

Retornando al planteamiento inicial, se buscó y encontró por un procedimiento algo más elaborado, una segunda manera de abordar el problema con ayuda del pensamiento lateral. A continuación se presenta la argumentación que sirve de base a este segundo punto de vista.

Desde hace mucho tiempo, la industria quesera ha estado enfrentando el reto de disponer adecuadamente sus desechos sin afectar severamente sus costos de producción. Un análisis de alternativas de solución a éste problema, no está completo si no incluye la opción de estudiar el proceso productor de los desechos en busca de modificaciones al mismo, tales que sin afectar seriamente a los productos, promuevan una reducción en el grado de dificultad de procesamiento de los desechos o de su asimilación por el medio ambiente. En el caso de la industria quesera, la bibliografia y la heuristica reportan que existen oportunidades de reducción de desechos para algunos tipos de quesos, bajo determinadas circunstancias.

Investigando respecto al proceso quesero se encontró que a pesar de la rigidez que la tradición impone a la elaboración de queso, la cual se justifica parcialmente por el hecho de que el sabor, la textura, el aroma y el cuerpo del producto son dificiles de igualar cuando se siguen rutas diferentes 
de las que por muchos años se han ido delineando, las necesidades actuales han promovido algunos cambios recientes al proceso, especialmente para queso frescos o de poca maduración. Ejemplos de ello son el empleo de agentes coagulantes de origen distinto de las vísceras de bovino, el uso de cultivos lácticos diversos y bien definidos, la reducción del tiempo de maduración hecha sobre una base más científica y menos empírica, los estudios para realizar el proceso en forma continua, el desarrollo de aditivos para mejorar y realzar el sabor y aroma del queso, la incorporación de agentes extensores del rendimiento del producto, la aplicación de membranas como medio de separación en el proceso, etcétera.

Nuestro interés se centró en los dos últimos puntos citados en el párrafo anterior: La extensión del rendimiento mediante la adición de caseína, por ser una práctica útil en la reducción de costos que se usa comúnmente en muchos paises, y la modificación de la composición de la leche por ultrafiltración, porque a pesar de que aún no se usa en México, en opinión del autor es una manera interesante y poco estudiada de contribuir a reducir la problemática del lactosuero. Más aún, porque ambas estrategias son compatibles, y por tanto pueden combinarse para dar un proceso quesero modificado, interesante de cvaluar

Conceptuando al queso como un concentrado selectivo de la leche, el cual ha sido fermentado también selectivamente, se puede ver al proceso quesero tradicional como una secuencia de transformaciones, al final de las cuales se obtienen a partir de una corriente de entrada (leche fresca), tres corrientes de salida (queso, crema y lactosuero), de las cuales, la última no está sujeta a especificaciones de proceso y por tanto es considerada una corriente de desecho (figura 3-3).

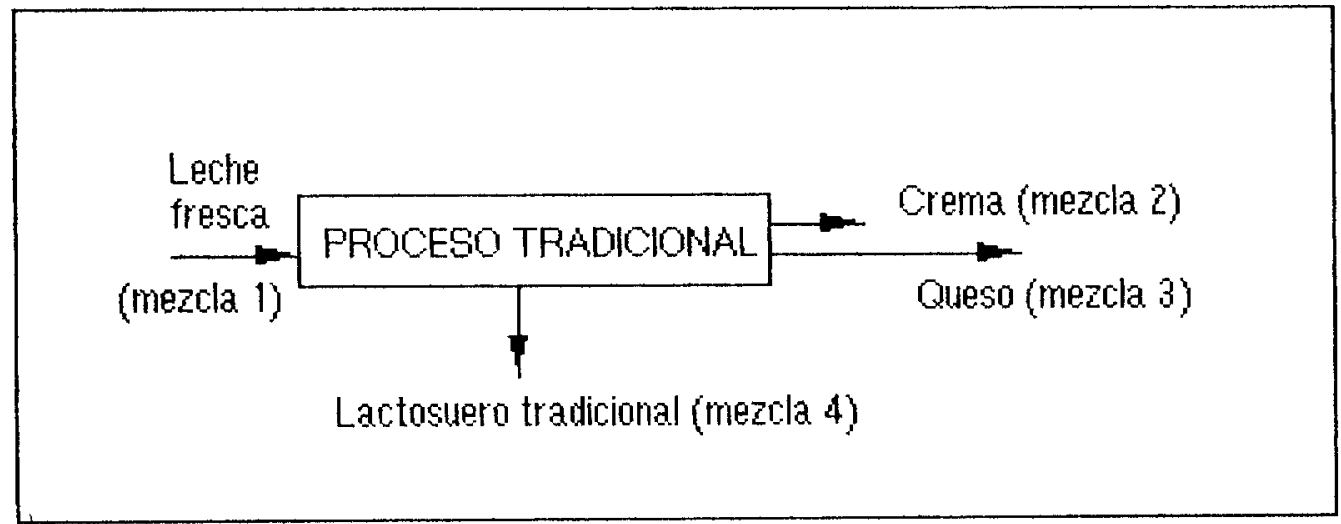

FIGURA 3-3

PROCESO QUESERO TRADICIONAL VISTO COMO IAA FRAGMENTACION DE UNA MEZCLA COMPLEJA EN TRES MEZCLAS MAS SIMPLES

Un balance de masa considerando a la materia prima (leche) y a los productos deseados (queso y crema), pone de manifiesto que se recjuiere considerar una corriente adicional en el proceso conformada por el excedente de materiales provenientes de la leche. Mediante una modificación en la secuencia de transformaciones de la materia prima, se puede reducir la corriente de desecho producida por el proceso tradicional y generar en cambio una corriente con especificaciones de proceso. 
La estructura de la leche es tal (ver Apéndice D), que su alteración por ultrafiltración y adición de caseína es perfectamente compatible con el propósito de fabricar queso.

Un análisis de la bibliografia dejó claro el hecho de que la tecnologia de ultrafiltración está ganando terreno en la industria quesera. Su aplicación más exitosa hasta ahora ha sido con el queso Feta, del cual se producian por ultrafiltración 100,000 toneladas anuales en 1987, lo que representaba en ese año la cuarla parte de la producción mundial de dicho queso. Considerando las situaciones de hambruna y pobreza en muchas regiones del mundo, no es decabellado suponer que la producción de quesos de bajo precio como éste, haya aumentado notablemente en los últimos años.

Todos los quesos que existen se caracterizan por contener un cociente lactosa/proteína o lactosa/grasa más bajo que la leche que los formó. Gran parte de la lactosa y el agua tienen que ser removidas de la leche durante la formación del queso. En muchos de los casos, también hay excedentes de sales y grasa. En todos los casos se busca aprovechar toda la caseína disponible de la leche.

La concentración de suspensiones por medio de membranas semipermeables es bastante menos intensiva en energía que la evaporación, y posee la ventaja adicional de mantener inalteradas las proteínas y grasa, cuya exposición al calor generalınente las deteriora, por lo que es idónea para el proceso quesero.

Para obtener un determinado tipo de queso, el paso inicial es estandarizar la leche, término que significa remover la grasa excedente a fin de dejar una proporción predefinida de grasa y caseína. Usualmente se separa la grasa por centrifugación, ajustando así la relación grasa/caseína. Para separar una buena parte de la lactosa y el agua excedentes, es posible usar ultrafiltración. Este método tiene la característica de poder segregar de la leche agua, lactosa y sales exclusivamente. Después de esta operación, el retentato debe ser ajustado en su composición salina.

De este modo, la modificación al proceso tradicional contempla una concentración selectiva de los componentes de la leche utilizando operaciones simples y bien conocidas como la centrifugación (para separar crema) y la ultrafiltración (para separar agua, lactosa y sales excedentes). Este concentrado, cuya composición se ha aproximado a la del producto final, puede producir un queso con baja sinéresis, con lo que se logra reducir considerablemente la corriente de desecho sin especificaciones del proceso tradicional. En algunos paises se ha estudiado la ultrafiltración de leche a pequeña y mediana escala incluso en las propias cuencas lecheras, donde pueden obtenerse interesantes ahorros derivados de la reducción en los costos de transporte y almacenamiento frío de la leche.

En relación a la modificación considerada, se han reportado resultados exitosos desde el punto de vista técnico del uso de ultrafiltración para toda clase de quesos blandos y semiduros, y se encuentran en desarrollo procesos para elaborar quesos madurados como el Cheddar y otros (285), (12), (125), (107), (231). Es pertinente señalar que muy poco se ha estudiado respecto de la economía de estos procesos modificados.

Como resultado de la ultrafiltración, se tiene una corriente de desecho (lactosuero) disminuida, y una corriente nueva compuesta por el permeato de la ultrafiltración, la cual consiste en una disolución de lactosa y sales en agua. Las características del permeato le permiten una gran variedad de aplicaciones en la industria alimenticia y en los procesos biotecnológicos; aunque 
hasta ahora no cuenta con un mercado en México debido a que no se produce. En la tabla 3-1 se presenta una lista parcial comparativa de los atributos del permeato y el lactosuero.

TABLA 3-1

COMPARATIVO CUALITATIVO DE AIGUNAS PROPIEDADES DE LACTOSUTRO Y PERMEATO

\begin{tabular}{|l|c|c|}
\hline ATRIBUTO & $\begin{array}{c}\text { LACTOSUE- } \\
\text { RO }\end{array}$ & PERMLATO \\
\hline $\begin{array}{l}\text { Es una corriente residual y por tanto no tiene especificaciones } \\
\text { de pureza (puede contener literalmente "cualquier cosa") }\end{array}$ & $\mathrm{si}$ & no \\
\hline Puede contener actividad residual de renina y otros & $\mathrm{si}$ & no \\
\hline Existe alto riesgo de que contenga fagos debido a su manejo & si & no \\
\hline $\begin{array}{l}\text { Puede iniciar su fermentación con más facilidad por la } \\
\text { presencia de bacterias acidolácticas del proceso quesero }\end{array}$ & no \\
\hline $\begin{array}{l}\text { Es más recomendable para aplicaciones de alta pureza } \\
\text { las reacciones de Maillard por desnaturalización de proteinas }\end{array}$ & si & no \\
\hline $\begin{array}{l}\text { Es mejor opción para cristalización de lactosa de grado } \\
\text { farmacéutico }\end{array}$ & no \\
\hline $\begin{array}{l}\text { Su producción y manejo puede hacerse fuera del area del } \\
\text { proceso quesero }\end{array}$ & no & si \\
\hline $\begin{array}{l}\text { Puede usarse directamente como base para preparar bebidas de } \\
\text { consumo humano }\end{array}$ & no & si \\
\hline \begin{tabular}{l} 
Es una mejor opción para reciclarse al ganado como bebida \\
\hline
\end{tabular} & no & si \\
\hline
\end{tabular}

La adición de caseína por su parte, es una práctica común en muchos países donde existe déficit lechero, donde hay aceptación de los consumidores por los productos obtenidos y donde la legislación competente no impide su aplicación. Tal es el caso de nuestro país. Su efecto económico es benéfico porque aumenta el rendimiento del producto. l a importancia de estudiar este proceso modificado es aún más acetuada en México en virtud de que una gran proporción de las queserias mexicanas producen principalmente queso no madurado.

El análisis económico comparativo del proceso quesero tradicional y el modificado según se planteó, para diferentes tipos de quesos, a diferentes escalas y condiciones de proceso, constituye la problemática a resolver desde el segundo punto de vista.

El estudio de este planteamiento incluye la identificación de las mejores condiciones para el proceso reconvertido, la búsqueda de formas simplificadas que permitan estimar la inversión y rentabilidad y el análisis del efecto de parámetros selectos sobre la rentabilidad, dentro de una región de condiciones de interés, con el mínimo esfuerzo de cálculo posible y dentro de una precisión aceptable. El desarrollo de soluciones para este segundo punto de vista, se presenta en el Capítulo 5.

Heurísticas.

Los aspectos heurísticos implicados en el desarrollo de los dos puntos de vista planteados en este capítulo, corresponden a criterios y estimaciones que sólo la experiencia podría establecer acerladamente, basada en el conocimiento de los procesos alimenticios, el mercado de los 
productos y materias primas consideradas y las prácticas ingenieriles de disefío de procesos. A esta parte heurística correspondieron decisiones tomadas a lo largo del trabajo acerca de: - Relación entre inversión de equipos de ultrafiltración e inversión en terrenos e instalaciones para el adecuado funcionamiento de dichos equipos

-Relación entre costo de operación del equipo de proceso y costo de tratamiento de efluentes.

-Valores minimos aceptables para la tasa de retorno de la inversión.

-Precios de productos derivados del lactosuero.

- Costo unitario de mano de obra y servicios.

- Relaciones de costos de supervisión y costos de mantenimiento a costos de mano de obra

-Tasas de impuestos y períodos de depreciación aplicables.

-Límites permisibles para la ultrafiltración y la adición de caseína.

-Criterios para definir los quesos susceptibles de tener proceso reconvertido.

-Criterio de rentabilidad mínima atractiva para la reconversión del proceso quesero.

- Valores de flujo de permeato y estructura de ciclos de ultrafiltración para la membrana ABCOR HFM-100-SO procesando leche.

Un gran número de publicaciones, folletos y expertos entrevistados contribuyeron a establecer de la manera más equilibrada posible las mencionadas heurísticas. 


\section{CAPITULO 4: DESARROLLO DESDE, EI, PRIMER PUNTO DE VISTA}

Planteamiento del problema.

Este capítulo se dedica a identificar dentro de un conjunto definido de opciones aquellas que resultan económicamente más convenientes para el procesamiento de lactosuero, considerando a éste como materia prima en forma completamente desligada del proceso quesero que le dió origen. En tales condiciones, la escala del proceso puede ser muy variable, desde volúmenes provenientes de una pequeña quesería hasta centros de acopio de lactosuero, donde se concentran los efluentes de diversas instalaciones queseras. El problema se aborda de tal suerte que no se trata de determinar el óptimo para un proceso dado, sino más bien de determinar la trayectoria que sigue el óptimo de un proceso dado en función de la escala. Más aún; además de conocer el proceso mejor y las condiciones óptimas de proceso según la escala, se desea conocer el conjunto de rentabilidades económicas del proceso en una región de valores circunvecinos a las condiciones económicas y de mereado escogidas como base, las cuales fueron completamente apegadas a la realidad del año 1993. Complementando lo anterior, se busca en este capítulo utilizar los resultados de las situaciones anteriormente descritas para establecer métodos cortos de cálculo basados en modelos empíricos que permitan visualizar el comportamiento económico de un proceso económicamente seleccionado para procesar lactosuero, dentro de una región de valores paramétricos próximos al conjunto base de datos económicos y de mercado.

Como se mencionó en el Capitulo 2, son muchos los productos que se pueden obtener a partir de lactosuero; sin embargo, sus demandas en el mercado pueden ser de diferente magnitud y también diferentes pueden ser las condiciones de rentabilidad económica que presenten como proyectos de inversión. Dado que el número de alternativas es muy grande, es de gran utilidad contar con un instrumento que permita su evaluación económica individual, con objeto de poder seleccionar de entre ellas a las de más interés desde el punto de vista económico.

Las rutas más usuales de procesamiento de lactosuero incluyen operaciones unitarias que se combinan de diversas maneras para lograr cuatro separaciones principales (deshidratación, desproteinado, desmineralizado y delactosado) y una transformación ordenada (hidrólisis) de la lactosa. Los productos que se pueden obtener por la aplicación de estas operaciones sobre el lactosuero (que pueden llamarse derivados primarios del lactosuero), son muy variados y dependiendo del caso pueden estar destinados a consumo final o a usarse como materias primas en procesos de manufactura subsecuentes, obteniéndose entonces derivados secundarios del lactostuero. No se consideró al metano como producto de interés por los riesgos implicados en su producción y almacenamiento, por lo costoso de su purificación, porque su precio está sujeto a control estatal, por la dificultad de producir grandes volúmenes y por las complicaciones legales derivadas de la posible violación a leyes mexicanas relacionadas con la exclusividad de PEMEX para producir petroquímicos primarios. El presente capítulo contempla opciones de procesamiento basadas en las separaciones y transformaciones antes mencionadas, cuya representación se muestra en la figura 4-1. 


\section{LACTOSUERO}

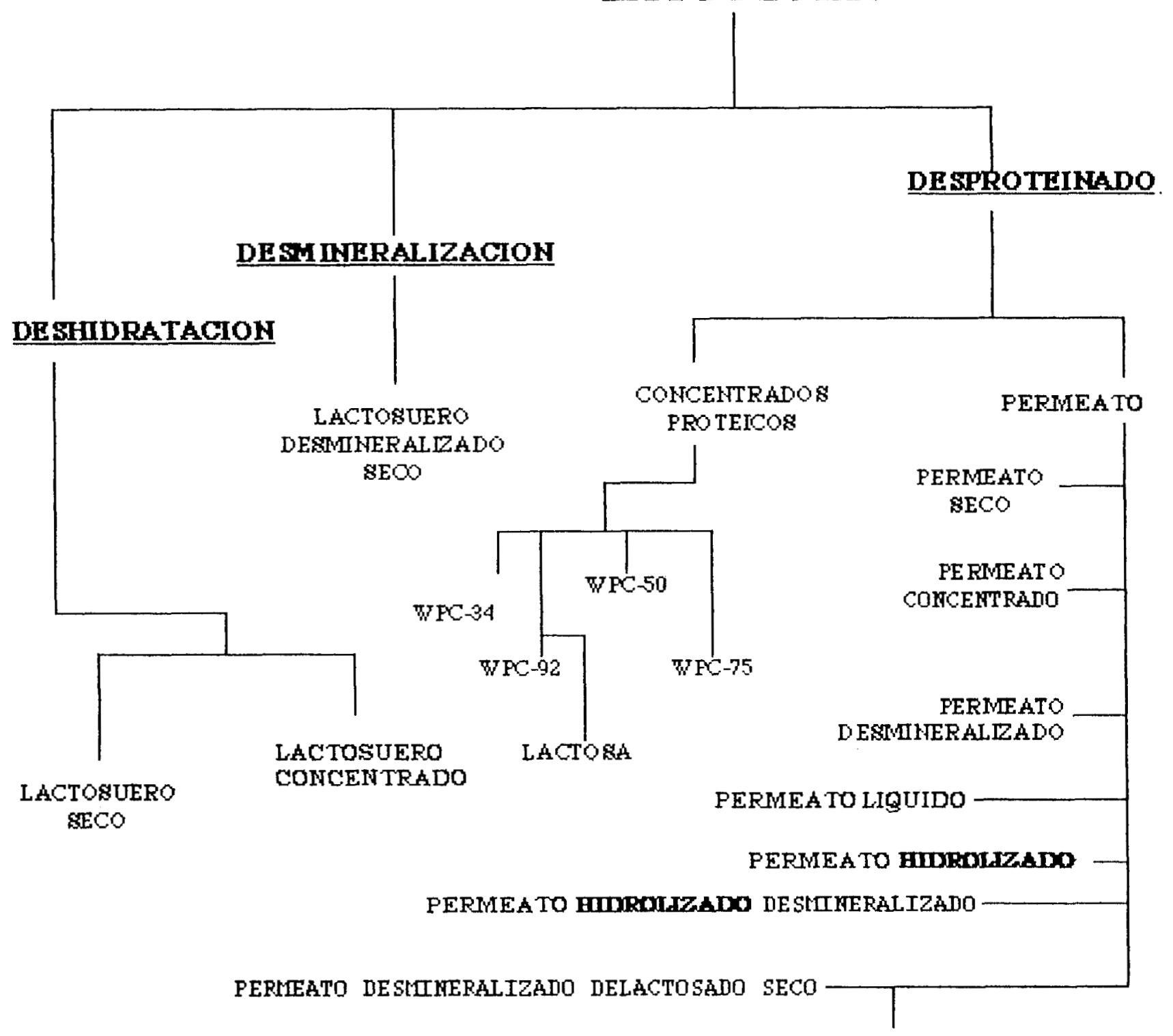

LACTOSA

FIGURA 4-1

RUTAS DE PROCESO EXPLORADAS EN ESTE TRABAJO

Para abordar las opciones de procesamiento consideradas, se desarrolló un simulador capaz de construír los procesos deseados mediante la conexión apropiada de módulos, consistentes éstos de operaciones unitarias. Una vez elaborado el ensamble de interés, el simulador procede a calcular balances de materia y energía para los módulos y para el conjunto; posteriormente se calculan los costos del proceso a partir de los costos calculados de cada módulo. Una subrutina de optimización determina el número y tamaño de los equipos de modo que el costo del proceso sea mínimo. 
Posteriormente se calculan las utilidades bruta y neta anuales y por último la lasa de retorno de la inversión, la cual constituye una medida de la rentabilidad del proceso.

En la construcción del mencionado simulador se partió de un esquema previo, que fué desarrollado por otros autores $(144,76)$ y de un algoritmo de optimización construido separadamente $(188)$. $\wedge$ este conjunto básico, se le hicieron las adecuaciones necesarias, quedando finalmente como se muestra en el Apéndice A.

Las operaciones unitarias utilizadas por las diferentes rutas de procesamiento de lactosuero ensayadas en este estudio fueron las siguientes:

-evaporación de múltiple efecto

-secado por aspersión

-ultrafiltración

-ósmosis inversa

-desmineralización por intercambio iónico

-centrifugación

-cristalización

-hidrólisis de lactosa en reactor enzimático inmovilizado

Algunos de los parámetros económicos que deben suministrarse al simulador son los siguientes:

-tasa de impuestos sobre utilidades netas

-tasa de inflación anual promedio

-período de vida del proyecto

-Gastos extras/costo total de mano de obra

-período de depreciación de equipo

-costo de seguros y administración/costo de mano de obra por operación

-costo de supervisión/costo de mano de obra

-costo de mantenimiento/costo de mano de obra

-Indice Marshall-Swift

-horas de trabajo por día 
-días de trabajo por año

-costo unitario de mano de obra

-costo unitario de mantenimiento

-costo unitario de servicios (electricidad, petróleo, gas, vapor, agua, aire comprimido)

En este estudio se consideró como inversión total a la suma de la inversión en equipos de proceso más la inversión en terreno e instalaciones para el adecuado funcionamiento de los equipos de proceso. Se estimó que el costo de terreno e instalaciones se podía aproximar al costo de equipos de proceso, de modo que la inversión total se tomó como el doble del costo del equipo de proceso. Se asumió en todos los casos un costo de tratamiento de efluentes en los procesos equivalente al $5 \%$ de su costo de operación. A fin de considerar un amplio espectro de situaciones de oferta de lactosuero y demanda de productos, las escalas de operación ensayadas fueron como se muestra en la tabla 4-4. Se consideraron 31 procesos de interés, los cuales se resumen en la tabla 4-5.

Algunos otros datos suministrados se muestran en las tablas 4-1, 4-2, 4-3, los cuales fueron recabados de la literatura y de heurísticas aplicables.

TABLA 4-1

PRINCIPALES DATOS ECONOMICOS UTILIZADOS

\begin{tabular}{|l|c|c|}
\hline PARAMETRO Y UNIDADES & VALOR & REF \\
\hline Tasa de impuestos sobre utilidades netas & 0.48 & 157 \\
\hline Tasa de inflación anual promedio & 0.035 & 157 \\
\hline Periodo de vida del proyecto (años) & 10 & 157 \\
\hline Gastos extras/costo total de mano de obra & 0.8 & 157 \\
\hline Período de depreciación de equipo (años) & 6 & 157 \\
\hline $\begin{array}{l}\text { Costo de seguros y administración/costo de mano de obra } \\
\text { por operación }\end{array}$ & 0.04 & 157 \\
\hline Costo de supervisión/costo de mano de obra & 0.15 & 157 \\
\hline Costo de mantenimiento/costo de mano de obra & 1.0 & 157 \\
\hline Indice Marshall-Swift de 1993 & 955 & 157 \\
\hline Horas de trabajo por dia & 20 & 144 \\
\hline Días de trabajo por año & 360 & 144 \\
\hline Costo unitario de mano de obra (N\$/hora-hombre) & 11.71 & $\mathrm{E}-1$ \\
\hline Costo unitario de mantenimiento $(\mathrm{N} \$ / \mathrm{hora}-$ hombre) & 23.43 & 144 \\
\hline Costo unitario de electricidad (N\$/Kw-h) & 0.142 & $\mathrm{E}-2$ \\
\hline Costo unitario de Combustóleo N\$/gal) & 1.13 & 157 \\
\hline Costo unitario de gas (N\$pie cúbico) & 0.0067 & 157 \\
\hline Costo unitario de vapor (N\$/lb) & 0.0039 & 157 \\
\hline Costo unitario de agua (N\$/gal) & 0.0098 & 157 \\
\hline Costo unitario de aire comprimido (N\$/pie cúbico) & 0.00042 & 157 \\
\hline
\end{tabular}

$\mathrm{E}-1=$ DR. SRGIO REVAH M. UAM-I

$\mathrm{E}-2$ = Tarifas CFE, México 1993 
IABIA 4-2

PRECIOS (1993) DE LOS PRODUCTOS CONSIDERADOS

\begin{tabular}{|c|c|c|c|}
\hline PRODUCTO & US DOL $\triangle R E S / 1000 \mathrm{lb}$ & $\mathrm{N} \$ / \mathrm{kg}$ & REF \\
\hline $\begin{array}{l}\text { CONCENTRADO PROTEICO SECO } \\
34 \%\end{array}$ & 1000 & 7.27 & $\mathrm{~F}-\mathrm{I}$ \\
\hline $\begin{array}{l}\text { CONCENTRADO PROTEICO SECO } \\
50 \%\end{array}$ & 2200 & 15.99 & $\mathrm{~F}-1$ \\
\hline $\begin{array}{l}\text { CONCENTRADO PROTEICO SECO } \\
75 \%\end{array}$ & 4800 & 34.89 & $\mathrm{~F}-1$ \\
\hline $\begin{array}{l}\text { CONCENTRADO PROTEICO SFCO } \\
92 \%\end{array}$ & 8000 & 58.15 & $\mathrm{~F}-1$ \\
\hline PERMEATO LIQUIDO & 13.76 & 0.1 & $F-2$ \\
\hline PERMEATO CONCENTRADO & 40 & 0.29 & $\mathrm{~F}-2$ \\
\hline PERMEATO SECO & 138 & 1.00 & $F-2$ \\
\hline LACTOSUERO CONCENTRADO & 70 & 0.51 & $\mathrm{~F}-2$ \\
\hline LACTOSUERO SECO & 226 & 1.64 & $\mathrm{~F}-2$ \\
\hline $\begin{array}{l}\text { LACTOSUERO DESMINIRAIIZAIOO } \\
\text { SECO }\end{array}$ & 275 & 2.00 & $\mathrm{~F}-2$ \\
\hline LACTOSA PURA & 250 & 1.82 & $\mathrm{~F}-2$ \\
\hline PERMEATO HIDROLIZADO & 400 & 2.90 & $F-1$ \\
\hline PERAEATO DESMINERALIZADO & 150 & 1.09 & $\mathrm{~F}-1$ \\
\hline $\begin{array}{l}\text { PERMEATO HIDROLIZADO } \\
\text { DESMINERALIZADO }\end{array}$ & 650 & 4.72 & $\mathrm{~F}-2$ \\
\hline $\begin{array}{l}\text { PERMEATO DESMINERALIZADO } \\
\text { DELACTOSADO SECO }\end{array}$ & 210 & 1.53 & $\mathrm{~F}-2$ \\
\hline
\end{tabular}

F-1= Dr. Norman Olsen, Center for Dairy Research, U. de Wisconsin

F-2 $=$ The Whey Products Institute, Comunicación personal 
TABLA 4-3

COMPOSICION DE LOS PRODUCTOS CONSIDERADOS

\begin{tabular}{|c|c|c|c|c|c|}
\hline PRODUCTO & $\begin{array}{c}\% \\
\mathrm{AGUA}\end{array}$ & $\begin{array}{c}\% \text { SOLI- } \\
\text { DOS } \\
\text { TOTALE } \\
\text { S }\end{array}$ & $\begin{array}{c}\% \\
\text { PRO- } \\
\text { TEIN } \\
\text { A }\end{array}$ & $\begin{array}{c}\% \\
\text { LAC- } \\
\text { TOSA }\end{array}$ & $\begin{array}{c}\% \\
\text { SALE } \\
\mathrm{S}\end{array}$ \\
\hline $\begin{array}{l}\text { CONCENTRADO PROTEICO SECO } \\
34 \%\end{array}$ & 2.0 & 98.0 & 34.0 & 55.9 & 5.8 \\
\hline $\begin{array}{l}\text { CONCENTRADO PRO'IEICO SECO } \\
50 \%\end{array}$ & 2.0 & 98.0 & 50.0 & 41.9 & 4.4 \\
\hline $\begin{array}{l}\text { CONCENTRADO PROTEICO SECO } \\
75 \%\end{array}$ & 2.0 & 98.0 & 75.0 & 20.1 & 2.1 \\
\hline $\begin{array}{l}\text { CONCENTRADO PROTEICO SECO } \\
92 \%\end{array}$ & 0.2 & 99.8 & 92.0 & 4.6 & 2.3 \\
\hline PERMEATO LIQUIDO & 94.5 & 5.5 & 0.0 & 4.8 & 0.5 \\
\hline PERMEATO CONCENTRADO & 50.0 & 50.0 & 0.0 & 42.8 & 4.5 \\
\hline PERMEATO SECO & 6.0 & 94.0 & 0.0 & 82.0 & 8.6 \\
\hline LACTOSUERO CONCENTRADO & 60.0 & 40.0 & 5.1 & 30.5 & 3.2 \\
\hline LACTOSUERO SECO & 6.0 & 94.0 & 11.9 & 71.6 & 7.5 \\
\hline $\begin{array}{l}\text { LACTOSUERO DESMINERALIZADO } \\
\text { SECO }\end{array}$ & 6.0 & 94.0 & 12.9 & 77.4 & 0.8 \\
\hline LACTOSA PURA & 0.0 & 100.0 & 0.0 & 100.0 & 0.0 \\
\hline PERMEATO HIDROLIZADO & 51.0 & 49.0 & 0.0 & 15.0 & 4.4 \\
\hline PERMEATO DESMINERALIZADO & 51.0 & 49.0 & 0.0 & 46.6 & 0.1 \\
\hline $\begin{array}{l}\text { PERMEATO HIDROLIZADO } \\
\text { DESMINERALIZADO }\end{array}$ & 51.0 & 49.0 & 0.0 & 16.5 & 0.1 \\
\hline $\begin{array}{l}\text { PERMEATO DESMINERALIZADO } \\
\text { DELACTOSADO SECO }\end{array}$ & 6.0 & 94.0 & 0.0 & 85.1 & 0.0 \\
\hline
\end{tabular}

La simulación requiere como información de entrada entre otros datos, cuál es la secuencia de operaciones (proceso) que se intenta estudiar y cuál es la escala del proceso; es decir, la cantidad de materia prima (lactosuero) a procesar. Las secuencias de proceso se decidieron de acuerdo a la bibliografia para cada producto de interés y son presentadas en la tabla A-3.1 del Apéndice B bajo el encabezado "Diagrama de flujo del proceso ", de la HOJA 1: "Datos técnicos del proceso". Deseando conocer el efecto del parámetro escala de proceso sobre la economía de éste, se ensayaron 7 escalas que cubren un amplio intervalo de posibilidades. Se consideraron 20 horas de trabajo por día(ver tabla 4-4). 
TABLA 4.4

ESCALAS DE OPERACION DE

LACTOSUERO PROCESADO

\begin{tabular}{|c|c|}
\hline ESCALA & LD/hr \\
\hline 1 & 500 \\
2 & 1500 \\
3 & 2500 \\
4 & 5000 \\
5 & 15000 \\
6 & 25000 \\
7 & 50000 \\
\hline
\end{tabular}

El correcto funcionamiento del simulador en la parte técnica se comprobó reproduciendo los resultados esperados para algunos de los procesos más simples, los cuales habian sido reportados previamente (144). Posteriormente se amplió el simulador introduciendo cálculos económicos complementarios y se aplicó a los 31 procesos de interés presentados en la tabla 4-5. 
TABLA 4-5

PROCESOS Y PRODUCTOS CONSIDERADOS

\begin{tabular}{|c|c|}
\hline $\begin{array}{l}\text { PROCESO } \\
\mathrm{N}^{\circ}\end{array}$ & PRODUCTOS \\
\hline 1 & LACTOSUERO SECO \\
\hline 2 & LACTOSUERO CONCENTRADO \\
\hline 3 & LACTOSUERO DESMINERALIZADO SECO \\
\hline 4 & CONCENTRADO PROTEICO SECO DE $34 \%$ Y PERMEATO LIQUIDO \\
\hline 5 & CONCENTRADO PROTEICO SECO DE 50\% Y PERMEATO LIQUIDO \\
\hline 6 & CONCENTRADO PROIEICO SECO DE $75 \%$ Y PERMEATO LIQUIDO \\
\hline 7 & CONCENTRADO PROTEICO SECO DE $92 \%$, LACTOSA Y PERMEATO LIQUIDO \\
\hline 8 & CONCENTRADO PROTEICO SECO DE $34 \%$ Y PERMEATO SECO \\
\hline 9 & CONCENTRADO PROTEICO SECO DE $50 \%$ Y PERMEATO SECO \\
\hline 10 & CONCENTRADO PROTEICO SECO DE $75 \%$ Y PERMEATO SECO \\
\hline 11 & CONCENTRADO PROTEICO SECO DE $92 \%$, LACTOSA Y PERMEATO SECO \\
\hline 12 & CONCENTRADO PROTEICO SECO DE $34 \%$ Y PERMEATO HIDROLIZADO \\
\hline 13 & CONCENTRADO PROTEICO SECO DE $50 \%$ Y PERMEATO HIDROLIZADO \\
\hline 14 & CONCENTRADO PROTEICO SECO DE $75 \%$ Y PERMEATO HIDROLIZADO \\
\hline 15 & $\begin{array}{l}\text { CONCENTRADO PROTEICO SECO DE } 92 \% \text {, LACTOSA Y PERMEATO } \\
\text { HIDROLIZADO }\end{array}$ \\
\hline 16 & CONCENTRADO PROTEICO SECO DE $34 \%$ Y PERMEATO DESMINERALIZADO \\
\hline 17 & CONCENTRADO PROTEICO SECO DE $50 \%$ Y PERMEATO DESMINERALIZADO \\
\hline 18 & CONCENTRADO PROTEICO SECO DE $75 \%$ Y PERMEATO DESMINERALIZADO \\
\hline 19 & $\begin{array}{l}\text { CONCENTRADO PROTEICO SECO DE } 92 \% \text {, LACTOSA Y PERMEATO } \\
\text { DESMINERALIZADO }\end{array}$ \\
\hline 20 & $\begin{array}{l}\text { CONCENTRADO PROTEICO SECO DE } 34 \% \text { Y PERMEATO HIDROLIZADO } \\
\text { DESMINERALIZADO }\end{array}$ \\
\hline 21 & $\begin{array}{l}\text { CONCENTRADO PROTEICO SECO DE } 50 \% \text { Y PERMEATO HIDROLIZADO } \\
\text { DESMINERALIZADO }\end{array}$ \\
\hline 22 & $\begin{array}{l}\text { CONCENTRADO PROTEICO SECO DE } 75 \% \text { Y PERMEATO HIDROLIZADO } \\
\text { DESMINERALIZADO }\end{array}$ \\
\hline 23 & $\begin{array}{l}\text { CONCENTRADO PROTEICO SECO DE } 92 \% \text {, LACTOSA Y PERMEATO } \\
\text { HIDROLIZADO DESMINERALIZADO }\end{array}$ \\
\hline 24 & CONCENTRADO PROTEICO SECO DE $34 \%$ Y PERMEATO CONCENTRADO \\
\hline 25 & CONCENTRADO PROTEICO SECO DE 50\% Y PERMEATO CONCENTRADO \\
\hline 26 & CONCENTRADO PROTEICO SECO DE $75 \%$ Y PERMEATO CONCENTRADO \\
\hline 27 & $\begin{array}{l}\text { CONCENTRADO PROTEICO SECO DE } 92 \% \text {, LACTOSA Y PERMEATO } \\
\text { CONCENTRADO }\end{array}$ \\
\hline 28 & $\begin{array}{l}\text { LACTOSA, CONCENTRADO PROTEICO SECO DE } 34 \% \text { Y PERMEATO } \\
\text { DESMINERALIZADO DELACTOSADO SECO }\end{array}$ \\
\hline 29 & $\begin{array}{l}\text { LACTOSA, CONCENTRADO PROTEICO SECO DE } 50 \% \text { Y PERMEATO } \\
\text { DESMINERALIZADO DELACTOSADO SECO }\end{array}$ \\
\hline 30 & $\begin{array}{l}\text { LACTOSA, CONCENTRADO PROTEICO SECO DE } 75 \% \text { Y PERMEATO } \\
\text { DESMINERALIZADO DELACTOSADO SECO }\end{array}$ \\
\hline 31 & $\begin{array}{l}\text { LACTOSA, CONCENTRADO PROTEICO SECO DE } 92 \% \text { Y PERMEATO } \\
\text { DESMINERALIZADO DELACTOSADO SECO }\end{array}$ \\
\hline
\end{tabular}


Resultados de la simulación.

Los resultados de las corridas realizadas se presentan en el $\Lambda$ péndice $B$ mediante una secuencia de tres hojas por proceso; la primera hoja (denominada "IIOJA I"), contiene los datos técnicos del proceso, con información que permite deducir su diagrama de flujo. En las composiciones establecidas como fijas se presentan los porcentajes de cada componente en la materia prima y los productos. En todos los casos, los porcentajes de sólidos totales (que se muestran) y de agua (que no se muestran), suman 100\%. Para representar mejor la realidad, se permitió en la composición de los sólidos totales del lactosuero entrante un $0.2 \%$ de materiales no identificados, considerados como impurezas. En la segunda hoja (denominada "HOI^2") se dan algunos de los resultados obtenidos mediante el simulador, relativos a los equipos de proceso necesarios. El rubro "U" se refiere al número de unidades utilizadas en la operación en cuestión. El rubro " $T$ " corresponde al tamaño, y sus unidades dependen de la operación de que se trate, conforme a la tabla 4-6.

TABLA 4-6

DESCRIPCION DE LAS UNIDADES USADAS AL REFERIRSE AL TAMAÑO DE LOS EQUIPOS DE PROCESO EN LAS HOJAS DOS DEL APENDICE B

\begin{tabular}{|l|l} 
OPERACION & UNIDADES DE TAMAÑO \\
ULTRAFILTRACION & Pies $^{2}$ de membrana \\
OSMOSIS INVERSA & Pies $^{2}$ de membrana \\
EVAPORACION MULTIPLE EFECTO & pies $^{2}$ de superficie por efecto \\
SECADO POR ASPERSION & Lb de agua evaporada por hora \\
INTERCAMBIO IONICO & Pies $^{3}$ de columna catiónica \\
COLUMNA ENZIMATICA & Pie $^{3}$ de columna enzimática \\
CRISTALIZACION & Pies de diámetro \\
CENTRIFUGACION & HP de potencia del motor
\end{tabular}

La última hoja (denominada "HOJA 3") muestra datos económicos obtenidos del simulador, como el costo anual de operación, la inversión en equipo de proceso, los flujos producidos del producto principal y del denominado producto principal equivalente, que es un flujo de producto principal, equivalente en términos de dinero a la suma de los flujos de todos los productos del proceso. El ROI de cada proceso a cada escala se calculó a partir de los precios del producto principal y de los resultados del simulador aplicados a ecuaciones económicas apropiadas.

En las tablas A-3.1 del Apéndice B se presentan los datos de inversión de equipo de proceso y costo anual de operación, obtenidos de la simulación. EI ROI se calcula como

$\mathrm{ROI}=\mathrm{P} / 1$

en donde l es la inversión total requerida, la cual fué estimada como el doble de la inversión en equipo de proceso para tomar en consideración construcciones, terrenos y servicios necesarios. $P$ es la utilidad neta, la cual se calcula como $\quad P-R-e^{*} I-t\left(R-d e{ }^{*} I\right)$

en donde $e=0.1$ (factor de depreciación de la inversión para fines contables) $t=0.5$ (tasa de impuestos)

dep $=0.1$ (factor de depreciación de la inversión para fines de impuestos) 
$\mathrm{R}=$ utilidad bruta

$\wedge$ su vez, la utilidad bruta se calcula por la expresión $\quad R=S-G-1)$

en donde $\mathrm{S}$ son los ingresos anuales por ventas, los cuales se calculan multiplicando el precio del producto principal por la producción equivalente de producto principal, calculada por el simulador y reportada en las tablas A-3.1 del Apéndice B.

$\mathrm{G}$ es el costo anual de operación, calculado también por el simulador y reportado en las tablas A-3.1. $D$ es el costo anual de disposición de efluentes, el cual se estimó como el $5 \%$ del costo anual de operación.

Los cálculos se realizaron en una hoja electrónica de cálculo y los resultados de ROI se concentraron en la tabla 4-7.

Siguiendo la opinión de expertos, se consideraron de interés potencial sólo aquellos valores de ROI superiores a 0.1. La última columna de la tabla 4-7 es una calificación asignada para los 31 procesos estudiados, y que indica el número de escalas en las que un proceso obtiene valores de ROI superiores a 0.1 .

TABLA 4-7

VALORES DE LA TASA DE RETORNO DE INVERSION (ROI) OBTENIDOS PARA LOS DISTINTOS PROCESOS EN LAS DISTINTAS ESCALAS Y CON EL ESCENARIO ECONOMICO BASE DADO POR LAS TABLAS 4-1, 4-2 Y 4-8 (ESCENARIO O)

\begin{tabular}{|c|c|c|c|c|c|c|c|c|}
\hline PROCESO & $\mathrm{ESC} 1$ & $\operatorname{ESC} 2$ & ESC 3 & $\mathrm{ESC} 4$ & ESC 5 & ESC 6 & ESC 7 & CALIF \\
\hline 1 & .0134 & .0913 & .1244 & .1702 & .3015 & .3525 & .3892 & 5 \\
\hline 2 & 0122 & .0895 & .1219 & .1658 & .2412 & .2805 & 3374 & 5 \\
\hline 3 & .0106 & 1069 & .1462 & .1996 & .3381 & 4093 & .4521 & 6 \\
\hline 4 & .0414 & .0713 & .0787 & .0859 & .0929 & .0969 & .0977 & 0 \\
\hline 5 & .0833 & 1084 & .1144 & .1200 & .1251 & 1266 & .1283 & 6 \\
\hline 6 & .1385 & .1517 & .1549 & .1579 & .1607 & .1614 & .1635 & 7 \\
\hline 7 & .1514 & .2030 & .2136 & .2191 & .2306 & .2321 & .2335 & 7 \\
\hline 8 & -.0277 & .0100 & .0209 & .0312 & .0421 & .0482 & .0517 & 0 \\
\hline 9 & .0055 & .0410 & .0508 & .0604 & .0711 & .0769 & .0810 & 0 \\
\hline 10 & .0512 & .0790 & .0871 & .0955 & .1078 & .1110 & .1155 & 3 \\
\hline 11 & .0716 & .1237 & .1373 & .1490 & .1708 & 1750 & .1803 & 6 \\
\hline 12 & -.0615 & -.0573 & -.0564 & -.0557 & -.0551 & -.0550 & -.0549 & 0 \\
\hline 13 & -.0578 & -.0540 & -.0532 & -.0526 & -.0521 & -.0520 & -.0519 & 0 \\
\hline 14 & -.0518 & -.0493 & -0487 & -.0483 & -.0480 & -.0479 & .0478 & 0 \\
\hline 15 & -.0474 & -.0432 & -.0427 & -.0421 & .0412 & -.0411 & $\begin{array}{r}.0410 \\
\end{array}$ & 0 \\
\hline 16 & -0056 & .0374 & .0489 & .0602 & .0722 & .0776 & .0810 & 0 \\
\hline 17 & .0305 & .0697 & .0804 & .0907 & .1016 & .1054 & .1093 & 3 \\
\hline 18 & .0784 & .1085 & .1170 & 1256 & .1350 & .1383 & .1431 & 6 \\
\hline 19 & .0967 & .1546 & .1691 & 1808 & 1991 & .2036 & .2087 & 6 \\
\hline 20 & -.0552 & -.0515 & -.0500 & -.0486 & -.0478 & -.0476 & -.0475 & 0 \\
\hline 21 & -0511 & .0470 & -.0468 & -0463 & -.0455 & -0447 & -.0445 & 0 \\
\hline 22 & -0453 & -.0433 & -.0425 & -.0421 & -.0414 & -.0406 & -.0405 & 0 \\
\hline 23 & -0411 & -0372 & -0358 & -.0354 & -0350 & -.0347 & -0344 & 0 \\
\hline 24 & -.0286 & .0066 & .0158 & .0249 & .0341 & .0382 & .0408 & 0 \\
\hline
\end{tabular}


TABLA 4-7 (CONTINUACION)

\begin{tabular}{|l|l|l|l|l|l|l|l|l|}
\hline 25 & .0054 & .0370 & .0466 & .0550 & .0638 & .0668 & .0701 & 0 \\
\hline 26 & .0531 & .0762 & .0842 & .0912 & .0988 & .1015 & .1051 & 2 \\
\hline 27 & .0744 & .1246 & .1370 & .1471 & .1629 & .1667 & .1711 & 6 \\
\hline 28 & .0450 & .0066 & .0215 & .0347 & .0484 & .0540 & .0582 & 0 \\
\hline 29 & -.0103 & .0382 & .0512 & .0637 & .0766 & .0810 & .0860 & 0 \\
\hline 30 & .0358 & .0756 & .0864 & .0978 & .1097 & .1138 & .1194 & 3 \\
\hline 31 & .0570 & .1194 & .1357 & .1499 & .1708 & .1760 & .1824 & 6 \\
\hline
\end{tabular}

en la tabla 4-8 se presenta la inversión necesaria en equipos de proceso, calculada por el simulador, para cada proceso y escala cuyo ROI fué mayor de 0.1

TABLA 4-8

INVERSION REQUERIDA PARA EQUIPO DE PROCESO EN MILES DE NUEVOS PESOS (1993) PARA LAS POSICIONES CON ROI MAYOR A 0.1

\begin{tabular}{|c|c|c|c|c|c|c|c|}
\hline SISTEMA & $\begin{array}{l}\text { ESCALA } \\
1\end{array}$ & $\begin{array}{l}\text { ESCALA } \\
2\end{array}$ & $\begin{array}{l}\text { ESCALA } \\
3\end{array}$ & $\begin{array}{l}\text { ESCALA } \\
4\end{array}$ & $\begin{array}{l}\text { ESCALA } \\
5\end{array}$ & ${ }_{6}^{\text {ESCALA }}$ & ${ }_{7}^{\text {ESCALA }}$ \\
\hline 1 & & & 904.53 & 1538.46 & 3069.33 & 4537.5 & 8444.7 \\
\hline 2 & & & 635.91 & 1088.01 & 2564.1 & 3828 & 6639.6 \\
\hline 3 & & 619.74 & 916.08 & 1558.26 & 3185.16 & 4577.1 & 8494.2 \\
\hline 5 & & 2024.55 & 3342.9 & 6606.6 & 19536 & 32379.6 & 64350 \\
\hline 6 & 790.35 & 2338.38 & 3877.5 & 7708.8 & 22958.1 & 38181 & 75669 \\
\hline 7 & 919.38 & 2436.06 & 3963.3 & 7863.9 & 22882.2 & 38016 & 75768 \\
\hline 10 & & & & & 25886.5 & 42513.9 & 83136.9 \\
\hline 11 & & 3007.6 & 4814 & 9315.24 & 25801.7 & 42391.8 & 83216.1 \\
\hline 17 & & & & & 219126 & 35917.2 & 70547.4 \\
\hline 18 & & 2776.9 & 4524.6 & 8810 & 25536.4 & 42022.2 & 82275.6 \\
\hline 19 & & 2873.3 & 4612.4 & 8970 & 25452.6 & 41844 & 82368 \\
\hline 26 & & & & & & 41946.3 & 82265.7 \\
\hline 27 & & 2863.7 & 4598.9 & 8947.6 & 25402.1 & 41768.1 & 82229.4 \\
\hline 30 & & & & & 26918.1 & 44078.1 & 85823.1 \\
\hline 31 & & 3106.6 & 4959.2 & 9562 & 26829 & 43893.3 & 85892.4 \\
\hline
\end{tabular}

Los resultados de las tablas 4-7 y 4-8 permiten hacer una discriminación entre alternativas de procesamiento de lactosuero.

Se puede ver que para los procesos donde la reconversión es favorable $(\mathrm{ROI}>0)$, la rentabilidad se favorece cuando la escala del proceso aumenta. Este fenómeno, que es común a casi todos los procesos, llamado economia de escala, se presenta con distinta intensidad, según el tipo de proceso de que se trate. Por ejemplo, procesos como el 1, 2 y 3 ven incrementado su ROI entre 30 y 40 veces al pasar de la escala 1 a la 7 , en tanto que otros, como los procesos 18 y 26 , con ese mismo cambio de escala aumentan solamente en casi 2 veces su valor de ROl. El primer grupo de procesos es altamente sensible a la escala y debe ser operado a la mayor escala posible, en tanto que en el segundo es más recomendable operar a baja escala. 
Si la instalación de procesamiento es un centro de acopio de lactosuero y puede operar a altas escalas, son recomendables procesos como el 3,1 y 2 , si existe demanda suficiente para los productos implicados. Cuando la demanda les favorece, otros procesos como el 11, 19,27 y 31 pueden ser viables a alta escala.

Si la instalación de procesamiento maneja bajos volúmenes de lactosuero, es conveniente escoger procesos cuyo ROI sea suficientemente alto a baja escala. Tal es el caso de los procesos $6,7 \mathrm{y}$ posiblemente el 19.

Procesos cuyo ROI es bajo o negativo en todo el intervalo, como el 8,12 a 16, 20 a 24 y 28 a 29 , deberán ser descartados como opciones de procesamiento de lactosuero.

En cuanto a la inversión, cada opción tiene distinto costo de inversión, independientemente del ROI obtenido. Asi, desde el punto de vista de inversión el proceso 1 a la escala 3 es casi tan costoso como el proceso 7 a la escala 1. Consultando la tabla 4-7 puede verse que es más rentable elegir el proceso 7 .

Los procesos 30 y 31 a la escala 7 son similares en costo; sin embargo, según la tabla 4-7 conviene más invertir en el proceso 31. Este tipo de comparaciones debe considerar además la demanda de los productos a producir. En este aspecto, merece mención especial el lactosuero seco, obtenido del proceso I, el cual es el producto de mayor demanda establecida. A nivel mundial, los concentrados proteicos también tienen una gran demanda.

En función de lo anteriormente dicho, es posible llegar a una selección de los procesos más atractivos para un caso particular. Estos procesos elegidos deberán ser subsecuentemente investigados para conocer con más detalle algunas otras características de su comportamiento económico. Para esa siguiente etapa de estudio se eligieron en este trabajo los procesos 1, 3 y 7 .

Comportamiento económico de procesos selectos.

A partir de los resultados de la simulación, los procesos 1, 3 y 7 parecen pertenecer al grupo de los que ofrecen las mejores alternativas de procesamiento de lactosuero. En la figura 4-2, se presenta el ROI en función de la escala para estos tres procesos. la dinámica económica mostrada pudo ser adecuadamente expresada mediante una ecuación empírica del tipo

$$
\mathrm{ROI}=\mathrm{M} 1 * \mathrm{ESC} /(\mathrm{M} 2+\mathrm{ESC})
$$

en donde ESC es la escala en miles de libras de lactosuero procesado por hora, considerando 20 horas de trabajo al dia, y M1 y M2 son parámetro empíricos cuyos valores reflejan algunos razgos del comportamiento de la curva.

Ml es el valor asintótico que alcanzaría ROI a una escala infinita.

El inverso de $\mathrm{M} 2$ es la pendiente con que crece el ROI en función de la escala para valores de escala próximos a cero. Para valores mayores de escala, esta pendiente tiende a ser proporcional al inverso del cuadrado de la escala.

Los parámetros de la ecuación empírica ajustados a los procesos de interés, se muestran en la tabla 4-9. 


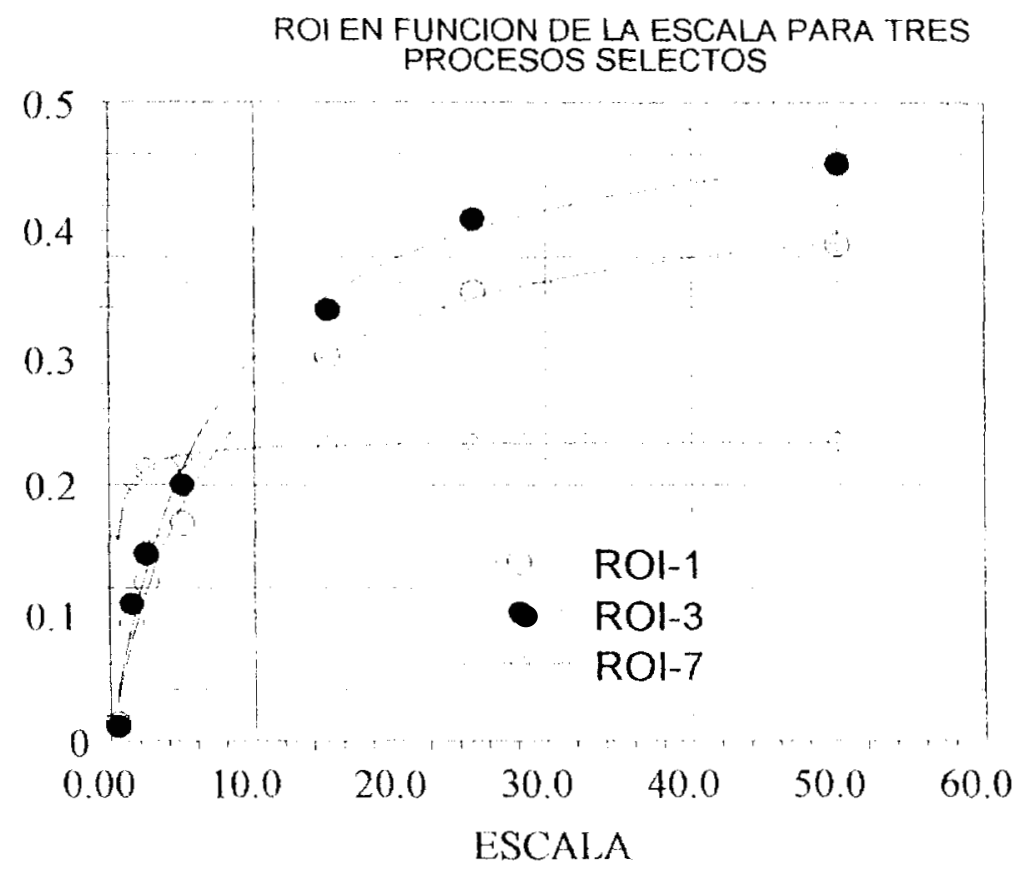

FIG 4-2

ROI VS. ESCALA EN MILES DE LB/HR DE LACTOSUERO PROCESADO

PARA LOS PROCESOS 1,3 Y 7

TABLA 4-9

VALORES DE LOS PARAMETROS DE AJUSTE

PARA LOS TRES PROCESOS DE INTERES

\begin{tabular}{|l|l:l:l} 
& PROCES & PROCES & PROCES \\
\hline$M$ & 0.4457 & 0.5164 & 07 \\
\hline 1 & & 0.2400 \\
\hline$M$ & 7.2195 & 7.0247 & 0.2649 \\
\hline 2 & & &
\end{tabular}

La representación del comportamiento económico mediante la ecuación empírica propuesta facilita la visualización de algunas de las características de los tres procesos:

Para el proceso 7, la economía de escala deja de operar alrededor de las $10,000 \mathrm{lb} / \mathrm{hr}$, mientras que para los procesos 1 y 3 continúa más allá de las $50,000 \mathrm{lb} / \mathrm{hr}$. 
Aunque a las escalas más bajas $(4,000 \mathrm{lb} / \mathrm{hr}$ y menores $)$ el proceso 7 es superior a los otros, las rentabilidades se aproximan entre sí para escalas de 5000-8000 lb/hr y desde estas escalas en adelante, los procesos 1 y 3 superan significativamente en rentabilidad al proceso 7 .

Existe una marcada superioridad del proceso 3 sobre el 1 desde escalas muy bajas. Considerando los valores asintóticos de ROI, representados por el parámetro $\mathrm{Ml}$, se puede decir que a escala completamente desarrollada el proceso 1 está $13.69 \%$ abajo del proceso 3 y el proceso 7 está $53.52 \%$ abajo del proceso 3 .

Comparando entre si los procesos 1 y 7 se tiene que respecto al ROI máximo el proceso 7 está $46.15 \%$ abajo del proceso 1.

Respecto a la rapidez con que ROI crece inicialmente con la escala y que se representa por el inverso de $\mathrm{M} 2$, el proceso más rápido es el 7 y respecto a éste, el proceso 1 es $96.33 \%$ más lento y el proceso 3 es $96.23 \%$ más lento.

Comparando entre sí los procesos 1 y 3 se puede decir que el proceso 1 es inicialmente $2.67 \%$ más lento que el proceso 3.

La ecuación empírica de tipo Monod y la tabla 4-9 constituyen un método corto para estimar la rentabilidad económica en función de la escala de los tres procesos elegidos.

Análisis de sensibilidad.

Además del comportamiento económico frente a la escala, resulta de interés conocer la forma en que la economía de cada proceso responde ante un cambio en parámetros económicos clave. Se desea saber qué pasaría con la rentabilidad cuando un determinado parámetro económico resultase ser en la práctica un poco mayor o un poco menor del valor estimado en el escenario base. Se escogieron como parámetros de interés el precio de productos, la inversión y el costo de operación. En la tabla 4-10 se resumen las condiciones estudiadas en este análisis de sensibilidad.

TABLA $4-10$

\begin{tabular}{|c|c|}
\hline ESCENARIO & CONDICIONES \\
\hline $\mathrm{O}$ & $\begin{array}{l}\text { Condiciones normales de mercado, es decir, las mismas de las } \\
\text { tablas } 4-1,4-2 \text { y } 4-8\end{array}$ \\
\hline$A$ & $\begin{array}{l}\text { Las del escenario } O \text {, excepto que se considero un precio de } \\
\text { productos } 20 \% \text { mayor }\end{array}$ \\
\hline B & $\begin{array}{l}\text { Las del escenario } O \text {, excepto que se consideró un precio de } \\
\text { productos } 20 \% \text { menor }\end{array}$ \\
\hline $\mathrm{C}$ & $\begin{array}{l}\text { Las del escenario } \mathrm{O} \text {, excepto que se consideró una inversión } \\
20 \% \text { mayor }\end{array}$ \\
\hline D & $\begin{array}{l}\text { Las del escenario } O \text {, excepto que se consideró una inversión } \\
20 \% \text { menor }\end{array}$ \\
\hline $\mathrm{E}$ & $\begin{array}{l}\text { Las del escenario O, excepto que se consideró un costo de } \\
\text { operación } 20 \% \text { mayor }\end{array}$ \\
\hline $\mathrm{F}$ & $\begin{array}{l}\text { Las del escenario } O \text {, excepto que se consideró un costo de } \\
\text { operación } 20 \% \text { menor }\end{array}$ \\
\hline
\end{tabular}

Con ayuda de los resultados previos del simulador y una hoja electrónica de cálculo, se determinaron los valores de ROI en función de la escala para los procesos 1, 3 y 7 . El ajuste de estos datos a la expresión empírica usada proporcionó los resultados mostrados en la tabla 4-11. 
TABLA 4-11

VALORES DE LOS PARAMETROS DE AJUSTE M1 Y M2

PARA LOS PROCESOS 1,3 Y 7 EN LOS DISTINTOS ESCENARIOS ENSA YADOS

\begin{tabular}{|c|c|c|c|c|c|c|}
\hline & $\begin{array}{l}\text { PROCES } \\
\mathrm{O}\end{array}$ & UNO & $\begin{array}{l}\text { PROCES } \\
\mathrm{O}\end{array}$ & TRES & $\begin{array}{l}\text { PROCES } \\
\mathrm{O}\end{array}$ & SIETE \\
\hline $\begin{array}{c}\text { ESCENA } \\
\text { RIO }\end{array}$ & Ml & $\mathrm{M} 2$ & $\mathrm{Ml}$ & $\mathrm{M} 2$ & $M I$ & M2 \\
\hline $\mathrm{O}$ & 4457 & 7.2195 & 5164 & 7.0247 & 2400 & .2649 \\
\hline$A$ & 5450 & 5.9144 & 6266 & 6.0064 & 2989 & 2230 \\
\hline B & .3393 & 9.5913 & .3998 & 9.7462 & .1697 & 3370 \\
\hline $\mathrm{C}$ & .3741 & 8.4712 & 4231 & 7.8170 & 1857 & 2705 \\
\hline D & .5623 & 6.4630 & 6376 & 6.3056 & 3055 & .2431 \\
\hline$E$ & .4235 & 7.9859 & .5090 & 8.5175 & .2260 & .2952 \\
\hline$F$ & .4552 & 6.1937 & .5206 & 6.0397 & .2426 & .2404 \\
\hline
\end{tabular}

Para dar una interpretación gráfica sencilla a los efectos económicos de cada escenario, se prepararon las figuras 4-3, 4-4 y 4-5, en donde se presentan sobre escalas normalizadas las variaciones en $\mathrm{M} 1$ y $\mathrm{M} 2$ debidas a la aplicación de un escenario económico determinado. El análisis se realizó para cada proceso por separado. 


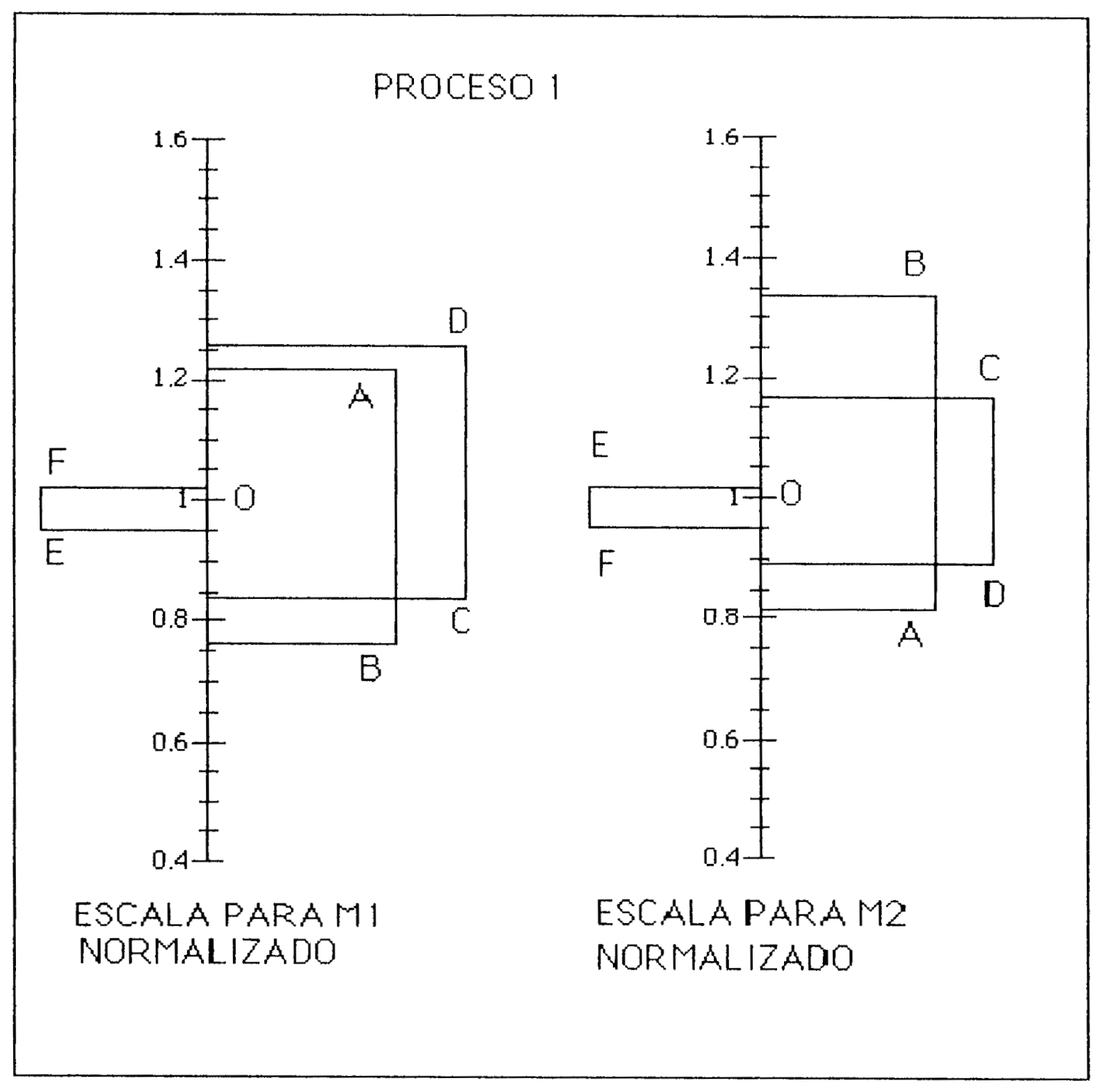

FIG, 4-3

VARIACIONES DEL VALOR DE ROI PARA DIFERENTES ESCENARIOS (PROCESO 1) 
Los efectos que aquí se analizan mediante ajuste empírico, permiten establecer comparaciones cuantitativas respecto del impacto de variables económicas sobre la rentabilidad y también facilitan la identificación de los sitios donde la atención gerencial debe ser prioritaria, en virtud de los efectos esperados.

Globalmente se observa que para el proceso 1, cambios del mismo orden de magnitud sobre la inversión y los precios afectan mucho más que sobre el costo de operación.

Para este mismo proceso, la escala normalizada para MI indica en la figura 4-3, que si la inversión resultara ser $20 \%$ menor a la estimada, la rentabilidad (interpretada por el aumento en el ROI asintótico), podría mejorar en casi $25 \%$. Como la rentabilidad es función de la escala, la reducción en inversión reduce también en casi $10 \%$ el valor de $\mathrm{M} 2$, lo que implica un crecimiento inicial de ROI casi 10\% más rápido también. Si por el contrario, la inversión resultara $20 \%$ mayor a la prevista (escenario $\mathrm{C}$ ), se podría anticipar una reducción del ROI asintótico de casi 16\% y una disminución de la rapidez inicial de crecimiento de ROI con la escala de alrededor de $17 \%$. El impacto del costo de operación se midió a través de los escenarios E y F. Como puede verse, un aumento del $20 \%$ en el costo de operación representa una disminución del $5 \%$ en el valor asintótico de ROI, y una disminución del mismo orden de magnitud en el costo de operación podría elevar el ROI asintótico en sólo 2 o $3 \%$.

Si los precios cambiaran un $20 \%$ hacia arriba, la economía del proceso podría mejorar en casi $22 \%$ a grandes escalas, y la rapidez inicial de crecimiento de ROI con la escala podría mejorar en casi $18 \%$.

Para el escenario B, que contiene un abatimiento de $20 \%$ en los precios, se prevé una drástica disminución en la rapidez de crecimiento del ROI a bajas escalas (casi 35\% menos) y una pérdida de casi el $25 \%$ en la rentabilidad a escala asintótica.

Para el proceso 1, y si los cambios son del mismo orden de magnitud, cabría esperar efectos más graves en la pendiente de ROI contra escala si los precios bajan que si la inversión sube. 


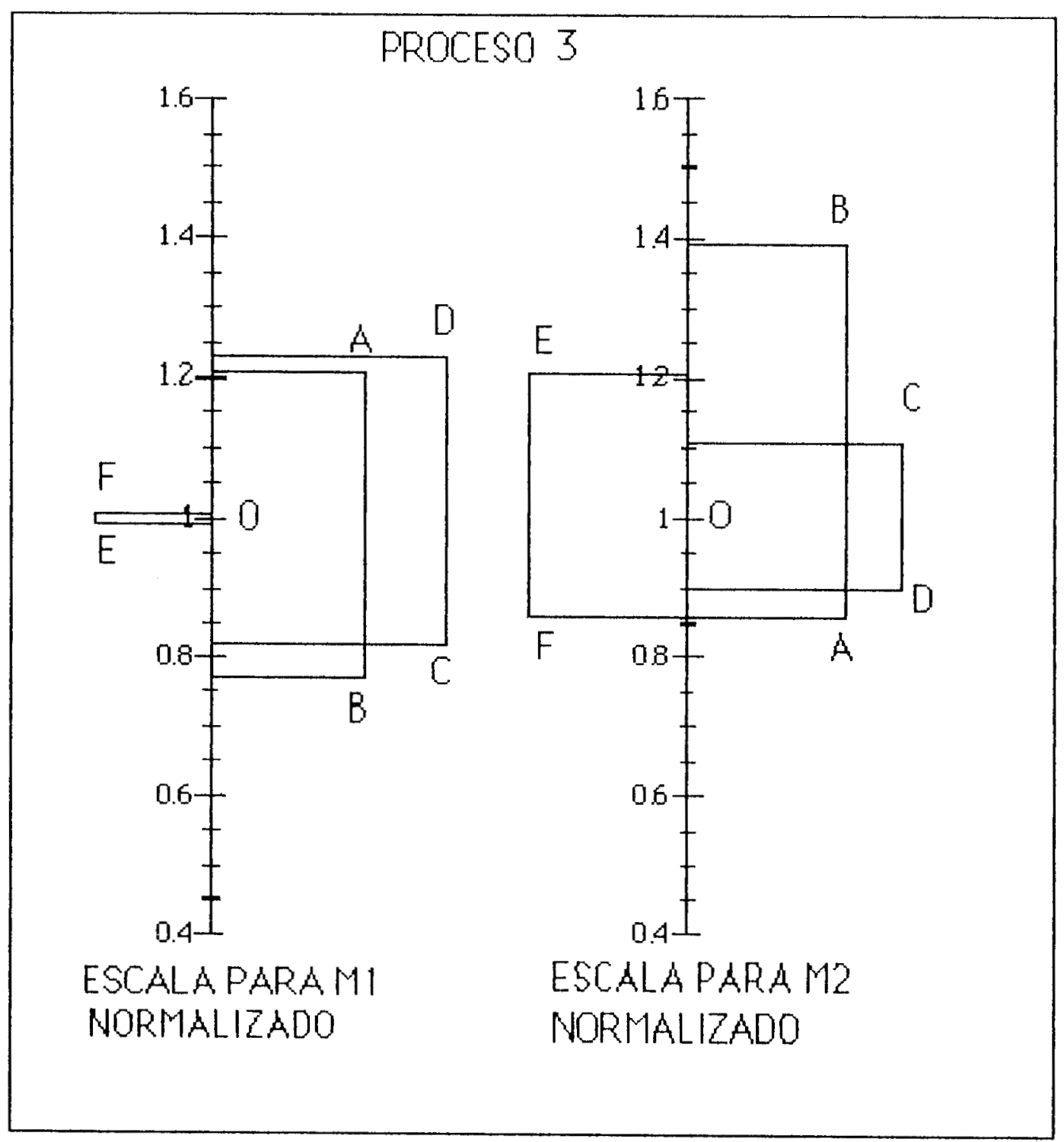

FIG. 4-4

VARIACIONES DEL VALOR DE ROI PARA DIFERENTES ESCENARIOS (PROCESO 3) 


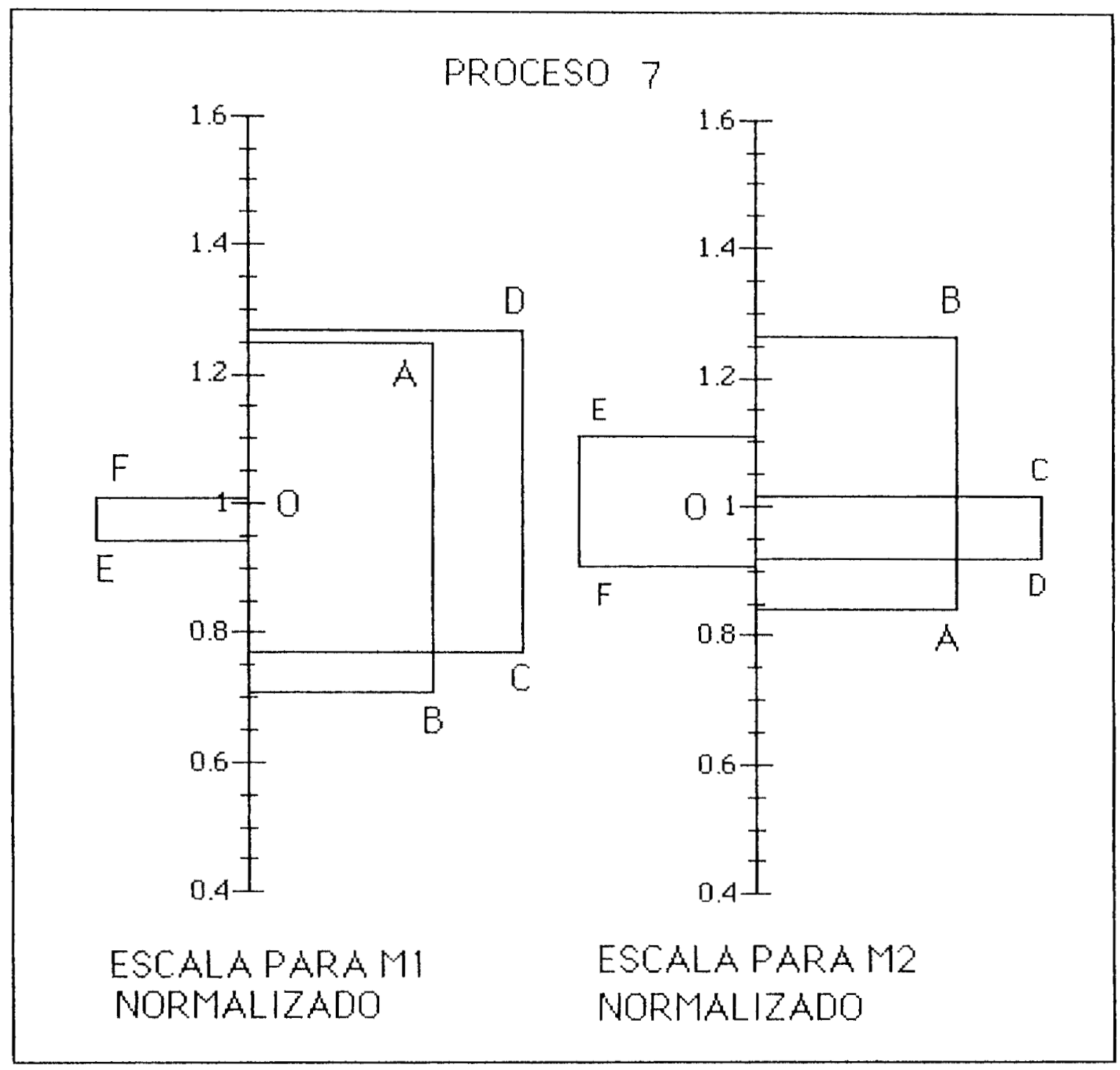

FIG. 4-5

VARIACIONES DEL VALOR DE ROI PARA DIFERENTES ESCENARIOS (PROCESO 7)

Esta información también puede servir para priorizar y ubicar mejor los recursos destinado a ciertas acciones de mejora, tales como estrategias de ventas, investigación y desarrollo, ingreso a nuevos mercados, etc.

Las figuras 4-4 y 4-5 presentan las peculiaridades de los procesos 3 y 7 respectivamente, los cuales podrian comentarse en términos similares a los que se usaron para el proceso 1. 
También es posible hacer un análisis comparativo entre los tres procesos. El costo de operación es el factor menos relevante en ellos. El proceso 3 presenta la mínima afectación en el ROI asintótico y la máxima afectación en la pendiente inicial de ROI VS escala. Esto es, que a grandes escalas los cambios en el costo de operación le afectan menos y a pequeñas escalas le afectan más.

Gráficamente se aprecia que en los tres procesos, el efecto más adverso es una reducción en el precio de los productos. Para el caso del efecto más favorable, la situación no es fácil de dilucidar a partir de las figuras; podria ser una reducción en la inversión prevista, un aumento en el precio de productos o una combinación de ambos.

Tratando de establecer mejor el peso relativo que cada parámetro tiene sobre el ROI para un proceso dado y en una escala determinada, se extendió el estudio de sensibilidad paramétrica con ayuda de los datos de la tabla 4-11 y un paquete computacional de ajuste de datos (Kaleidagraph). Se estudiaron para cada escala los conjuntos de escenarios B-O-A, D-O-C y F-O-E, normalizando el parámetro variado (PARAM*) de modo que sus valores fuesen $0.8,1$ y 1.2 respectivamente. Posteriormente se ajustaron a una recta estos tres datos (lo cual se logró sin dificultad en todos los casos). La pendiente de la recta ROI vs PARAM* representa para la escala estudiada, la magnitud del efecto sobre ROI de un cambio unitario en el parámetro estudiado. Comparando estas pendientes para cada escala y para cada parámetro normalizado (precios, inversión, costos de operación), fué posible encontrar la sensibilidad del ROI a cada uno de ellos en forma individual. Los resultados se muestran gráficamente en la figura 4-6 para el proceso 1.

PROCESO 1

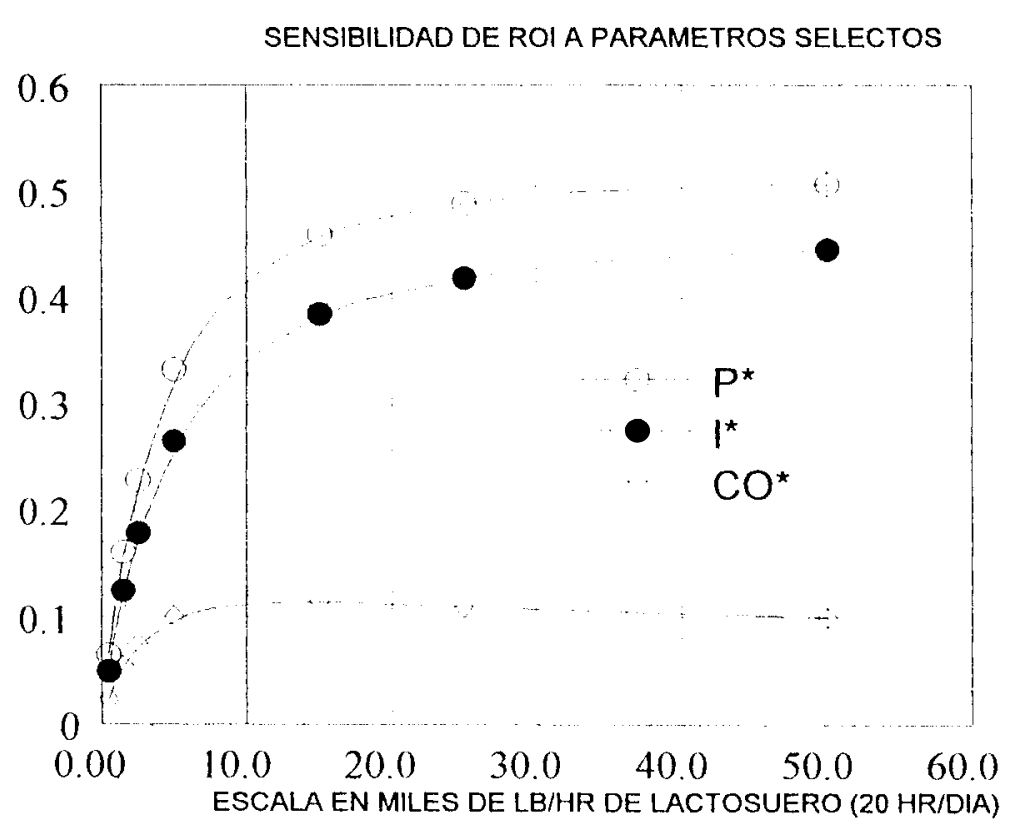

FIGURA 4-6

SENSIBILIDAD DE ROI A PARAMETROS SELECTOS (PROCESO I) 
De manera similar se hicieron análisis para los procesos 3 y 7 , cuyos resultados se muestran en las figuras 4-7 y 4-8. la escala del eje vertical es la misma en las tres figuras y sirve para establecer comparaciones entre los efectos individuales de cambios en precios, inversión y costo de operación.

\section{PROCESO 3}

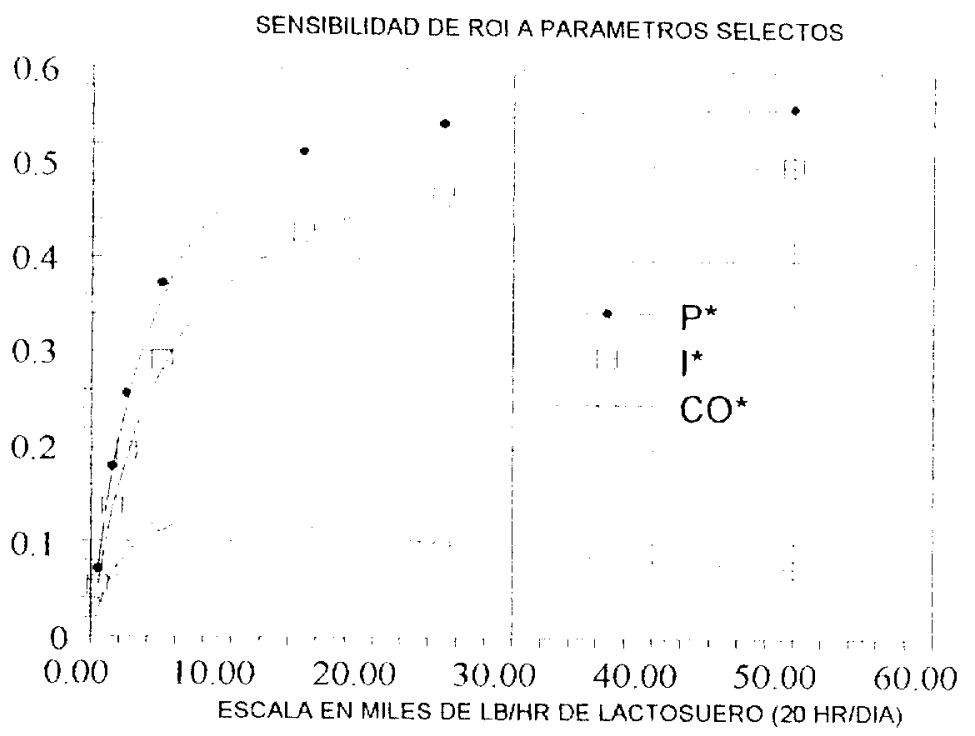

FIGURA 4-7

SENSIBILIDAD DE ROI A PARAMETROS SELECTOS (PROCESO 3)

PROCESO 7

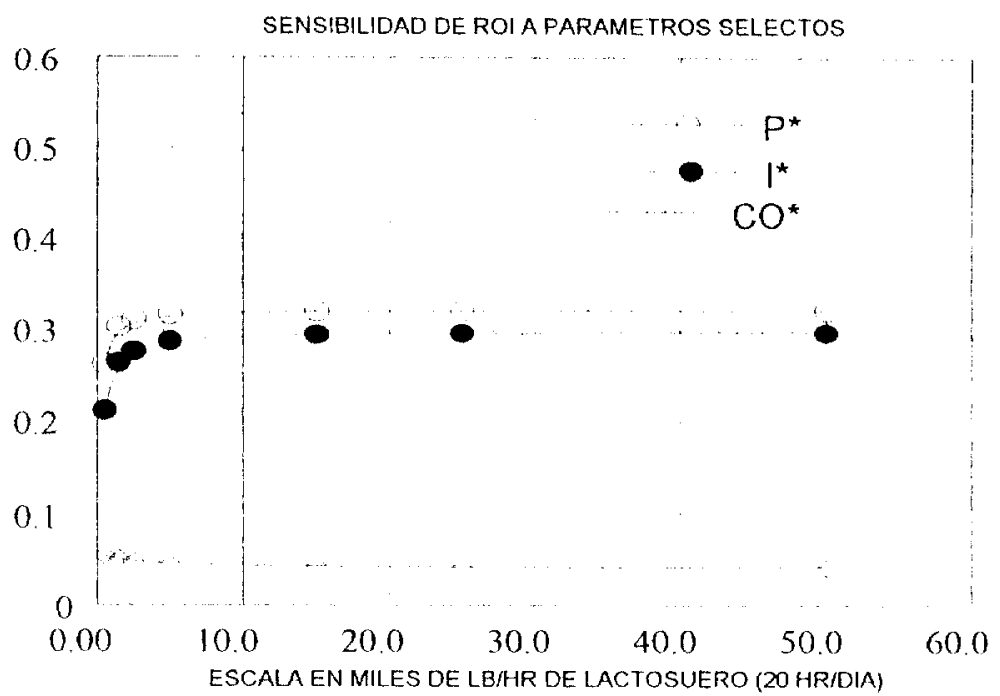

FIGURA 4-8

SENSIBILIDAD DE ROI A PARAMETROS SELECTOS (PROCESO 7) 
Estas representaciones tienen la ventaja sobre los gráficos de las figuras 4-3, 4-4 y 4-5, de mostrar con mayor claridad el peso relativo de los parámetros selectos en función de la escala.

Con los datos de ROI obtenidos para los distintos escenarios, escalas y procesos, se obtuvo mediante un paquete computacional de ajuste de datos (Kaleidagraph), el ajuste de los parámetros M1 y M2 de la ecuación empírica de ROI en función de la inversión normalizada, precios de productos normalizados y costos de operación normalizados.

PROCESO 1

$\mathrm{MI}=0.485+0.514\left(\mathrm{P}^{*}\right)-0.471\left(\mathrm{I}^{*}\right)-0.079\left(\mathrm{C}^{*}\right)$

$M 2=7.097-9.192\left(\mathrm{P}^{*}\right)+5.02\left(\mathrm{I}^{*}\right)+4.48\left(\mathrm{C}^{*}\right)$

\section{PROCESO 3}

$\mathrm{M} 1=0.517+0.567\left(\mathrm{P}^{*}\right)-0.536\left(\mathrm{I}^{*}\right)-0.029\left(\mathrm{C}^{*}\right)$

$\mathrm{M} 2=6.728-9.349\left(\mathrm{P}^{*}\right)+3.778\left(\mathrm{I}^{*}\right)+6.194\left(\mathrm{C}^{*}\right)$

PROCESO 7

$\mathrm{M} 1=0.256+0.323\left(\mathrm{P}^{*}\right)-0.3\left(\mathrm{I}^{*}\right)-0.041\left(\mathrm{C}^{*}\right)$

$\mathrm{M} 2=0.347-0.285\left(\mathrm{P}^{*}\right)+0.068\left(\mathrm{I}^{*}\right)+0.137\left(\mathrm{C}^{*}\right)$

en donde $\mathrm{P}^{*}$ es el cociente entre el precio del producto tomado como producto principal del proceso en un escenario determinado y este mismo precio para el escenario de referencia (escenario $\mathrm{O}$ ), $\mathrm{I}^{*}$ es el cociente entre la inversión requerida por el proceso en un escenario determinado y la inversión para el escenario de referencia (escenario O) y $\mathrm{C}^{*}$ es el cociente entre el costo de operación del proceso en un escenario determinado y este mismo precio para el escenario de referencia (escenario O). Acoplando estas ecuaciones con la ecuación empírica de ROI en función de la escala, es posible predecir valores de ROI ajustando las condiciones de los parámetros económicos que se deseen manejar.

En las expresiones obtenidas del ajuste multivariable para $\mathrm{Ml}$ y $\mathrm{M} 2$, la magnitud del coeficiente que multiplica a cada parámetro normalizado representa en una escala comparativa el factor de peso de ese parámetro sobre $\mathrm{M} 1$ o $\mathrm{M} 2$ y su signo representa la condición de incremento o decremento para ROI por la contribución de dicho parámetro. 
En la tabla 4-12 se presentan algunas comparaciones entre valores calculados para ROI en los procesos 1, 3 y 7 mediante simulación extensa y mediante el método corto de las ecuaciones empiricas.

TABLA 4-12

COMPARACION ENTRE DOS METODOS DE OBTENCION DE ROI PARA ALGUNOS CASOS AL AZAR EN LOS PROCESOS 1, 3 Y 7.

\begin{tabular}{|c|c|c|c|c|c|c|}
\hline CONDICIONES & $\mathrm{p}^{*}$ & $1^{*}$ & $\mathrm{C}^{*}$ & $\begin{array}{l}\text { ROI POR } \\
\text { SIMULADOR }\end{array}$ & $\begin{array}{l}\text { ROI POR } \\
\text { METODO } \\
\text { CORTO }\end{array}$ & $\begin{array}{l}\% \\
\text { DESVIACION }\end{array}$ \\
\hline $\begin{array}{l}\text { PROCESO 1, } \\
\text { ESCALA } 50,000 \\
\text { LB/HR }\end{array}$ & 1 & 1.2 & 0.8 & 0.3307 & 0.3221 & 2.6 \\
\hline IDEM & 0.8 & 1 & 1 & 0.2819 & 0.2922 & -3.6 \\
\hline IDEM & 1 & 0.8 & 1.2 & 0.4745 & 0.4602 & 3.0 \\
\hline $\begin{array}{l}\text { PROCESO 3, } \\
\text { ESCALA } 25,000 \\
\text { LB/HR }\end{array}$ & 1.2 & 1 & 1 & 0.5202 & 0.5187 & 0.29 \\
\hline IDEM & 1.2 & 0.8 & 0.8 & 0.6863 & 0.6541 & 4.7 \\
\hline IDEM & 1 & 1.2 & 0.8 & 0.3486 & 0.3276 & 6.2 \\
\hline $\begin{array}{l}\text { PROCESO 7, } \\
\text { ESCALA } 5,000 \\
\text { LB/HR }\end{array}$ & 0.8 & 1.2 & 1 & 0.1224 & 0.1063 & 13.1 \\
\hline IDEM & 1 & 1.2 & 1 & 0.1742 & 0.1686 & 3.2 \\
\hline IDEM & 1.2 & 0.8 & 1 & 0.3640 & 0.3490 & 4.1 \\
\hline
\end{tabular}

Como puede verse, el método corto proporciona aproximaciones del valor de ROI dentro de un $10 \%$ aproximadamente, con un tiempo de cálculo extremadamente reducido. 
CAPITULO 5

\section{DESARROLLO DESDE EL SEGUNDO PUNTO DE VISTA}

Planteamiento del problema.

Este capítulo se dedica a explorar el impacto económico de una tecnología limpia en el proceso quesero para reducir la producción de desechos y aumentar la productividad en el mismo, concebida mediante la aplicación del pensamiento lateral a la problemática original planteada en el Capítulo 3.

Se comparan económicamente el proceso quesero tradicional y un proceso modificado que incluye ultrafiltración y adición de caseína mediante un simulador desarrollado originalmente para determinar los casos y las condiciones de proceso para los que la modificación es atractiva. Se estudiará el efecto de la escala de proceso en un caso selecto.y la influencia relativa de algunos parámetros importantes sobre la rentabilidad global Posteriormente se buscará obtener expresiones simplificadas que conserven la información básica del comportamiento económico en función de los principales parámetros que pudieran afectar a la economia de la reconversión y una comparación entre los pesos relativos de éstos. De esta forma se busca desarrollar un conjunto de herramientas simples para evaluar la inversión necesaria del cambio hacia una tecnología más limpia en la industria quesera y de las condiciones bajo las que este costo puede ser más bien un beneficio.

A pesar de las importaciones cuantiosas de leche en el pais, la industria quesera mexicana tiene presencia en el ámbito nacional, especialmente en el mercado de los quesos no madurados. Existe una composición bien definida para un gran número de quesos, la cual debe ser respetada por los productores. En la tabla 4.1 se presentan algunos de los quesos más importantes y su composición, así como la composición de la leche fresca.

TABI., $5-1$

COMPOSICION REPORTADA DE LECHE Y ALGUNOS

QUESOS RECONOCIDOS INTERNACIONALMENTE

\begin{tabular}{|l|l|l|l|l|l|l|}
\hline NOMBRE & REF & \%AGUA & \%GRASA & \%PROT & \%CARBOH & \%SALES \\
\hline LECHE & $\mathrm{D}$ & 87.5 & 3.5 & 3.3 & 5 & 0.7 \\
\hline BEL PAESE & $\mathrm{A}$ & 40.8 & 31 & 26 & 0.2 & 2 \\
\hline BRIE & $\mathrm{A}$ & 47.1 & 28.5 & 22.5 & 0.2 & 1.7 \\
\hline COTTAGE & $\mathrm{A}$ & 78 & 4.5 & 12.5 & 3.5 & 1.5 \\
\hline EDAM & $\mathrm{A}$ & 45.2 & 25 & 27 & 1.2 & 1.6 \\
\hline EMMENTAL & $\mathrm{A}$ & 36.9 & 31 & 29 & 1.4 & 1.7 \\
\hline FETA & $\mathrm{A}$ & 56 & 23 & 15.5 & 1.5 & 4 \\
\hline GORGONZOLA & $\mathrm{A}$ & 44 & 32.5 & 20.5 & 1 & 2 \\
\hline GOUDA & $\mathrm{A}$ & 37 & 30.9 & 27 & 1 & 4.1 \\
\hline GRUYERE & $\mathrm{A}$ & 32.8 & 32.5 & 29.5 & 1 & 4.2 \\
\hline MANCHEGO & $\mathrm{A}$ & 33.9 & 34.5 & 26.5 & 1.1 & 4 \\
\hline PARMESANO & $\mathrm{A}$ & 30.5 & 27 & 35.5 & 1.2 & 5.8 \\
\hline QUARG & $\mathrm{A}$ & 76 & 6 & 13.6 & 3.5 & 0.9 \\
\hline ROQUEFORT & $\mathrm{A}$ & 40 & 31 & 22 & 1 & 6 \\
\hline
\end{tabular}


TABLA 5-1 (CONTINUACION)

\begin{tabular}{|l|l|l|l|l|l|l|}
\hline NOMBRE & REF & $\% A G U A$ & $\% G R A S A$ & $\% P R O T$ & $\%$ ARIBOH & $\%$ SALES \\
\hline BLUE MOLD & B & 42.41 & 28.74 & 21.4 & 2.34 & 5.11 \\
\hline BRICK & B & 41.11 & 29.68 & 23.24 & 2.79 & 3.18 \\
\hline CAMEMBERT & B & 51.8 & 24.26 & 19.8 & 0.46 & 3.68 \\
\hline CHEDDAR & B & 36.75 & 33.14 & 24.9 & 1.28 & 3.93 \\
\hline CREMA & B & 53.75 & 34.87 & 7.55 & 2.6 & 1.23 \\
\hline LIMBURGER & B & 48.42 & 27.25 & 20.05 & 0.49 & 3.79 \\
\hline MOZZARELLA & B & 54.14 & 21.6 & 19.42 & 2.22 & 2.62 \\
\hline SUIZO & B & 37.21 & 25.45 & 28.43 & 3.38 & 5.53 \\
\hline RICOTTA & B & 71.7 & 12.98 & 11.26 & 3.04 & 1.02 \\
\hline Q. FRESCO & C & 79 & 7.5 & 8.5 & 4 & 1 \\
\hline PB Y CE $\left(^{*}\right)$ & $\mathrm{C}$ & 50 & 24 & 20 & 4 & 2 \\
\hline PB Y CL $\left(^{*}\right)$ & $\mathrm{C}$ & 50 & 24 & 20 & 4 & 2 \\
\hline PPNC $(+)$ & $\mathrm{C}$ & 40 & 24 & 28 & 3 & 5 \\
\hline PPC $(++)$ & $\mathrm{C}$ & 35 & 28 & 29 & 2.5 & 5.5 \\
\hline C/MOHO & $\mathrm{C}$ & 40 & 32 & 21 & 1.8 & 5.2 \\
\hline
\end{tabular}

Referencias: $A=(45), B=(358), C=(83), D=(12)$

Notas: $\left(^{*}\right)$ se refiere a dos tipos de queso que tienen la misma composición macro; los de pasta blanda y corteza enmohecida y los de pasta blanda y corteza lavada. (+) se refiere a los quesos de pasta prensada no cocida. $(+t)$ se refiere a los quesos de pasta prensada cocida.

Partiendo de que los procesos queseros con una ligera o inexistente maduración son susceptibles de ser modificados, como se vió en el Capítulo 3, el presente Capítulo está dedicado a definir el entorno de condiciones bajo las cuales es posible modificar el proceso de ésta manera y a evaluar la repercusión económica global de dicha modificación, incluyendo el aspecto de costos por disposición de efluentes.

La modificación considerada contempla la ultrafiltración de leche y eventual adición de caseína antes del proceso quesero.

Se sabe que técnicamente es posible concentrar la leche a nivel industrial por ultrafiltración hasta por un factor de 7 (este factor, conocido como factor de concentración y denominado XUF, se define como el cociente del peso de la leche entrante entre el peso de la leche concentrada por ultrafiltración) y que la presencia de proteínas de lactosuero y el aumento de la cantidad de carbohidratos fermentables en la cuajada, producidos por la concentración de la leche, tiende a alterar los patrones de maduración del producto y con ello algunas de sus propiedades (189). La literatura reporta aplicaciones exitosas de la ultrafiltración en quesos de pH bajos (4.6-4.8), de altos contenidos de humedad y que no dependan fuertemente de la proteólisis para desarrollar su aroma y sabor, ya que es en éstos donde se interfiere menos con las microtransformaciones del proceso (193).

Considerando todo lo anterior y después de revisar un buen número de estudios al respecto (193), (189), (107), (18), (285), (125), (51), (122), (172), (110), (111), (312), (276), (147), (231), (38), (283), (83) y de consultar criterios heurísticos, se adoptaron en este trabajo los siguientes 
requisitos para seleccionar los tipos de queso viables y para definir los límites de ultrafiltración y adición de caseína en el proceso modificado propuesto:

a) Se consideraron como quesos susceptibles de ser procesados sin problemas de modo no tradicional, aquellos cuyo contenido de agua en el producto final fuese mayor o igual al $50 \%$ en peso

b) Para los quesos indicados en el punto anterior, se estableció como límite máximo de ultrafiltración, la condición de alcanzar un factor de concentración igual a 5 o bien un contenido de proteínas de lactosuero equivalente al $20 \%$ de la fracción proteica total.

La limitación de 5 para el factor de concentración es con el fin de asegurar la viabilidad técnica y reducir los problemas por obstrucciones y bajos flujos que pudieran presentarse, y las limitaciones al contenido de proteínas de lactosuero son para prevenir problemas derivados de las alteraciones en las propiedades sensoriales del producto, que pueden aparecer cuando se excede el límite indicado.

Aplicando estos criterios a los quesos de la tabla 5.1 se definió la lista de quesos de interés y los límites permisibles de ultrafiltración (tabla 5-2).

TABLA 5-2

QUESOS DE INTERES Y LIMITES DE OPERACION RESPECTO DE LA ULTRAFILTRACION

\begin{tabular}{|c|c|c|c|c|c|}
\hline QUESO TIPO & $\begin{array}{l}X \mathrm{LI} \\
\mathrm{M}\end{array}$ & $\begin{array}{l}\text { \% PROT LS } \\
\text { EN } \\
\text { PROTEINA } \\
\text { DEL QUESO }\end{array}$ & QUESO TIPO & $\begin{array}{l}\text { XLI } \\
M\end{array}$ & $\begin{array}{l}\% \text { PRO'T LS } \\
\text { EN } \\
\text { PROTEINA } \\
\text { DEL QUESO }\end{array}$ \\
\hline CAMEMBERT & 5 & 10.13 & COTTAGE & 3.7 & 20 \\
\hline CREMA & 5 & 16.96 & FETA & 5 & 13.30 \\
\hline MOZZARELLA & 5 & 10.98 & RICOTTA & 4 & 20 \\
\hline Q. FRESCO & 2.6 & 20 & $\begin{array}{l}\text { PASTA } \\
\text { BLANDA }\end{array}$ & 5 & 9.73 \\
\hline QUARG & 4.1 & 20 & & & \\
\hline
\end{tabular}

Con respecto a la adición de caseína, ocurre que en los países de mayor tradición quesera se clasifica a los productos obtenidos por adición de caseína como análogos de quesos, para diferenciarlos de los quesos "auténticos", los cuales deben provenir del proceso tradicional para ser considerados como tales. No obstante, en otros países se considera aceptable la adición de caseína dentro de ciertos límites, porque permite obtener un producto más barato sin demérito de su valor nutricional. Así, en determinados países de la Unión Europea (EU), se ha autorizado desde 1980 el uso de caseína hasta $5 \mathrm{~g}$ de proteína por litro de leche, para quesos que no tengan denominación de origen (83). 


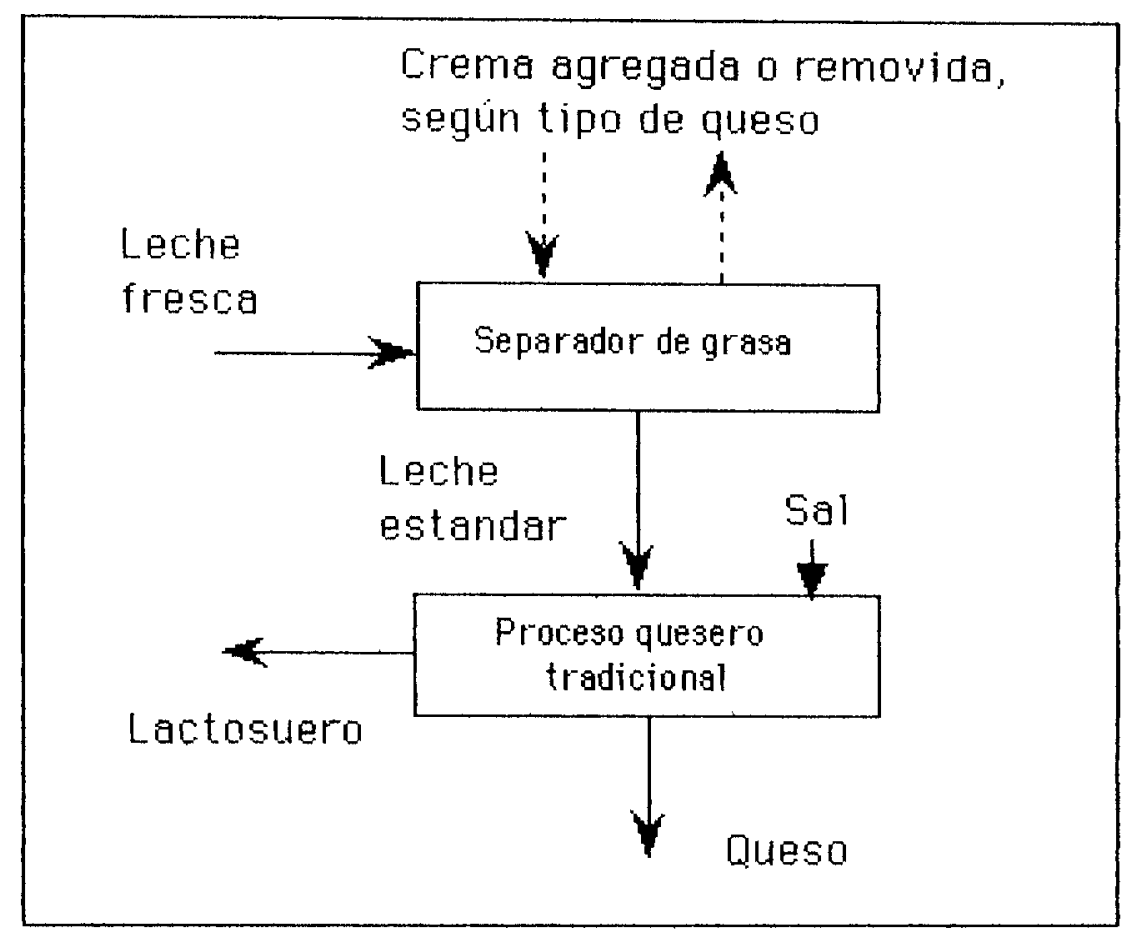

FIGURA 5-1

PROCESO QUESERO TRADICIONAL

En México, parece ser que no existe un límite legal para la adición de caseína. Las principales limitaciones son técnicas y se derivan de dificultades de operación por inconveniencias en solubilidad y viscosidad, las cuales están en función de la temperatura, el pH, el tipo de caseína o caseinato agregado, la concentración presente de sales y la concentración de caseína (183). Comercialmente se han desarrollado diversas formulaciones, cada una de las cuales posee un conjunto de instrucciones particulares de uso. La que se consideró en este estudio por razones de accesibilidad de información, se conoce comercialmente como ALANATE 391 (caseinato de calcio dispersable), cuya composición es: Proteína (caseína) 90.7\%, Sales 3.8\%, Agua 3.7\%, Grasa $1.4 \%$ y Lactosa $0.4 \%$, a la cual se hará referencia en el resto de este trabajo como CC.

Considerando que la norma de la EU pudiera ser muy estricta para el caso mexicano, se estableció en este estudio un límite máximo de adición de CC de $2 \mathrm{~kg}$. por $100 \mathrm{~kg}$. de leche fresca, cantidad que se encuentra ampliamente avalada por la práctica industrial. 


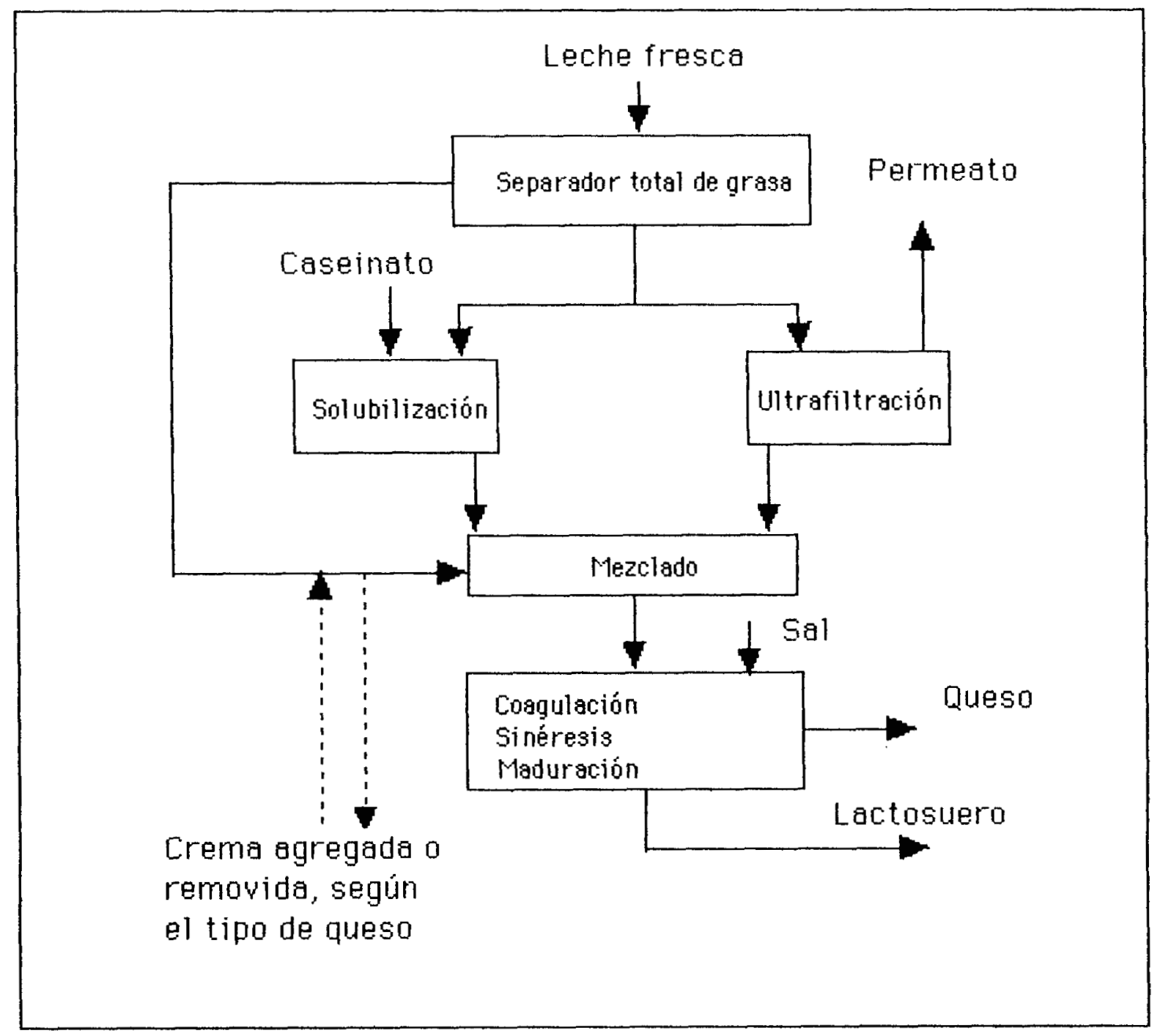

FIGURA 5-2

PROCESO MODIFICADO POR ULTRAFILTRACION Y ADICION DE CASEINA

En la modelación hecha de los procesos queseros se consideraron válidas las siguientes condiciones:

a) Se usó una composición única de leche, la cual está reportada como típica en la literatura (ver tabla 5.1).

b) En la leche fresca, el $78 \%$ del total de proteinas son caseínas (265).

c) La composición de cada tipo de queso es fija y única, y corresponde a la reportada en la literatura ((ver tabla 5-1). 
d) La crema contiene $40 \%$ de grasa en leche desengrasada.

e) Para tomar en cuenta la situación muy común en la práctica, de que por diversas razones una pequeña fracción de caseína y otra de grasa no son aprovechadas en el queso sino que se pierden durante el proceso de fabricación, se ha modificado la composición original de la leche a otra en donde las cantidades de componentes que se pierden han sido restadas de la composición original. Se asumió conforme a la literatura, una pérdida del $8 \%$ de la grasa y de $0.1 \mathrm{Kg}$. en $100 \mathrm{Kg}$. de leche, de la caseina presente en la leche originalmente (46), (184), (12), (265).

f) La grasa y caseina son insolubles en agua después de la coagulación.

g) Las proteinas totales de la leche se pueden dividir en dos grupos; uno de ellos conteniendo caseina y el otro conteniendo una mezcla de proteinas, a las cuales se les llamará proteínas de lactosuero.

h) Las proteínas de lactosuero, lactosa y sales se encuentran disueltas en agua después de la coagulación de la caseína, formando el llamado lactosuero tradicional.

i) La estructura sólida del coágulo está formada por caseína. En esta estructura está la grasa como emulsión atrapada y el líquido presente es lactosuero. Los poros del coágulo son menores que el tamaño de las partículas de grasa.

j) La membrana de ultrafiltración retiene totalmente la caseína, grasa y proteínas de lactosuero, mientras que el resto de los componentes considerados (agua, lactosa y sales) pasan libremente por sus poros.

k) Debido a que los ciclos de operación en la ultrafiltración son cortos y con lapsos frecuentes de limpieza, se decidió simular la operación usando flujos de permeato promedio constantes durante el ciclo, cuyos valores fueron caracterizados experimentalmente por otros autores para la membrana usada(Tabla A4.2-2 del Apéndice E).

El diagrama de flujo que corresponde al proceso modificado se muestra en la figura 5-2. Como se indica en él, la leche entrante es completamente descremada y distribuída en dos corrientes; por una de las corrientes la leche descremada se concentra por ultrafiltración hasta un grado que será definido en función de la rentabilidad óptima del proceso. La otra corriente de leche descremada se mezcla con un caseinato soluble de modo que a la salida del solubilizador la corriente contiene $10 \%$ de caseinato (este límite se debe a la capacidad de disolución del caseinato). Ambas corrientes de leche, una ultrafiltrada y otra saturada de caseina se mezclan con la cantidad de crema ( $40 \%$ de grasa en leche descremada) que sea necesaria para dar la relación grasa/proteina requerida por el tipo de queso que se vaya a elaborar. Esta mezcla estandarizada es procesada en el equipo quesero convencional y produce un queso de baja sinéresis y rendimiento extendido respecto del proceso tradicional. 
Como resultado de la ultrafiltración, se obtiene una corriente de permeato, libre de grasa y proteínas, con especificaciones de proceso y alta pureza.

Se escribió un programa de cómputo para realizar los balances de masa requeridos en los procesos tradicional y modificado. Para poder realizar la comparación económica el programa fué provisto de ecuaciones económicas para estimar la diferencia de rentabilidades entre los procesos. El citado programa se presenta en el Apéndice C.

Los parámetros manejados por el simulador se pueden agrupar de la siguiente manera:

a) Datos de balances de masa (como cantidades de queso, crema, lactosuero y permeato). Estos se obtienen de la solución a los balances de masa en los diagramas mostrados en las figuras 5-1 y 5-2.

b) Factores empíricos (como tasas de depreciación de inversión, tasas de impuestos y otros factores de ponderación). Se asignaron valores típicos, tomados de la literatura y de la heurística. Véase tabla 5-3.

c) Precios de mercado (como precios de tratamiento de efluentes no vendidos, precios de equipos de ultrafiltración, membranas, productos químicos de limpieza, precios de queso, crema, lactosuero y permeato). Se recurrió a la heurística. Además se consultaron publicaciones técnicas especializadas, como Lacteos y Cárnicos Mexicanos, Alimentos Procesados, Industria Alimentaria, así como folletos técnicos de vendedores de equipos de ultrafiltración. Se contó también con información de origen internacional proveniente del Center for Dairy Research, de la Universidad de Wisconsin, del Dairy Market Statistics y el Farm Reporter, del US Department of Agriculture, así como listas de precios aparecidas en The Cheese Reporter (16), publicación oficial de diversas asociaciones queseras norteamericanas, e información de carácter confidencial (291).

Los valores que aparecen en la tabla 5-4 son algunos de los resultados de esta compilación de datos.

d) Especificaciones del equipo UF y sus necesidades (como consumo eléctrico del equipo de ultrafiltración y mano de obra requerida).

Las necesidades del equipo de ultrafiltración hubieron de ser precisadas a partir de otros estudios. En el Apéndice E se presenta la información técnica que sirvió de base para obtener los datos utilizados en la simulación. Los costos de mano de obra se calcularon sobre la base de un salario mensual de $\mathrm{N} \$ 2,000$ y los de consumo eléctrico sobre la tarifa mexicana vigente en 1993 de $0.138 \mathrm{~N} \$ / \mathrm{kilowatt-}$ hora (19).

e) Parámetros a manipular (como escalas a considerar en el proceso, cantidades de caseína agregada y concentración de la leche después de la ultrafiltración).

Estos valores se eligieron en forma arbitraria pero razonable, a fin de apreciar el comportamiento económico del proceso modificado respecto del tradicional bajo diferentes condiciones de interés. Se consideraron tres escalas de proceso, con $5,000 \mathrm{~kg}$./día de leche fresca (escala 1), 30,000 (escala 2) y 100,000 (escala 3). Para el factor de concentración XUF se ensayaron valores de 2, 3, 4 y 5. Las cantidades de caseína agregada que se ensayaron fueron las correspondientes a la adición de $0,0.5,1$, 1.5 y $2 \mathrm{~kg}$. de la formulación de caseinato de calcio estudiada por cada $100 \mathrm{~kg}$. de leche fresca. 
TABLA $5-3$

VALORES DE LOS FACTORES DE PONDERACION USADOS EN LAS ECUACIONES ECONOMICAS

\begin{tabular}{|c|c|c|c|}
\hline $\begin{array}{l}\text { PARAME- } \\
\text { TRO }\end{array}$ & SIGNIFICADO & VALOR ASIGNADO & REF \\
\hline a & $\begin{array}{l}\text { Factor sobre la inversion para considerar } \\
\text { regalías, mantenimiento, seguros, etcétera }\end{array}$ & 0.05 & E-1 \\
\hline $\mathrm{e}$ & $\begin{array}{l}\text { Factor de depreciación de la inversión para } \\
\text { fines contables }\end{array}$ & 0.1 & $\mathrm{E}-1$ \\
\hline$t$ & Tasa de impuestos & 0.5 & $E-1$ \\
\hline dep & $\begin{array}{l}\text { Factor de depreciación de la inversión para } \\
\text { fines de impuestos }\end{array}$ & 0.1 & E-1 \\
\hline
\end{tabular}

E-I = Dr. Arturo Jiménez Gutiérrez, I.T. de Celaya

TABLA 5-4

PRECIOS DIVERSOS EMPLEADOS EN EL SIMULADOR

\begin{tabular}{|l|l|l|}
\hline ITEM & $\mathrm{N} \$ / \mathrm{KG}$ & $\mathrm{REF}$ \\
\hline CREMA & 4.125 & $\mathrm{~F}-1, \mathrm{~F}-3$ \\
\hline LACTOSUERO & 0.3 & $\mathrm{~F}-1, \mathrm{~F}-3$ \\
\hline PERMEATO & 0.1 & $\mathrm{~F}-1, \mathrm{~F}-3$ \\
\hline QUESO FRESCO & 4.65 & $\mathrm{~F}-1, \mathrm{~F}-3$ \\
\hline COTTAGE & 5.15 & $\mathrm{~F}-5$ \\
\hline QUARG & 6.20 & $\mathrm{~F}-1, \mathrm{~F}-3$ \\
\hline RICOTTA & 6.20 & $\mathrm{~F}-2$ \\
\hline TIPO PASTA BLANDA & 11.35 & $\mathrm{~F}-1, \mathrm{~F}-3$ \\
\hline MOZZARELLA & 12.90 & $\mathrm{~F}-1, \mathrm{~F}-3$ \\
\hline CREMA & 7.0 & $\mathrm{~F}-1, \mathrm{~F}-3$ \\
\hline FETA & 8.78 & $\mathrm{~F}-1, \mathrm{~F}-3$ \\
\hline CAMEMBERT & 10.56 & $\mathrm{~F}-1, \mathrm{~F}-3$ \\
\hline $\begin{array}{l}\text { TRATAMIENTO POR } \\
\text { DISPOSICION DE } \\
\text { LACTOSUERO/PERMEATO }\end{array}$ & 0.02 & $\mathrm{~F}-4$ \\
\hline
\end{tabular}

$\mathrm{F}-1=$ The Cheese Reporter

F-2= Ing. Francisco Lémus, San Miguel de Allende, Gto.

F-3 = Dr. Sergio Revah M. UAM-I

F-4 = Dr. Dale F. Rudd, U. de Wisconsin

Dado que se asume que el proceso tradicional ya existe, se calcula la diferencial de inversiones y la diferencial de utilidades netas, y estas dos cantidades se relacionan de la misma forma que se construye la tasa de retorno de la inversión ( $\mathrm{ROI}=\mathrm{P} / \mathrm{I}$ ) obteniendo un indicador diferencial 
proceso tradicional. Si DROI $>0$ la economía favorece a la modificación, tanto más cuanto mayor sea el valor positivo de DROI.

El mínimo valor atractivo de DROI debe ser mayor que el mínimo valor atractivo de ROI, el cual fué establecido en el Capítulo anterior como 0.1. De conformidad con heurísticas de este campo, se estableció el minimo valor atractivo para DROI en 1993 como 0.15.

En el Apéndice E se presenta en detalle el marco económico del simulador y la información de campo que sirvió de base para estimar el comportamiento físico del equipo de ultrafiltración. El listado del simulador se muestra en el Apéndice C.

Fué necesario establecer un marco económico de referencia para el simulador, el cual se constituyó por los datos de las tablas $5-3$ y $5-4$, así como por valores de demanda de lactosuero y permeato.

La demanda de lactosuero en la mayoría de los casos es escasa y sujeta a factores de mercado, por lo que se decidió establecerla como cero en el marco económico base.

El permeato es un producto nuevo en México (porque no se produce hasta ahora), pero con muchas aplicaciones potenciales en el area de alimentos y otros. Optimistamente se decidió establecer su demanda en el marco económico base como 0.95 . De este modo quedó definido un escenario económico denominado en lo sucesivo como escenario $\mathrm{O}$.

Corriendo el simulador en el marco del escenario $O$, a las distintas escalas estudiadas y a las distintas condiciones de ultrafiltración y adición de caseína que cada queso en particular permitía, fué posible generar un conjunto de valores de DROI, cuyo análisis permitió determinar las mejores condiciones de proceso para cada caso (los valores completos se presentan en las tablas del Apéndice F). En la tabla 5-5 se muestra el conjunto de condiciones correspondientes al mejor DROI de cada caso.

TABLA 5-5

CONDICIONES CORRESPONDIENTES AL MEJOR DROI DEL ESCENARIO O

\begin{tabular}{|c|c|c|c|}
\hline & $\begin{array}{l}\text { SIN ADICION } \\
\text { DE CASEINA }\end{array}$ & \multicolumn{2}{|c|}{ CON ADICION DE CASEINA } \\
\hline $\begin{array}{l}\text { QUESO Y } \\
\text { ESCALA }\end{array}$ & $\begin{array}{c}\text { CONDICION } \\
\text { ES DE } \\
\text { PROCESO } \\
\text { (XUF) } \\
\end{array}$ & $\begin{array}{c}\text { CONDICION } \\
\text { ES DE } \\
\text { PROCESO } \\
\text { (XUF) } \\
\end{array}$ & $\begin{array}{c}\text { CONDICION } \\
\text { ES DE } \\
\text { PROCESO } \\
\text { (CC) }\end{array}$ \\
\hline CAMEMBERT ESC 1 & 3 & 3 & 1.5 \\
\hline ESC 2 & 4 & 4 & 0.5 \\
\hline ESC 3 & 3 & 3 & 2 \\
\hline COTTAGE ESC 1 & 3 & 3 & 2 \\
\hline ESC 2 & 3 & 3 & 2 \\
\hline $\mathrm{ESC} 3$ & 3 & 3 & 2 \\
\hline CREMA ESC 1 & 3 & 3 & 2 \\
\hline $\mathrm{ESC} 2$ & 4 & 4 & 0.5 \\
\hline ESC 3 & 3 & 2 & 2 \\
\hline FETA ESC 1 & 3 & 3 & 2 \\
\hline $\mathrm{ESC} 2$ & 5 & 4 & 0.5 \\
\hline $\mathrm{ESC} 3$ & 3 & 3 & 2 \\
\hline $\begin{array}{l}\text { MOZZARELLA ESC } \\
1\end{array}$ & 5 & 2 & 2 \\
\hline
\end{tabular}




\begin{tabular}{|l|c|c|c|}
\hline ESC 2 & 5 & 5 & 0 \\
\hline ESC 3 & 3 & 2 & 2 \\
\hline Q. FRESCO ESC 1 & 2 & 2 & 2 \\
\hline ESC 2 & 2 & 2 & 2 \\
\hline ESC 3 & 2 & 2 & 2 \\
\hline QUARG ESC 1 & 4 & 4 & 0 \\
\hline ESC 2 & 4 & 4 & 0.5 \\
\hline ESC 3 & 4 & 3 & 2 \\
\hline P. BLANDA ESC 1 & 3 & 2 & 2 \\
\hline ESC 2 & 4 & 2 & 2 \\
\hline ESC 3 & 3 & 2 & 2 \\
\hline RICOTTA ESC 1 & 4 & 4 & 0 \\
\hline ESC 2 & 4 & 4 & 0.5 \\
\hline ESC 3 & 4 & 3 & 2 \\
\hline
\end{tabular}

Una discusión sobre los resultados anteriores se da a continuación.

En el proceso tradicional cada queso genera diferente cantidad de lactosuero (tabla 5-6).

En un proceso reconvertido, la adición de caseína no implica más costo que el caseinato gastado, ya que no es preciso comprar equipo especial para la operación. Su efecto en el proceso es extender el grado de recuperación de los componentes de la leche en el producto, ya que la caseína constituye el ingrediente limitante de formación del queso y de este modo se reduce en alguna medida (aunque no considerablemente) la cantidad de lactosuero generado durante la sinéresis y se aumenta el rendimiento quesero. Adicionar caseina implica también reducir las cantidades de leche a ultrafiltrar, con lo que los costos de ultrafiltración se teducen.

Por su parte, la ultrafiltración concentra las proteinas de la leche y separa una fracción importante del agua, lactosa y sales excedentes, que de otra manera se hubiesen incorporado a la corriente residual y hubiesen deteriorado su pureza por adición de toda clase de elementos sobrantes e indeseables (microorganismos, enzimas, fagos, etc) que el proceso desecha hacia esta corriente denominada lactosuero.

En cambio, recuperados por ultrafiltración los componentes del permeato tienen una excelente calidad bacteriológica y composición definida. Prácticamente carecen de impurezas y son susceptibles de aplicaciones en alimentos, farmacia, procesos biotecnológicos, etc.

Al separar el permeato de la leche original, la ultrafiltración permite que durante la cuajada una mayor proporción de proteínas quede retenida, resultando así en un rendimiento quesero extendido y en una operación de baja sinéresis.

La adición de caseína y la ultrafiltración compiten económicamente por llevarse una mayor proporción de la leche fresca alimentada, y dado que el proceso reconvertido paga los costos de tratamiento de sus efluentes no vendidos, la conveniencia económica no siempre aconseja utilizar al máximo la adición de caseína, como puede verse en la tabla 5-5.

Con respecto a la inversión de reconversión, esta no depende del tipo de queso producido sino sólo de las condiciones de proceso. Los datos de la tabla 5-7 reflejan el hecho de que para lograr mayores grados de concentración se requiere usar mayores presiones y los equipos necesarios son más costosos. Asimismo, el incremento de inversión con la escala es el resultado de utilizar equipos de ultrafiltración apropiados para la cantidad de leche a procesar. La disminución de la inversión con la cantidad de caseina agregada se debe a que la corriente a ultrafiltrar se reduce cuando se adiciona caseína, por la existencia de una corriente de leche para dilución del caseinato, la cual no pasa por ultrafiltración (figura 5-2). 
En la economía global del proceso también compiten las corrientes de lactosuero y permeato con sus cantidades, precios y demandas. Para considerar una diversidad de condiciones económicas que una quesería reconvertida podría tener, se consideró conveniente extender el análisis a un conjunto de escenarios en donde se contemplaran situaciones menos favorables a la recoversión que el escenario $\mathrm{O}$, con variación de un solo parámetro a la vez. El conjunto de escenarios considerados se muestra en la tabla 5-8.

TАBIA 5-6

RESULTADOS DE LA SIMULACION (BALANCES DE MASA) PARA EL PROCESO QUESERO TRADICIONAL (DATOS PARA $100 \mathrm{KG}$ DE LECHE FRESCA)

\begin{tabular}{|c|c|c|c|c|}
\hline $\begin{array}{l}\text { NOMBRE } \\
\text { QUESO }\end{array}$ & $\begin{array}{l}\text { KG } \\
\text { LACTOSUERO } \\
\text { TRADICIONAL }\end{array}$ & KG. QUESO & $\begin{array}{l}\text { KG. CREMA } \\
\text { SOBRANTE }\end{array}$ & $\begin{array}{l}\% \text { LACTOSA } \\
\text { EN } \\
\text { L,ACTOSUERO }\end{array}$ \\
\hline MOZZARELLA & 85.78 & 12.96 & 1.05 & 5.33 \\
\hline COTTAGE & 73.70 & 20.12 & 5.79 & 5.32 \\
\hline FETA & 84.82 & 16.61 & -1.50 & 5.33 \\
\hline QUARG & 75.79 & 18.45 & 5.28 & 5.32 \\
\hline CAMEMBERT & 86.65 & 12.75 & 0.32 & 5.32 \\
\hline CREMA & 86.47 & 40.79 & -27.51 & 5.32 \\
\hline RICOTTA & 75.81 & 23.12 & 0.55 & 5.33 \\
\hline Q. FRESCO & 66.25 & 31.10 & 2.22 & 5.33 \\
\hline $\begin{array}{l}\text { PASTA } \\
\text { BLANDA }\end{array}$ & 86.88 & 12.59 & 0.49 & 5.32 \\
\hline BEL PAESE & 89.36 & 9.60 & 0.61 & 5.33 \\
\hline BRIE & 88.22 & 11.18 & 0.08 & 5.33 \\
\hline EDAM & 88.12 & 9.16 & 2.33 & 5.32 \\
\hline EMMENTAL & 89.71 & 8.55 & 1.43 & 5.32 \\
\hline GORGONZOLA & 89.25 & 12.44 & -2.06 & 5.32 \\
\hline GOUDA & 89.72 & 9.21 & 0.93 & 5.33 \\
\hline SUIZO & 88.98 & 8.66 & 2.54 & $5 . \overline{33}$ \\
\hline $\operatorname{PPNC}(*)$ & 88.53 & 8.79 & 2.78 & 5.32 \\
\hline BRICK & 89.14 & 10.80 & 0.04 & 5.32 \\
\hline CHEDDAR & 90.13 & 10.08 & -0.30 & 5.33 \\
\hline LIMBURGER & 87.68 & 12.64 & -0.56 & 5.32 \\
\hline ROQUEFORT & 89.49 & 11.48 & -0.85 & 5.32 \\
\hline BLUE MOLD & 88.81 & 11.78 & -0.42 & 5.33 \\
\hline MANCHEGO & 90.54 & 9.44 & -0.09 & 5.32 \\
\hline PARMESANO & 89.68 & 6.87 & 3.41 & 5.32 \\
\hline $\operatorname{PPC}(* *)$ & 89.51 & 8.50 & 2.10 & 5.32 \\
\hline $\mathrm{C} / \mathrm{MOHO}$ & 89.68 & 12.09 & -1.62 & 5.32 \\
\hline GRUYERE & 90.25 & 8.40 & 1.22 & 5.32 \\
\hline
\end{tabular}

$(*)=$ Pasta prensada no cocida $\quad(* *)=$ Pasta prensada cocida 
TABL $\triangle 5-7$

INVERSION DE RECONVERSION IEN MILES DE N\$ DF 1993 PARA QUFSO DE CUAIQQUIER TIPO

\begin{tabular}{|c|c|c|c|c|c|}
\hline$x=2$ & $C C=0.0$ & $\mathrm{CC}=0.5$ & $\mathrm{CC}=1.0$ & $C C=1.5$ & $C C=2.0$ \\
\hline ESC 1 & 202.75 & 192.17 & 181.24 & 170.66 & 159.73 \\
\hline $\mathrm{ESC} 2$ & 543.51 & 520.30 & 496.83 & 473.63 & 450.16 \\
\hline $\mathrm{ESC} 3$ & 111432 & 1062.55 & 1010.26 & 958.48 & 906.45 \\
\hline \multicolumn{6}{|l|}{$x=3$} \\
\hline ESC I & 319.83 & 307.84 & 290.54 & 273.62 & 256.69 \\
\hline ESC 2 & 806.72 & 770.25 & 733.53 & 697.05 & 660.58 \\
\hline $\mathrm{ESC} 3$ & 1699.17 & 1618.31 & 1536.95 & 1456.10 & 1347.74 \\
\hline \multicolumn{6}{|l|}{$X=4$} \\
\hline $\mathrm{ESC} 1$ & 376.19 & 361.15 & 346.10 & 331.05 & 316.00 \\
\hline $\mathrm{ESC} 2$ & 875.59 & 835.81 & 795.76 & 755.97 & 715.93 \\
\hline $\mathrm{ESC} 3$ & 2074.10 & 1974.63 & 1874.39 & 1774.91 & 1674.94 \\
\hline \multicolumn{6}{|l|}{$x=5$} \\
\hline ESC 1 & 436.89 & 418.79 & 400.68 & 382.83 & 364.72 \\
\hline $\mathrm{ESC} 2$ & 1037.30 & 989.60 & 941.40 & 893.70 & 845.50 \\
\hline $\mathrm{ESC} 3$ & 2478.87 & 2359.51 & 2238.86 & 2119.50 & 1998.86 \\
\hline
\end{tabular}

TABLA 5-8

ESCENARIOS ECONOMICOS

\begin{tabular}{|c|c|}
\hline ESCENARIO & CONDICIONES \\
\hline $\mathrm{O}$ & $\begin{array}{l}\text { - Toda la producción de queso y crema se vende. } \\
\text { - Los precios de venta de queso, crema, lactosuero y permeato así como los } \\
\text { costos de disposición de efluentes son los mostrados en la tabla } 5.4 \text { (valores } \\
\text { normales). } \\
\text { - El factor de demanda del permeato es de } \mathrm{F}_{\mathrm{P}}=0.95 \\
\text { - El factor de demanda del lactosuero es de } \mathrm{F}_{\mathrm{L}}=0.0\end{array}$ \\
\hline$\Lambda$ & $\begin{array}{l}\text { Igual al escenario } O \text {, excepto que los precios de queso y crema son } 20 \% \\
\text { menores que los normales }\end{array}$ \\
\hline B & $\begin{array}{l}\text { lgual al escenario O, excepto que los costos de disposición de efluentes no } \\
\text { vendidos son } 20 \% \text { mayores que los normales }\end{array}$ \\
\hline $\mathrm{C}$ & $\begin{array}{l}\text { Igual al escenario } O \text {, excepto que el precio del permeato es } 20 \% \text { mas bajo que el } \\
\text { normal }\end{array}$ \\
\hline D-1 & Igual al escenario $O$, excepto que el factor de demanda del permeato es 0.50 \\
\hline D-2 & Igual al escenario $O$, excepto que el factor de demanda del permeato es 0.0 \\
\hline $\mathrm{E}-1$ & Igual al escenario $O$, excepto que el factor de demanda del lactosuero es 0.50 \\
\hline E-2 & Igual al escenario $O$, excepto que el factor de demanda del lactosuero es 0.95 \\
\hline
\end{tabular}

Los rubros sujetos a variación en estos escenarios fueron los siguientes: 
- Precios (en conjunto) de queso y crema

- Precio de permeato

- Costo del tratamiento de efluentes desechados

- Demanda de lactosuero

- Demanda de permeato

En el caso de los precios de queso y crema, se consideró el precio normal de estos y una baja conjunta del $20 \%$. Para el permeato se analizó su precio normal y un decremento del $20 \%$; para el lactosuero se ensayaron su precio normal y un aumento del $20 \%$. Se consideró el costo normal del tratamiento de efluentes y un incremento del $20 \%$ en el mismo. En cuanto a las demandas de lactosuero y permeato, dada la amplitud de las posibilidades entre una quesería y otra, se tomaron valores de demanda de $0,0.50$ y 0.95 .

$\mathrm{El}$ conjunto de escenarios del $\mathrm{O}$ al $\mathrm{E}$, constituyen marcos económicos hipotéticos (aunque posibles) dentro de los cuales se calculó la ventaja económica de la reconversión en términos de DROI. Los resultados completos se presentan en el Apéndice F.

Se consideró sin embargo, que dentro de estas posibilidades estudiadas se encuentran la mayoría de las condiciones reales de las queserías mexicanas que son susceptibles a la reconversión. Si bien el escenario $O$ es el escenario al que seguramente accederían las queserías reconvertidas una vez que el permeato tuviese el mercado suficiente, se estimó más realista asumir en un principio unas condiciones como las del escenario E-1, en donde se reconoce que aunque insuficiente, existe una demanda local por el lactosuero. Debido a lo anterior, se seleccionaron de entre un conjunto de resultados, los valores de DROI correspondientes al escenario E-1, para cada tipo de queso y escala, calculados a las mejores condiciones de proceso obtenidas para el escenario $\mathrm{O}$ (de este modo, los valores de DROI presentados son comparables con los mejores del escenario $\mathrm{O}$, ya que comparten las mismas condiciones de proceso). Los resultados se presentan en la tabla 5-9. 
TABLA 5-9

VALORES DE DROI EN EL ESCENARIO E-1, A LAS MEIORES CONDICIONES OBTENIDAS PARA EI ESCENARIOO.

\begin{tabular}{|c|c|c|}
\hline & VALOR & DROI \\
\hline QUESO Y ESCALA & SIN CASEINA & CON CASEINA \\
\hline CAMEMBERT ESCAL $\triangle 1$ & -0.025 & 0.0403 \\
\hline ESCALA 2 & -0.0709 & -0.0078 \\
\hline ESCALA 3 & -0.0099 & 0.3643 \\
\hline COTTAGE ESCALA 1 & 0.1212 & 0.1102 \\
\hline ESCALA 2 & 0.3866 & 0.3664 \\
\hline ESCALA 3 & 0.5403 & 0.5619 \\
\hline CREMA ESCALA 1 & 0.2506 & 0.3536 \\
\hline ESCALA 2 & 0.7024 & 0.7545 \\
\hline ESCALA 3 & 1.0277 & 1.8747 \\
\hline FETA ESCALA 1 & 0.0254 & 0.1019 \\
\hline ESCALA 2 & 0.1055 & 0.1597 \\
\hline ESCALA 3 & 0.1797 & 0.5310 \\
\hline MOZZARELLA ESCALA 1 & -0.0140 & 0.1228 \\
\hline ESCALA 2 & 0.1394 & 0.1394 \\
\hline ESCALA 3 & 0.2021 & 0.6089 \\
\hline QUESO FRESCO ESCALA & 0.3186 & 0.2841 \\
\hline ESCALA 2 & 0.8300 & 0.7814 \\
\hline ESCALA 3 & 1.3790 & 1.2618 \\
\hline QUARG ESCALA 1 & 0.1385 & 0.1385 \\
\hline ESCALA 2 & 0.5326 & 0.5265 \\
\hline ESCALA 3 & 0.6026 & 0.6130 \\
\hline P. BLANDA ESCALA 1 & -0.0196 & 0.0465 \\
\hline ESCALA 2 & -0.0531 & 0.0102 \\
\hline ESCALA 3 & 0.0102 & 0.4276 \\
\hline RICOTTA ESCALA 1 & 0.1920 & 0.1920 \\
\hline ESCALA 2 & 0.6706 & 0.6624 \\
\hline ESCALA 3 & 0.7967 & 0.8441 \\
\hline
\end{tabular}


Analizando los datos de inversión presentados en la tabla 5-7 se puede ver que la adición de caseína reduce siempre la inversión requerida, y que adicionada hasta su límite de $2 \mathrm{~kg}$ de caseinato por $100 \mathrm{~kg}$ de leche fresca, reduce las inversiones en equipo de ultrafiltración en alrededor de $20 \%$. También es observable que existe un comportamiento no lineal entre la inversión y la escala de proceso, y entre la inversión y el grado de concentración de leche. A partir de los valores de DROI de la tabla 5-9 es posible agrupar los tipos de quesos estudiados como se muestra a continuación:

a) Grupo de baja rentabilidad, formado por los quesos Camembert y Pasta Blanda. Ambos quesos tienen un comportamiento muy similar con o sin adición de caseína. I a adición de caseína tiene una influencia especialmente importante en la escala 3, donde gracias a ella es posible alcanzar la rentabilidad económica.

b) Grupo de rentabilidad moderada (Feta, Mozzarella). Estos quesos también presentan un comportamiento muy cercano entre sí, para los casos con y sin adición de caseína. Su rendimiento económico es superior a los del grupo anterior, ya que la rentabilidad económica se da aproximadamente a partir de la escala 2. La adición de caseína a la escala 2 no promueve mejorías para el queso mozzarella.

c) Grupo de rentabilidad media. En éste se encuentran Cottage y Quarg. La rentabilidad inicia un poco más arriba de la escala 1. La adición de caseína en este grupo no tiene efecto significativo en el valor de DROI, pero sí lo tiene en la inversión, la cual se reduce de manera importante con dicha adición.

d) Grupo de alta rentabilidad. Para los quesos de este grupo (Crema y Ricotta) se observa rentabilidad económica a las tres escalas y un efecto poco significativo en el valor de DROI por adición de caseína a la escala 2 . Arriba de esta escala, el queso Crema parece beneficiarse más que el Ricotta por la caseína agregada.

e) Grupo de muy alta rentabilidad. Por su excepcionalmente alta rentabilidad, el Queso Fresco es considerado aparte de los demás quesos. Para este caso, la adición de caseína reduce los valores de DROI a las tres escalas, aunque también reduce significativamente las inversiones requeridas.

Lo anterior pone de manifiesto que si bien la adición de caseina reduce las inversiones requeridas por la ultrafiltración, ello no necesariamente mejora la rentabilidad del proceso. La caseina adicionada en queso fresco fué desventajosa respecto al DROI, mientras que en feta, mozzarella y otros resultó benéfica y en quarg prácticamente no tuvo efecto.

Por medio de la información anterior es posible jerarquizar los tipos de quesos elegibles en función de su potencial económico de reconversión, así como el grado de conveniencia de adicionar caseína. La selección del queso y la escala más conveniente depende también de factores como la cantidad de dinero disponible para invertir, la demanda de mercado para cada queso viable y el tipo de instalación existente operando por el proceso tradicional.

En las figuras 5-3 y 5-4 se muestran los méritos de algunos de los quesos mejor calificados. 
DROI VS ESCALA PARA LOS TRES PROCESOS MAS ATRACTIVOS EN EL ESCENARIO E-1, A LAS MEJORES CONDICIONES OBTENIDAS PARA EL ESCENARIO O

SIN ADICION DE CASEINA

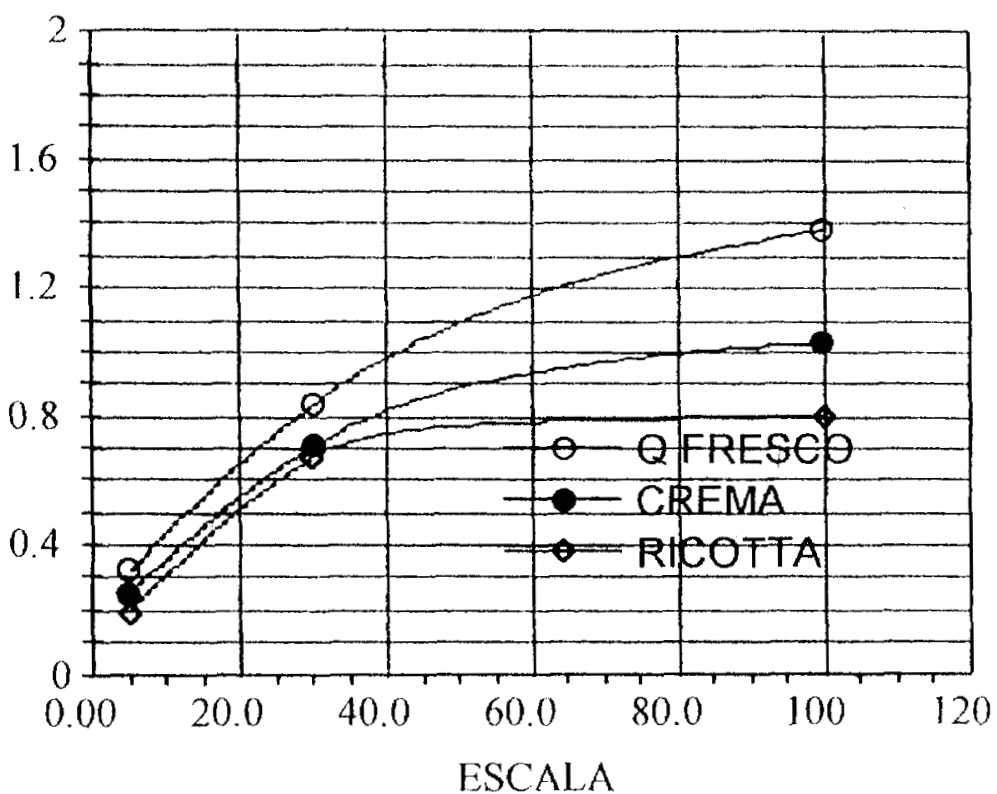

FIGURA 5-3

DROI VS ESCALA PARA LOS TRES QUESOS MAS ATRACTIVOS SIN ADICION DE CASEINA

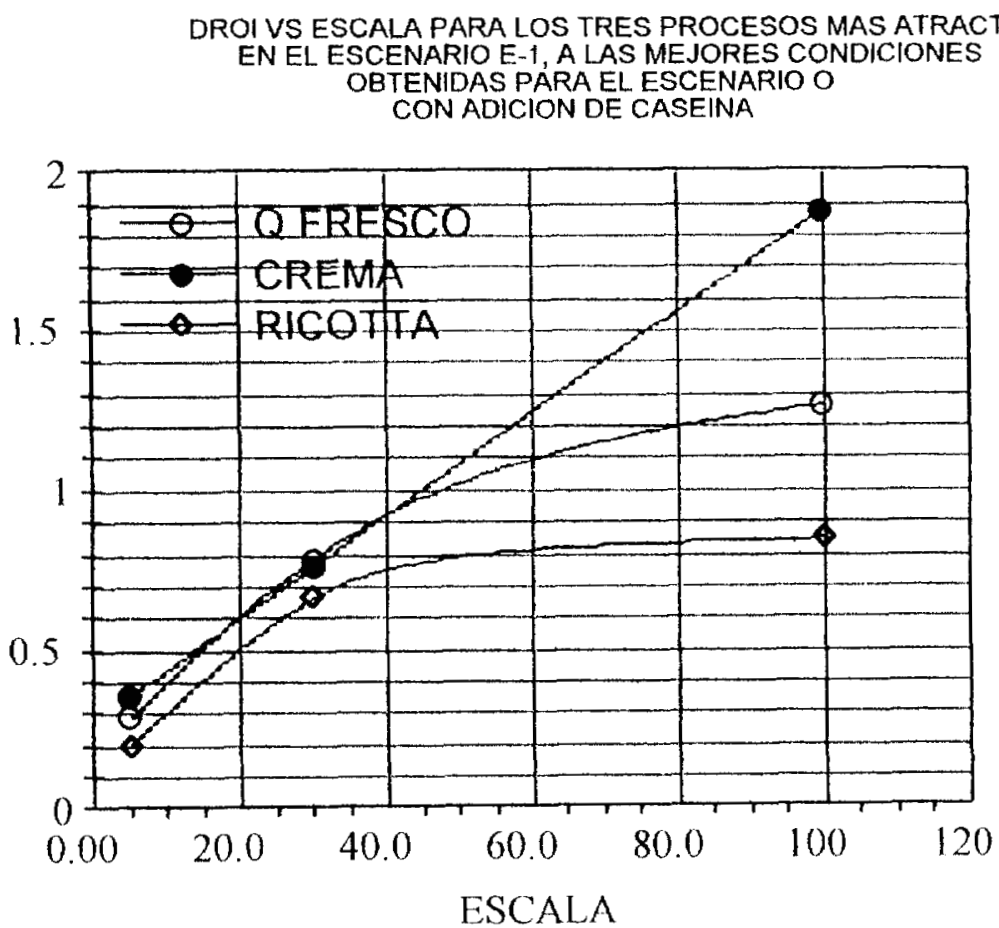

FIGURA 5-4

DROI VS ESCALA PARA LOS TRES QUESOS MAS ATRACTIVOS CON ADICION DE CASEINA 
Para extender más el análisis de la economía del proceso reconvertido, fué preciso elegir un queso en particular como caso de interés. Se decidió estudiar como ejemplo el queso crema, el cual fué uno de los prospectos de reconversión más interesantes.

Primeramente, la inversión de reconversión, que es común para todos los quesos (tabla 5-7) fué reducida a ecuaciones empíricas, con ayuda de un paquete computacional de ajuste de datos (Kaleidagraph), obteniéndose discrepancias inferiores a 5\% respecto de los datos originales. Las ecuaciones empíricas obtenidas fueron las siguientes:

$\mathrm{I}=\mathrm{A}+\mathrm{B}^{*} \mathrm{X}+\mathrm{C}^{*} \mathrm{X}^{2}$

en donde

$\mathrm{A}=\mathrm{a} 1+\mathrm{a} 2 * \mathrm{CC}$

$B=b 1+b 2 * C C$

$\mathrm{C}=\mathrm{cl}+\mathrm{c} 2 * \mathrm{CC}$

y a su vez

$\mathrm{al}=-146.278-15^{*} \mathrm{ESC}+0.0528^{*} \mathrm{ESC}^{2}$

$\mathrm{a} 2=15.9+1.147 * \mathrm{ESC}-0.00146 * \mathrm{ESC}^{2}$

$\mathrm{b} 1=162.46+18.466^{*} \mathrm{ESC}-0.0716^{*} \mathrm{ESC}^{2}$

$\mathrm{b} 2=-19.86-1.2857 * \mathrm{ESC}+0.00159 * \mathrm{ESC}^{2}$

$\mathrm{c} 1=-14.3-2.1447 * \mathrm{ESC}+0.011^{*} \mathrm{ESC}^{2}$

$\mathrm{c} 2=2.46278+0.1152 * \mathrm{ESC}-0.0001^{*} \mathrm{ESC}^{2}$

para $\mathrm{I}=$ Inversión de reconversión en miles de $\mathrm{N} \$$ de 1993

$X_{U F}=$ Grado de concentración por ultrafiltración

$\mathrm{CC}=\mathrm{kg}$ de caseinato agregado por $100 \mathrm{~kg}$ de leche fresca

$\mathrm{ESC}=$ escala en miles de $\mathrm{kg} /$ día de leche fresca

En el caso de la rentabilidad, ésta no pudo reducirse a expresiones empíricas simples. No obstante, con los datos obtenidos de la simulación se llevó a cabo un análisis de sensibilidad paramétrica.

De la tabla 5-5 se tiene que para este queso crema, las condiciones a las que se obtiene el mejor DROI son como se muestra en la tabla 5-10: 
TABLA 5-10

LAS MEJORES CONDICIONES DE OPERACION PARA EL, QUESO CREMA EN EL ESCENARIOO.

\begin{tabular}{|l|l|l|}
\cline { 2 - 3 } \multicolumn{1}{c|}{} & SIN CASEINA & CON CASEINA \\
\hline ESC 1 & $X U F=3$ & $X U F=3, C C=2$ \\
\hline ESC 2 & $X U F=4$ & $X U F=4, C C=0.5$ \\
\hline ESC 3 & $X U F=3$ & $X U F=2, C C=2$ \\
\hline
\end{tabular}

Se seleccionaron del Apéndice $\mathrm{F}$ los valores de DROI para el queso crema en los distintos escenarios, a las condiciones de operación de la tabla 5-10 y se presentan en la tabla 5-11.

TABLA 5-11 LOS MEJORES VALORES DE DROI PARA QUESO CREMA, ESCENARIO O

\begin{tabular}{|c|c|c|c|}
\hline & & VALORES & DROI \\
\hline ESCENARIO & ESCALA & SIN CASEINA & CON CASEINA \\
\hline \multirow[t]{3}{*}{$\mathrm{O}$} & 1 & 0.3962 & 0.4107 \\
\hline & 2 & 1.1803 & 1.1927 \\
\hline & 3 & 1.5756 & 1.6869 \\
\hline \multirow[t]{3}{*}{$\mathrm{A}$} & 1 & 0.3121 & 0.3196 \\
\hline & 2 & 0.9319 & 0.9464 \\
\hline & 3 & 1.2589 & 1.3555 \\
\hline \multirow[t]{3}{*}{$B$} & 1 & 0.3928 & 0.4049 \\
\hline & 2 & 1.1750 & 1.1864 \\
\hline & 3 & 1.5630 & 1.6442 \\
\hline \multirow[t]{3}{*}{$\mathrm{C}$} & 1 & 0.3635 & 0.3782 \\
\hline & 2 & 1.0998 & 1.1126 \\
\hline & 3 & 1.4527 & 1.5487 \\
\hline \multirow[t]{3}{*}{ D-1 } & 1 & 0.3019 & 0.3167 \\
\hline & 2 & 0.9477 & 0.9613 \\
\hline & 3 & 1.2205 & 1.2876 \\
\hline \multirow[t]{3}{*}{ D-2 } & 1 & 0.1971 & 0.2122 \\
\hline & 2 & 0.6894 & 0.7041 \\
\hline & 3 & 0.8261 & 0.8439 \\
\hline \multirow[t]{3}{*}{ E-1 } & 1 & 0.2506 & 0.3536 \\
\hline & 2 & 0.7024 & 0.7545 \\
\hline & 3 & 1.0277 & 1.8747 \\
\hline \multirow[t]{3}{*}{$\mathrm{E}-2$} & 1 & -0.0761 & -0.0535 \\
\hline & 2 & -0.0136 & 0.0044 \\
\hline & 3 & -0.2022 & -0.1750 \\
\hline
\end{tabular}


En virtud de que la magnitud del cambio en el parámetro modificado es moderada $(20 \%)$ para los escenarios $A, B$ y C, se asumió linealidad entre el valor de DROI y el valor del parámetro modificado. En el caso de los escenarios D y E, se pudo comprobar que los valores de DROI frente a los del parámetro modificado (escenarios $\mathrm{O}, \mathrm{D}-1$, y D-2, así como $\mathrm{O}, \mathrm{E}-1$ y $\mathrm{E}-2$ ) presentaron también un comportamiento aproximadamente lineal. Aplicando estas suposiciones a los datos de la tabla 5-11 se obtuvieron ecuaciones empíricas de la forma DROI $=a+b$ PARAM* en donde PARAM* es el valor del parámetro que se modificó en un escenario distinto al escenario $O$. Este valor en la ecuación está normalizado (de modo que para el escenario $O$ vale 1). Las expresiones obtenidas se presentan en la tabla 5-12.

TABLA 5-12

EXPRESIONES EMPIRICAS PARA QUESO CREMA CASOS SIN CASEINA

\begin{tabular}{|c|c|c|c|}
\hline ESCENARIOS & ESCALA & SIN CASEINA & CON CASEINA \\
\hline $0-\mathrm{A}$ & 1 & $\mathrm{DROI}=-0.0243+0.4205 \mathrm{P}^{*}$ & DROI $=-0.0448+0.4555 \mathrm{P}^{*}$ \\
\hline $\mathrm{O}-\mathrm{B}$ & 1 & $\mathrm{DROI}=0.4132-0.017 \mathrm{C}^{*}$ & DROI $0.4397-0.029 C^{*}$ \\
\hline $\mathrm{O}-\mathrm{C}$ & 1 & DROI $=0.2327+0.1635 P^{*}$ & $\mathrm{DROI}=0.2482+0.1625 \mathrm{PP}^{*}$ \\
\hline $0-\mathrm{D} 1-\mathrm{D} 2$ & 1 & $\mathrm{DROI}=0.1971+0.20958 \mathrm{Dem} *$ & DROI $=0.21221+0.20895 \mathrm{Dem}^{*}$ \\
\hline O-E1-E2 & 1 & $\mathrm{DROI}=0.42869-0.49336 \mathrm{Del}^{*}$ & DROI $=0.46977-0.48172 \mathrm{Del}^{*}$ \\
\hline $0-A$ & 2 & $\mathrm{DROI}=-0.0617+1.242 \mathrm{P}^{*}$ & DROI $=-0.0388+1.2315 \mathrm{P}^{*}$ \\
\hline $\mathrm{O}-\mathrm{B}$ & 2 & $\mathrm{DROI}=1.2068-0.0265 \mathrm{C}^{*}$ & $\mathrm{DROI}=1.2242-0.0315 \mathrm{C}^{*}$ \\
\hline $\mathrm{O}-\mathrm{C}$ & 2 & $\mathrm{DROI}=0.7778+0.4025 \mathrm{PP} *$ & DROI $0.70411+0.51432 P^{*} *$ \\
\hline $0-\mathrm{D} 1-\mathrm{D} 2$ & 2 & $\mathrm{DROI}=0.6893+0.51673 \mathrm{Dem}^{*}$ & DROI $=0.70411+0.51432 \mathrm{Dem}^{*}$ \\
\hline $\mathrm{O}-\mathrm{E} 1-\mathrm{E} 2$ & 2 & $\mathrm{DROI}=1.2278-1.2512 \mathrm{Del}^{*}$ & DROI $=1.2518-1.2439 \mathrm{Del}^{*}$ \\
\hline $0-\mathrm{A}$ & 3 & DROI $=-0.0079+1.5835 \mathrm{P}^{*}$ & $\mathrm{DROI}=0.0299+1.657 \mathrm{P}^{*}$ \\
\hline $\mathrm{O}-\mathrm{B}$ & 3 & DROI $=1.6386-0.063 \mathrm{C}^{*}$ & $\mathrm{DROI}=1.9004-0.2135 \mathrm{C}^{*}$ \\
\hline $\mathrm{O}-\mathrm{C}$ & 3 & DROI $=0.9611+0.6145 P^{*}$ & DROI $=0.9959+0.691 \mathrm{PP}^{*}$ \\
\hline $0-\mathrm{D} 1-\mathrm{D} 2$ & 3 & DROI $=0.8261+0.78894 \mathrm{Dem} *$ & DROI $=0.84391+0.88737 \mathrm{Dem}^{*}$ \\
\hline $\mathrm{O}-\mathrm{E} 1-\mathrm{E} 2$ & 3 & DROI $=1.6979-1.8571 \mathrm{Del}^{*}$ & DROI $=2.0553-1.9168 \mathrm{Del}^{*}$ \\
\hline
\end{tabular}

Nota:

$\mathrm{P}^{*}=$ Precio normalizado de queso y crema producidos

$\mathrm{C}^{*}=$ Costo unitario normalizado de disposición de efluentes

$\mathrm{PP}^{*}=$ Precio normalizado de permeato

Dem $*=$ Demanda de permeato(no normalizada, sino como fracción de la cantidad producida en el proceso reconvertido)

Del* $=$ Demanda de lactosuero(no normalizada, sino como fracción de la cantidad producida en el proceso tradicional)

El valor absoluto de las pendientes de las rectas en la tabla 5-12, representa el factor de peso con el que cada parámetro afecta al valor de DROI y su signo indica si el parámetro contribuye al incremento o decremento de ROI.

En las figuras 5-5 a la 5-9 se presentan los factores de peso de cada parámetro sobre ROI, en función de la escala para los casos con y sin adición de caseína. 
QUESO CREMA

FACTOR DE PESO DEL PARAMETRO PRECIO DE PRODUCTOS EN FUNCION DE ESCALA, CON Y SIN ADICION DE CSEINA

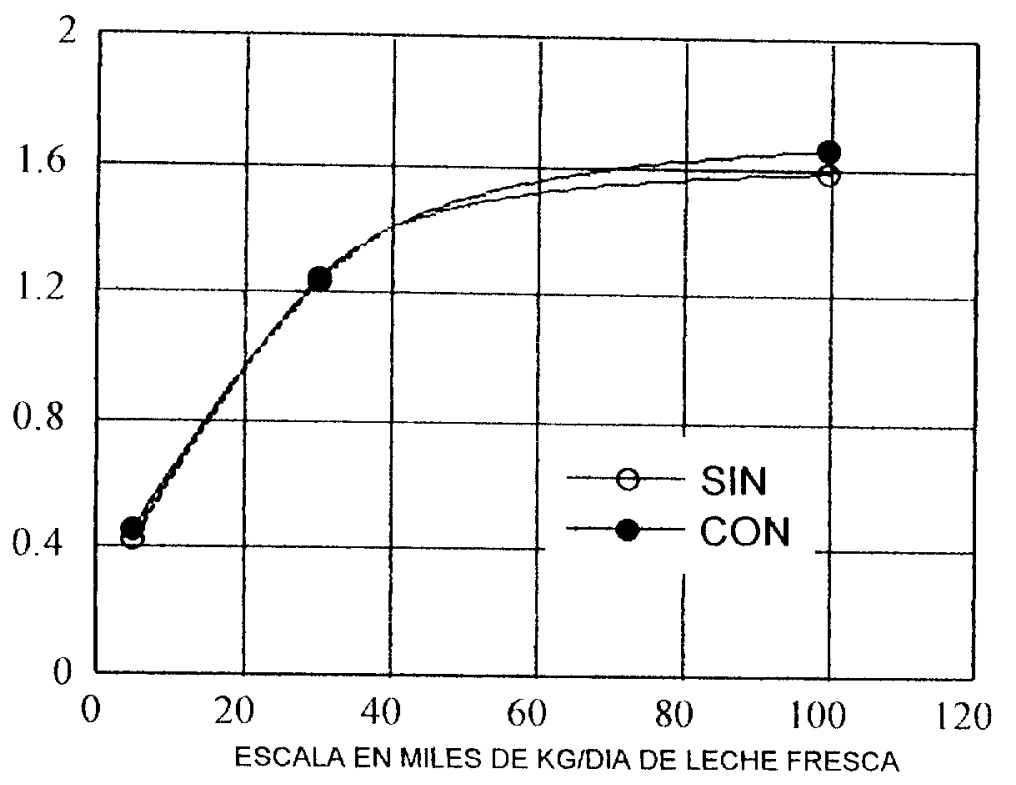

FIGURA 5-5

FACTOR DE PESO VS ESCALA PARA QUESO CREMA

QUESO CREMA

FACTOR DE PESO DEL PARAMETRO

COSTO UNITARIO DE DISPOSICION DE EFLUENTES

EN FUNCION DE ESCALA, CON Y SIN ADICION DE CASEINA

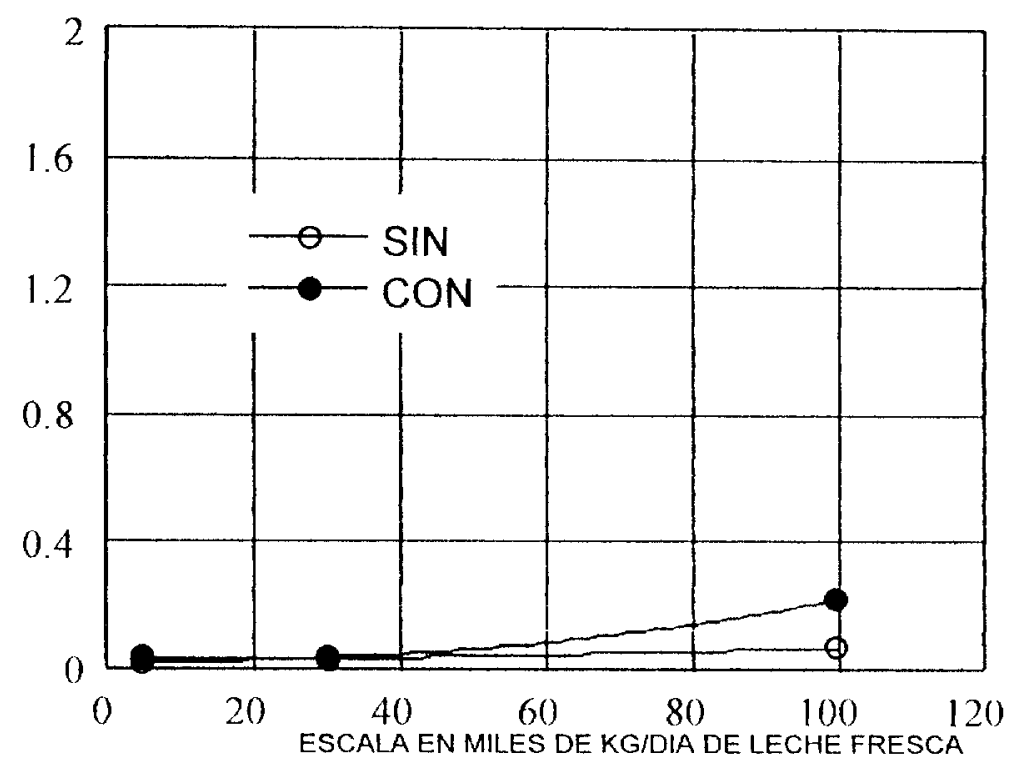

FIGURA 5-6

FACTOR DE PESO VS ESCALA PARA QUESO CREMA 


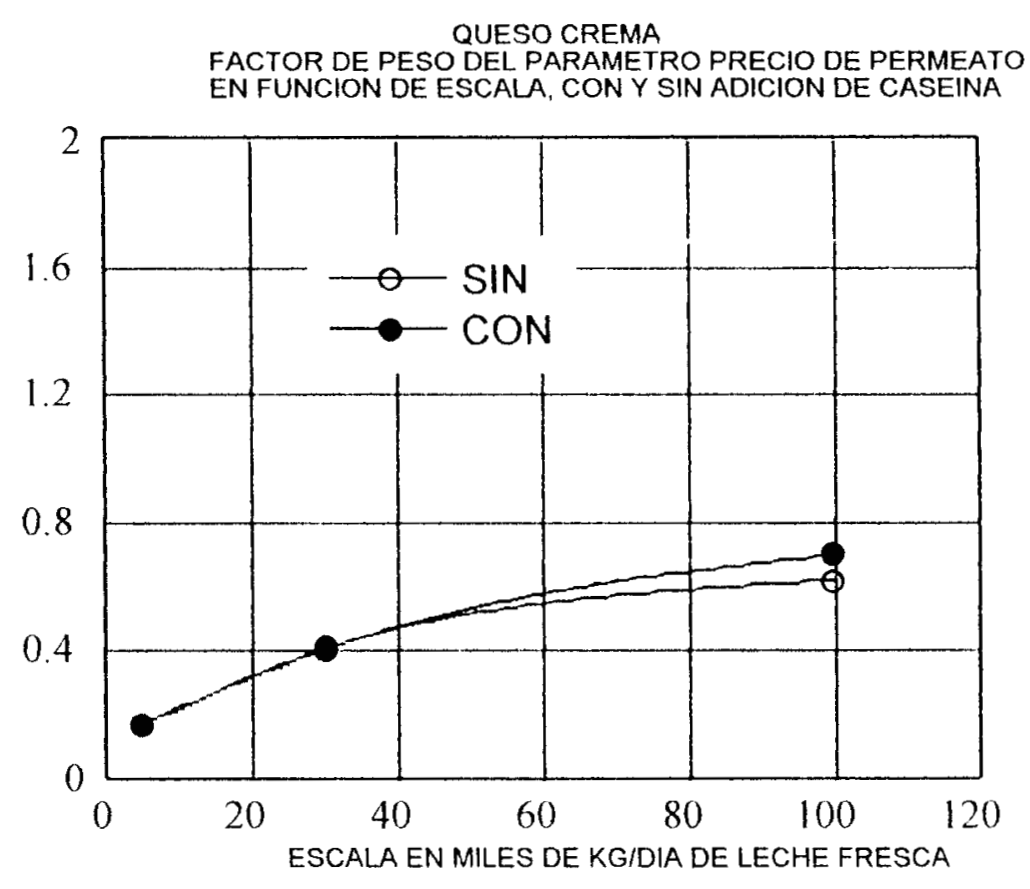

FIGURA 5-7

FACTOR DE PESO VS ESCALA PARA QUESO CREMA

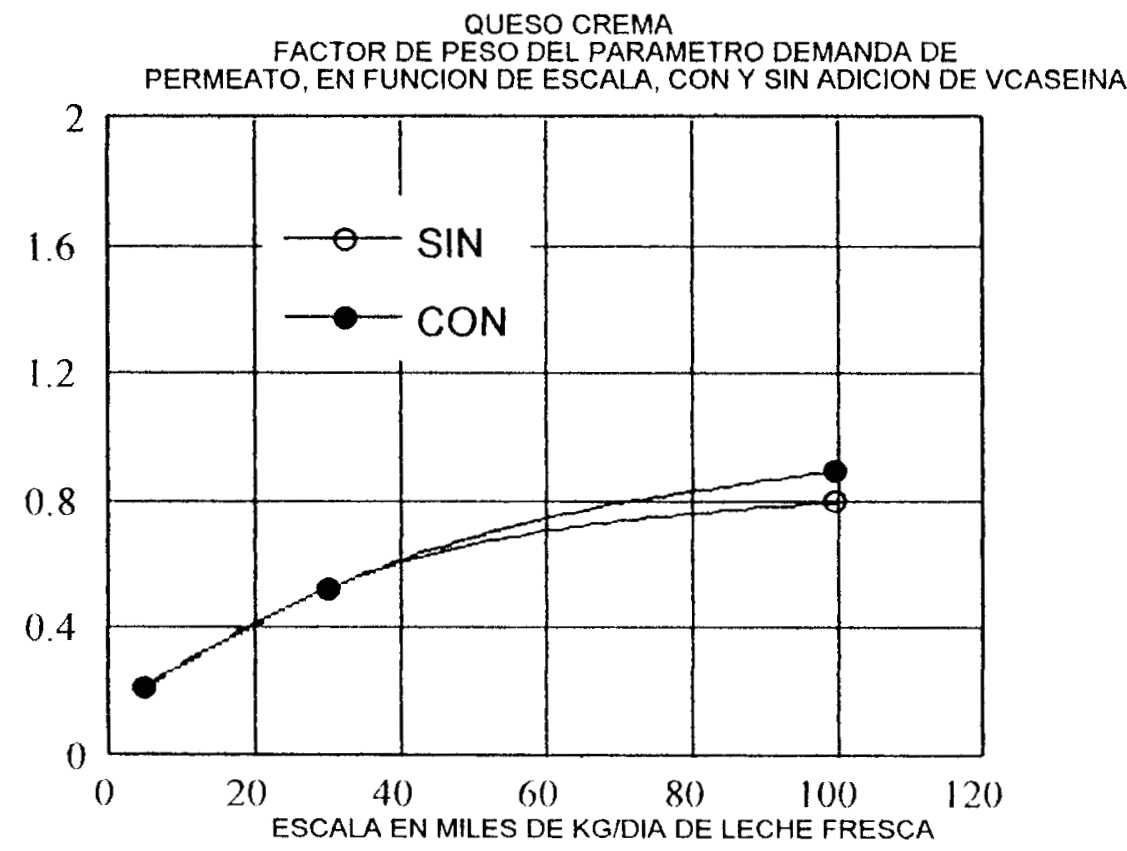

FIGURA 5-8

FACTOR DE PESO VS ESCALA PARA QUESO CREMA 


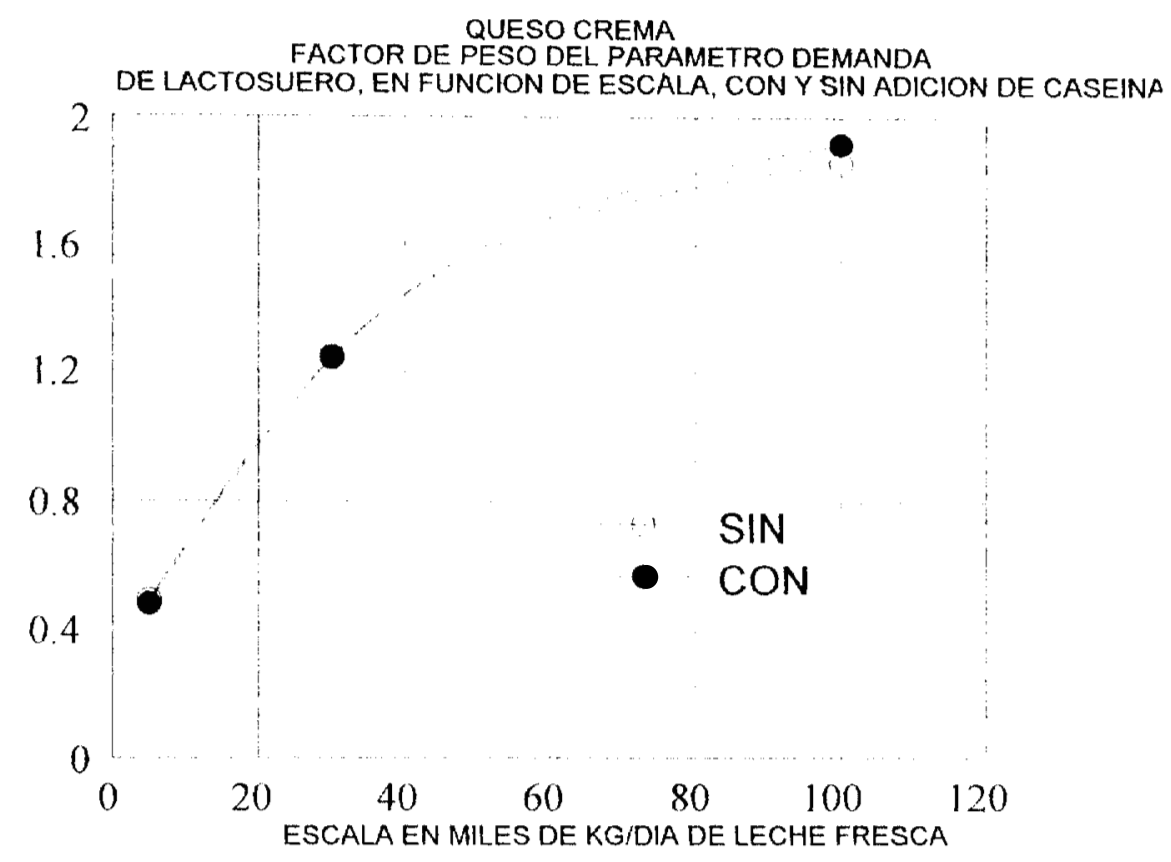

FIGURA 5-9

FACTOR DE PESO VS ESCALA PARA QUESO CREMA

La observación de las figuras 5-5 a 5-9 permite inferir que los factores de mas alto peso son la demanda de lactosuero y el precio de productos, por lo que deberán ser estimados con la mayor precisión posible. Con un peso moderado se encuentran el precio y la demanda de permeato y finalmente, con un peso marginal está el costo de disposición de efluentes. La adición de caseína reduce la importancia de los factores de peso en una cantidad insignificante, a escalas abajo de $60,000 \mathrm{~kg} / \mathrm{dia}$ de leche y para escalas mayores, el efecto es bastante pequeño. 
CAPITULO 6:

CONCLUSIONISS Y RI:COMLNDACIONISS

En este trabajo se desarrolló una metodologia para discriminar distintas estrategias de acción tendientes a reubicar el efluente descartado por la industria quesera bajo el proceso tradicional (lactosuero), con el fin de reducir los daños al medio ambiente, sin perder de vista la competitividad de la industria en el mercado.

La decisión sobre el destino del lactosuero generado en el proceso quesero, constituye un problema de gran importancia para esta industria. en virtud de la limitada demanda local del mencionado producto residual y de su condición altamente contaminante. Numerosas investigaciones han estudiado las posibilidades de aprovechamiento del lactosuero, aunque pocas de ellas han analizado los aspectos económicos.

Se consideraron dos posturas básicas en este trabajo:

La primera se dedicó a estudiar las alternativas de procesamiento del lactosuero, generado en el proceso quesero tradicional, para detectar oportunidades económicamente atractivas.

La segunda se encargó de delinear una tecnología limpia, de aplicación limitada a quesos no madurados y evaluar su impacto económico respecto del proceso tradicional.

Para el primer punto de vista, las rutas de proceso de lactosuero más interesantes encontradas fueron hacia lactosuero desmineralizado seco, lactosuero seco y concentrado proteico seco de 92\%. Los procesos de interés mostraron distinta sensibilidad a la escala de proceso; el caso del concentrado proteico seco de $92 \%$ exhibió la menor dependencia en sus parámetros económicos respecto de la escala. La inversión requerida para este proceso es alta respecto de los otros dos seleccionados, sin embargo, este proceso ofrece tasas de retorno adecuadas desde la más baja escala estudiada, por lo que se puede considerar como una opción recomendable para bajas escalas de proceso

Respecto a la opción con la más alta tasa de retorno de inversión, a escalas medianas y altas ésta correspondió al proceso de producción de lactosuero desmineralizado seco, por lo que este proceso se recomienda para ese intervalo de escalas.

El proceso de producción de lactosuero seco se recomienda para escalas de mediana a alta, en virtud de que sus tasas de retorno de inversión son de las más altas encontradas y además porque cuenta con una bien establecida demanda de producto.

La economia de los procesos seleccionados (medida por el valor de la tasa de retorno de la inversión $\mathrm{ROI}$ ), fué modelada en función de la escala por una expresión empírica de dos constantes. Por medio de técnicas de correlación múltiple, se obtuvieron expresiones para estas dos constantes en función de precios, inversiones y costos de operación. Los ajustes empíricos realizados constituyen un método corto de estimación de rentabilidades para los tres procesos seleccionados, con discrepancias inferiores al $10 \%$ en la mayoría de los casos respecto de la simulación completa de los procesos

Fué posible también conocer la influencia relativa de parámetros como la inversión, el precio de productos y el costo de operación sobre la rentabilidad (ROI) de los procesos seleccionados en función de la escala (figuras 4-6 a 4-8). 
Para el segundo punto de vista, se encontraron susceptibles de modificar su proceso tradicional de manufactura los quesos cottage, feta, quarg, camembert, crema, mozzarella, ricolta pasta blanday queso fresco. Varios de estos quesos tienen una demanda considerable en México. Se fijaron heuristicamente los limites a la modificación como sigue: Un factor de concentración por ultrafiltración de 5 o bien un contenido de $20 \%$ de proteinas de lactosuero en la fracción proteica del queso producido. Respecto a la caseína agregada, se consideró como valor limite $2 \mathrm{~kg}$ del concentrado caseínico comercial estudiado (90.7\% de cascína) en $100 \mathrm{~kg}$ de leche fresca. Los resultados se compararon para una condición de demanda media de lactostero (tabla 5-9). encontrándose condiciones favorables a la modificación del proceso para inuchos de los quesos estudiados, especialmente a las dos escalas mayores ensayadas. Entre los productos mejor calificados se encontraron los quesos crema, ricotta y queso fresco. Las mejores condiciones económicas para la modificación corresponden en la mavoria de los casos a la máxima cantidad de caseína agregada y a valores medios en la concentración de leche por ultrafiltración (tabla 5-5).

Tomando como caso de estudio al queso crema, fué posible predecir la inversión de reconversión con discrepancias inferiores a $5 \%$ respecto de la simulación completa, mediante expresiones polinomiales empíricas de $1^{\circ}$ y $2^{\circ}$ grado.

Fué posible también estimar, en forma relativa y en función de la escala, los cambios previsibles en la rentabilidad de la reconversión del proceso quesero (medidos a través del parámetro DROl) debidos a cambios en el precio de productos, precio de permeato, demanda de permeato, demanda de laciosuero y costo de disposición de elluentes (liguras 5-5 a 5-9). Y se encontró que los parámetros con mayor influencia fueron la demanda de lactosuero y el precio de ios productos. En todas las anteriores condiciones, se efectuaron las evaluaciones tanto con adición de caseína como sin ella, y se encontró que el efecto de esta adición sólo es significativo en la inversión, la cual se reduce proporcionalmente a la adición, alcanzando en el caso máximo de adición una reducción de inversión del orden de $20 \%$.

Los resultados anteriores se obtuvieron con datos económicos del año 1993

Se recomienda para estudios posteriores complementar el trabajo que aquí se realizó con una determinación de los valores reales de la demanda de lactosuero en queserías, asi como sus fluctuaciones con el tiempo y sus precios.

También sería útil hacer un estudio de caracterización de la composición de diversos quesos frescos mexicanos, a fin de ampliar el conjunto de quesos estudiados bajo este punto de vista. Seria de interés estudiar la viabilidad técnica y el impacto económico de otras posibilidades. al parecer todavía inexploradas, de aprovechamiento del lactosuero producido, tales como el cocomposteo de residuos sólidos domésticos o agricolas y lactosuero crudo.

Se sugiere para estudios posteriores, la obtención experimental por el proceso modificado de los quesos más viables según este estudio, para evaluar su calidad por pruebas sensoriales y su composición por métodos analíticos, comparando los resultados con los del proceso tradicional. Asimismo, seria interesante medir experimentalmente los rendimientos queseros obtenidos y la cantidad de lactosuero y permeato generados, con respecto a las estimaciones teóricas de este estudio.

También se recomienda estudiar las ventajas del permeato sobre el lactosuero como sustrato en procesos de producción de solventes y gomas mediante bioconversión por lermentación y 
subsecuente concentración de los productos obtenidos, así como en la producción de bebidas de consumo humano y en programas de reciclo como complemento de bebida para el ganado.

Cuando se considera la modificación de un proceso o el aprovechamiento de una corriente residual, la utilidad de estudios como el que aquí se presenta consiste en que permiten determinar con relativa rapidez y bajo costo, las modalidades de inversión más prometedoras, y por tanto las opciones tecnológicas que por su impacto económico se deben estudiar con profundidad, evitando asi la necesidad de realizar indiscriminadamente extensos y costosos experimentos tendientes a confirmar factibilidades técnicas en todas direcciones, pero que son en su mayoría poco recomendables de llevarse a la práctica, debido a razones económicas.

Aunque la metodología se desarrolló para el caso específico del lactosuero, los conceptos básicos en que se sustenta son bastante generales y podría adaptarse para tratar otros problemas de selección de alternativas. 
CAPITULO 7:

BIBLIOGRAFIA

1 Acevedo, F. (1987). CRC Crit. Rev. Biotechnol. 6 (4), 309.

2 Aeschlimann, A., Von Stockar, U. (1989). Biotechnol. Lett. 11 (3), 195.

3 Afschar, A., Biebl, H., Schaller, K., Schugerl, K. (1985). Appl. Microbiol. Biotechnol. 22, 394.

4 Agrawal, P., Koshy, G., Ramseier, M. (1989). Biotechnol. Bioeng. 33, 115.

5 Al-Mashikhi, S.., Nakai, S. (1987). J. Dairy Sci. 70, 2486.

6 Alam, S., Stevens, D., Bajpai, R. (1988). J. Ind. Microbiol. 2, 359

7 Allen, D., Page, R. (March, 1975). Chem. Eng. 142.

8 American Dairy Products Institute. (1986). Whey Products. A Sinvey of ltitization and Production Trends 1986. Bulletin No 25. Chicago.

9 Andersen, M. (1989). North Europ. Food Dairy J. 1, 11.

10 Anderson, G., Saw, C., Fernández, M. (Dec. 1986). Proc. Biochem. 174.

11 Anónimo. (1980). Rama Industrial de la Leche y Productos Lácteos. Lvolución, Sintución Actual y Perspectivas. Documento de Archivo. CANACINTRA, México.

12 Anónimo. (1985). Dairy Sciece and Technology. Principles and Applications. La Fondation du Technologie Laitiere du Quebec, Inc., Quebec.

13 Anónimo. (1985). Production Yearbook Vol 39. LAO Statistics Series $N^{\circ} 70$. Food and Agriculture Organization of The United Nations., New York.

14 Anónimo. (1988). Production Yearbook Vol 42. FA() Statistics Series $N^{\circ} 88$. Food and Agriculture Organization of The United Nations., New York.

15 Anónimo. (1990). Folleto Técnico Ultra-Filtration (arbosep. Societe de Fabrication d'Elements Catalytiques. Francia.

16 Anónimo. (1993). Dairy Producr Markets. En The Cheese Reporter. Vols 117-118, Madison, Wisconsin.

17 Anónimo. (1994). Dairy Market Statistics. 1993 Annual Summary. U.S. Department of Agriculture, Washington.

18 Anónimo. (Dec. 10, 1984). Holstein World. 44.

19 Anónimo. Tarifas de linergía liléctrica para 1993. Comisión Federal de Electricidad. México.

20 Asher, Y, Cosentino, G., Duvnjak, Z., Kosaric, N., Lim, H., Luttmann, R., Magee, R., Munack, A., Parulekar, S., Thoma, M., Wieczorek, A. (1985). Agricullural reedsrock and Waste Treatment and lingineering. Springer-Verlag, Berlin. 
21 Ayers, J., Petersen, M. (1985). N. Z. J. Dairy Sci. Technol. 20, 129.

22 Bakken, A., Hill, Ch., Amundson, C. (1989). Biotechnol. Bioeng. 33, 1249.

23 Ballongue, J., Masion, I., Amine, J., Petitdemange, II, Gay, R. (1987). Appl. Microbiol. Biotechnol. 26, 568 .

24 Barry, F., Beechinor, F., Foley, J. (1988). Irish J. Food Sci. Technol. 12, 25.

25 Batchelder, B. (1987). Bull. Int. Dairy Fed. 212, 84.

26 Batsalova, K., Kunchev, K., Popova, Y., Koshukharova, A., Kirova, N. (1987). Appl.

Microbiol. Biotechnol. 26, 227.

27 Belfort, G. (1989). Biotechnol. Bioeng. 33, 1047.

28 Berezny-Leh, M., Charles, M. (1989). J. Ind. Microbiol. 4, 71.

29 Betancourt, R. (1986). Appl. Econ. 18, 915.

30 Blanc, P., Goma, C. (1989). Biotechnol. Lett. 11 (3), 189.

31 Blank, S., Schmiesing, B. (1988). North Cent. J. Agric. Econ. 10 (1), 35.

32 Booy, C. (1987). Bull. Int. Dairy Fed. 212, 62.

33 Boyaval, P., Corre, C. (1987). Boitechnol. Lett. 9 (11), 801.

34 Boyaval, P., Corre, C., Terre, S. (1987). Biotechnol. Lett. 9 (3), 207.

35 Boyaval, P., Terre, S., Corre, C. (1988). Le Lait 68(1), 65.

36 Bradford, I., Cail, R., Callander, I., Floyd, E. (1986). Biotechnol. Bioeng. 28, 1601 .

37 Bradford, J., Galpin, D., Parkin, M. (1986). N.Z.J. Dairy Sci. Technol. 21, 65.

38 Brown, R., Ernstrom, C. (1982). I. Dairy Sci. 65 (12), 2391.

39 Bulock, J., Kristiansen, B. (Eds.). (1987). Basic Biolechnology. Academic Press, Londres.

40 Busche, R. (1983). Biotechnol. Bioeng. Symp. 13, 597.

41 Calibo, R., Matsumura, M., Kataoka, H. (1989). J. Ferment. Bioeng. 67 (1), 40.

42 Callebaut, a. Voets, A., Motte, J. (1990). Biotechnol. Lett. 12 (3), 215.

43 Cameron D. (1989). Reporte Interno. University of Wisconsin

44 Castillo, F., Blanch, H., Wilke, Ch. (1984). Biotechnol. Lett. 6 (9), 593.

45 Censano, I., Madrid, A., Madrid, R. (1991). Lácteos Mexicanos. 6 (1), 14.

46 Center for Dairy Research. (1989). Annual Report 1987-88. College of Agricultural and Life Sciences. University of Wisconsin.

47 Chambers, J., Marks, J., Perry, T., Lonergan, D. (1987). Bull. Int. Dairy Fed. 212, 132.

48 Chiang, B., Cheryan, M. (1987). J. Food Eng. 6, 241.

49 Chiang, B., Pan, W. (1989). Proc. Nat. Sci. Counc. Rep. China, Part A. 13 (4), 211.

50 Chiu, C., Kosikowski, F. (1985). J. Dairy Sci. 68, 16.

51 Christensen, P., Colding, H. (1988). North Europ. Food Dairy J. 3, 99.

52 Clark, W. (1987). Bull. Int. Dairy Fed. 212,6. 
53 Clausen, E., Gaddy, J. (1981). en Advances in Biotechnology, Vol. II. editado por Moo-Young M., Pergamon, Toronto. p. 63.

54 Córdoba P., Sánchez-Riera, F., Sineriz, F. (1984). Biotechnol. Letl. 6(11), 753.

55 Craig, K., Norback, J., Johnson, M. (1989). J. Dairy sci. 72 (11), 3098.

56 D'Amore, T., Panchal, Ch., Russell, I., Stewart, G. (1990). CRC Crit. Rev. Biotechnol. 9 (4), 287.

57 Dadgar, A., Foutch, G. (1988). Biotechnol. Prog. 4 (1), 36.

58 Dahlgran, R. (1985). North Cent. J. Agric. Econ. 7 (1), 132.

59 Damerdji, O., Derouiche, F., Legrand, C., Capiaumont, J., Bour, J., Maugras, M., Belleville, F., Nabet, P., Paquet, D., Linden, G. (1988). Biotechnol. 'Techniq. 2 (4), 253.

60 Daniels, M. (Oct. 1985). Food Technol., 68.

61 Darvish, T., Eckstein, S. (1988). Appl. Econ. $20,113$.

62 Datar, R. (Feb. 1986). Proc. Biochem. 19.

63 De Haast J., Britz, T., Novello, J., Verwey, E. (1985). J. Dairy Res. 52, 457.

64 De Haast, J., Britz, T., Novello, J. (1986). J. Dairy Res. 53, 467.

65 De Raucourt, A., Girard, D., Prigent, Y., Boyaval, P. (1989). App. Microbiol. Biotechnol. 30, 521.

66 De Raucourt, A., Girard, D., Prigent, Y., Boyaval, P. (1989). App. Microbiol. Biotechnol. 30, 528.

67 De Rham, O., Chanton, S. (1986). J. Dairy Res. 53, 271.

68 Decleire, M., Van Huyhn, N., Motte, I. (1985). App. Microbiol. Biotechnol. 21, 103.

69 Defrise, D., Gekas, V. (Aug. 1988). Proc. Biochem. 105.

70 Del Valle C. (1984). Cienc. y Des. 58, 29.

71 Delaney, R. (May. 1981). Cult. Dairy Prod. J. 11.

72 Dellweg, H., Luca, S. (Aug. 1988). Proc. Biochem. 100.

73 Detroy, R., Hesseltine, C. (Sept. 1978). Proc. Biochem. 2.

74 Dewitt, I., Hontelez-Backx, E., Adamse, M. (1988). Neth. Milk Dairy J. 42, 155.

75 Dewitt, J., Klarenbeek, G. (1984). J. Dairy Sci. 67 (11), 2701.

76 Díaz, H. (1984). A Modeling Approach for Multiproduct Process Plaming with a Case Shady of the lood Processing Industry. M.C. Thesis, Purdue University.

77 Díaz, H. (1986). Gest. Tec. 4, 37.

78 Donnelly, T. (Jun. 1978). Proc. Biochem. 14.

79 Donovan, M., Mulvihill, D. (1987). Irish J. Food Sci. 'Technol. 11 (1), 77.

80 Donovan, M., Mulvihill, D. (1987). Irish J. Food Sci. Technol. 11 (1), 87.

81 Doremus, M., Linden, J., Moreira, A. (1985). Biotechnol. Bioeng. 27, 852.

82 Doyle, C., Mason, V., Baker, R. (1988). Biol. Wastes 23, 39. 
83 Eck A. (Ed.). (1990). El Queso. Omega. Barcelona.

84 Edgar, T., Himmelblau, D. (1988). Optimization of (hemical Processes. Mc Graw Hill, New York.

85 El-Samragy, Y., Chen, J., Zall, R. (Feb. 1988). Proc. Biochem. 28.

86 El-Samragy, Y., Zall, R. (1988). J. Dairy Sci. 71 (5), 1135.

87 England, R., Abed-Ali, S., Brisdon, B. (1990). Biotechnol. Prog. 6 (2), 93.

88 Ennis, B., Gutiérrez, N., Maddox, I. (Oct. 1986). Proc. Biochem. 131

89 Ennis, B., Maddox, 1. (1987). Biotechnol. Bioeng. 29, 329.

90 Ennis, B., Maddox, I. (1987). N.Z.I. Dairy Sci. Technol. 22, 75.

91 Ennis, B., Maddox, I., Schoutens, G. (1986). N.Z.J. Dairy Sci. Technol. 21, 99.

92 Fabiani, C., Giubileo, G., Pizzichini, M., Violante, V. (1987). Biotechnol. Bioeng. 30, 458.

93 Fahim-Naser, S., Fournier, R. (1988). Biotechnol. Bioeng. 32, 628.

94 Fang, H. (1990). Biotechnol. Techniq. 4 (1), 1.

95 Farimani, M., Buongiorno, J., Thompson, H. (1988). Appl. Econ. 20, 767.

96 Ferras, E., Minier, M., Goma, G. (1986). Biotechnol. Bioeng. 28, 523.

97 Fick, M., Pierrot, P., Engasser, J. (1985). Biotechnol. Lett. 7 (7), 503.

98 Finnigan, T. (1988). J. Soc. Dairy Technol. 41 (3), 65.

99 Fond, O., Engasser, J., Matta-El-Almouri, G., Petitdemange, H. (1986). Biotechnol. Bioeng. 28,160 .

100 Fond, O., Engasser, J., Matta-El-Almouri, G., Petitdemange, H. (1986). Biotechnol. Bioeng. $28,167$.

101 Fournier, R. (1986). Biotechnol. Bioeng. 28, 1206.

102 Fournier, R. (1988). Biotechnol. Bioeng. 31, 235.

103 Fox, P. (Ed.). (1985). Developments in Dairy (hemistry 3:Lactose and Minor Constituents. Elsevier, London.

104 García-Garibay M., López-Munguía, A. (1984). Cienc. y Des. 58, 39.

105 Garoutte, C. (1983). Studies on Whey Processing and (heese Manufacture by Illrafiltration. Ph.D. Thesis, University of Wisconsin.

106 Garret, J., Stairs, R., Annett, R. (1988). J. Dairy Sci. 71 (1), 10.

107 Garrett, N. (1987). North Europ. Food Dairy J. 5, 135.

108 Gekas, V., López-Leyva, M. (Feb. 1985). Proc. Biochem. 2.

109 Gianetto, A., Berruti, F., Glick, B., Kempton, A. (1986). App. Microbiol. Biotechnol. 24, 277. 
110 Gilles, J. (1984). N.Z.J. Dairy Sci. Technol. 19 (1), 37.

111 Gilles, J., Lawrence, R. (1981). N.Z.J. Dairy Sci. Technol. 16 (1), 1.

112 Glas, C., Friesland, C., Leeuwarden, C. (1987). Bull. Int. Dairy Fed. 212, 125.

113 Godia, F., Casas, C., Sola, C. (Apr. 1987). Proc. Biochem. 43

114 Godin, C., Engasser, J. (1988). Biotechnol. Lett. 10 (6), 389

115 González, J., Damodaran, S. (1990)). J. Food Sci. 55 (6), 1559.

116 Gooding, C. (Jan. 1985). Chem. Ling. 7, 56

117 Gregory, A. (1987). Bull. Int. Dairy Fed. 212, 38.

118 Groot, W., Van der Oever, C., Kossen, N. (1984). Biotechnol. Lett. 6 (11), 709.

119 Haden, K., Van Tassell, L. (1988). North Cent. I. Agric. Econ. 10 (2), 209

120 Haggstrom, L. (1985). Biotechnol. Adv. 3, 13

121 Haji, J. (1987). Appl. Econ. 19, 1187.

122 Hansen, R. (1987). North Europ. Food Dairy J. 1, 21.

123 Hansen, R. (1987). North Europ. Food Dairy J. 5, 162.

124 Hansen, R. (1988). North Europ. Food Dairy J. 3, 87.

125 Hansen, R. (1988). North Europ. Food Dairy J. 9, 310.

126 Hansen, R. (1989). North Europ. Food Dairy J. I, 1.

127 Hansen, R. (1989). North Europ. Food Dairy J. 2, 30.

128 Hansen, R. (1989). North Europ. Food Dairy J. 3, 72.

129 Hansen, R. (1989). North Europ. Food Dairy J. 8, 168.

130 Harju, M. (1987). Bull. Int. Dairy Fed. 212, 50.

131 Harper, W. (1984). J. Dairy Sci. 67 (11), 2745

132 Hartmanis, M., Ahlam, H., Gatenbeck, S. (1986). App. Microbiol. Biotechnol. 23, 369.

133 Hartmeier, W., Jankovic, E., Tramm-Werner, S. (1984). The Proccedings of Biotech'8t Firope, 187.

134 Hayes, K. (1987). Appl Lcon. 19, 417.

135 Heideger, T., Prenosil, I. (1985). Biotechnol. Prog. 1 (4), 216.

136 Henry, E. (1987). Irish J. Agric. Econ. Rur. Soc. 12, 1.

137 Herzka, A., Booth, R. (Eds.). (1981). Food Industry Wastes: Disposal and Recovery. Applied Science, London

138 Hettinga, D.H. (1989). I. Dairy Sci. 72 (10), 2790.

139 I liddink, I., Van der Waal, M. (1984). J. Food Eng. 3, 225.

140 Hirschorn, J., Jackson, T., Baas, L. (1993). Towards Prevention -the emerging environmental management paradigm- en (lean Production Strategies. Jackson, T. Editor. Lewis Publishers, USA. 
141 Hobman, P. (1984). J. Dairy Sci. 67, 2630

142 Horton, B. (1987). Bull. Int. Dairy Fed. 212, 77.

143 Hsu, K., Fennema, O. (1989). J. Dairy Sci. 72 94), 829.

144 Hsu, S. (1984). A Mulitevel Approach for Preliminary Process Development and a Demonstration on Developing Whey Processing Systems. Ph.D. Thesis, University of Purdue.

145 Huang, X., Akehata, T., Unno, H., Hirasa, O. (1989). Biotechnol. Bioeng. 34, 102.

146 Huffman, L., Harper, W. (1985). N.Z.J. Dairy Sci. Technol. 20, 57.

147 Huffman, L., Kristoffersen, T. (1984). N.Z.J. Dairy Sci. Technol. 2 (19), 151.

148 Hugunin, A. (1987). Bull. Int. Dairy Fed. 212, 135.

149 Hustedt, H., Kroner, K., Papamichael, N. (Oct. 1988). Proc. Biochem. 129.

150 Hyun-Park, T., Ho-Kim, I. (1986). App. Microbiol. Biotechnol. 24, 102.

151 Ingram, L. (1990). CRC Crit. Rev. Biotechnol. 9 (4), 305.

152 Izaguirre, M., Castillo, F. (1982). Biotechnol. Lett. 4 (4), 257.

153 Jackson, A., De Silva, R. (Dec. 1985). Proc. Biochem. 185.

154 Janssens, J., Bernard, A., Bailey, R. (1984). Biotechnol. Bioeng. 26, 1.

155 Jelen, P. (1979). J. Agric. Food Chem. 27 (4), 658

156 Jensen, G., Oxlund, J. (1988). Bull. Int. Dairy Fed. 233, 4.

157 Jiménez, A. (1992). Diseño de Procesos en Ingeniería Química. Instituto Tecnológico de Celaya.

158 Jiménez, A., Chávez, O. (1988). Chem. Eng. J. 37, B1.

159 Jiménez, A., Rudd, D. (1987). Chem. Eng. Comm. 42, 203.

160 Jiménez, A., Rudd, D. (1987). Comput. Chem. Engng. 11 (3), 291.

161 Jiménez, A., Rudd, D. (1989). Chem. Eng. Comm. 42, 203.

162 Johnson, S. (1981). Feasibility of Production and Combustion of a Solid livel from Cheese Whey. M.S. Thesis, University of Wisconsin.

163 Jonsson, H., Arph, S. (1987). Bull. Int. Dairy Fed. 212, 91.

164 Joshi, M., Gowda, L., Bhat, S. (1987). Biotechnol. Lett. 9 (8), 549.

165 Juengst, F. (1979). J. Dairy Sci. 62 (1), 106.

166 Junelles, A., Janati-Idrissi, R., El-Kanouni, A., Petitdemange, H., Gay, R. (1987). Biotechnol. Lett. 9 (3), 175.

167 Kaiser, J., Glatz, C. (1988). Biotechnol. Prog. 4 (4), 242.

168 Kamel, B. (Dec. 1985). Proc. Biochem. 190.

169 Kamini, N., Gunasekaran, P. (1989). J. Ferment. Bioeng. 68 (5), 305.

170 Kardasz, S., Stollery, K. (1988). Appl. Econ. 20, 473.

171 Kaul, R., D'Souza, S., Nadkarni, G. (1984). Biotechnol. Bioeng. 26, 901.

172 Kelly, P. (1987). Irish J. Food Sci. Technol. 11 (2), 153. 
173 Kester, I., Richardson, T. (1984). J. Dairy Sci. 67 (11), 2757.

174 Kida, k., Asano, S., Yamadaki, M., Iwasaki, K., Yamaguchi, T., Sonoda, Y. (1990). J. Ferment. Bioeng. 69 (1), 39.

175 Kierstan, M., Corcoran, E. (1984). Biotechnol. Lett. 6(12), 813.

176 Kilara, A. (1984). J. Dairy Sci 67 (11), 2734.

177 Kim, S., Morr, C., Seo, A., Surak, J. (1989). J. Food Sci. 54 (1), 25.

178 Kissalita, W., Lo, K., Pinder, K. (1989). Biotechnol. Bioeng. 33, 623.

179 Kissalita, W., Lo, K., Pinder, K. (1989). Biotechnol. Bioeng. 34, 1235.

180 Kissalita, W., Pinder, K., Lo, K. (1987). Biotechnol. Bioeng. $30,88$.

181 Kjaergaard-Jensen, G. (1987). Bull. Int. Dairy Fed. 212, 27.

182 Knopf, F., Okos, M., Fouts, D, Syverson, A. (1979). J. Food Sci. 44, 896.

183 Konstance, R., Strange, E. (1991). J. Food Sci. 56 (2), 556.

184 Kosikowski, F. (1982). (heese and liermented Milk lionds. Kosikowski and Assoc., New York

185 Kravchenko, E. (1988). Bull. Int. Dairy Fed. 233, 61.

186 Lalande, M., Tissier, J., Corrieu, G. (1985). Biotechnol. Prog. 1 (2), 131.

187 Larson, B., Kuchler, F. (1990). North Cent. J. Agric. Econ. 12 (1), 109.

188 Lasdon, L., Waren, A. (1989). CRRCi2 User's (inde. University of Texas.

189 Lawrence, R. (1989). Bull. Int. Dairy Fed. 240, 2.

190 Lee, H., Maddox, I. (1984). Biotechnol. Lett. 6 (12), 815.

191 Leh, M., Charles, M. (1989). J. Ind. Microbiol. 4, 65.

192 Leh, M., Charles, M. (1989). J. Ind. Microbiol. 4, 77.

193 Lelievre, J., Lawrence, R. (1988). J. Dairy Res. 55, 465.

194 Lemus, F. (1991). Comunicación personal. El Sauz, México.

195 Liao, J. (1989). Biotechnol. Bioeng. 33, 613.

196 Lindemann-Schneider, U., Fennema, O. (1989). J. Dairy Sci. 72 (7), 1740.

197 Lindum-Moller, J. (1987). North Europ. Food Dairy J. 9, 298.

198 Linko, P. (1985). Biotechnol. Adv. 3, 39.

199 Lipinsky, E., Sinclair, R. (Aug. 1986). Chem. Eng. Prog. 26.

200 Lo, K., Liao, P. (1989). Biol. Wastes 28, 91.

201 López-Leyva M. (1988). Lebensm. Wiss. U. Technol. 21, 119.

202 López-Leyva M. (1988). Lebensm. Wiss. U. Technol. 21, 177.

203 López-Leyva, M., Gekas, V. (Feb. 1986). Proc. Biochem. 27.

204 Lovitt, R., Hong-Kim, B., Shen, G. (1988). CRC Crit. Rev. Biotechnol. 7 (2), 107.

205 Lynk, E. (1986). App. Econ. 18, 113.

206 Lyons, T., Cunningham, J. (1980). Amer. Dairy Rev. 42, (11), 42 A. 
207 Madrid, A. (1981). Modernas Técnicas de Aprovechamiento del Lachosuero. Antonio Madrid Ediciones, Madrid.

208 Maiorella, B., Blanch, H., Wilke, C. (1984). Biotechnol. Bioeng. 26, 1003.

209 Maiorella, B., Castillo, F. (Aug. 1984). Proc. Biochem. 157.

210 Malink, M., Kurim, M., Linden, J., Dale, B., Mihaltz, P. (1987). Biotechnol. Bioeng. 29, 370.

211 Mangino, M. (1984). J. Dairy Sci. 67 (11), 2711

212 Mangino, M., Fritsch, D., Liao, S. (1985). N.Z.J. Dairy Sci. Technol. 20, 103.

213 Mangino, M., Liao, Y., Harper, N., Morr, C., Zadow, J. (1987). J. Food Sci. 52 (6), 1522.

214 Manji, B., Kakuda, Y. (1987). J. Dairy Sci. 70, 1355.

215 Mann, S., Thompkinson, D. (Nov. 1988). Aust. J. Dairy Technol. 47.

216 Marchal, R., Blanchet, D., Vandecasteele, J. (1985). Appl. Microbiol. Biotechnol. $23,92$.

217 Marlatt, J., Datta, R. 91986). Biotechnol. prog. 2 (1), 23.

218 Marshall, K., Harper, W. (1988). Bull. Int. Dairy Fed. 233, 21.

219 Martini, G., Mignone, C., Ertola, R. (1989). Biotechnol. Lett. 11 (8), 545.

220 Marwaha, S., Kennedy, J. (1988). Int. J. Food Sci. Technol. 23, 323.

221 Marwaha, S., Kennedy, J. (Apr. 1984). Proc. Biochem. 79.

222 Marwaha, S., Kennedy, J., Sehgal, V. (Feb. 1988). Proc. Biochem. 17.

223 Marwaha, S., Kennedy, J., Tewari, H., Redhu, A. (Apr. 1989). Proc. Biochem. 46.

224 Masters, K., Vestergaard, I. (Jan. 1978). Proc. Biochem. 3.

225 Matsumura, M., Kataoka, H. (1987). Biotechnol. Bioeng. 30, 887.

226 Matsumura, M., Kataoka, H., Sueki, M., Araki, K. (1988). Bioproc. Eng. 3, 93.

227 Mattheus, M. (1984). J. Dairy Sci. 67, 2680.

228 Maubois, J., Mocquot, G. (1971). Le Lait. 507, 416.

229 Maubois, J., Pierre, A., Fauquant, J., Piot, M. (1987). Bull. Int. Dairy Fed. 212, 154.

230 Mawson, A. (1988). Biotechnol. Lett. $10(7), 503$.

231 Mc Gregor, J., White, C. (1990). J. Dairy Sci. 73 (2), 314.

232 Mc Guckin, T., Ghosh, S. (1989). North Cent. J. Agric. Econ. 11 (2), 277.

233 Mehaia, M., Cheryan, M. (1986). Enzyme Microbiol. Technol. 8, 289.

234 Mehaia, M., Cheryan, M. (1990). Bioproc. Eng. 5, 57.

235 Mehaia, M., Cheryan, M. (Dec. 1987). Proc. Biochem. 185.

236 Melachorius, N. (1984). J. Dairy Sci. 67, 2693.

237 Mellor, C., Hessener, C. (1986). Appl. Econ. 18, 663. 
238 Michel, A., Jacob, F., Perrier, J., Poncet, S. (1987). Biotechnol. Bioeng. 30, 780

239 Milner, C. (1988). Appl. Econ. 20, 295.

240 Mistry, V., Kosikowsyi, F., Bellamy, W. (1987). J. Dairy Sci. 70, 2220.

241 Mitchell, R., Arrowsmith, A., Ashton, N. (1987). Biotechnol. Bioeng. 30, 348.

242 Mizota, T., Tamura, Y., Tomita, M., Okonogi, S. (1987). Bull. Int. Dairy Fed. 212, 69.

243 Modak, I., Lim, H. (1989). Biotechnol. Bioeng. 33, 11.

244 Modler, H. (1987). Bull. Int. Dairy Fed. 212, 111.

245 Modler, H., Emmons, D., Rolland, J., Holme, J. (1987). J. Dairy Sci. 70, 766.

246 Modler, H., Muller, P., Elliot, J., Lmmons, D. (1980). J. Dairy Sci. 63 (5), 838.

247 Moo-Young, M. (Ed.) Comprehensive Biotechnology, Vol 3. Pergamon Press.

248 Morr, C. (1987). Bull. Int. Dairy Fed. 212, 145.

249 Moulin, G., Galzy, P. (1984). Biotechnol. Gen. Eng. Rev. 1, 347

250 Moulin, G., Galzy, P. (1984). en Advances in Biotechnology Vol II, Ed. Moo-Young M. Pergamon Press. p. 181.

251 Mulder, M., Smolders, C. (Apr. 1986). Proc. Biochem. 35.

252 Mulvihill, D., Donovan, M. (1987). Irish J. Food Sci. Technol. 11 (1), 43.

253 Muraki, M., Hayakawa, T. (1987). Can. J. Chem. Eng. 65, 250.

254 Murphy, B., Mulvihill, D. (1988). J. Soc. Dairy Technol. 41 (1), 22.

255 Murphy, E. (1988). Irish J. Agric. Econ. Rur. Soc. 13, 47.

256 Nakhapetyan, L., Motina, L. (1988). Biotek (1), 4.

257 Nickerson, T. (1979). J. Agric. Food Chem. 27 (4), 672.

258 Okyere, W., Johnson, S. (1987). Appl. Econ. 19, 1457.

259 Olano, A., Nickerson, 'T., Bernhard, R. (1977). J. Food Sci. 42 (6), 1481.

260 Palsson, B., Fathi-Afschar, S., Rudd, D., Lightfoot, E. (1981), Science 213, 513.

261 Park, Ch., Okos, M., Wankat, P. (1989). Biotechnol. Bioeng. 34, 18.

262 Paterson, R., Hill, Ch., Amundson, C. (1989). Biotechnol. Bioeng. 34, 429.

263 Pearce, R. (1987). Bull. Int. Dairy Fed. 212, 150.

264 Pepper, D., Pain, L. (1987). Bull. Int. Dairy Fed. 212, 25.

265 Peppler, H., Perlman, D. (Eds.). (1979). Microbial Technology Vol I. Academic Press, New York.

266 Perlman, D. (May, 1978). Proc. Biochem. 3.

267 Peterson, R. (1987). Lachose Hydrolysis by Immobilized Beta-Galactosidase in a (apillary Bed Reactor. Ph.D. Thesis, University of Wisconsin.

268 Peterson, R., Hill, Ch.,Amundson, C. (1989). Biotechnol. Bioeng. 34, 438.

269 Pham, C., Motoki, M., Matsumura, M., Kataoka, H. (1989). I. Ferment. Bioeng. 68 (1), 25. 
270 Pierre, A., Fauquant, J. (1986). Le Lait 66 (4), 405

271 Pierrot, P., Fick, M., Engasser, J. (1986). Biotechnol. Lett. 8 (4), 253.

272 Potgieter, A., Mostert, J., Downes, T., De Haast, J. (1987). N.Z.J. Dairy Sci. Technol. 22, 111.

273 Prenosil, J., Stuker, E, Bourne, J. (1987). Biotechnol. Bioeng. 30, 1026.

274 Prenosil, J., Stuker, E., Hediger, T., bourne, J. (May. 1984). Bio/Technol. 441.

275 Quickert, S., Bernhard, R. (1982). J. Food Sci. 47, 1705.

276 Quintana, M., Barneto, R., Martin, D. (1984). Rev. Agroquim. Tecnol. Alim. 2 (24), 256.

277 Rajagopalan, K., Kosikowski, F. (1982). Ind. Eng. Chem. Prod. Res. Dev. 21, 82.

278 Rajah, K., Blenford. D. (Eds.). (1988). Lactose in The Baking Industry. Association of Lactose Manufacturers, The Netherlands.

279 Rajah, K., Blenford. D. (Eds.). (1988). The ALM Guide to lactose Properties and (Ises. Association of Lactose Manufacturers, The Netherlands.

280 Rao, B., Goodbole, S., D'Souza, S. (1988). Biotechnol. Lett. 10 (6), 427.

281 Rao, G., Mutharasan, R. (1988). Biotechnol. Lett. $10(5), 313$.

282 Reesen, L., Strube, R. (1978). Proc. Biochem. 13 (11), 21.

283 Reinbold, R. (Feb. 1990). Modern Dairy 10.

284 Robinson, D., Wang, D. (1988). Biotechnol. Prog. 4 (4), 231.

285 Robinson, R. (Ed.). (1986). Modern lairy Technology Vol 1. Elsevier, London.

286 Roffler, S., Blanch, H., Wilke, C. (1988). Biotechnol. Bioeng. 31, 135.

287 Roffler, S., Blanch, H., Wilke, C. (1988). Biotechnol. Bioeng. 32, 192.

288 Roller, S., Bennetto, H., Delaney, G., Mason, J., Stirling, J., Thurston, C., White, D. (1983).

Proc. Int. Conf. Comm. Appl. Impl. Biotechnol., 655.

289 Roodpeyma, S. (1980). Use of Immobilized Lactase in Processing Cheese Whey Ultrafiltrate. M.C. Thesis, University of Wisconsin.

290 Rudd, D., Fathi-Afschar, S., Treviño, A., Stadtherr M. (1981). Petrochemical Technology Assessment. John Wiley and Sons, New York.

291 Rudd, D., Treviño, A., Jiménez, A. (1988). Reporte Interno. Dept. of Chem. Eng., Univ. of Wisconsin.

292 Ruggeri, B., Specchia, V., Gianetto, A. (1988). Chem. Eng. J. 37 , B23.

293 Ryder, D. (1988). Bull. Int. Dairy Fed. 233, 45.

294 Samishina, N., Lotmentseva, E., Borisova, V., Nakhapetyan, L., Sviridenko, Y., Borovkova, Y., Smurygin, V. (1987). Biotek 1, 61.

295 Sandfort, P. (1987). Bull. Int. Dairy Fed. 212, 21.

296 Sato, K., Yoshizawa, K. (1988). J. Ferment. Technol. 66 (6), 667.

297 Schingoethe, D. (1987). Bull. Int. Dairy Fed. 212, 106.

298 Schlote, D., Gottschalk, G. (1986). App. Microbiol. Biotechnol. 24, 1. 
Schmidt, R. Packard, V., Morris, H. (1984). J. Dairy Sci. 67 (11), 2723.

300 Schneider, H. (1989). CRC Crit. Rev. Biotechnol. 9(1), 1

301 Schnitkey, G., Arbaugh, D. (1989). North Cent. J. Agric. Econ. 11 (2), 203.

302 Schoutens, G., Groot, W. (Aug. 1985). Proc. Biochem. 117.

303 Schoutens, G., Kossen, N. (1986). Chem. Eng. I. 32, B51.

304 Schoutens, G., Nieuwenhuizen, M., Kossen, N. (1985). App. Microbiol. Biotechnol. $21,282$.

305 Schoutens, G., Van Beelen, P., Luyben, K. (1986). Chem. Eng. J. 32, B43.

306 Schroeder, E., De Haast, J. (1989). J. Dairy Res. 56, 129.

307 Schwartz, R. (1987). Bull. Int. Dairy Fed. 212, 56.

308 Scott, T., Hill, Ch., Amundson, C. (1986). Biotechnol. Bioeng. Symp. 17, 585.

309 Serra, A., Poch, M., Sola, C. (Oct. 1987). Proc. Biochem. 154.

310 Seth, H., Jelen, P., Shah, N. (1988). J. Food Sci. 53 (3), 746.

311 Shama, G. (Oct. 1988). Proc. Biochem. 138.

312 Shimp., L. (May, 1985). Food Technol. 63.

313 Skudder, P. (1985). J. Dairy Res. 52, 167.

314 Slack, A. (1981). Ultrafiltation of Raw Whole Milk on the Farm. M.S. Thesis, University of Wisconsin.

315 Slack, a. (1984). Lunctional Properties of Beta-Lactoglobulin and Alfa-Lactalbumin Enriched liractions Manufactured from Cheese Whey. Ph.D. Thesis, University of Wisconsin.

316 Slack, A., Amundson, C., Hill, Ch. (1986). J. Food Proc. Preser. 10, 19.

317 Slack, A., Amundson, C., Hill, Ch. (1986). I. Food Proc. Preser. 10, 31.

318 Slack, A., Amundson, C., Hill, Ch. (1986). J. Food Proc. Preser. 10, 81.

319 Smart, J., Crow, V., Thomas, T. (1985). N.Z.J. Dairy Sci. Technol. 20, 43.

320 Sokic, M., Zdravkovic, S., Trifunovic, Z. (1990). Can. J. Chem. Eng. 68, 119.

321 Soni, B., Das, K., Soucaille, P., Goma, G. (1986). Biotechnol. Bioeng. Symp. 17, 591.

322 Straight, J., Ramkrishna, D., Parulekar, S., Jansen, N. (1989). Biotechnol. Bioeng. 34, 705.

323 Strathmann, H. (1990). Food Biotechnol. 4 (1), 253.

324 Sun-Wang, N., Stephanopoulos, G. (1983). CRC Crit. Rev. Biotechnol. 2 (1), 1.

325 Taddei, C., Daufin, G., Aimar, P., Sánchez, V. (1989). Biotechnol. Bioeng. 34, 171.

326 Tahoun, M., El-Merheb, Z., Salam, A., Youssef, A. (1987). Biotechnol. Bioeng. $29,358$.

327 Tarnawski V., Jelen, P. (1986). J. Food Eng. 5, 75.

328 Teixeira, J., Mota, M., Goma, G. (1990). Bioproc. Eng. 5, 123.

329 Thompson, R. (1988). ^ppl. Econ. 20, 367.

330 Thorne, L., Tansey, L., Pollock, T. (1988). J. Ind. Microbiol. 3, 321.

331 Tong, P., Barbano, D., Jordan, W. (1988). J. Dairy Sci. 7I, 2342.

332 Tong, P., Barbano, D., Jordan, W. (1989). J. Dairy Sci. 72 (6), 1435. 
333 Trejo, R. (1985). Revisión del Estado del Arte en el Procesamiento de Basura Vrbana. Informe Final del proyecto COSNET 74.85. México.

334 Tsoutsas, T., Kanellaki, M., Psarianos, C., Kalliafas, A., Koutinas, A. (1990). J. Ferment. Bioeng. 69 (2), 93.

335 Tsuji, S., Shimizu, K., Matsubara, M. (1987). Biotechnol. Bioeng. 30, 420.

336 Van den Bos, M. (1987). Bull. Int. Dairy Fed. 212, 99

337 Van der Waal, M., Hiddink, J. (1985). J. Food Eng. 4, 53.

338 Van Griethuysen-Dilber, E., Flaschel, E., Renken, A. (Apr. 1988). Proc. Biochem. 55.

339 Van Hoogstraeten, J. (1987). Bull. Int. Dairy Fed. 212, 17.

340 Van Huynh, N., Decleire, M., Voets, A., Motte, J., Monseur, X. (Feb. 1986). Proc. Biochem. 31.

341 Vetter, J. (Ed.). (1984). Dairy Products for the ('ereal Processing Industry. The American Association of Cereal Chemists Inc. St. Paul, Minnesota.

342 Vienne, P., Vonstocker, U. (1985). Biotechnol. Lett. 7 (7), 521.

343 Vignes, I. (1976). Utilization of liresh liquid whey or condensed Whey (20\% I)M). M.S. Thesis, University of Wisconsin.

344 Vijaikishore, P., Karanth, N. (1984). Biotechnol. Lett. 6(2), 103.

345 Vijaikishore, P., Karanth, N. (1987). Biotechnol. Bioeng. 30, 325.

346 Vijaikishore, P., Karanth, N. (Apr. 1986). Proc. Biochem. 54.

347 Vijaikishore, P., Karanth, N. (Oct. 1986). Proc. Biochem. 160.

348 Visser, R., Van den Bos, M., Ferguson, W. (1988). Bull. Int. Dairy Fed. 233, 33.

349 Votruba, J., Volesky, B., Yerushalmi, L. (1986). Biotechnol. Bioeng. 28, 247.

350 Wang, N., Stephanopoulos, G. (1984). Biotechnol. Bioeng. Symp. 14, 635.

351 Watanabe, T., Aoki, T., Honda, H., Taya, M., Kobakashi, T. (1990). J. Ferment. Bioeng. 69 (1), 33 .

352 Wecker, M., Zall, R. (Oct. 1987). Proc. Biochem. 135.

353 Wehrenberg II, R. (Sep. 1981). Mat. Eng. 63.

354 Welsh, F., Veliky, I. (1984). Biotechnol. Lett. 6 (1), 61.

355 Welsh, F, Veliky, I. (1986). Biotechnol. Lett. 8 (1), 43.

356 Whalen, P., Shahani, K. (1987). Ponencia presentada en Novel Biotechniques and Processes for the Food Industry, Proceedings of the Conference held in London. October 1987. $\mathrm{p} 109$

357 Willets, A., Ugalde, U. (1987). Biotechnol. Lett. 9 (11), 795.

358 Wolf, I. (1982). CRC: Handhook of l'rocessing and Htilization in Agriculture. Volume I. Animal Products. CRC Press, Florida.

359 Yamade, K., Fukushima, S. (1989). I. Ferment. Bioeng. 67 (2), 97

360 Yan, J., Lo, K., Liao, P. (1989). Biol. Wastes 28, 289. 
361 Yang, S., Okos, M. (1989). Biotechnol. Bioeng. 34, 763.

362 Yang, S., Tang, I., Okos, M. (1988). Biotechnol. Bioeng. 32, 28.

363 Ykema, A., Kater, M., Smith, H. (1989). Biotechnol. Lett. 11 (7), 477

364 Zacchi, G., Axelsson, ^. (1989). Biotechnol. Bioeng. 34, 223.

365 Zadow, J. (1984). J. Dairy Sci. 67, 2654.

366 Zadow, J. (1987). Bull. Int. Dairy Fed. 212, 12.

367 Zadow, J. (1988). Bull. Int. Dairy Fed. 233, 53.

368 Zall, R. (1984). I. Dairy Sci. 67, 2621.

369 Zall, R. (1987). Bull. Int. Dairy Fed. 212, 103.

370 Zayed, G., Foley, J. (1987). Irish .J. Food Sci. Technol. 11 (2), 109.

371 Zertuche, L., Zall, R. (1985). Biotechnol. Bioeng. 27, 547.

372 Clift, R. (1995). J. Chem. Tech. Biotechnol. 62, 321-326 


\section{APENDICE A}

\section{LISTADO DEL SIMULADOR DE PROCESOS EMPLEADO EN EL CAPITULO 4}

Este simulador, escrito en lenguaje FORTRAN, calcula la inversión requerida, los costos de operación y la producción esperada para cada proceso ensayado. Está constituido por un programa principal y un conjunto de subrutinas y archivos de datos.

Un diagrama de flujo resumido de la estructura del simulador se presenta en la figura A-3.0-1.

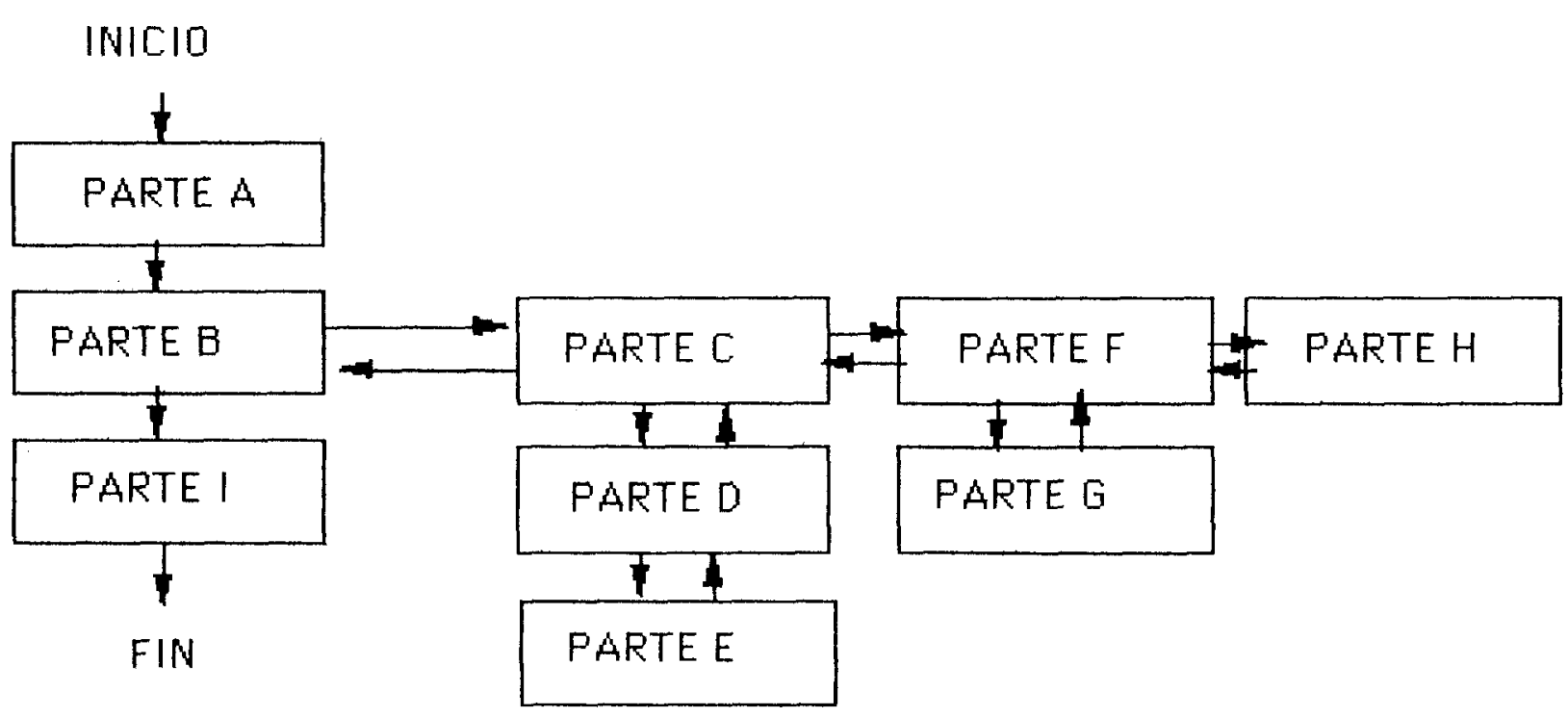

FIGURA A-3.0-1

DIAGRAMA DE FLUJO RESUMIDO DEL SIMULADOR UTILIZADO EN EL CAPITULO 4.

La parte $A$ consta de subrutinas encargadas de leer los datos de entrada y el archivo de datos de referencia, y con ellas formular matemáticamente el problema de optimización. En la parte B, hay una subrutina encargada de establecer el criterio de optimalidad. La parte $C$, genera un punto de partida factible para la optimización. En esta parte se hace intervenir a la subrutina de optimización GRG2, la cual no aparece en el listado del programa debido a que no se cuenta con permiso del autor del algoritmo (Dr. Lasdon, Universidad de Austin, Texas) para publicarla. También en esta parte C, se controla la secuencia de cálculos durante la optimización. 
La parte D contiene subrutinas encargadas de efectuar los balances de materia y energia involucrados y la parte E calcula los costos de las operaciones unitarias y sus insumos. De seleccionar en el momento apropiado cada operación unitaria se encargan las subrutinas de la parte $\mathrm{F}$, y los módulos de las operaciones unitarias disponibles se encuentran en un conjunto de subrutinas ubicado en la parte $\mathrm{G}$. La parte $\mathrm{H}$ contiene un conjunto de funciones destinadas a calcular propiedades fisicas, y la parte I contiene las subrutinas encargadas de imprimir los resultados de la simulación. 

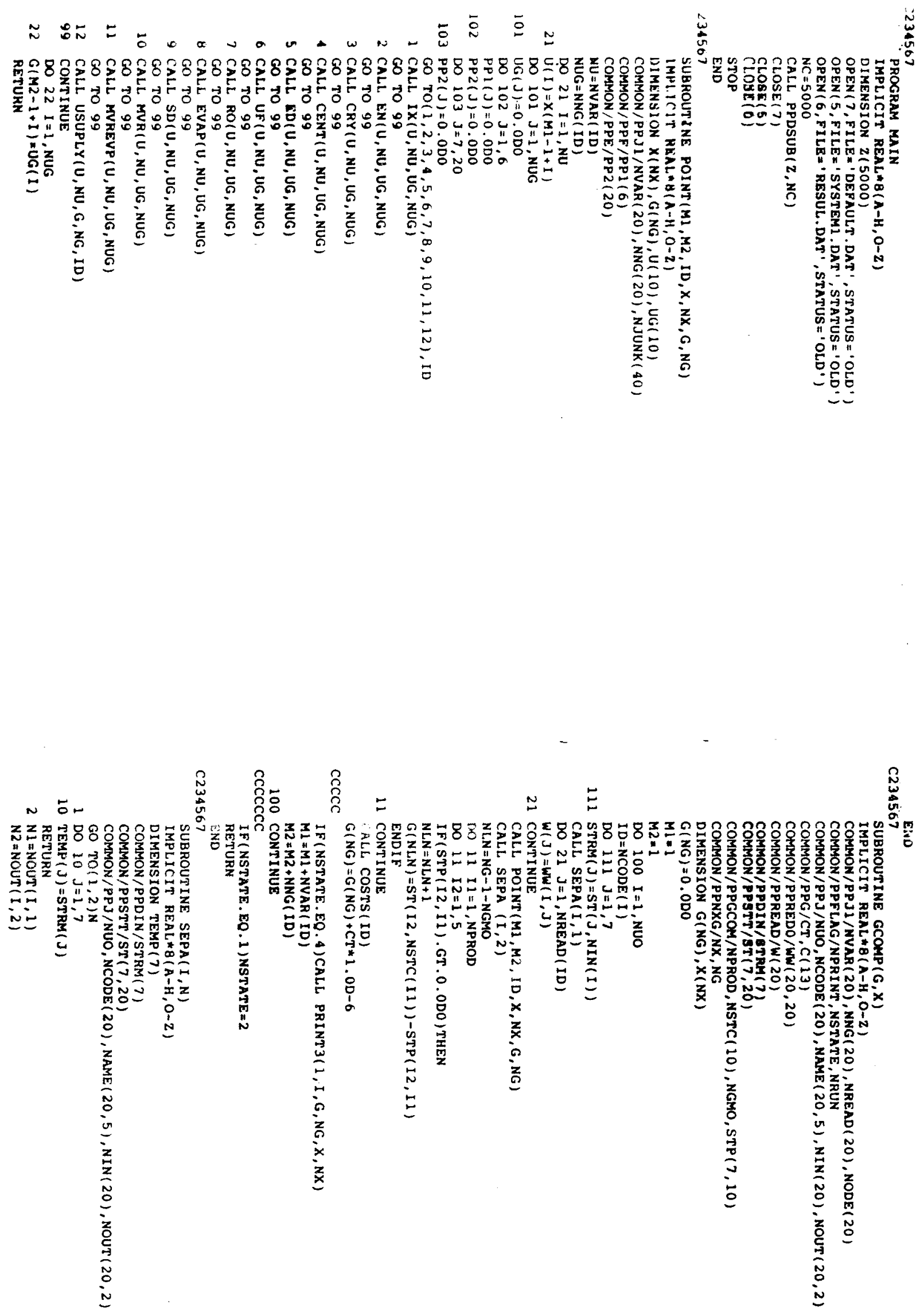

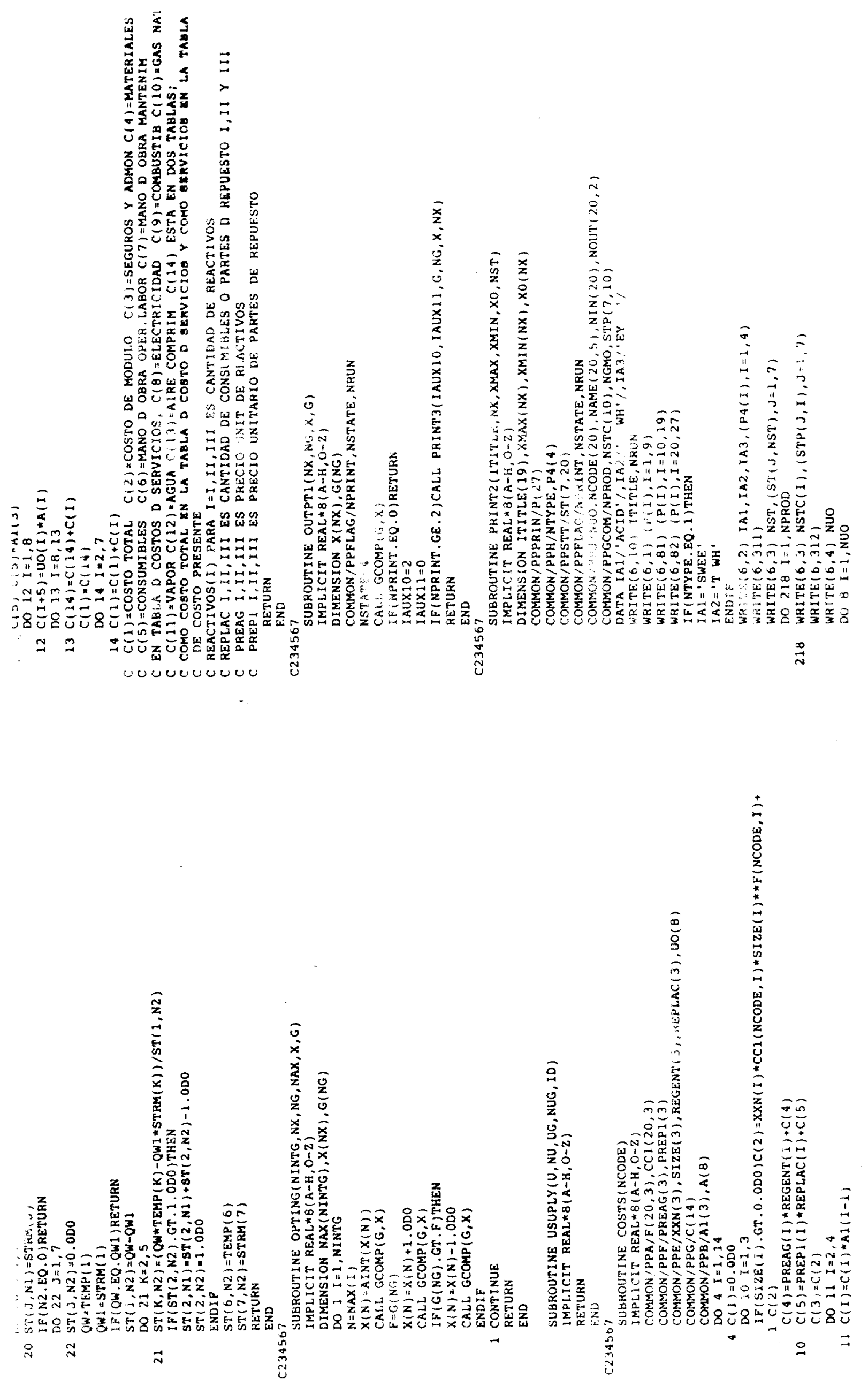


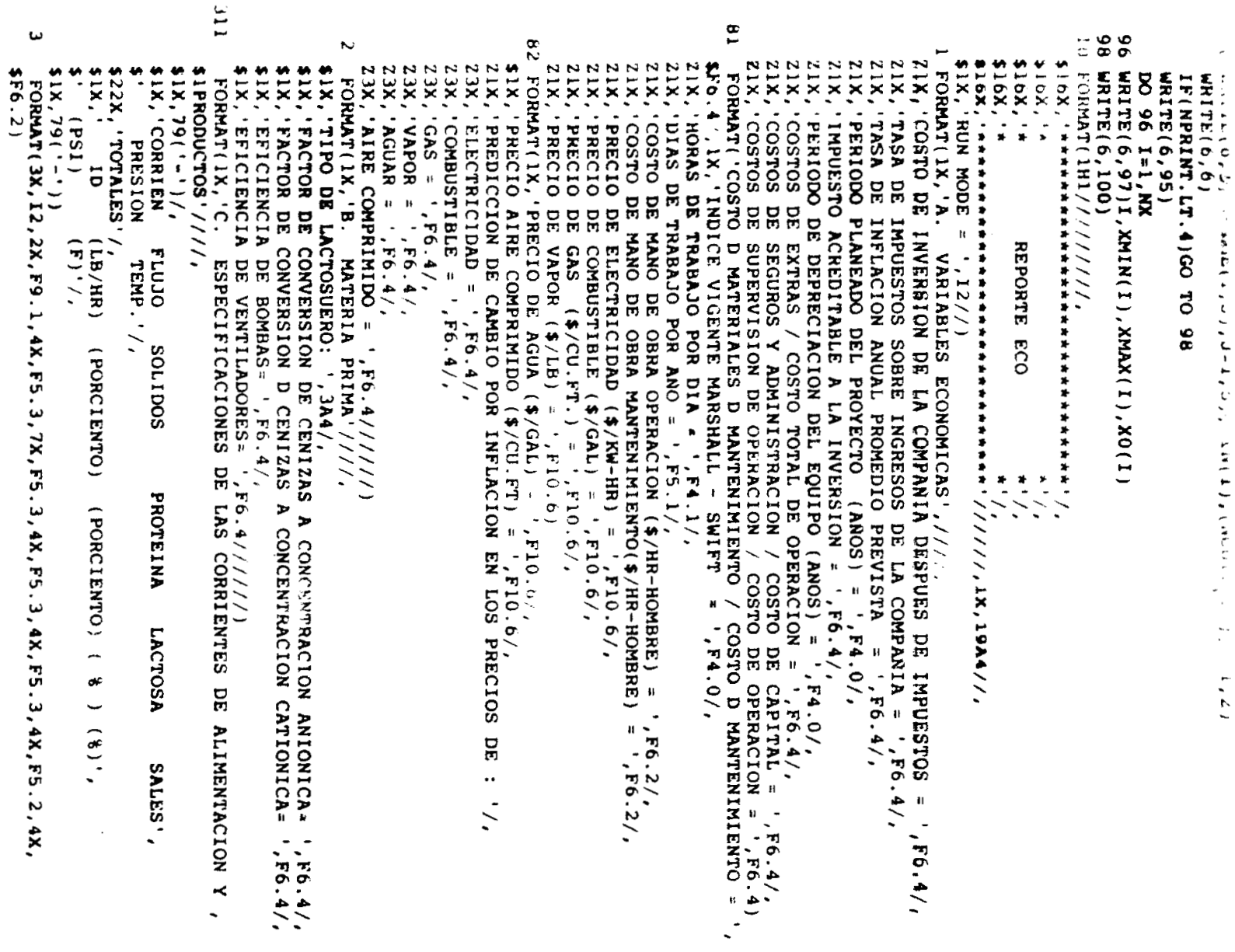

i

ก

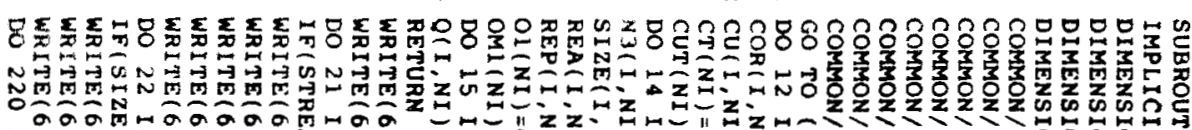

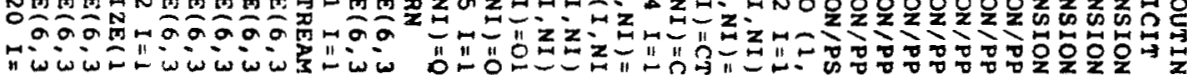
"wwis

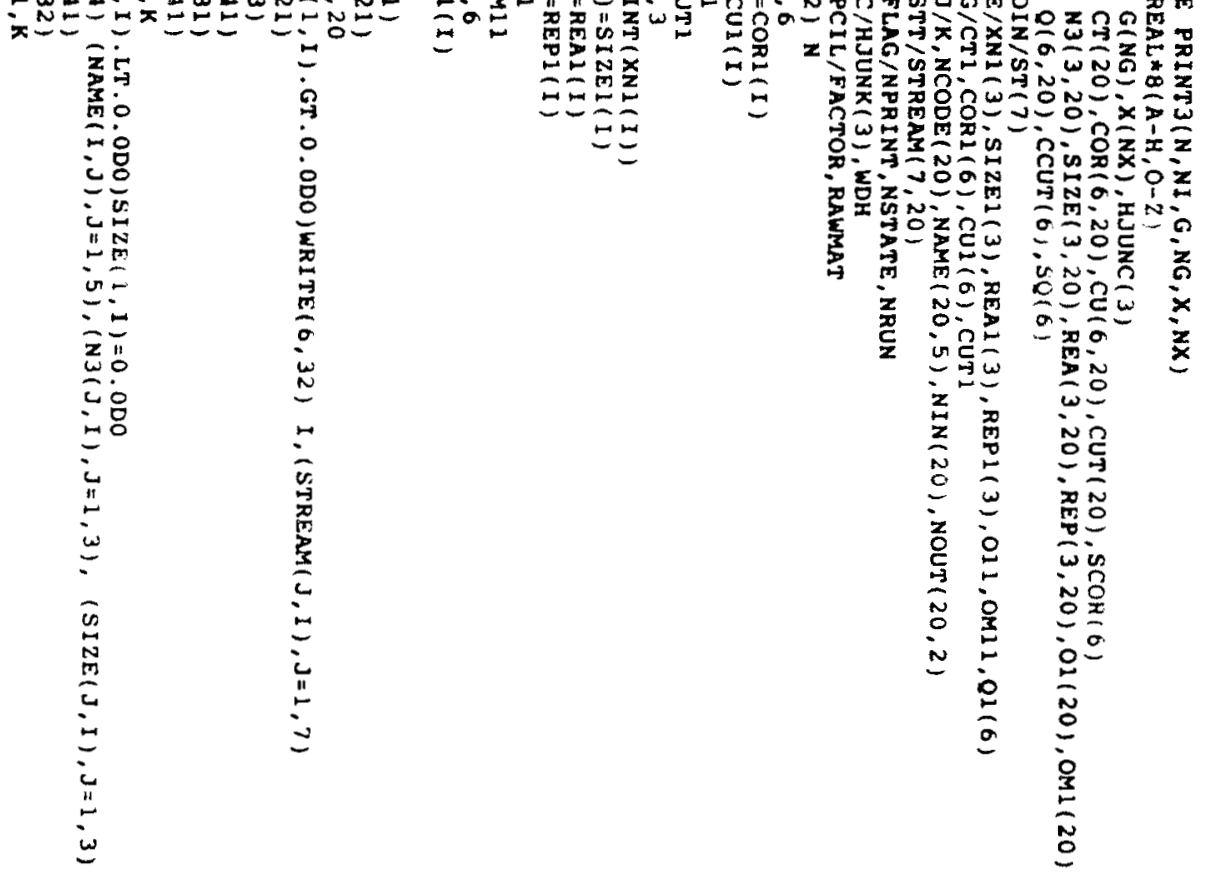

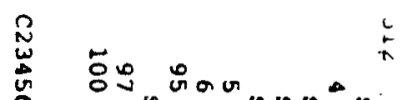

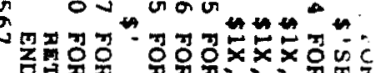

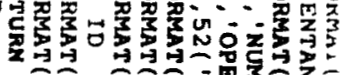

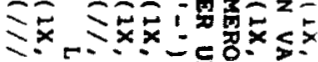

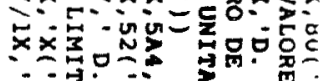

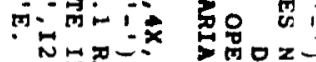

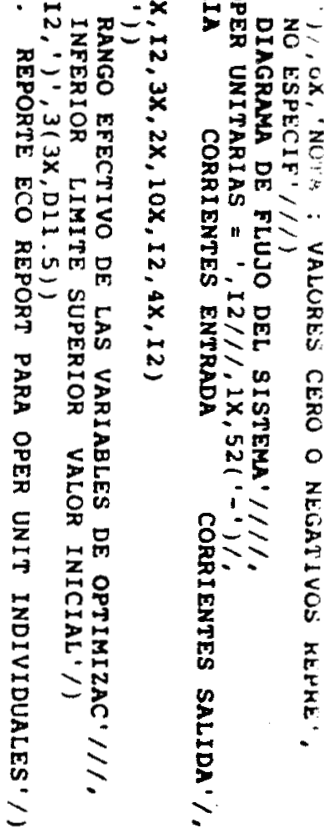



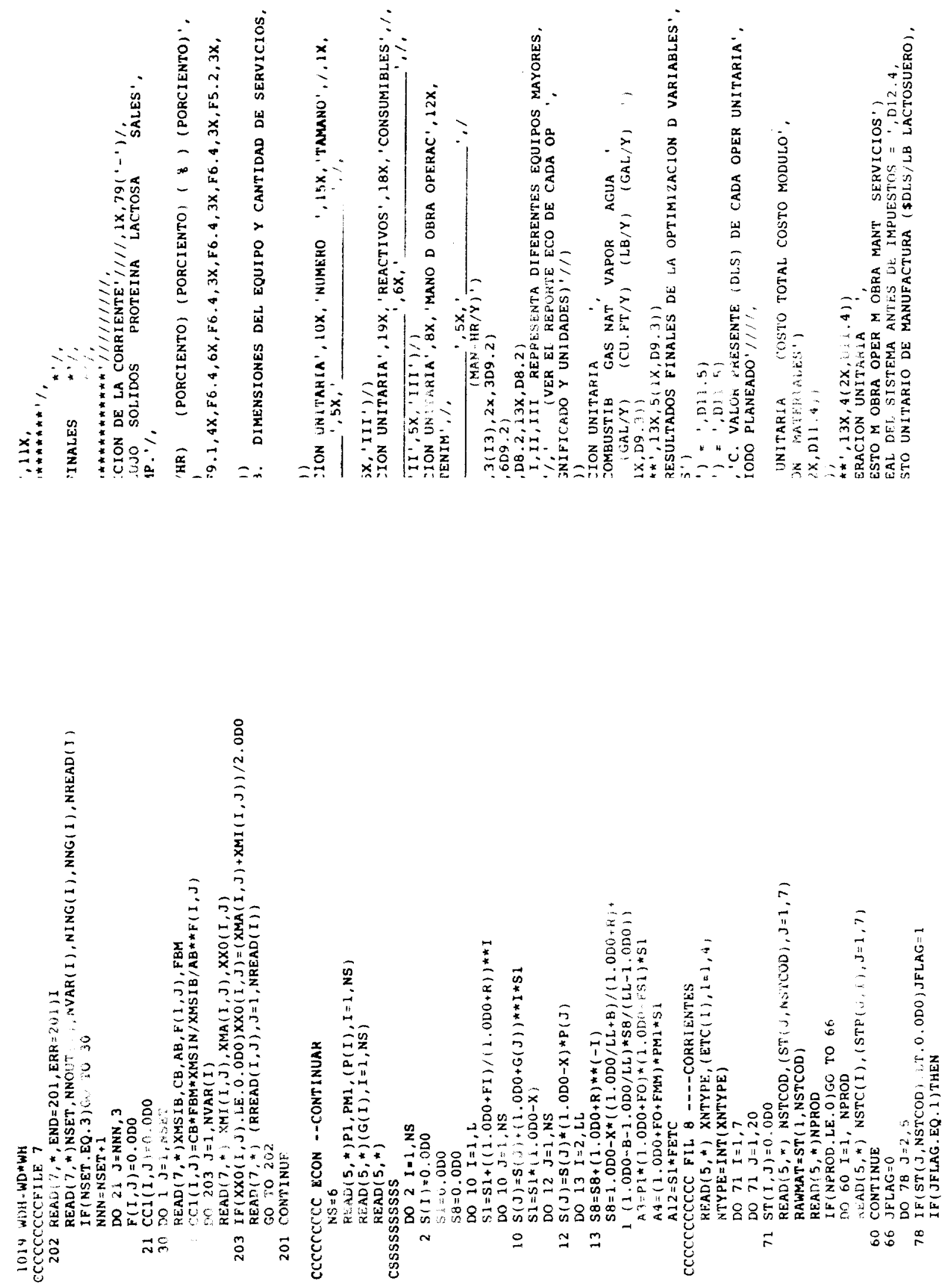


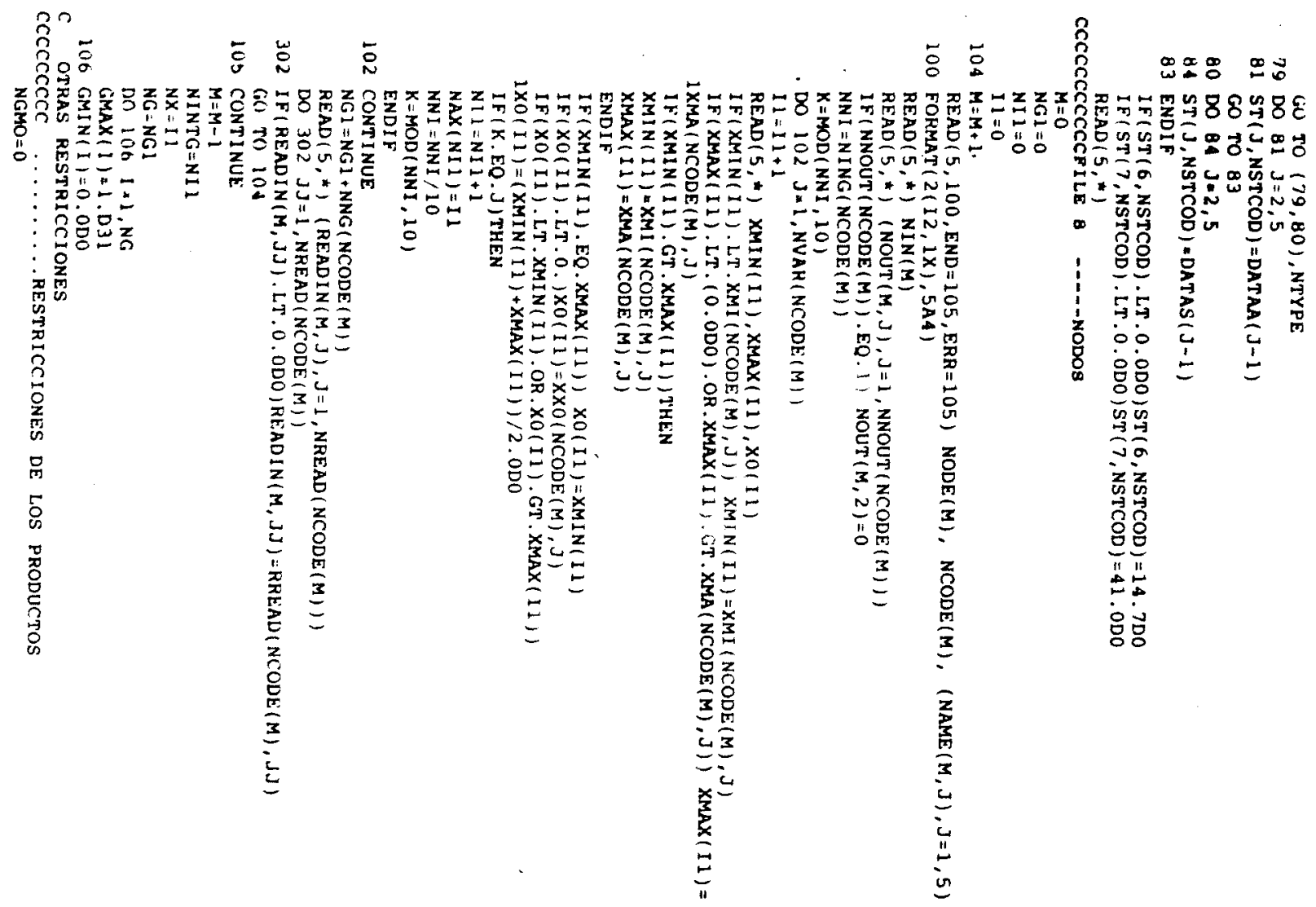

ธิ

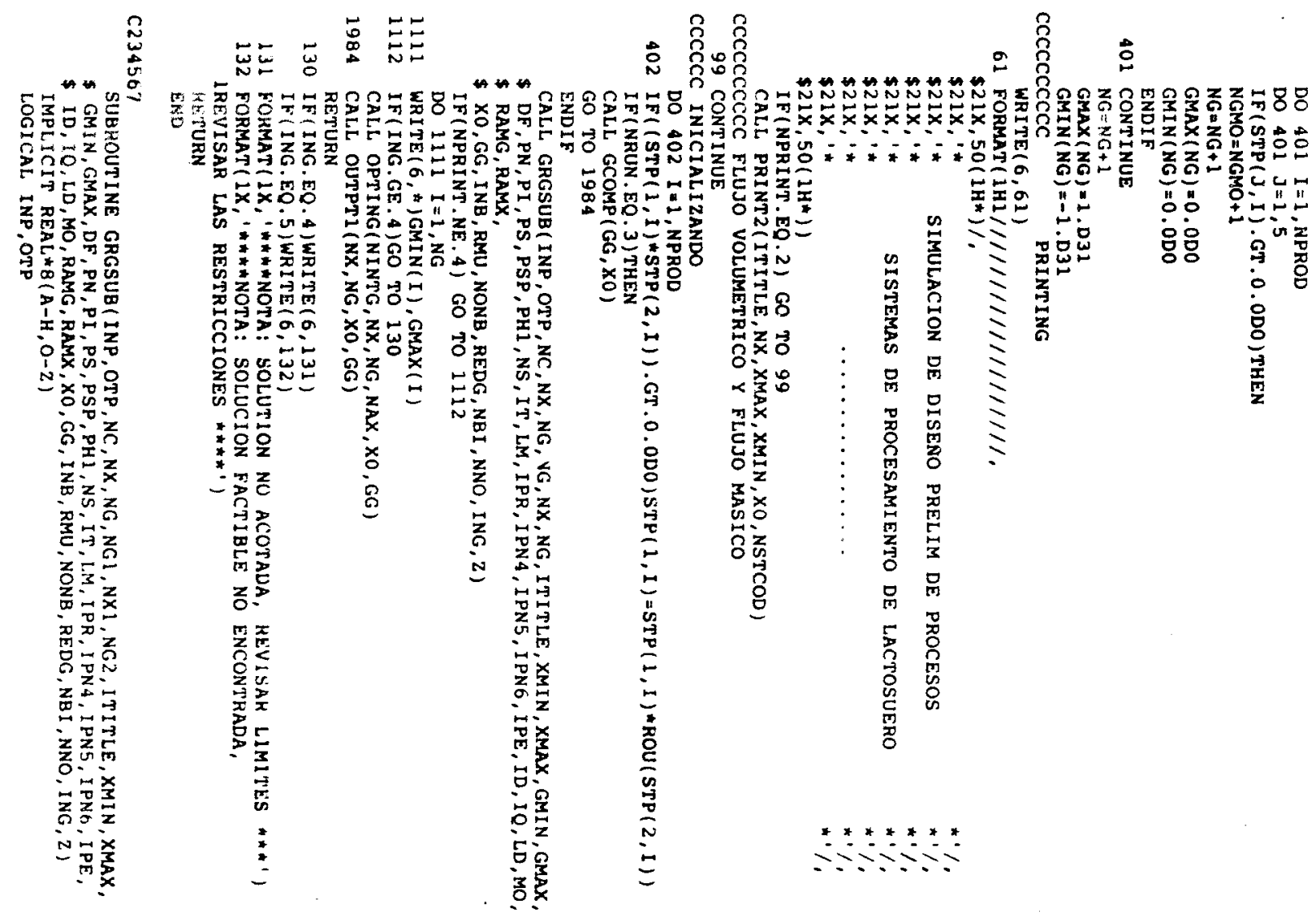



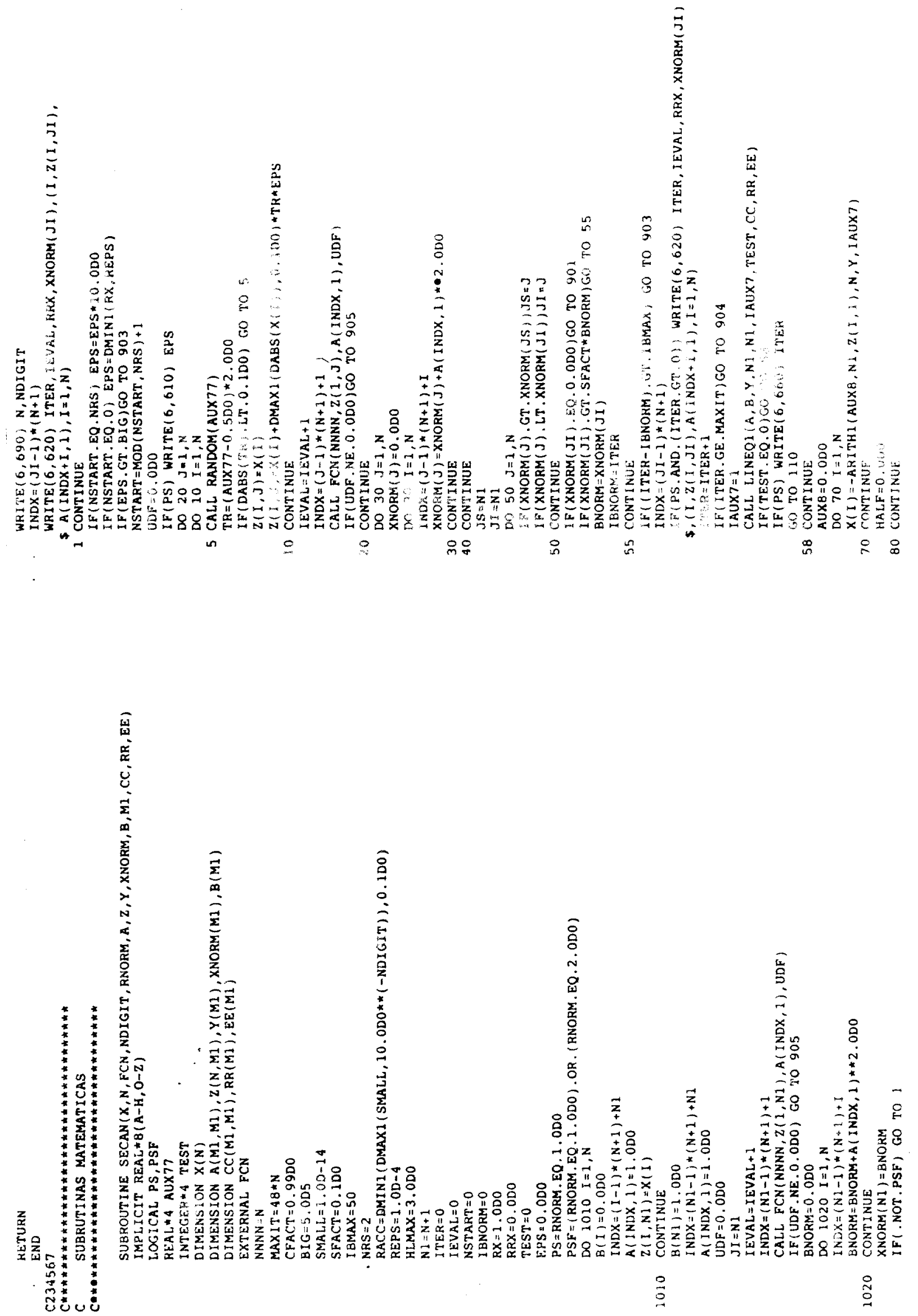

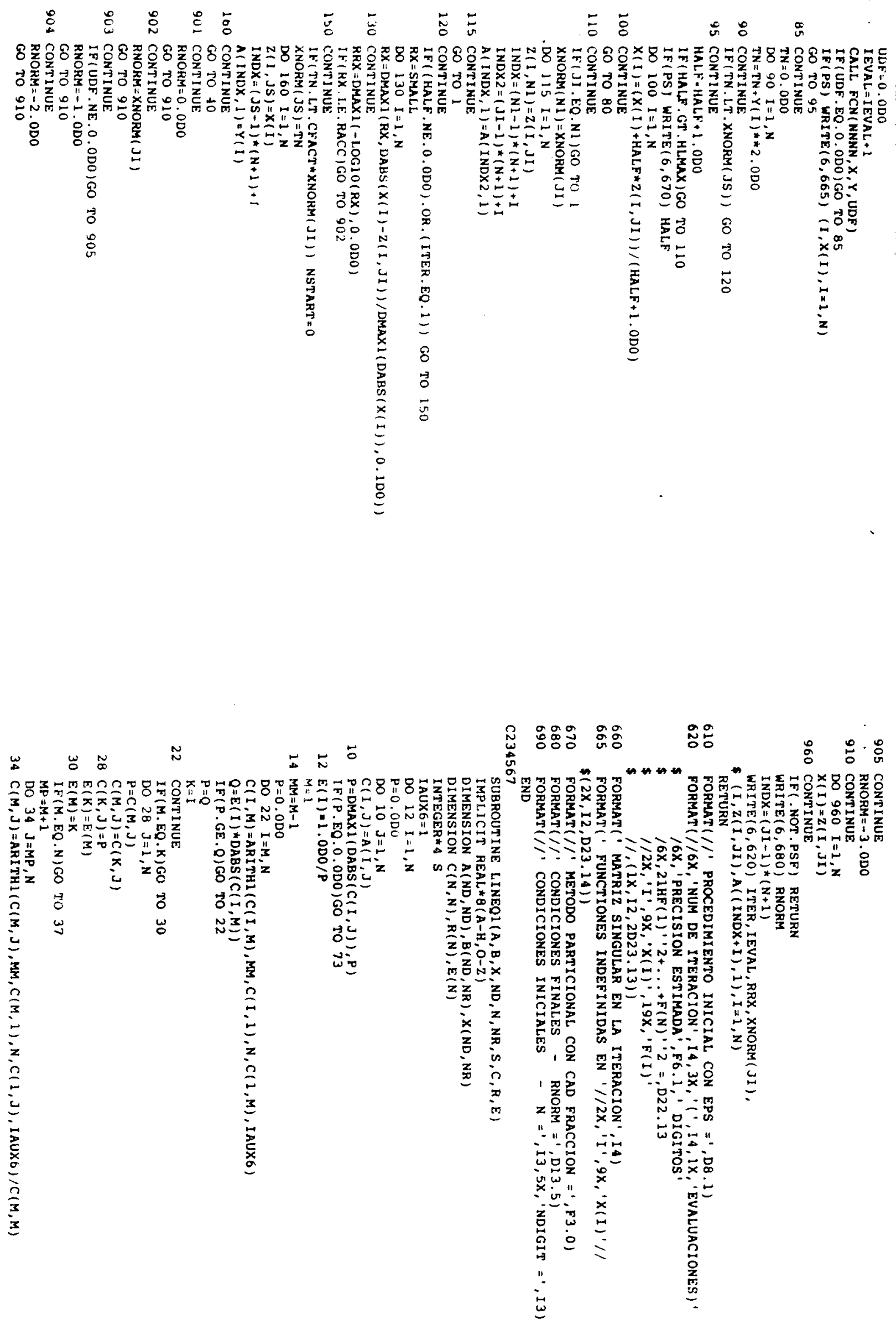


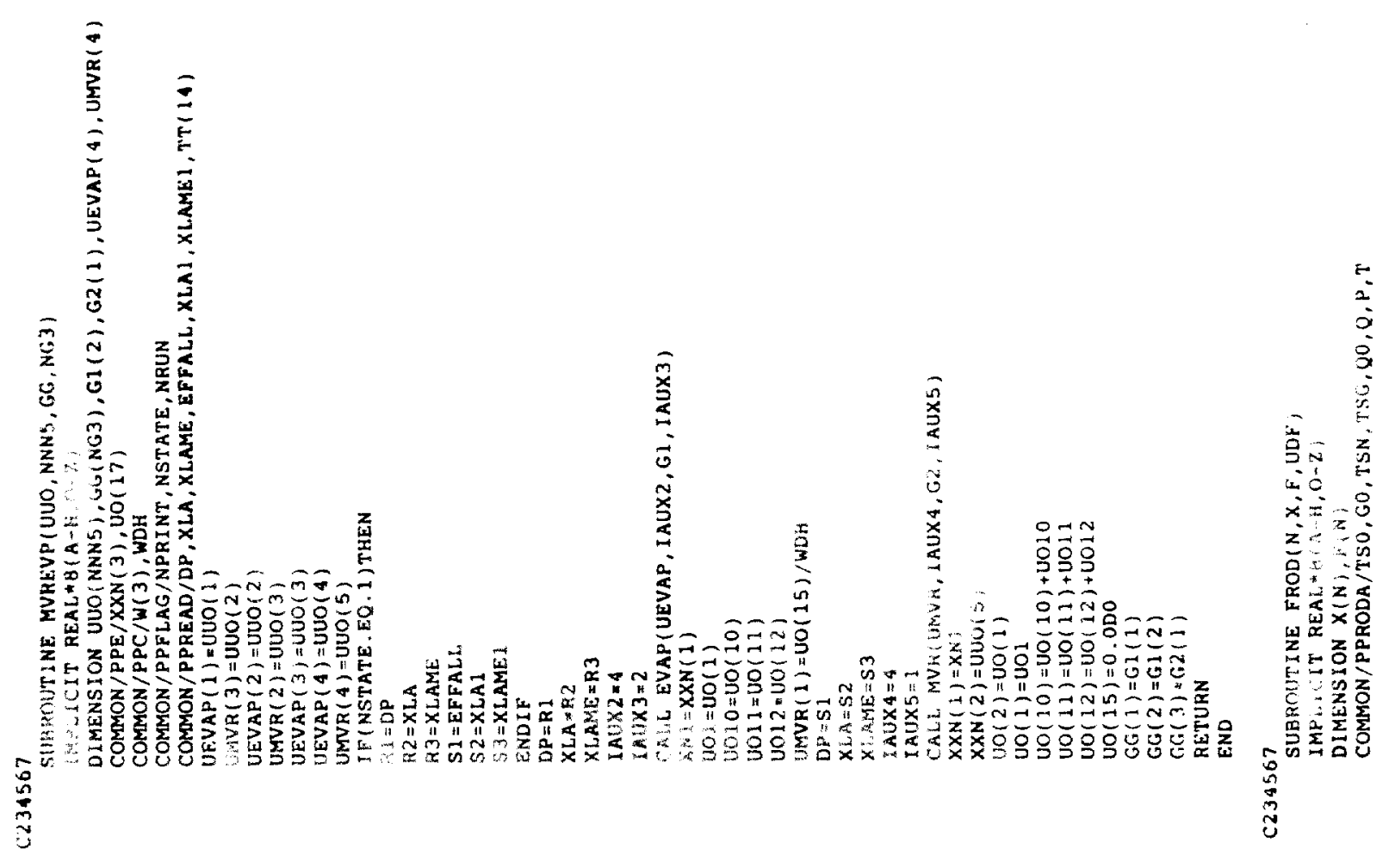

$\cong$

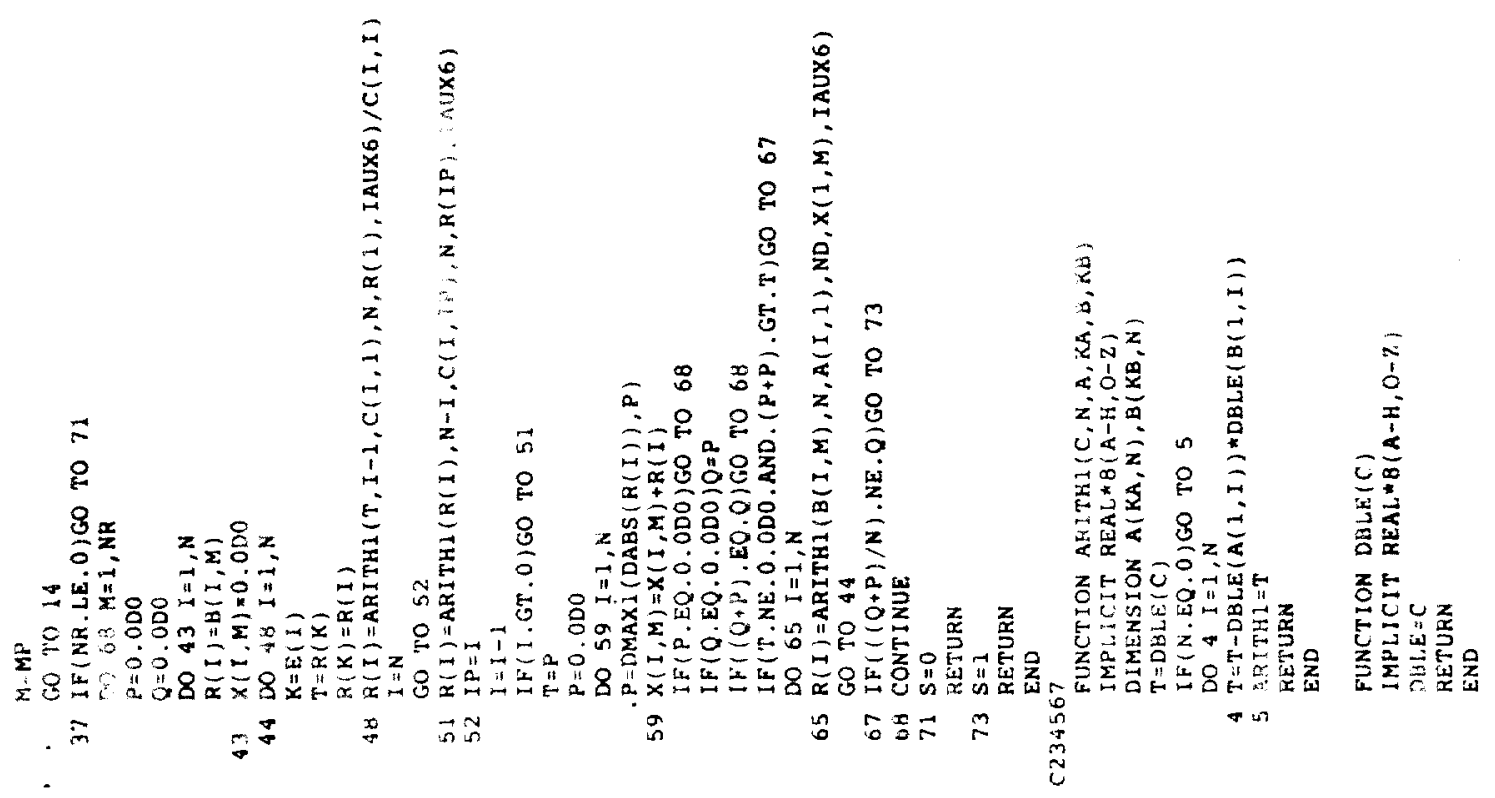



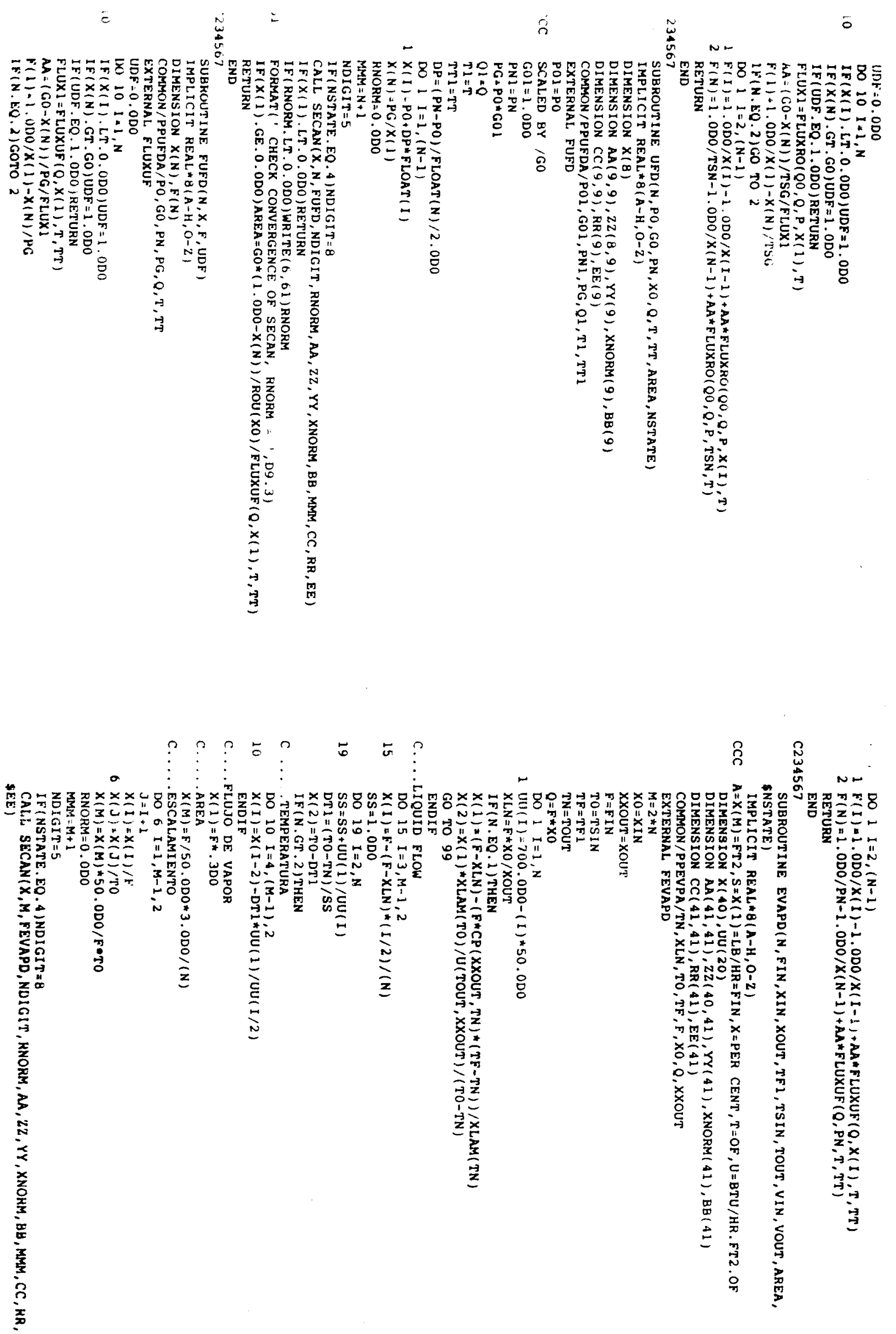

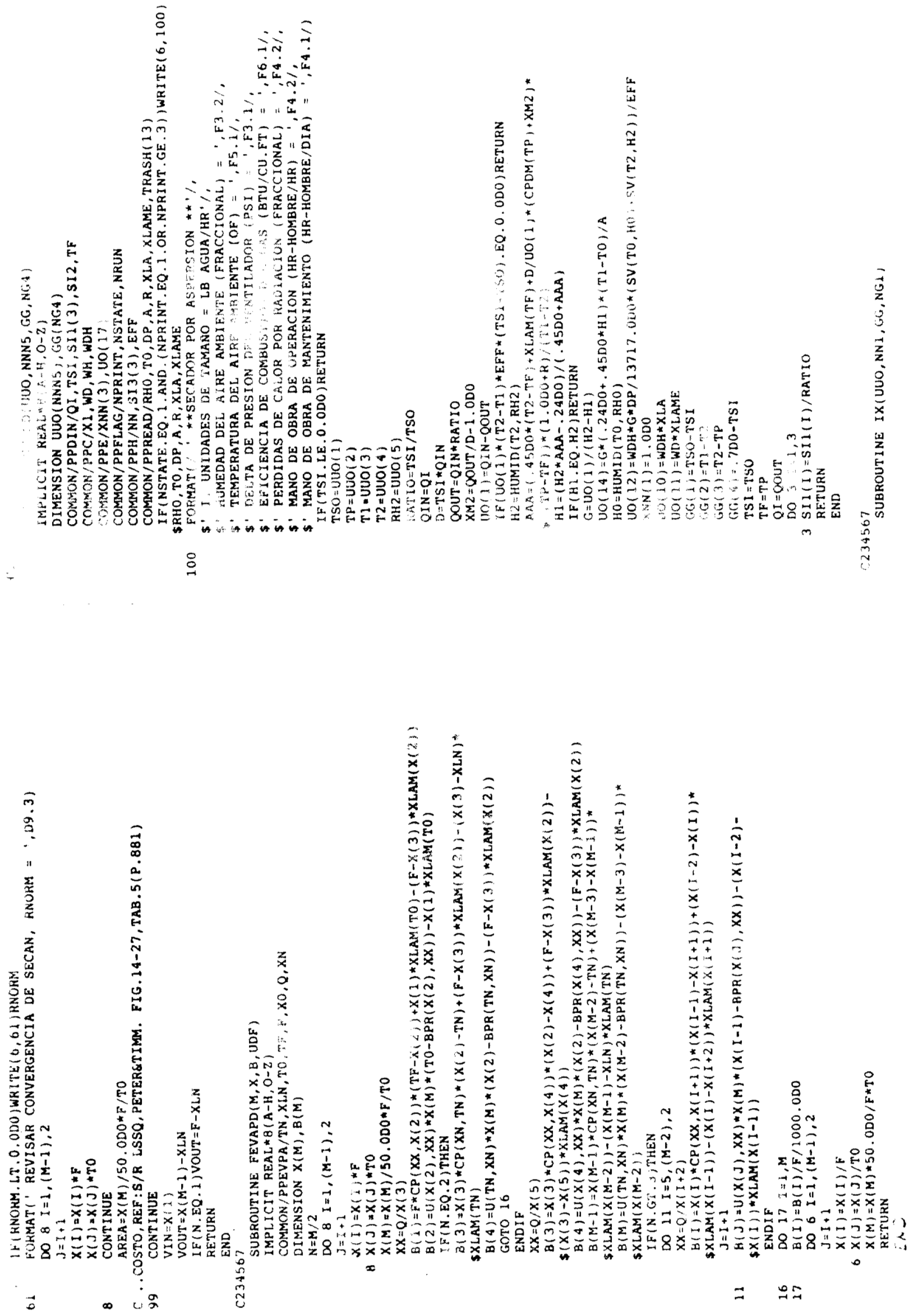

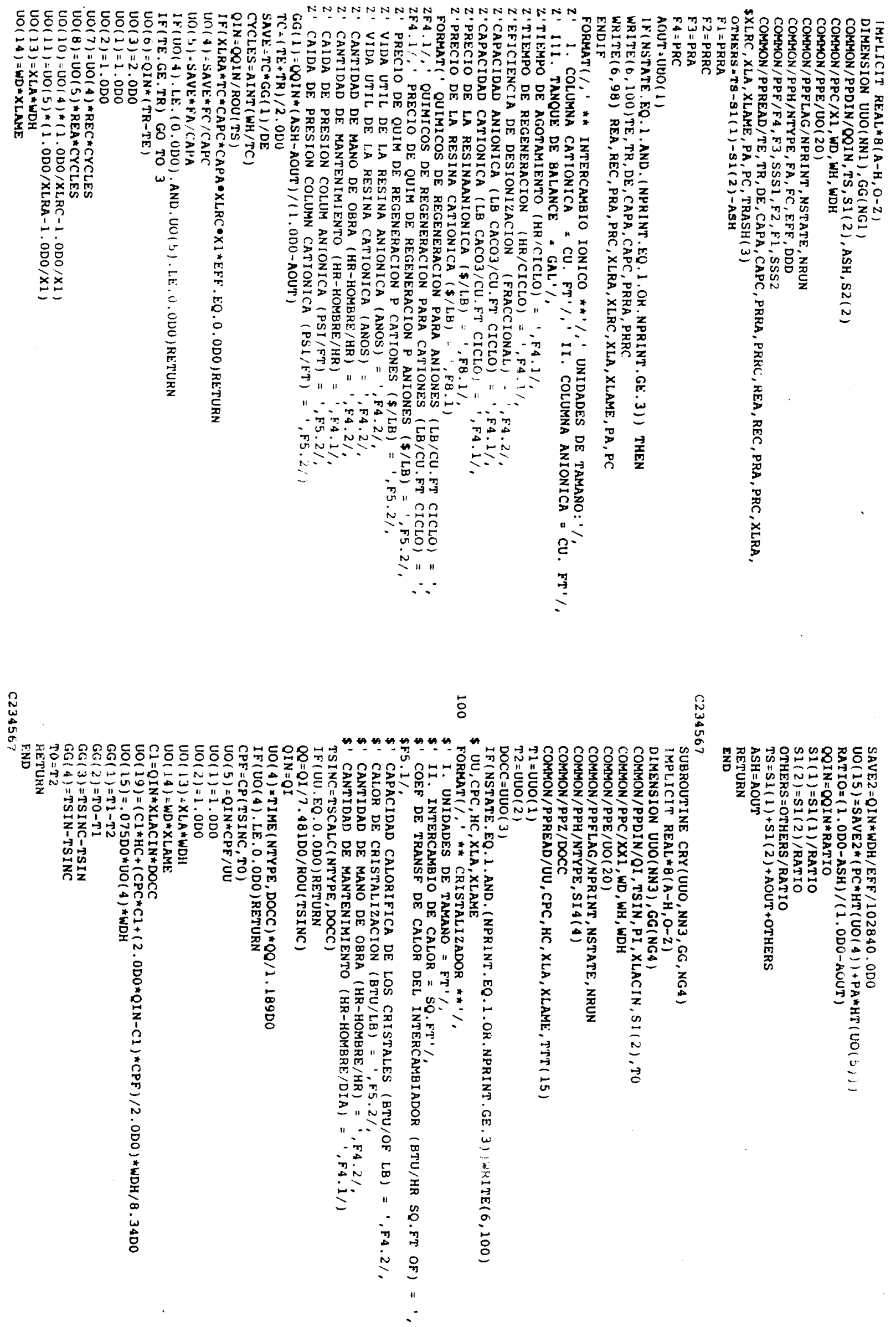

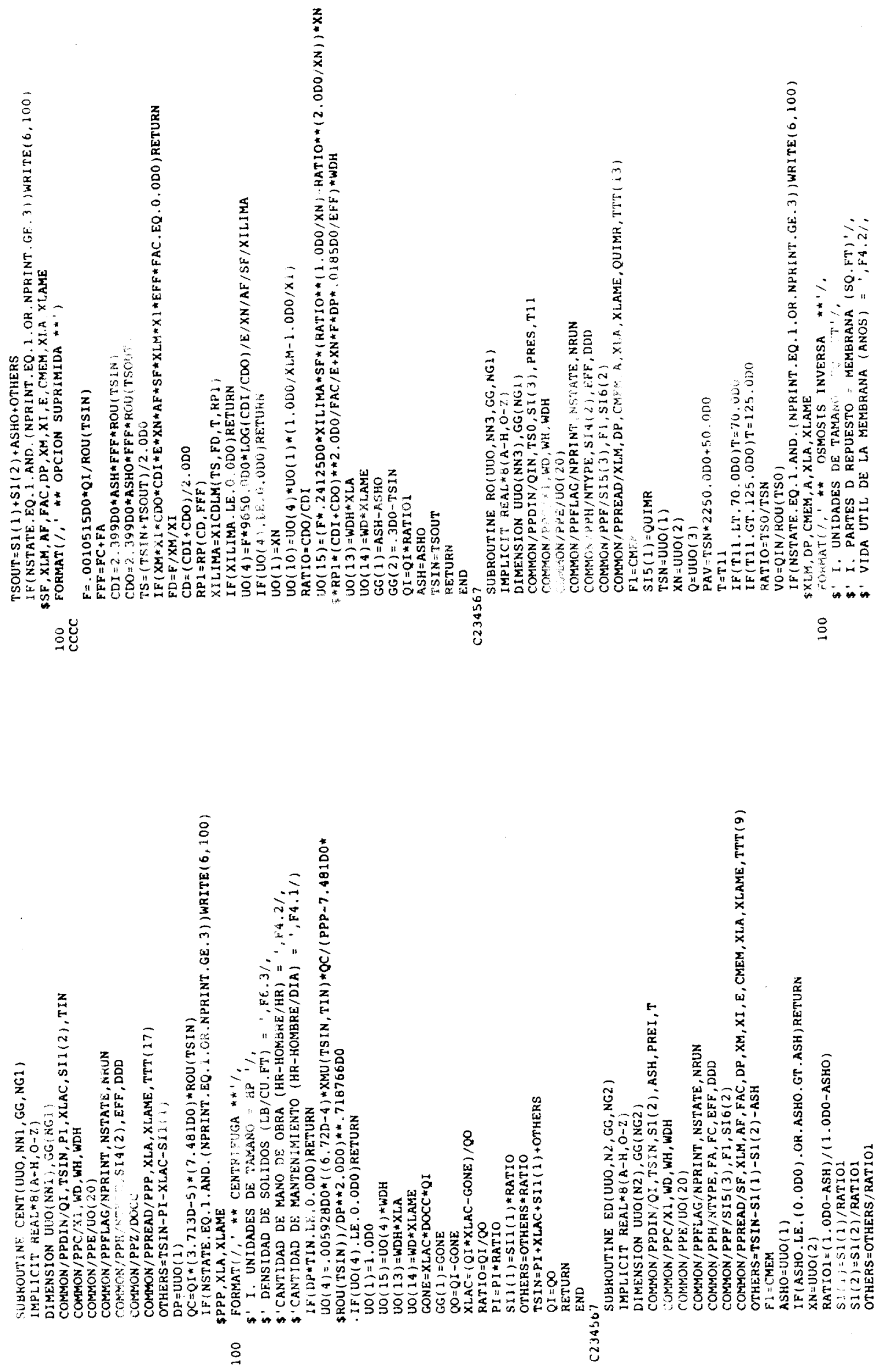

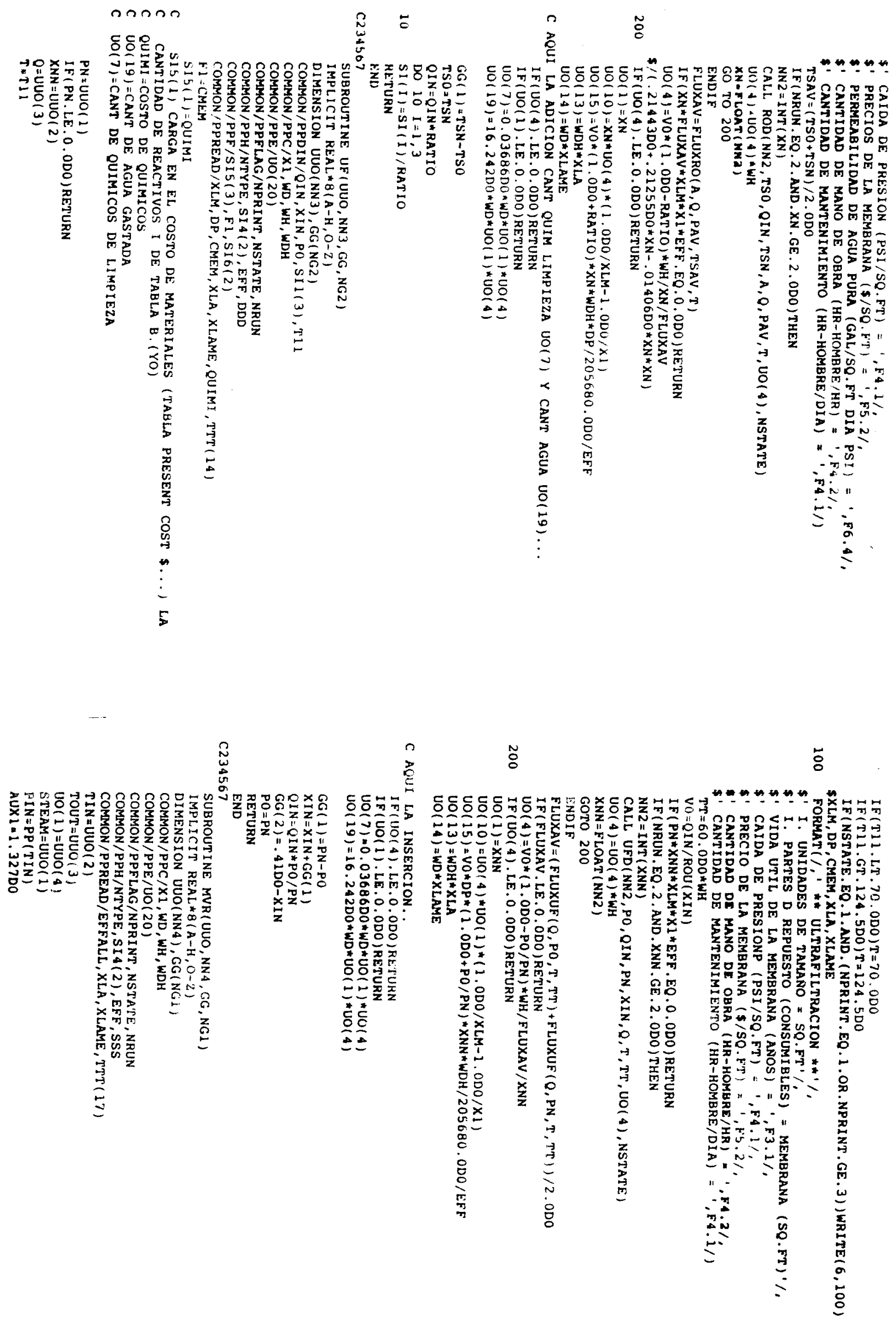

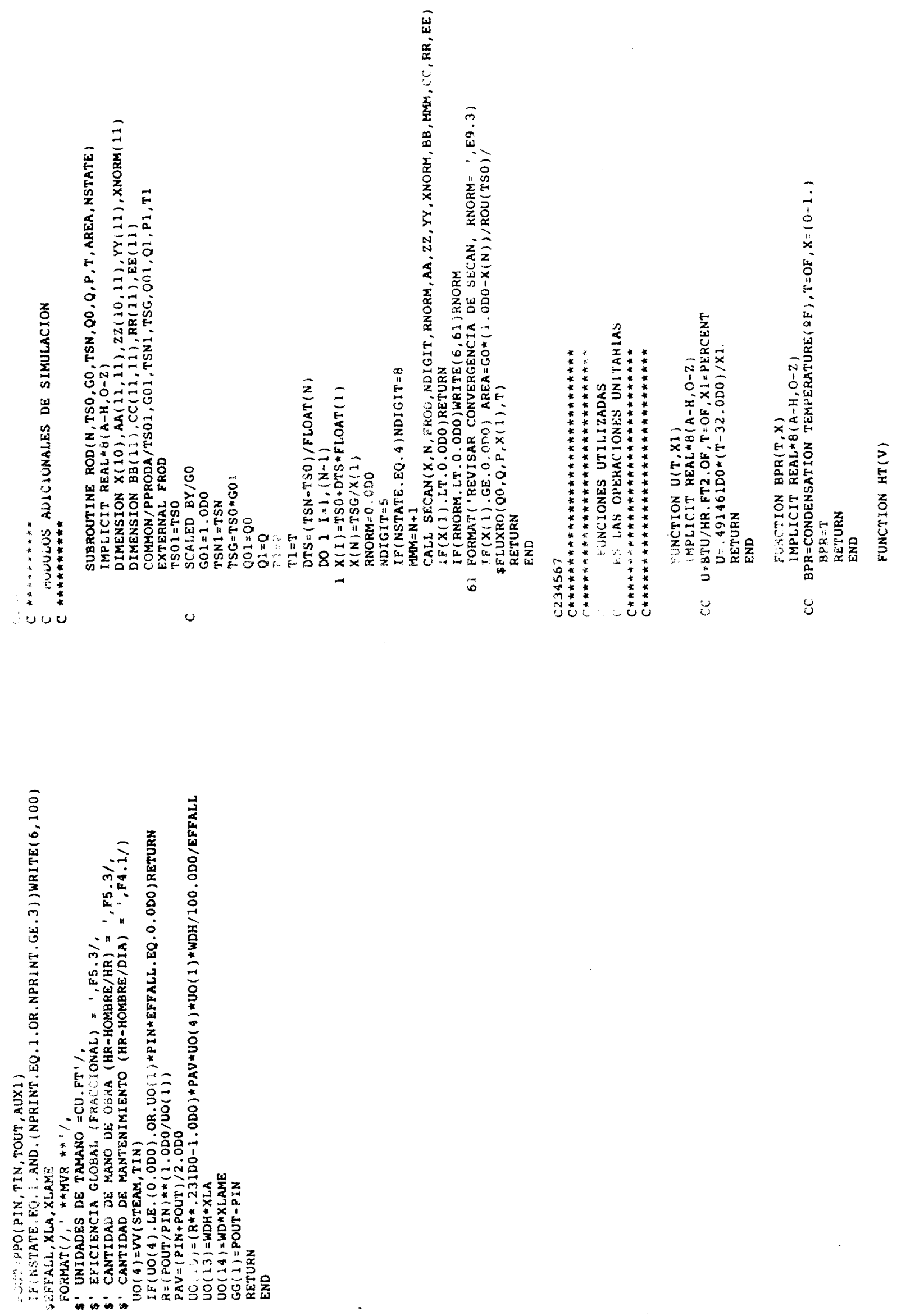

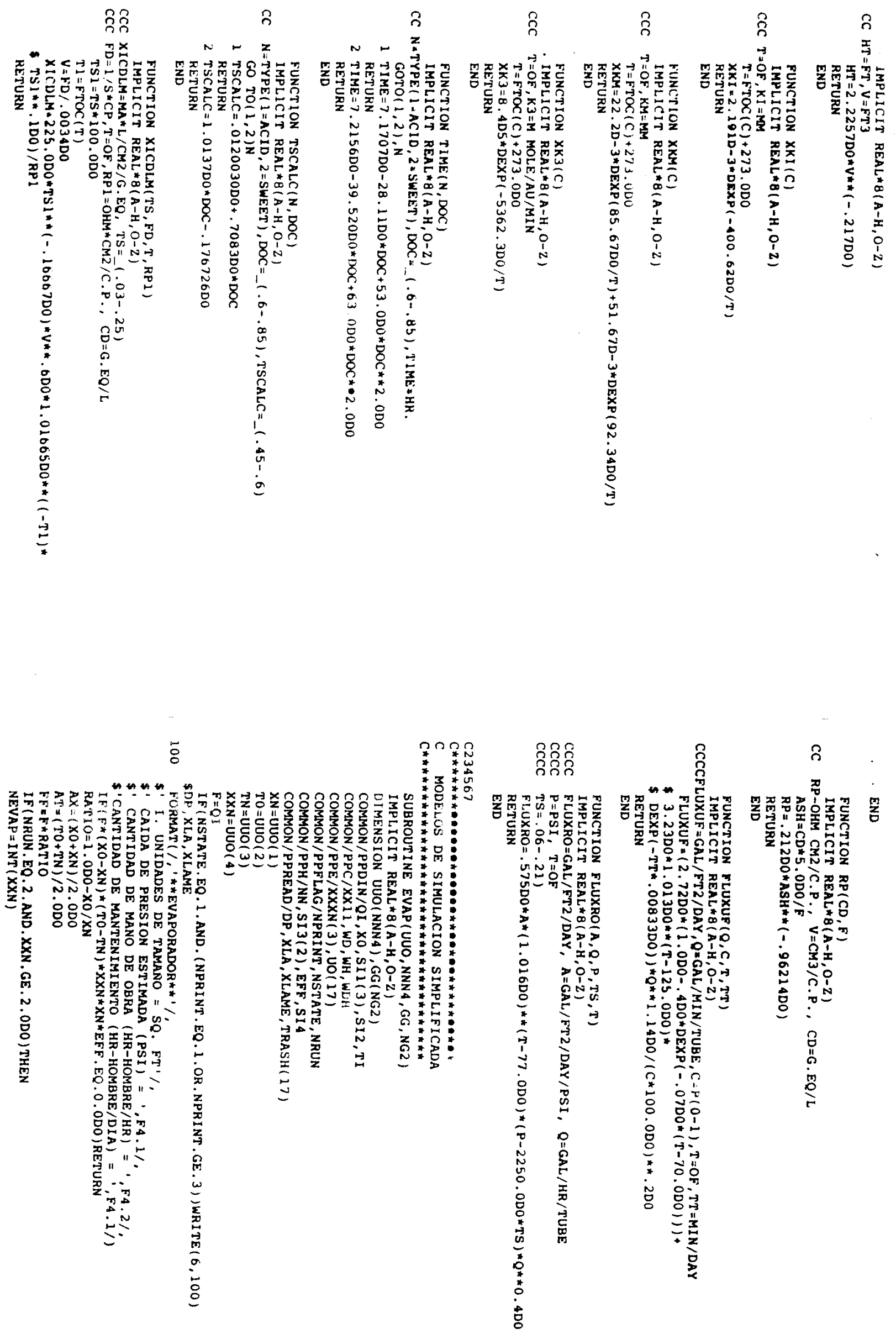


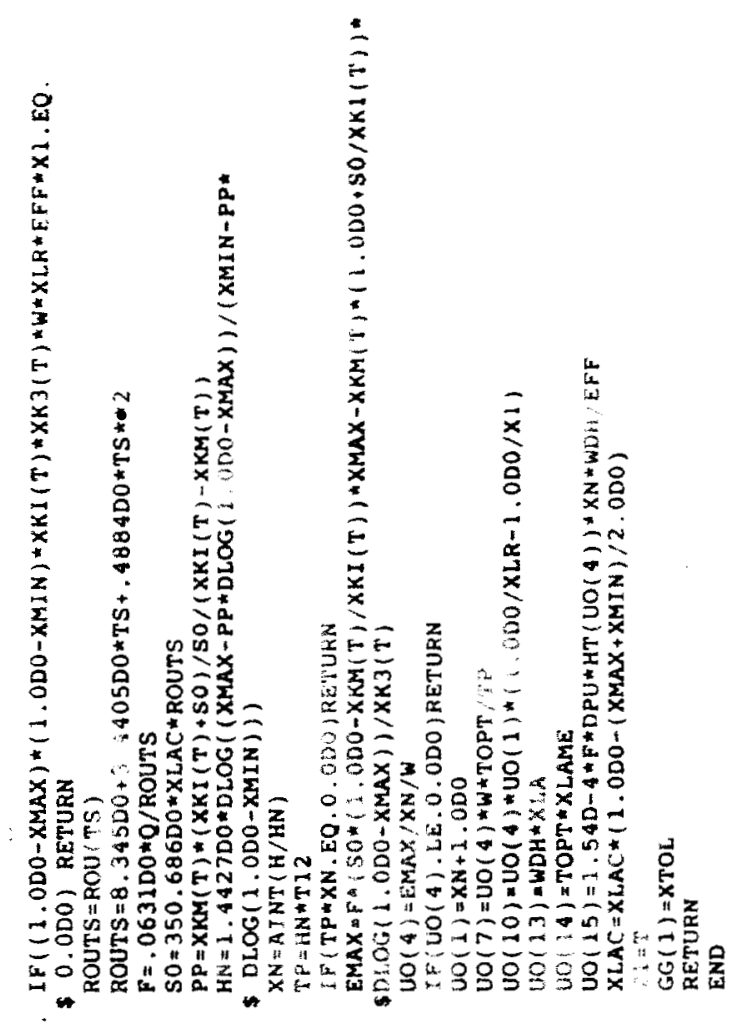

u

요
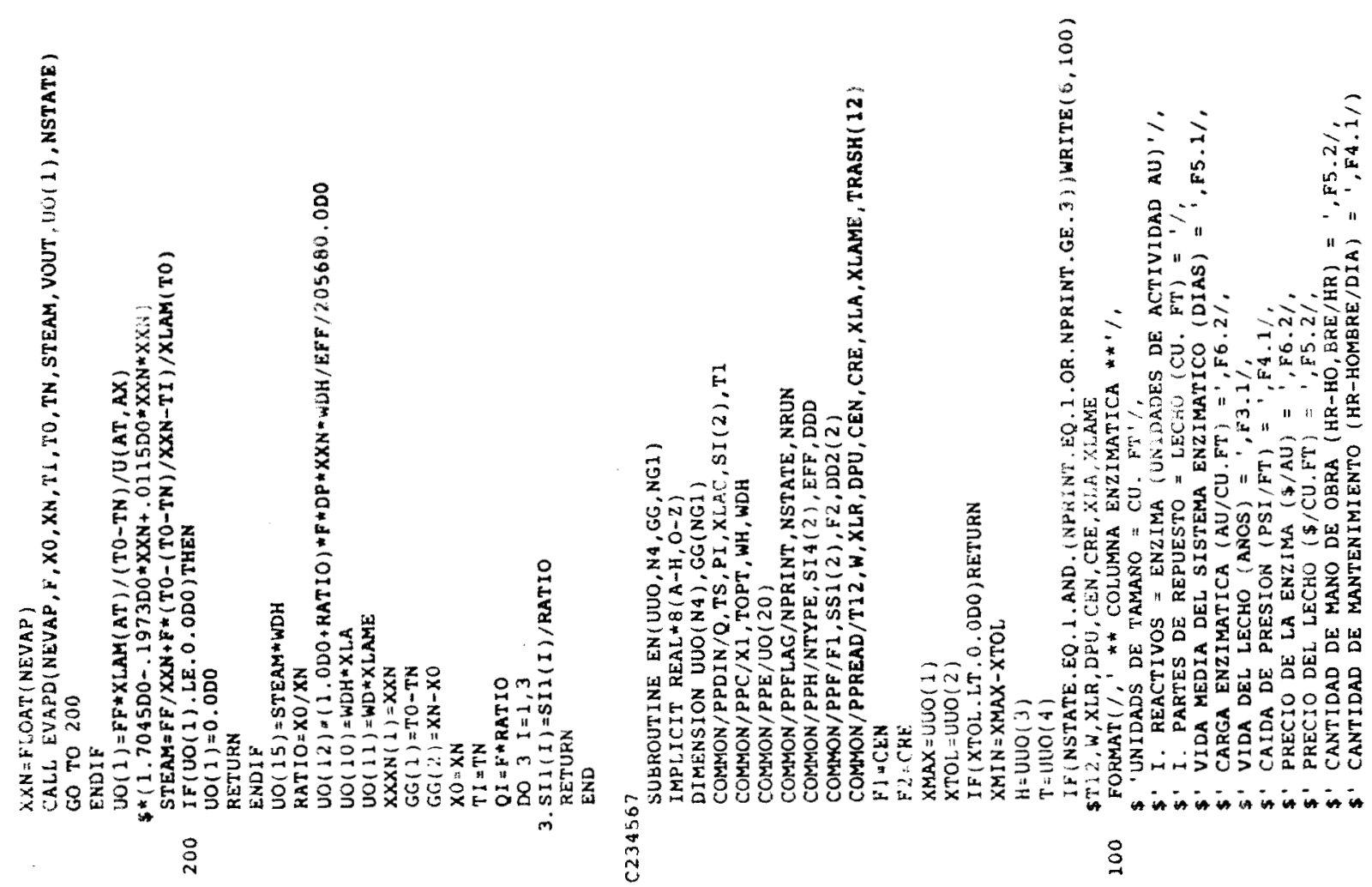

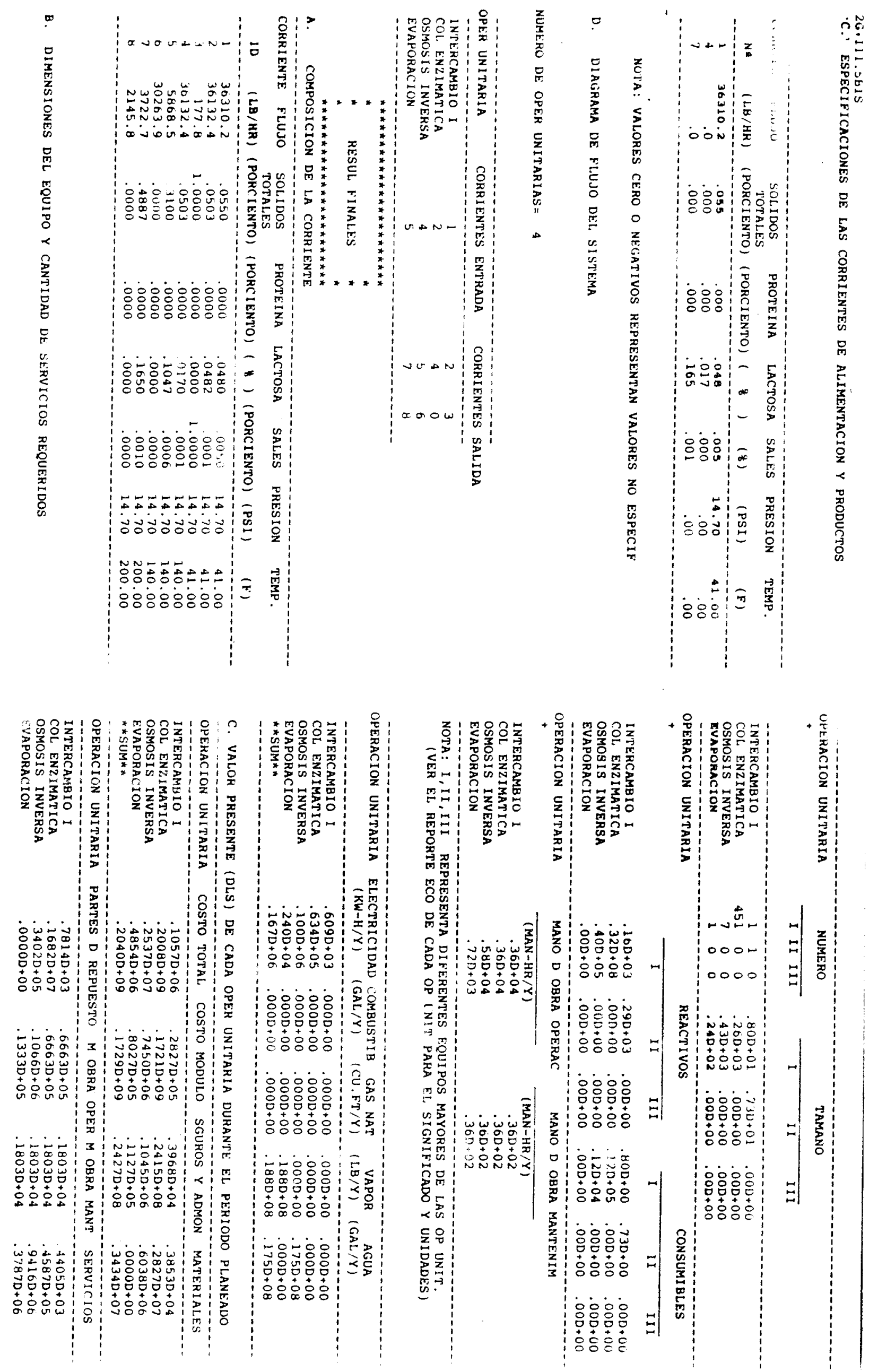
N

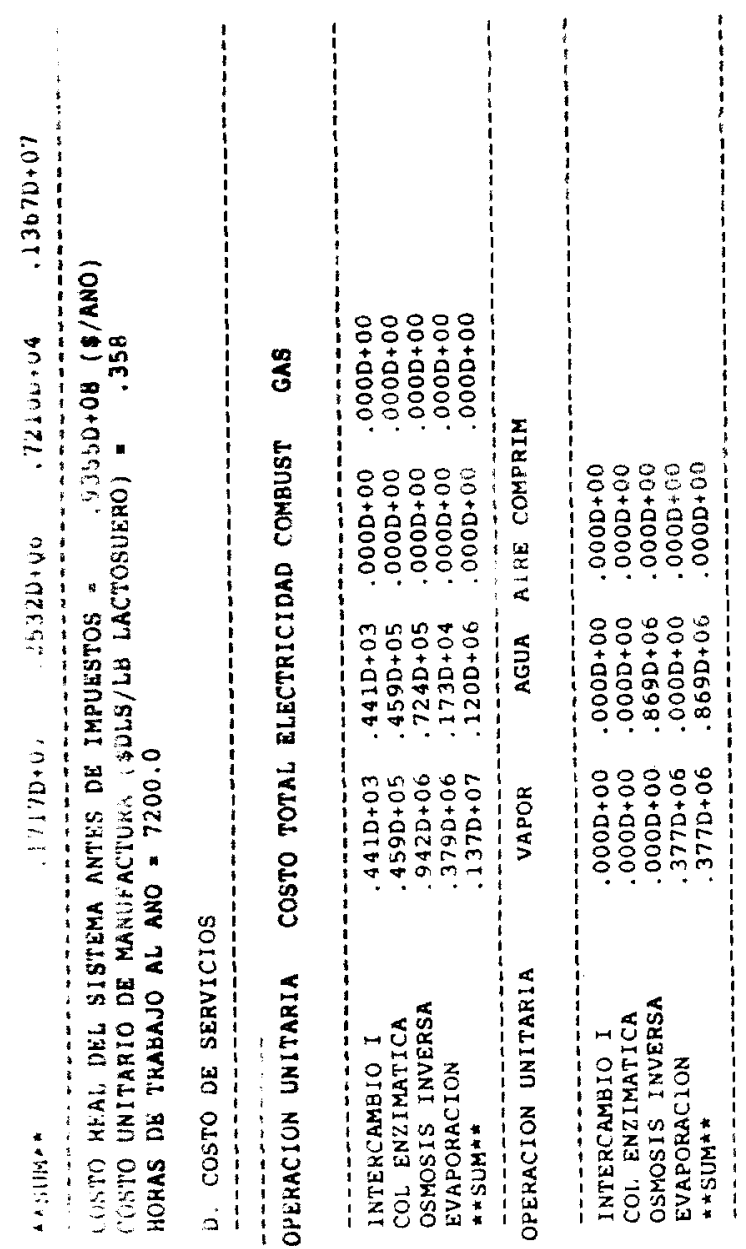



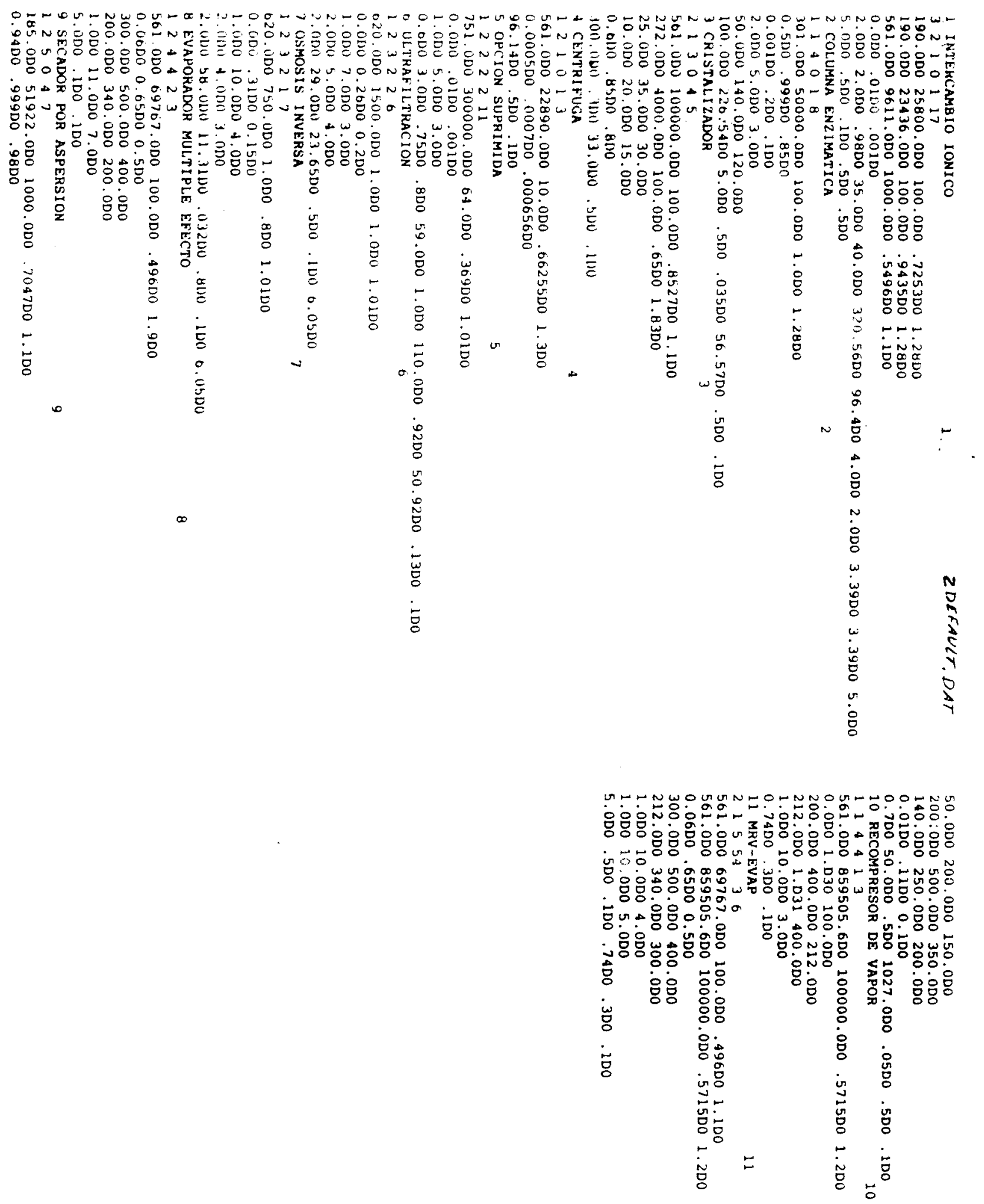

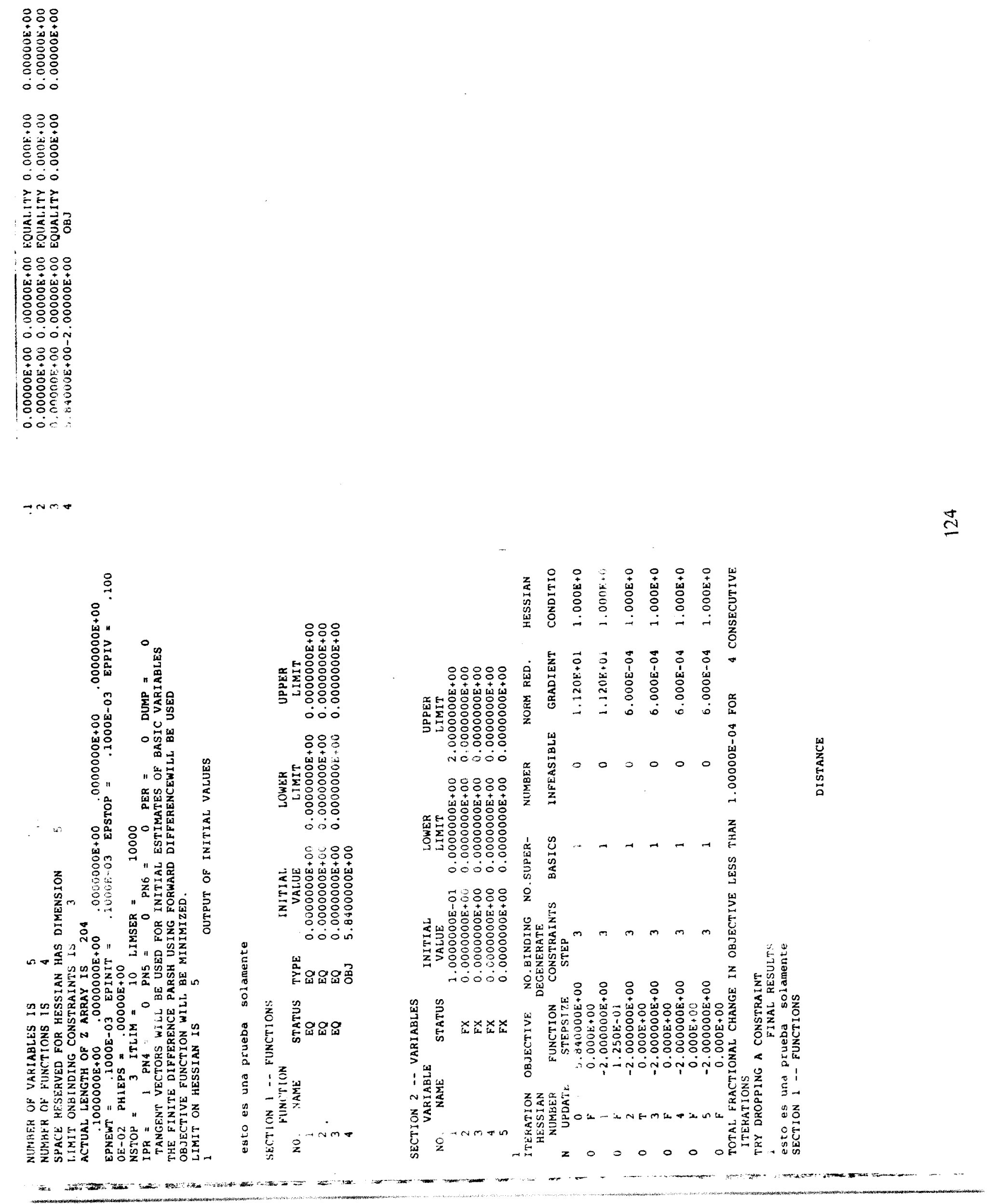


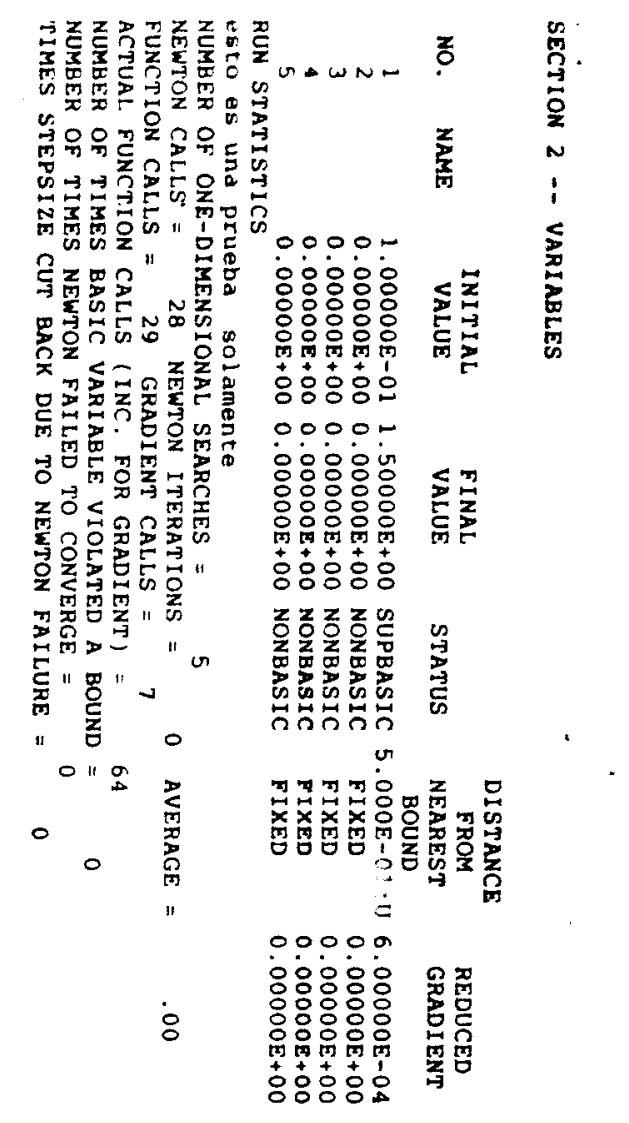



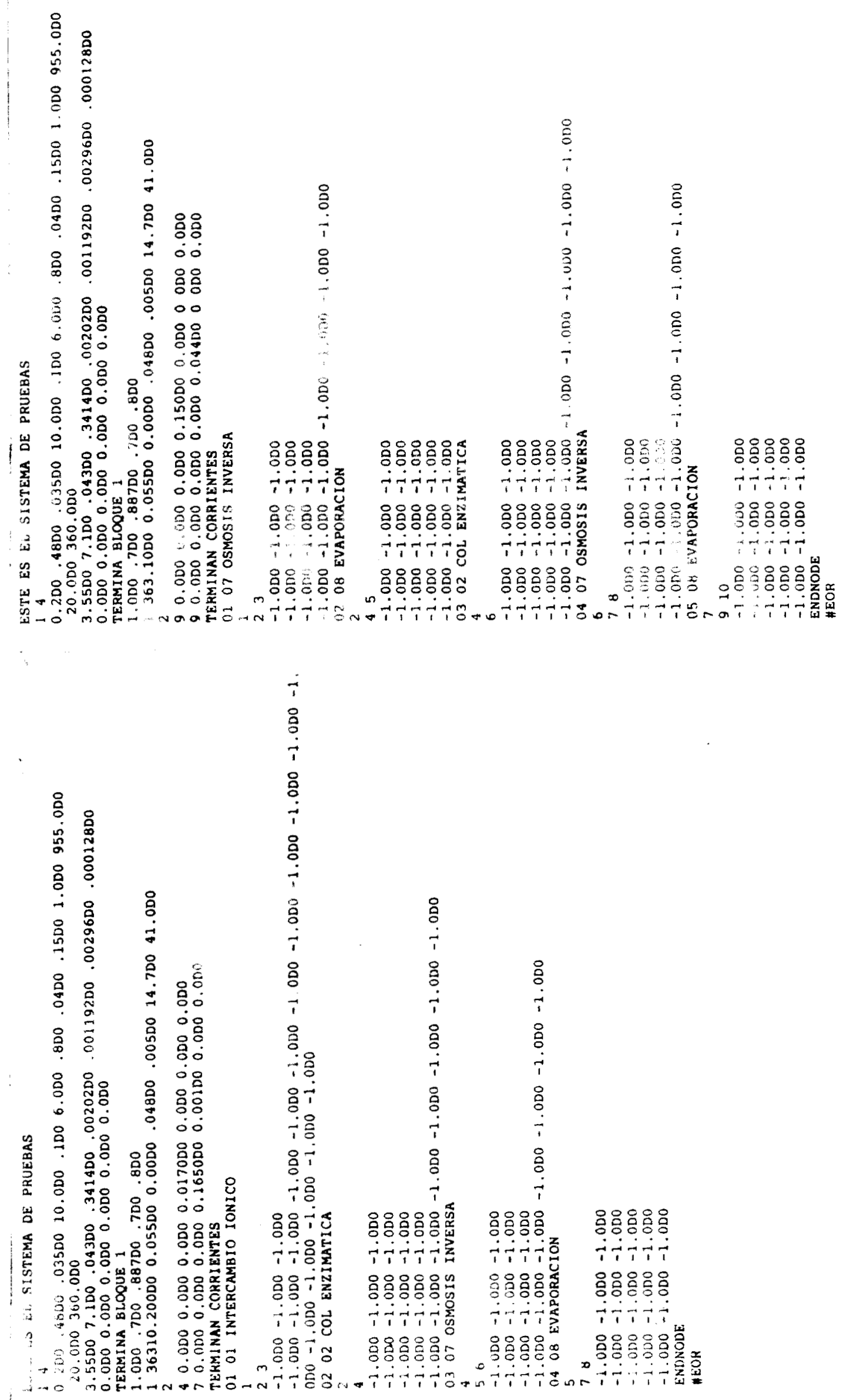


\section{APENDICE B}

\section{RESULTADOS DE LAS CORRIDAS DHI SIMULADOR DEL APENDICE A}

Este apéndice contiene los resultados de las simulaciones realizadas en el Capítulo 4. la información se presenta en tres partes:

En la denominada "HOJA 1", se identifica el númer del proceso simulado de acuerdo con la clasificación de la tabla 4-5 del Capítulo 4. Se describen las materias primas $y$ productos del proceso $y$ se da información suficiente para elaborar un diagrama de flujo del proceso, numerando las corrientes y presentando las operaciones unitaria involucradas. También se presentan las corrientes cuya composición fué establecida como fija antes de la simulación.

En la denominada "HOJA 2", se presenta para cada proceso y en cada una de las escalas ensayadas, el número de unidades requeridas óptimamente de cada equipo y su tamaño. La información sobre tamaños debe leerse de acuerdo con la nomenclatura presentada en la tabla 4-6 del Capítulo 4.

En la denominada "HOJA 3", se presenta para cada proceso y escala, el costo anual de operación y la inversión necesaria en equipo de proceso; ambos en miles de nuevos pesos de 1993. Se presenta también la producción de producto principal en $\mathrm{lb} / \mathrm{hr}$ (sobre la base de 20 horas por día, y 360 días por año). Cuando se obtiene más de un producto, el de mayor precio unitario se reconoce como el producto principal. Es posible representar la producción completa en función clel producto principal como una corriente hipotética de éste, que es equivalente a la producción completa en términos de dinero. La corriente de producto principal equivalente se presenta también en la HOJA 3 de este apéndice, para cada escala de proceso. 
Para mantener la información en la forma más compacta posible, se presentan en bloque primero todas las HOJAS 1, luego las HOJAS 2 y finalmente las HOJAS 3. Para evitar confusión, cada proceso considerado cuenta con un sólo número de tabla Por ejemplo, el proceso 17, está reportado en la tabla $\Lambda-3.1-17$, la cual está en tres partes. a primera parte en la página 132, la segunda en la página 140 y la tercera en la página 147. 

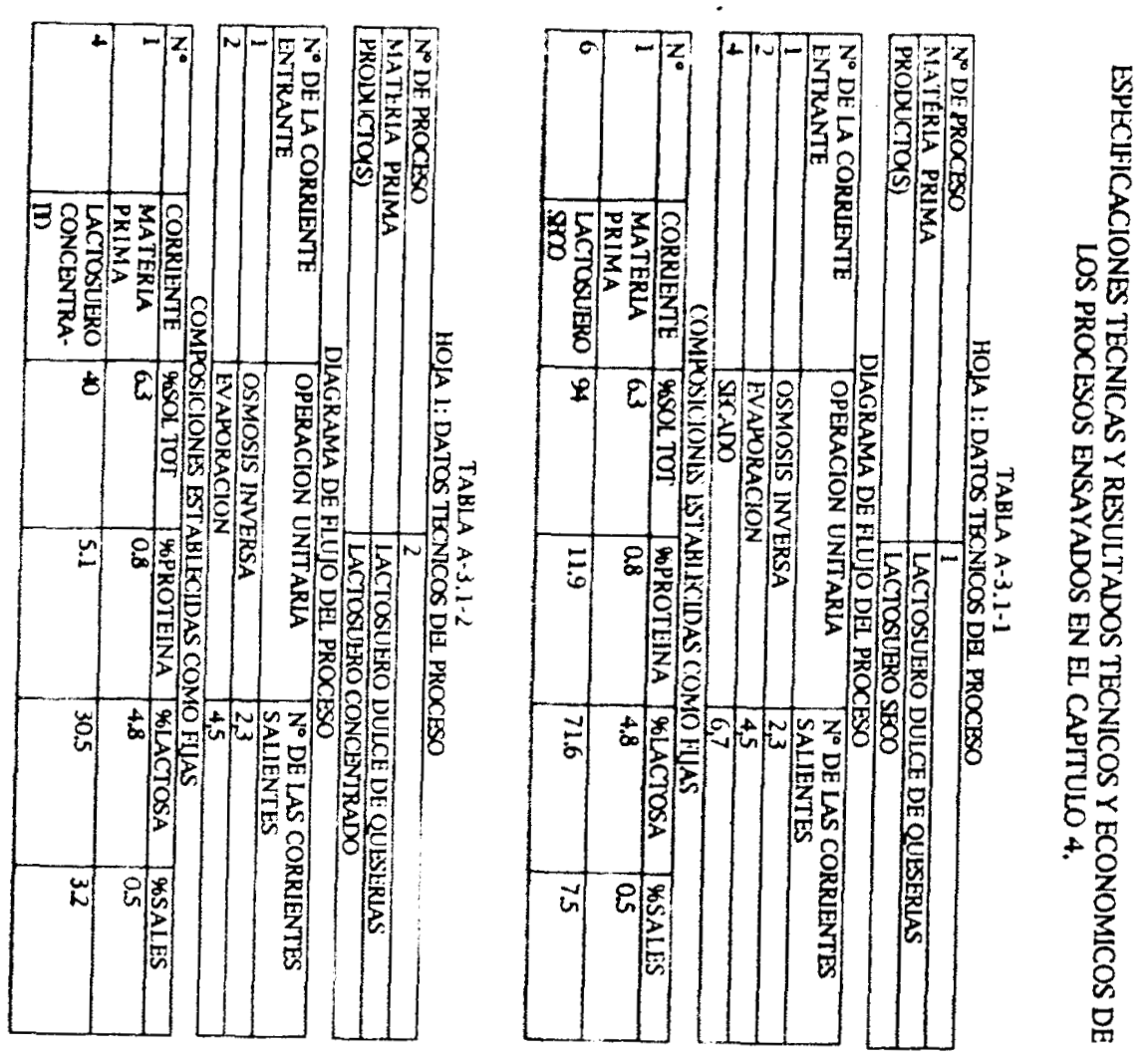

్ㅠ
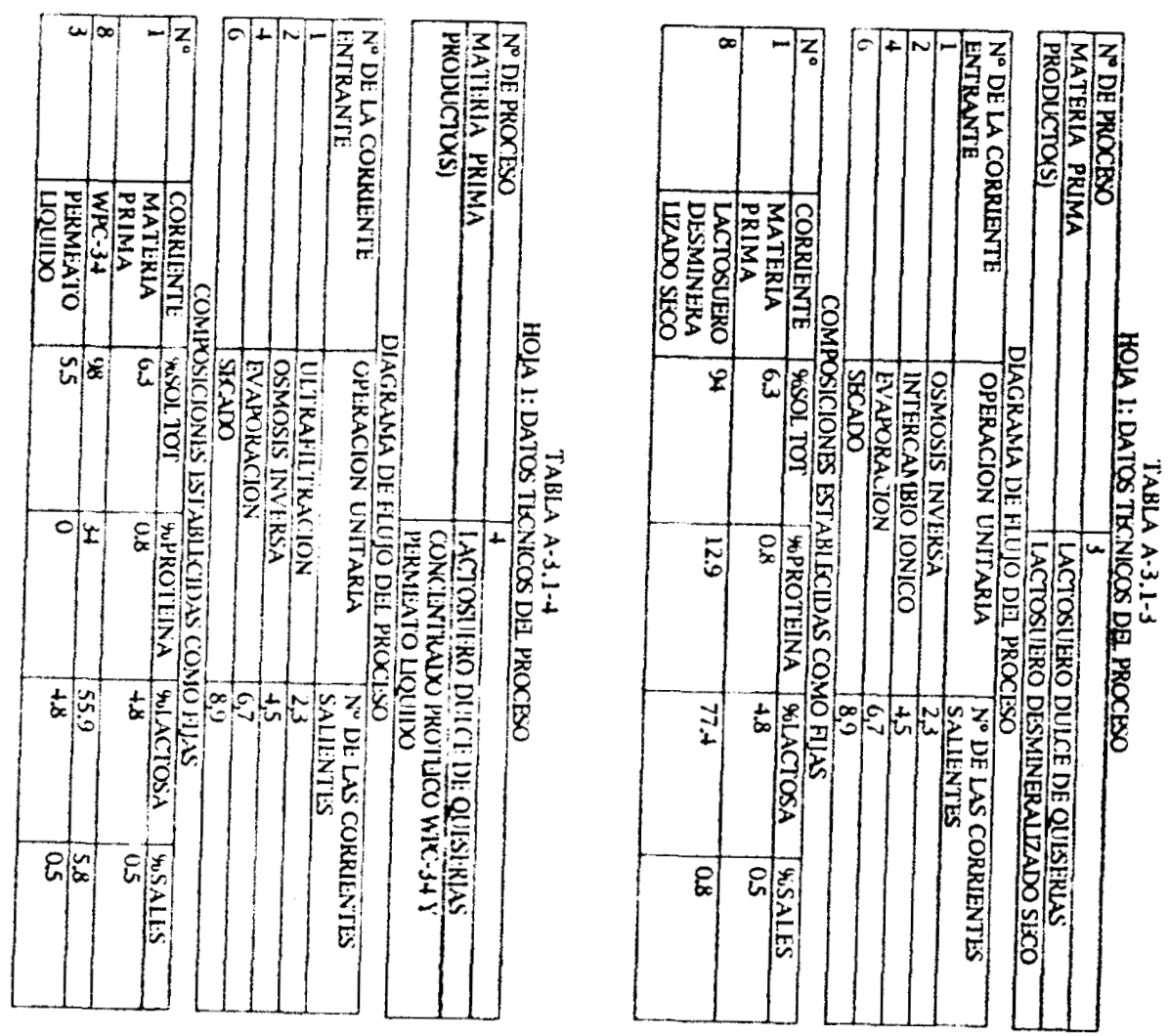

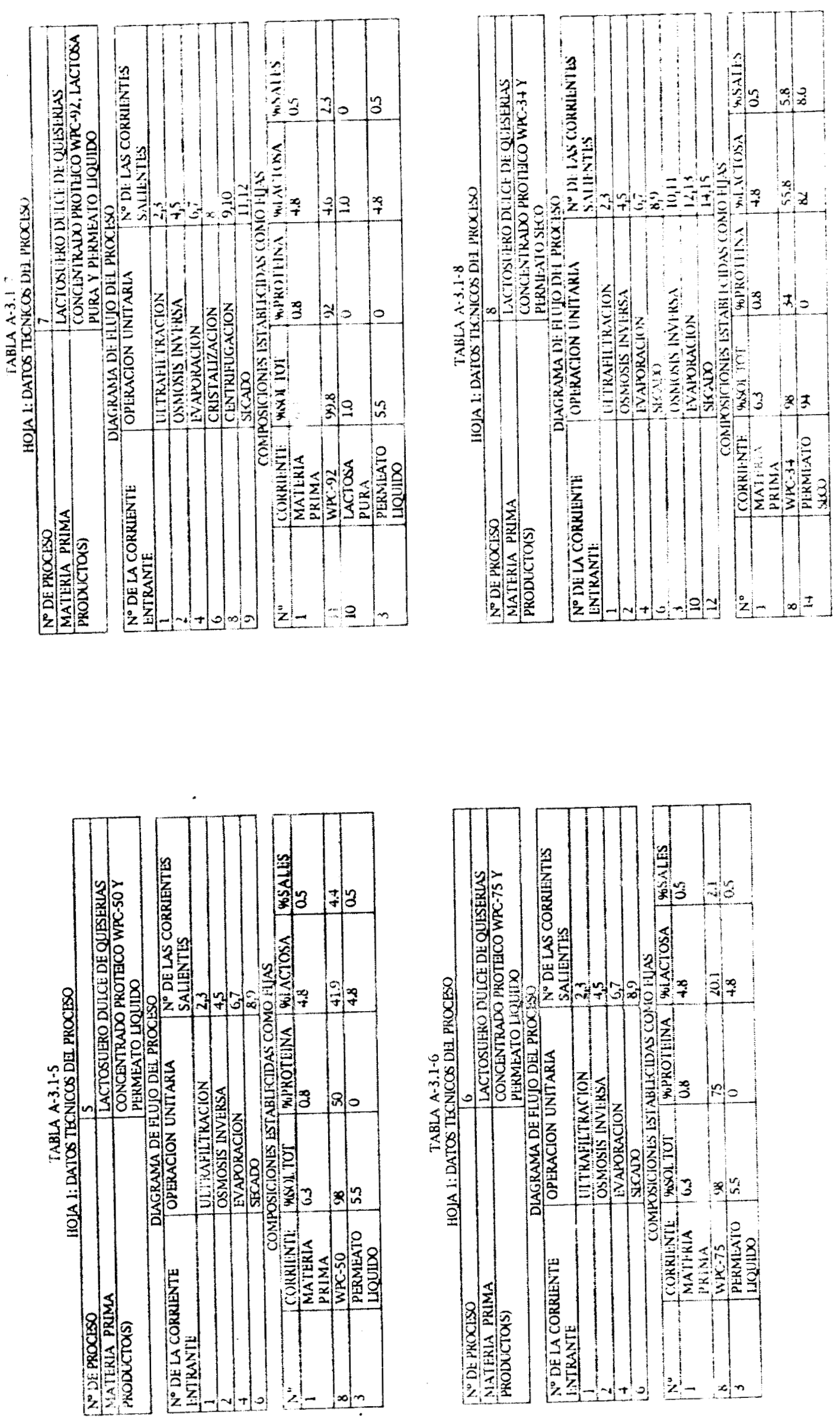

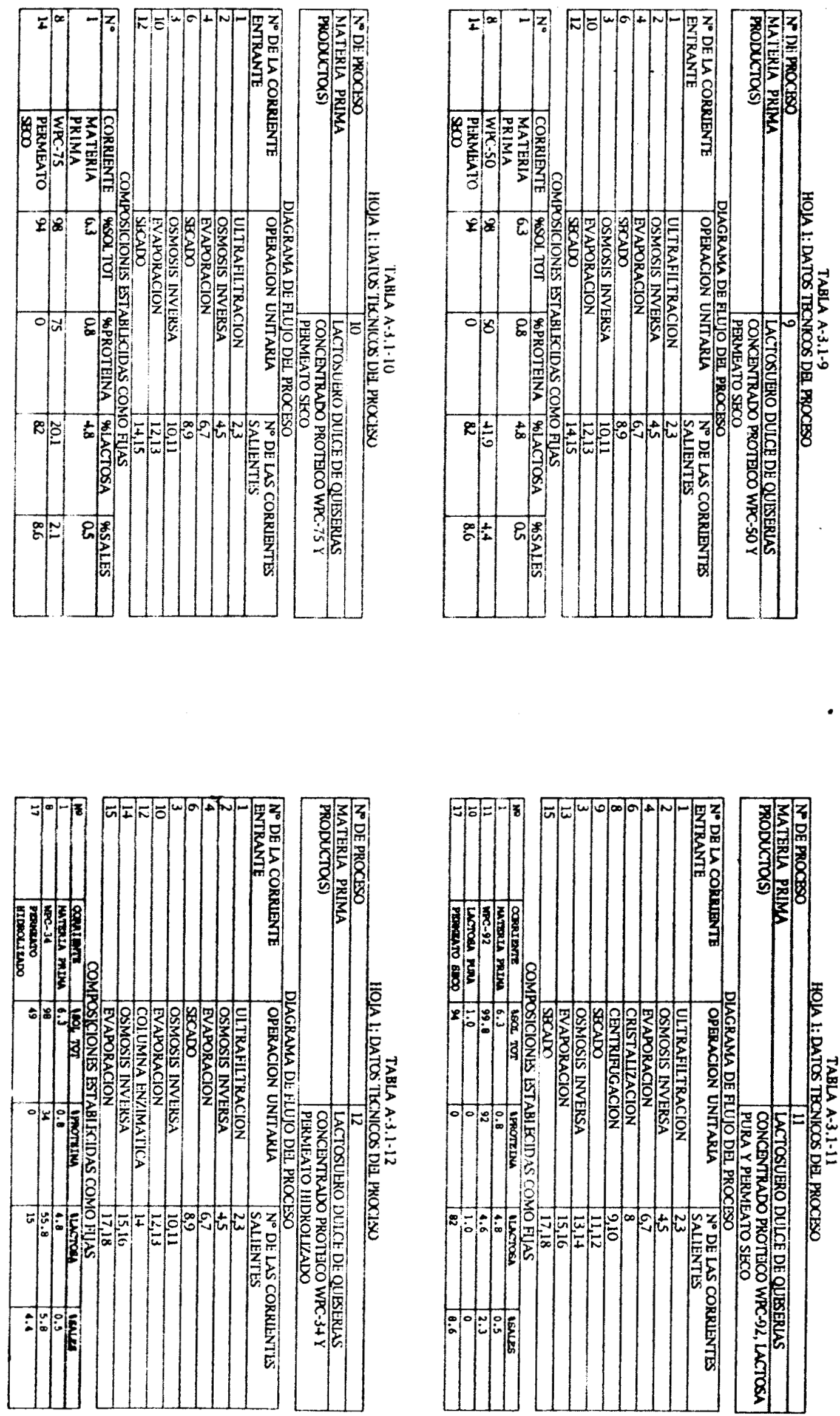

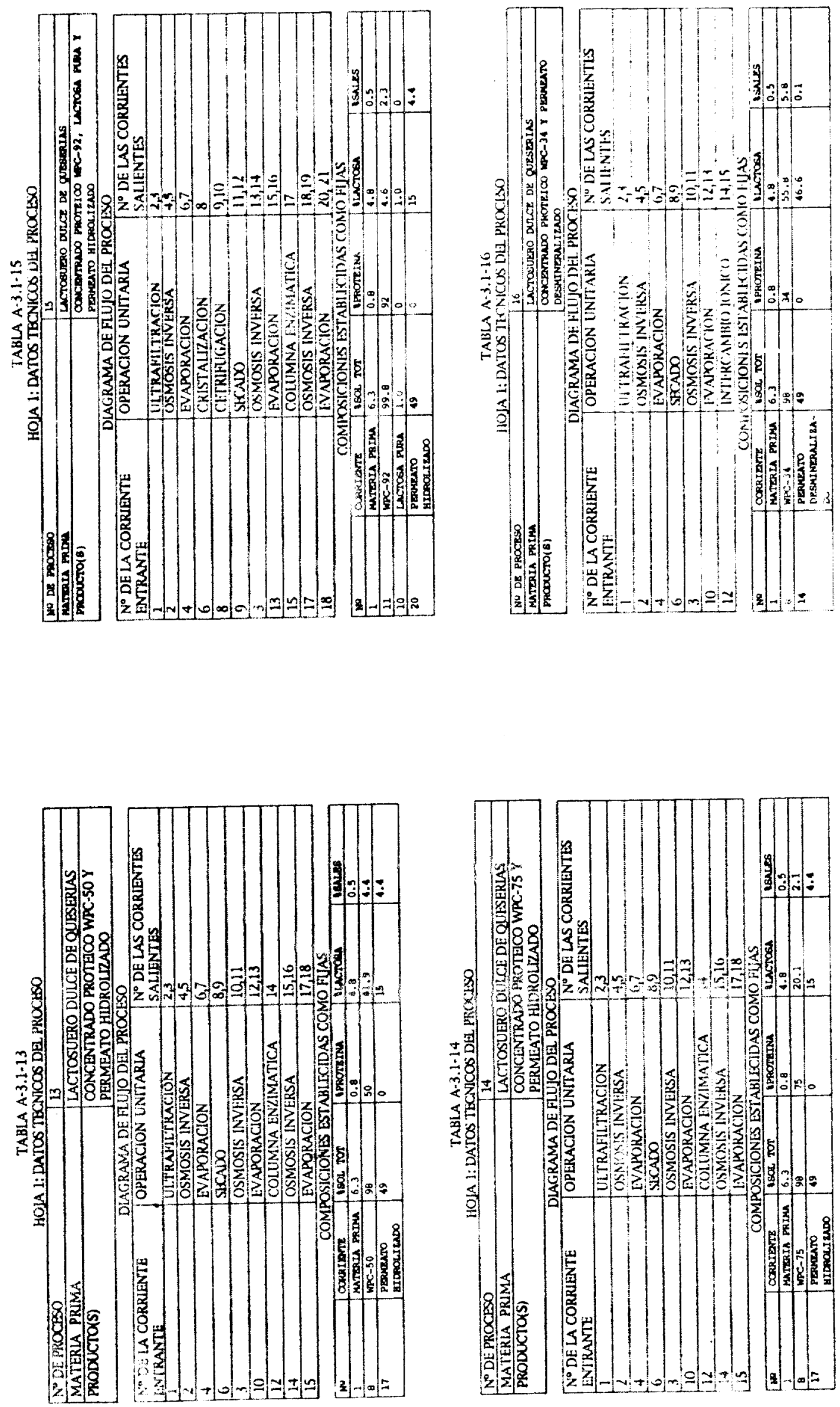



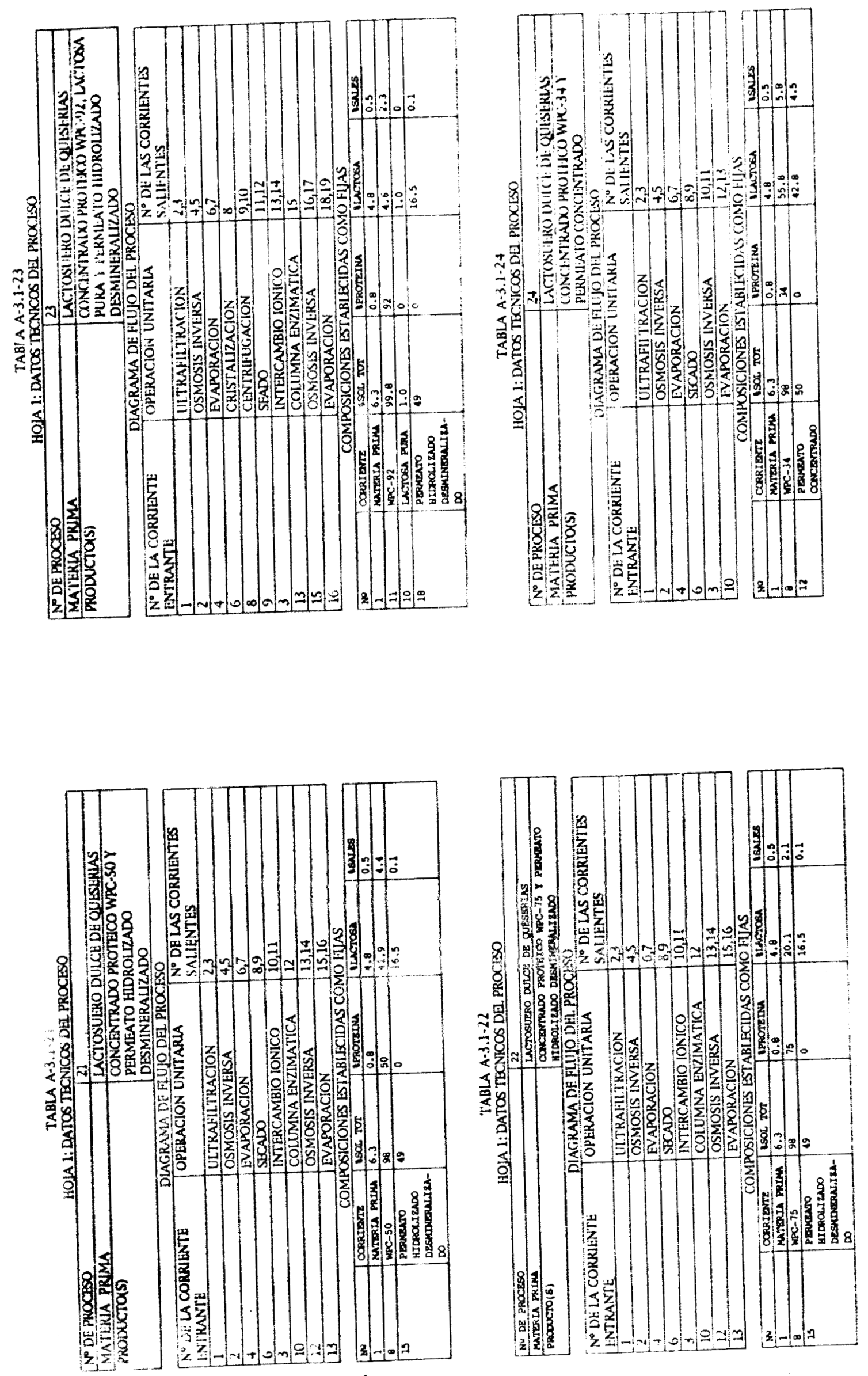

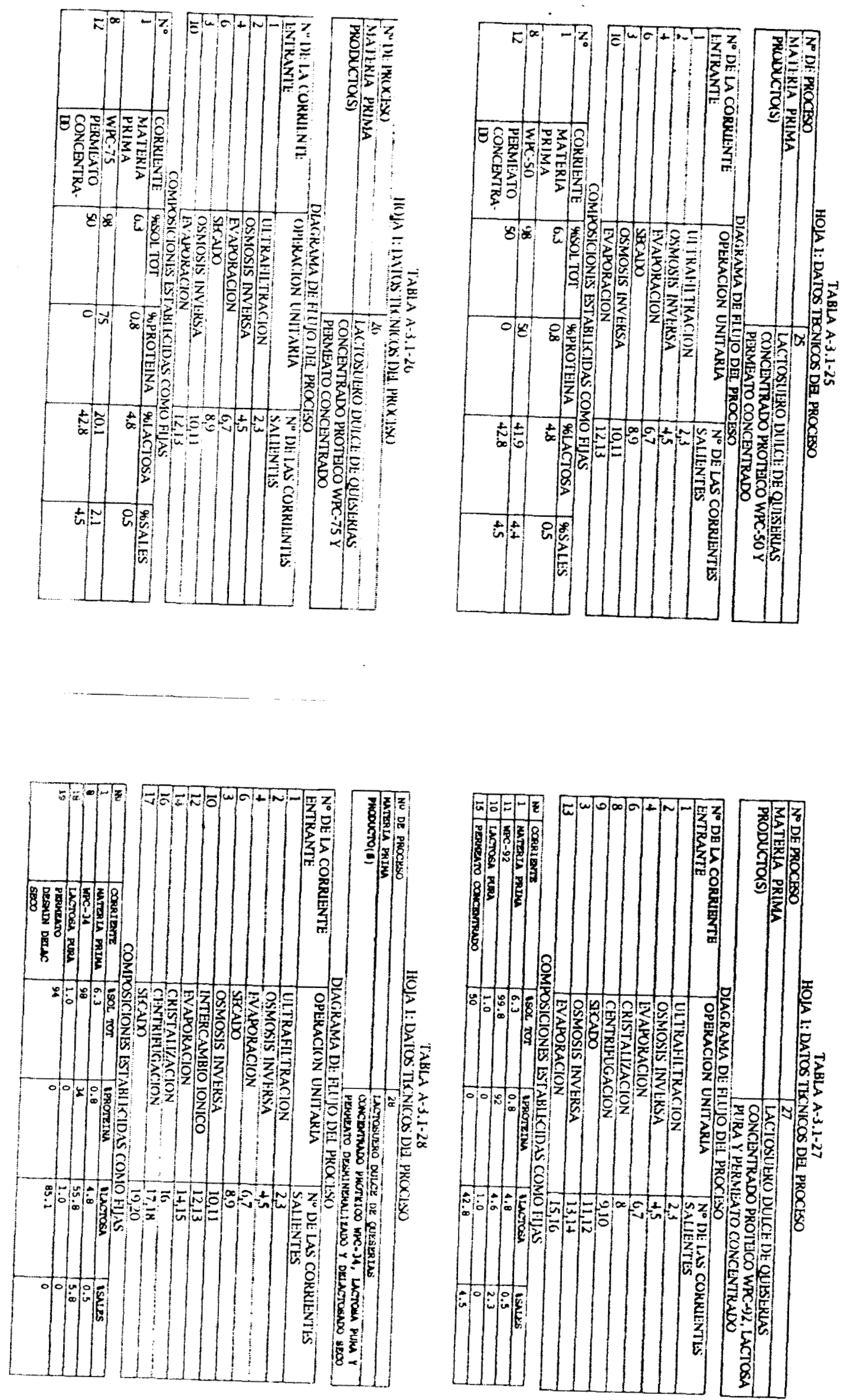


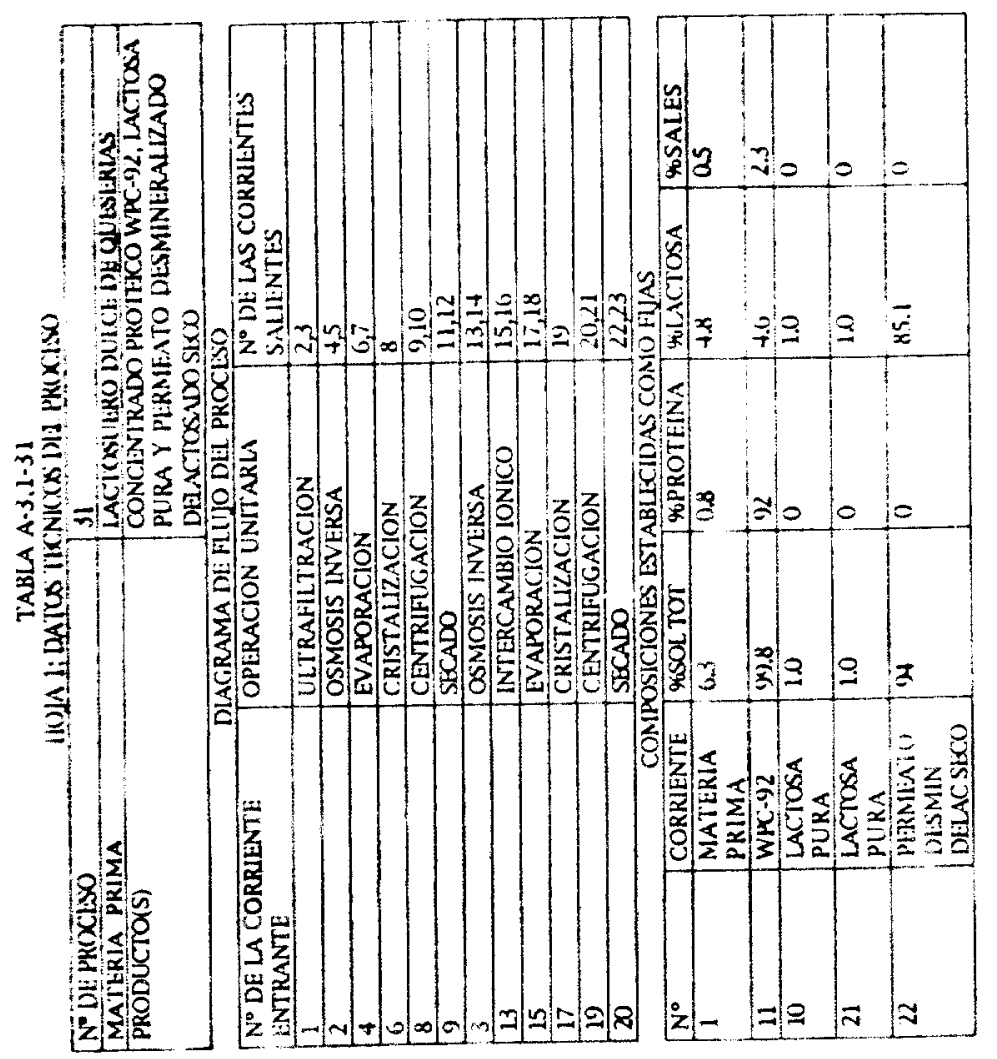

$\stackrel{\circ}{\circ}$
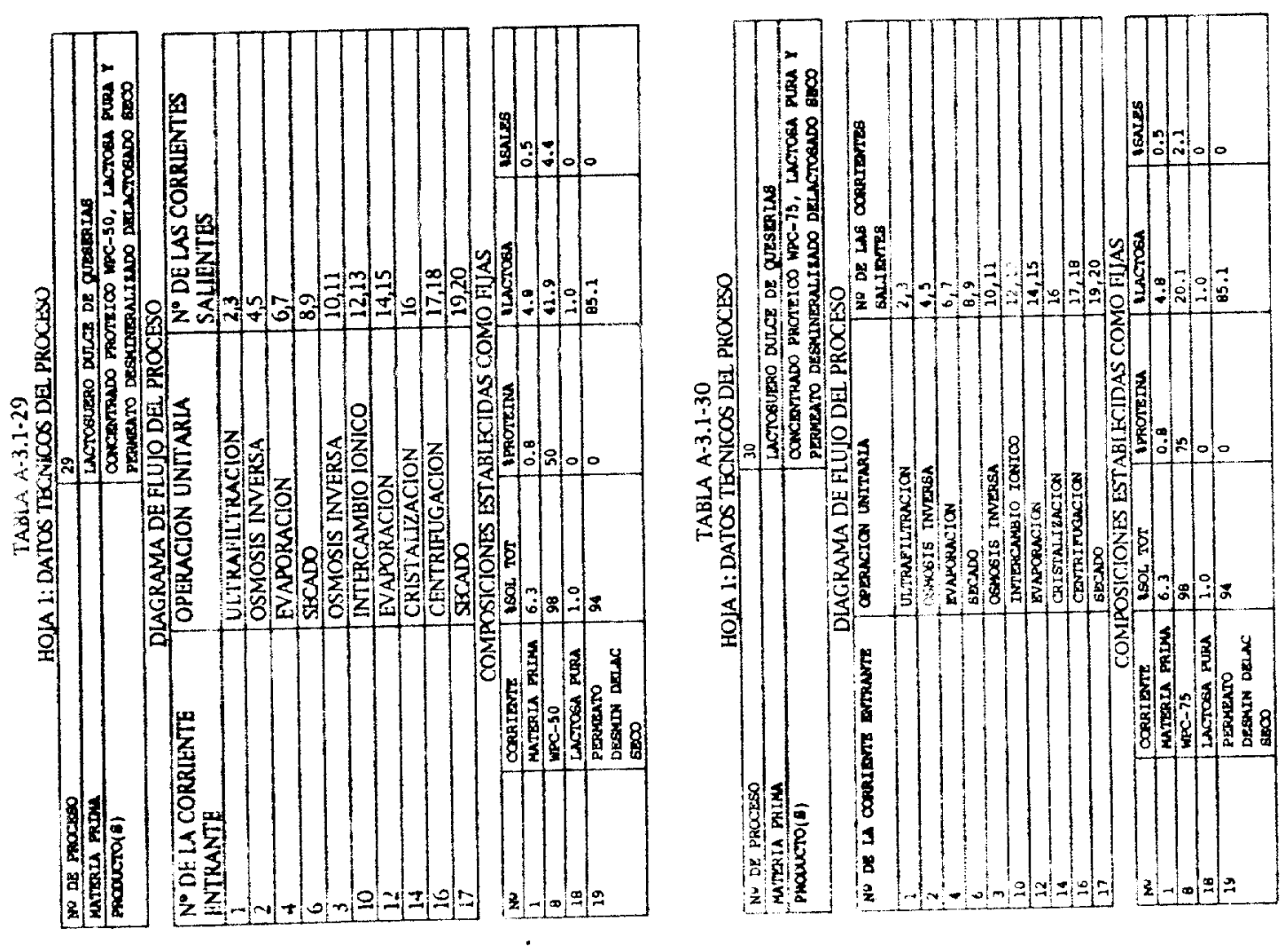
TABI.A A-3.1-1 (CONTINZACKON)

HOJA 2: RESLITADOS TECNICOS DE PROCESO MINTMIZANDO COSTOS

\begin{tabular}{|c|c|c|c|c|c|c|c|c|c|c|c|c|c|c|}
\hline PROCESO $N^{\circ} 1$ & \multicolumn{2}{|c|}{ ESCALA 1} & \multicolumn{2}{|c|}{ ESCAIA 2} & \multicolumn{2}{|c|}{ ESCALA 3} & \multicolumn{2}{|c|}{ ESCALA 4} & \multicolumn{2}{|c|}{ ESCALA 5} & \multicolumn{2}{|c|}{ ESCALA 6} & \multicolumn{2}{|c|}{ ECALA 7} \\
\hline OPERACIOA & $\mathrm{L}$ & $\mathrm{I}$ & ! & $\mathrm{T}$ & I & $\mathrm{T}$ & $\mathbf{U}$ & $T$ & $\mathbf{U}$ & $\mathbf{T}$ & $\mathrm{U}$ & $\mathbf{T}$ & $\mathrm{U}$ & $\mathbf{I}$ \\
\hline OSMOSIS INTERSA & 7 & $.14 E 2$ & 7 & $.42 \mathrm{~F} 2$ & 7 & $.7 \mathrm{E} 2$ & 7 & $.14 E 3$ & 7 & $.42 \mathrm{E3}$ & 7 & $.7 \mathrm{E3}$ & 7 & $14 E 4$ \\
\hline EVAPORACION & 0 & 0 & 0 & 0 & 0 & $\overline{0}$ & 0 & 0 & 1 & $22 \mathrm{E2}$ & 1 & $36 \mathrm{E} 2$ & 2 & $.12 \mathrm{E3}$ \\
\hline STCADO & 1 & $.68 E 2$ & 1 & $.2 E^{3}$ & 1 & $34 \mathrm{E} 3$ & 1 & $.68 E 3$ & 1 & $.45 \overline{E 3}$ & 1 & $.75 \mathrm{E} 3$ & 1 & $.15 \mathrm{E4}$ \\
\hline
\end{tabular}

TABLA A-3.1-2 (CONTINLACION)

HOJA 2: RESULTADOS TECNICOS DEI PROCESO MDNMIZANDO COSTOS

\begin{tabular}{|c|c|c|c|c|c|c|c|c|c|c|c|c|c|c|}
\hline \multirow{2}{*}{$\begin{array}{l}\text { PROCESO }{ }^{\circ} 2 \\
\text { OPERACKON }\end{array}$} & \multicolumn{2}{|c|}{$\overline{\text { ESCALA } 1}$} & \multicolumn{2}{|c|}{ ESCALA 2} & \multicolumn{2}{|c|}{ ESCALA 3} & \multicolumn{2}{|c|}{ ESCALA 4} & \multicolumn{2}{|c|}{ ESCALA 5} & \multicolumn{2}{|c|}{ ESCAIA 6} & \multicolumn{2}{|c|}{ ECALA 7} \\
\hline & $\mathbf{U}$ & $T$ & II & $T$ & $\mathrm{U}$ & $T$ & $\mathbf{U}$ & $T$ & $\mathrm{U}$ & $\mathrm{T}$ & $\mathbf{U}$ & $\mathrm{T}$ & $\mathbf{U}$ & $T$ \\
\hline OSMOSIS INTERSA & 7 & $.14 \mathrm{E2}$ & 7 & $.42 \mathrm{E} 2$ & 7 & $.7 \mathrm{E}$ & 7 & $.14 E 3$ & 7 & $.42 \mathrm{E} 3$ & 7 & $.7 \mathrm{E3}$ & 7 & $.14 F 4$ \\
\hline EVAPORACKO & 1 & 23 & 1 & 69 & 1 & $.12 \mathrm{EI}$ & 1 & $23 \mathrm{E1}$ & 1 & $.69 \mathrm{E} 1$ & 1 & $.12 \mathrm{E2}$ & 1 & $3 \mathrm{EZ}$ \\
\hline
\end{tabular}

TABLA A-3.1-3 (CONTINUACION)

HOJA 2: RESULTADOS TBCNICOS DEI PROCESO MINIMUZANDO COSTOS

\begin{tabular}{|c|c|c|c|c|c|c|c|c|c|c|c|c|c|c|}
\hline PROCESO N 3 & \multicolumn{2}{|c|}{ ESCALA 1} & \multicolumn{2}{|c|}{ ESCALA 2} & \multicolumn{2}{|c|}{ ESCALA 3} & \multicolumn{2}{|c|}{ ESCALA 4} & \multicolumn{2}{|c|}{ ESCANA 5} & \multicolumn{2}{|c|}{ ESCALA 6} & \multicolumn{2}{|c|}{ ESCALA 7} \\
\hline OPERACON & $\mathbf{U}$ & $\mathbf{T}$ & U & $\mathrm{T}$ & I & $\overline{\mathbf{T}}$ & $\bar{U}$ & $\bar{I}$ & $\mathbf{U}$ & $\mathrm{T}$ & $U$ & $\mathbf{T}$ & $\bar{U}$ & $\mathbf{T}$ \\
\hline OSMOSIS INVERSA & 7 & $.14 E 2$ & 7 & $.42 \mathrm{~F} 2$ & 7 & $.7 \mathbf{E Z}$ & 7 & $.14 E 3$ & 7 & $.42 \mathrm{E} 3$ & 7 & $.7 \mathrm{E} 3$ & 7 & $.14 E 4$ \\
\hline NTERCAM LONTCO & 1 & .1 & 1 & 31 & 1 & 51 & 1 & $.1 E 1$ & 1 & 31E1 & 1 & $51 \mathrm{E} 1$ & 1 & $.1 \mathrm{E}$ \\
\hline EVAPORACION & 0 & 0 & 0 & 0 & 0 & 0 & 0 & 0 & 1 & AE2 & 1 & 36E2 & 2 & $.12 \mathrm{E} 3$ \\
\hline SBCADO & 1 & $.68 E 2$ & 1 & $21 E 3$ & 1 & $34 \pm 3$ & 1 & .68E3 & 1 & $.42 \mathrm{E} 3$ & 1 & $.7 \mathrm{E3}$ & 1 & $.14 E_{4}$ \\
\hline
\end{tabular}

TABLA A-3.1-4 (CONTINUACION)

HOJA L: RESULTADOS TECNICOS DEI PROCESO MINIMIZANI DO OOSTOS

\begin{tabular}{|c|c|c|c|c|c|c|c|c|c|c|c|c|c|c|}
\hline PROCESO N ${ }^{\circ} 4$ & \multicolumn{2}{|c|}{ ESCALA 1} & \multicolumn{2}{|c|}{ ESCALA 2} & \multicolumn{2}{|c|}{ ESCALA 3} & \multicolumn{2}{|c|}{ ESCALA 4} & \multicolumn{2}{|c|}{ ESCALA S } & \multicolumn{2}{|c|}{$\overline{E S C A L A}$ G } & \multicolumn{2}{|c|}{$\overline{\text { ESCALA } 7}$} \\
\hline OPERACION & $t^{2}$ & $T$ & $\boldsymbol{I}$ & $T$ & $\mathrm{t}$ & $T$ & $\mathrm{u}$ & $\mathbf{T}$ & $\mathbf{u}$ & $T$ & $\overline{\mathbf{L}}^{*}$ & $T$ & $\mathbf{u}$ & $\mathbf{T}$ \\
\hline CLTRAFILTRACION & 1 & $.9 \mathrm{E} 2$ & 1 & $.27 \mathrm{E} 3$ & 1 & $.45 \mathrm{E}^{3}$ & 1 & $.9 \mathrm{E3}$ & 1 & $.27 E 4$ & 1 & $.45 \mathrm{E4}$ & 1 & $.9 E 4$ \\
\hline OSNOOS & $\overline{7}$ & $.37 \mathrm{E} 1$ & $=$ & $.11 E^{2}$ & $=$ & $19 E 2$ & 1 & $.37 E 2$ & 7 & $.11 \mathrm{E}^{3}$ & 7 & $.19 E 3$ & 7 & $.37 \mathrm{E3}$ \\
\hline EVAPORACKO & 0 & 0 & 0 & 0 & 0 & 0 & $\mathbf{0}$ & $\overline{0}$ & o & 0 & 1 & $.16 \mathrm{E} 2$ & D & 0 \\
\hline SBCADO & 1 & $.25 E 2$ & 1 & $.76 E_{2}$ & 1 & $.13 \mathrm{E} 3$ & 1 & $.25 \mathrm{E3}$ & 1 & $.76 E^{3}$ & 1 & 313 & 1 & $.25 \mathrm{E}$ \\
\hline
\end{tabular}


TABLA A-3.1-5 (CONTINTACJON

HOJA 2: REST ITADOS TECNKOS DE PR CESO MDIARZANDO COSTOOS

\begin{tabular}{|c|c|c|c|c|c|c|c|c|c|c|c|c|c|c|}
\hline PROCESO N 5 & \multicolumn{2}{|c|}{ ESCALA 1} & \multicolumn{2}{|c|}{ SCALA 2} & \multicolumn{2}{|c|}{ ESCALA 3} & \multicolumn{2}{|c|}{ ESCALA 4} & \multicolumn{2}{|c|}{ ESCALA 5} & \multicolumn{2}{|c|}{ ESCALA 6} & \multicolumn{2}{|c|}{ ESCALA 7} \\
\hline & 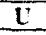 & 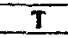 & & $T$ & & $\mathrm{~T}$ & $\mathrm{U}$ & & $\mathrm{U}$ & I & $\bar{L}$ & $\mathbf{I}$ & u & $T$ \\
\hline ULTI & 1 & $.1 \mathrm{IE}$ & 1 & $3 \overline{4 E^{3}}$ & 1 & $.56 \mathrm{E}$ & & 115 & & 3454 & -1 & $56 \mathrm{~K}$ & 2 & $.11 \mathrm{E}$ \\
\hline & 7 & & & $55 \mathrm{EI}$ & & .9 & & & 7 & $55 E$ & & $.92 \mathrm{E}$ & 7 & $.18 \mathrm{E} 3$ \\
\hline EAPP & 0 & 0 & 0 & 0 & 0 & 0 & 0 & 0 & 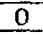 & 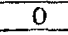 & 0 & 0 & 0 & 0 \\
\hline 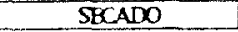 & . & $.17 E 2$ & 1 & $52 \mathrm{E} 2$ & & $.86 \mathrm{E} 2$ & 1 & $.17 \mathrm{E3}$ & 7 & $5 \geq 23$ & 1 & $86 E 3$ & 1 & .1764 \\
\hline
\end{tabular}

TABLA A-3.1-6 (CONTINL:ACION

HOJA 2: RESL ITADOS TECNICOS DE PROCESO MINLMDANDO COSTOOS

\begin{tabular}{|c|c|c|c|c|c|c|c|c|c|c|c|c|c|c|}
\hline PROCESO N 6 & \multicolumn{2}{|c|}{ ESCALA 1} & \multicolumn{2}{|c|}{ ESCALA 2} & \multicolumn{2}{|c|}{ ESCALA 3} & \multicolumn{2}{|c|}{ ESCAL A 4} & \multicolumn{2}{|c|}{ ESCALA 5} & \multicolumn{2}{|c|}{ ESCAIA 6} & \multicolumn{2}{|c|}{ ESAIA 7} \\
\hline OPE & $\mathbf{L}$ & $T$ & $\mathrm{~L}$ & $T$ & U & $T$ & $\mathrm{U}$ & $T$ & $\mathbf{U}$ & $\mathrm{I}$ & $\mathrm{U}$ & $I$ & E & $T$ \\
\hline ULTR & 1 & .145 & 1 & $.41 E$ & 1 & $\mathrm{BE} 3$ & 1 & 4E4 & 1 & $41 \mathrm{E} 4$ & 1 & $68 \mathrm{H}^{-}$ & 2 & $.68 E 4$ \\
\hline os & 0 & 0 & 0 & 7 & 0 & 0 & 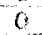 & 0 & 0 & 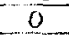 & 0 & 0 & 0 & 0 \\
\hline & 0 & 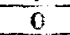 & 0 & 0 & 0 & 0 & , & 0 & 0 & $\theta$ & 0 & 0 & 1 & $33 E 2$ \\
\hline SKCADO & 1 & .172 & 1 & 51E2 & 1 & .8552 & 1 & $.1 \mathrm{E} 3$ & 1 & & 1 & $85 E 3$ & 1 & $27 \mathrm{E} 3$ \\
\hline
\end{tabular}

TABLA A-3.1-7 (CONTISLACION)

HOJA 2: RESIITADOS TBCNKOS DEL PROCESO MINTMIZANDO COSTOS

\begin{tabular}{|c|c|c|c|c|c|c|c|c|c|c|c|c|c|c|}
\hline PROCESO NO 7 & \multicolumn{2}{|c|}{ ESCALA I } & \multicolumn{2}{|c|}{ ESCALA 2} & \multicolumn{2}{|c|}{ ESCALA 3} & \multicolumn{2}{|c|}{ ESCALA 4} & \multicolumn{2}{|c|}{ ESCALA 5} & \multicolumn{2}{|c|}{ ESCAIA 6} & \multicolumn{2}{|c|}{ ESCALA 7} \\
\hline OPRAACION & $t$ & $\mathrm{~T}$ & 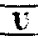 & $\bar{T}$ & $\mathrm{u}$ & $T$ & I & $\mathbf{T}$ & $\bar{v}$ & $\mathbf{T}$ & $\mathrm{U}$ & $\mathbf{I}$ & U & $\mathrm{I}$ \\
\hline ULTRAFILTRACIOX & 2 & 692 & 1 & $41 \mathrm{E3}$ & 1 & $.69 \mathrm{E3}$ & 1 & .14 E4 & 1 & .4E4 & 1 & $67 \mathrm{k4}$ & 1 & $.13 E 5$ \\
\hline OSMOSIS DSIERSA & 0 & 0 & 0 & 0 & 0 & 0 & 0 & 0 & 0 & 0 & 0 & 0 & 0 & 0 \\
\hline EYAPORACION & 6 & .15 & 0 & 0 & 1 & 6 & 1 & $.12 \mathrm{EI}$ & 1 & 55E1 & 1 & $.92 \mathrm{EI}$ & 1 & $.18 E 2$ \\
\hline CRISTAUIZACION & 1 & $.17 E 1$ & 1 & $11 \mathrm{E2}$ & 1 & $.84 \mathrm{E} 1$ & 1 & $.17 \mathrm{E} 2$ & 1 & $5 \% 2$ & 1 & .9902 & 1 & $.2 \mathrm{E} 3$ \\
\hline CF IRU GACHON & 1 & $62 E-1$ & 1 & 7812 & 1 & .19 & $I$ & 32 & 1 & $\therefore 8$ & 1 & $.11 \mathrm{EI}$ & 1 & $.19 \mathrm{EI}$ \\
\hline SE DO & 1 & $38 E 1$ & 1 & $43 \mathrm{E2}$ & 1 & $.2 \mathrm{EZ}$ & 1 & $39 E 2$ & 1 & $.1 \mathrm{E3}$ & 1 & $.17+3$ & 1 & $.33 E 3$ \\
\hline
\end{tabular}

TA 1 A A-3.1-8 (COBTINIACION)

HOJA 2: RESI LTAIXOS TECAKOS DFI PROCHO MIINIIZANDO SOSTOS

\begin{tabular}{|c|c|c|c|c|c|c|c|c|c|c|c|c|c|c|}
\hline PROCFSO ${ }^{\circ} 8$ & \multicolumn{2}{|c|}{ ESCALA 1} & \multicolumn{2}{|c|}{ ESCALA 2} & \multicolumn{2}{|c|}{ ESCALA 3} & \multicolumn{2}{|c|}{ ESCALA 4} & \multicolumn{2}{|c|}{ ESCALA 5} & \multicolumn{2}{|c|}{ ESCALA 6} & \multicolumn{2}{|c|}{ ESCALA } \\
\hline OPERACION & I: & $\mathbf{T}$ & I & I & $I^{i}$ & $\mathrm{~T}$ & i & $T$ & I & $T$ & I & $\mathrm{I}$ & I & I \\
\hline UITRAFILTRACIOS & 1 & .912 & 1 & $.27 \mathrm{E}$ & 1 & $55 \mathrm{E}^{3}$ & 1 & $.9 \mathrm{E}^{3}$ & 1 & 2.54 & $I$ & .4514 & 1 & $9 E 4$ \\
\hline OSNOOSIS INVIERSA & 7 & $37 \mathrm{E1}$ & 7 & $.11 \mathrm{E} 2$ & 7 & $.19 \mathrm{~L} 2$ & 7 & $.37 E 2$ & $\bar{t}$ & $.11 \mathrm{E}^{3}$ & 7 & .1913 & 7 & $.37 \mathrm{E3}$ \\
\hline BAPORACION & 0 & 0 & 0 & 0 & 0 & 0 & 0 & 0 & 0 & 0 & 1 & $.16 E 2$ & 0 & 0 \\
\hline SKCADO & 1 & $25 \mathrm{E} 2$ & 1 & $.76 E ?$ & 1 & $.13 \mathrm{ES}$ & 1 & $.25 \mathrm{E2}$ & 1 & $.76 \mathrm{E3}$ & 1 & $3 E^{3}$ & 1 & $.25 E 4$ \\
\hline OSIIOSIS INTERSA & 7 & $.1 E 2$ & 7 & $31 \mathrm{~L} 2$ & 7 & .5112 & 7 & .163 & 7 & $31 \mathrm{E3}$ & 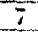 & $51 \mathrm{E}$ & 7 & .154 \\
\hline E'APORACION & 0 & 0 & $\overline{0}$ & 0 & 0 & 0 & 0 & 0 & 0 & 0 & 1 & $.42 \mathrm{E2}$ & 1 & $.72 \mathrm{E} 2$ \\
\hline SFCAIX & 1 & $.43 \mathrm{E}$ & 1 & .1353 & 1 & $.22 \mathrm{E}$ & 1 & $.43 \mathrm{E} 3$ & 1 & $.13 E$ & 1 & $47 \mathrm{E3}$ & 1 & $.95 \mathrm{E} 3$ \\
\hline
\end{tabular}


TABLA A.3.1-9 (CONTINLACION) HOJA 2: RESILTATOS TECNICOS DEI PROCESO MINIMIZANDO COSTÓS

\begin{tabular}{|c|c|c|c|c|c|c|c|c|c|c|c|c|c|c|}
\hline PROCESO N 9 & \multicolumn{2}{|c|}{ ESCALA 1} & \multicolumn{2}{|c|}{ ESCALA 2} & \multicolumn{2}{|c|}{ ESCAIA 3} & \multicolumn{4}{|c|}{ ESCALA 4 ESCALA 5} & \multicolumn{2}{|c|}{ ESCALA 6} & \multicolumn{2}{|c|}{ ESCALA 7} \\
\hline OPERACKON & l & $\mathrm{T}$ & l & $T$ & $\mathbf{C}^{\circ}$ & $\mathrm{T}$ & $\mathrm{L}$ & $\mathrm{T}$ & $\mathbf{U}$ & $T$ & I! & $T$ & $\mathrm{i}$ & $T$ \\
\hline LITRAFILTRACION & 1 & $.11 \mathrm{E} 3$ & 1 & $34 \mathrm{E}$ & 1 & $.56 E^{3}$ & 1 & $.11 \mathrm{E}^{4}$ & 1 & $.34 \mathrm{E}$ & 1 & .5654 & 1 & $.11 \mathrm{ES}$ \\
\hline OSNIOSIS INVERSA & 7 & $.18 \mathrm{E} 1$ & $\frac{2}{7}$ & $55 \mathrm{EI}$ & $\div$ & $.92 \mathrm{E} 1$ & 7 & $.18 \mathrm{E} 2$ & 7 & $.55 E^{2}$ & 7 & $.92 \mathrm{E} 2$ & $\frac{2}{7}$ & $.18 \mathrm{E}^{3}$ \\
\hline EAPORACION & 0 & 0 & 0 & 0 & 0 & 0 & 0 & 0 & 0 & 0 & 0 & 0 & 0 & 0 \\
\hline SXADO & 1 & $.17 \mathrm{E} 2$ & 1 & $.52 \mathrm{E} 2$ & 1 & $.86 E 2$ & 1 & $.17 \mathrm{E} 3$ & 1 & $52 \mathrm{E}$ & 1 & $86 \mathrm{E} 3$ & 1 & $.17 \mathrm{E} 4$ \\
\hline OSAIOSIS INVERSA & 7 & $.12 \mathrm{E} 2$ & 7 & $.36 \mathrm{E} 2$ & 7 & $.61 E 2$ & 7 & $.12 \mathrm{E} 3$ & 7 & $36 \mathrm{E} 3$ & 7 & $.61 E 3$ & $i$ & $.12 \mathrm{~F}-4$ \\
\hline EVAPORACION & 0 & 0 & 0 & 0 & 0 & 0 & 0 & 0 & 0 & 0 & 1 & $.27 \mathrm{E} 2$ & 1 & $54 E 2$ \\
\hline$S B A D O$ & 1 & $51 \mathrm{E2}$ & 1 & $.15 \mathrm{E} 3$ & 1 & $.26 \mathrm{E} 3$ & 1 & $.51 E 3$ & 1 & $.15 \mathrm{E} 4$ & 1 & $56 \mathrm{E} 3$ & 1 & $.11 \mathrm{~F} 4$ \\
\hline
\end{tabular}

TABLA A-3.1-10 (CONTINUACION)

HOJA 2: RESLITADOS TECNICOS DEI PROCESO MINIMIZANDO COSTOS

\begin{tabular}{|c|c|c|c|c|c|c|c|c|c|c|c|c|c|c|}
\hline \multirow{2}{*}{$\begin{array}{c}\text { PROCESO N } 10 \\
\text { OPERACION }\end{array}$} & \multicolumn{2}{|c|}{ ESCALA I } & \multicolumn{4}{|c|}{ ESCALA 2 ESCALA 3} & \multicolumn{2}{|c|}{ ESCAIA 4} & \multicolumn{2}{|c|}{$\overline{\text { ESCALA } 5}$} & \multicolumn{2}{|c|}{ ESCALA 6} & \multicolumn{2}{|c|}{ ESCALA 7} \\
\hline & I & $T$ & $\mathrm{~L}$ & $\mathrm{~T}$ & $\mathbf{L}^{-}$ & $\mathrm{T}$ & $\mathbf{t}$ & $\mathrm{I}$ & $\mathrm{U}$ & $\mathrm{T}$ & $\mathrm{L}:$ & $\mathbf{T}$ & $\overline{\mathrm{L}}$ & $\mathrm{I}$ \\
\hline LITRAFILTRACION & 1 & $.14 E 3$ & 1 & $.41 \mathrm{E}$ & 1 & $.68 \mathrm{E} 3$ & 1 & $.14 \mathrm{E} 4$ & $\mathrm{I}$ & $.41 \mathrm{E}$ & 1 & $.68 \mathrm{E} 4$ & 2 & $68 \mathrm{E} 4$ \\
\hline OSMOSIS DNERSA & 0 & 0 & 0 & 0 & 0 & 0 & 0 & 0 & 0 & 0 & 0 & 0 & 0 & 0 \\
\hline E'APORACION & 0 & 0 & $\overline{0}$ & 0 & 0 & 0 & 0 & 0 & 0 & 0 & 0 & 0 & 1 & $33 \mathrm{E} 2$ \\
\hline SECADO & 1 & $.17 \mathrm{E} 2$ & 1 & $.51 \mathrm{E} 2$ & 1 & $.85 \mathrm{E2}$ & 1 & $.17 \mathrm{E} 3$ & 1 & $51 \mathrm{E} 3$ & 1 & $.85 \mathrm{E}$ & 1 & $27 \mathrm{E} 3$ \\
\hline OSMOSIS INVERSA & 7 & $.13 \mathrm{E} 2$ & 7 & $.4 \mathrm{E}$ & 7 & $.67 \mathrm{E2}$ & 7 & $.13 \mathrm{E} 3$ & 7 & $.4 \mathrm{E} 3$ & 7 & $.67 \mathrm{E3}$ & 7 & $.13 E_{4}^{4}$ \\
\hline EAPORACION & 0 & 0 & 0 & 0 & 0 & 0 & 0 & 0 & 1 & $.18 \mathrm{E} 2$ & 1 & $3 E 2$ & 1 & $85 E 2$ \\
\hline SECADO & 1 & $57 E 2$ & 1 & $.17 \mathrm{E} 3$ & 1 & $.28 \mathrm{E} 3$ & 1 & $57 \mathrm{E} 3$ & 1 & $37 \mathrm{E} 3$ & 1 & $\frac{12}{62 \mathrm{E} 3}$ & $\frac{2}{1}$ & $.12 \mathrm{E}$ \\
\hline
\end{tabular}

TARA A-3.1-11 (CONTTMUACHON)

HOJA 2: RESUITADOS TECNTCOS DEI PROCESO MINIMIZANDO COSTOS

\begin{tabular}{|c|c|c|c|c|c|c|c|c|c|c|c|c|c|c|}
\hline PKOCESON $N^{\circ} 11$ & \multicolumn{2}{|c|}{ ESCAIA 1} & \multicolumn{2}{|c|}{ ESCALA 2} & \multicolumn{2}{|c|}{ ESCALA 3} & \multicolumn{2}{|c|}{ ESCALA 4} & \multicolumn{2}{|c|}{ ESCALA 5} & \multicolumn{2}{|c|}{ ESCALA 6} & \multicolumn{2}{|c|}{ ESCALA 7} \\
\hline OPERACION & t & $T$ & $\mathbf{t}$ & $T$ & $\mathbf{U}$ & $T$ & $\mathbf{U}$ & $\mathbf{T}$ & $\mathrm{U}$ & $T$ & $\overline{\mathrm{U}}$ & $\bar{T}$ & $\mathbf{L}$ & $\bar{I}$ \\
\hline ULTRAFILTRACION & 2 & $.69 \mathrm{E2}$ & 1 & $.41 \mathrm{E3}$ & 1 & $.69 \mathrm{E} 3$ & 1 & $.14 \sqrt{4}$ & 1 & $.4 E 4$ & 1 & $.67 \mathrm{E4}$ & 1 & $.13 E 5$ \\
\hline OSMOSIS NVERSA & 0 & 0 & 0 & 0 & 0 & 0 & 0 & o & 0 & 0 & 0 & 0 & 0 & $\overline{0}$ \\
\hline A'APORACION & 6 & .15 & 0 & 0 & 1 & .6 & 1 & $.12 \mathrm{E} 1$ & 1 & $.55 \mathrm{E} 1$ & 1 & $.92 \mathrm{E} 1$ & 1 & $.18 \mathrm{E} 2$ \\
\hline CRISTALIZACION & 1 & $.17 E 1$ & 1 & $.11 \mathrm{E}$ & 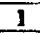 & $.84 \mathrm{El}$ & 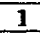 & $.17 \mathrm{E} 2$ & 1 & SOE2 & 1 & $.99 \mathrm{E} 2$ & 1 & $2 \mathrm{E} 3$ \\
\hline CETRIFLGACION & 1 & $.62 \mathrm{E}-1$ & 1 & $.78 \mathrm{E}-1$ & 1 & .19 & 1 & 32 & 1 & .78 & 1 & $.11 \mathrm{E} 1$ & 1 & $.19 \mathrm{E} 1$ \\
\hline SECADO & 1 & $.38 \mathrm{E} 1$ & $\mathbf{J}$ & $.43 E_{2}$ & 1 & $.2 \mathrm{E} 2$ & 1 & $39 \pm 2$ & 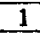 & $.1 \mathrm{E3}$ & 1 & $.17 \mathrm{E} 3$ & 1 & $33 \mathrm{E} 3$ \\
\hline OSAOOSIS INVERSA & 7 & $.14 \mathrm{E} 2$ & 7 & $.4 \mathrm{E} 2$ & 7 & $.67 \mathrm{E} 2$ & 7 & $.14 \mathrm{E} 3$ & 7 & $4 \mathrm{E3}$ & 7 & $.67 \mathrm{E} 3$ & 7 & $.13 E 4$ \\
\hline B'APORACION & 0 & $\underline{0}$ & 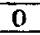 & 0 & 0 & 0 & 0 & 0 & 4 & $88 \mathrm{EZ}$ & 1 & $.43 \mathrm{E} 2$ & 1 & $86 E 2$ \\
\hline SECADO & 1 & $.57 \mathrm{E} 2$ & 1 & $.17 E^{3}$ & 1 & $.29 E^{3}$ & 7 & $5 \pi 3$ & 7 & $37 E 3$ & 1 & $.62 \mathrm{E} 3$ & 1 & $.12 \mathrm{F4}$ \\
\hline
\end{tabular}

TABLA A-3.1-12 (CONTINUACION)

HOJA 2: RESLILTADOS TECN]COS DEI PROCESO MINIMILANDO COSTOS

\begin{tabular}{|c|c|c|c|c|c|c|c|c|c|c|c|c|c|c|}
\hline PROCEXO N 12 & \multicolumn{2}{|c|}{ ESCAIA 1} & \multicolumn{4}{|c|}{ ESCALA $2:$ ESCAIA 3} & \multicolumn{2}{|c|}{ ESCALA 4} & \multicolumn{2}{|c|}{ ESCALA 5} & \multicolumn{2}{|c|}{ ESCANA 6} & \multicolumn{2}{|c|}{ ESCAIA } \\
\hline OPERACION & $i$ & 7 & i & $\mathrm{T}$ & I & $T$ & I & $T$ & I! & $T$ & I & $\mathrm{T}$ & $\mathbf{l}$ & $\mathrm{T}$ \\
\hline LLTRAFIITRACION & 1 & $9 \mathrm{I} 2$ & 1 & $.27 \mathrm{E}$ & 1 & $.45 \mathrm{E}^{2}$ & 3 & $.9 \mathrm{~F}$ & 1 & $2 \pi \mathrm{Kt}$ & 1 & $.45 F 4$ & 1 & .954 \\
\hline OSMIOSIS INVERSA & 7 & $.37 \mathrm{E1}$ & 7 & $.11 \mathrm{E} 2$ & 7 & $.19 \mathrm{E} 2$ & $i$ & $.37 \mathrm{E} 2$ & 7 & $.11 \mathrm{E}^{3}$ & 7 & $.19 \mathrm{E} 3$ & $i$ & $.37 \mathrm{E3}$ \\
\hline D'APORACION & 0 & 0 & 0 & 0 & 0 & 0 & 0 & 0 & 0 & 0 & 1 & $.16 \mathrm{E} 2$ & 0 & 0 \\
\hline SFCADO & 1 & $.25 \mathrm{E}$ & 1 & $.76 E 2$ & 1 & $.13 \mathrm{~F}^{3}$ & 1 & $.25 \mathrm{E} 3$ & 1 & $.76 \mathrm{E}^{3}$ & 1 & $3 E 3$ & 1 & $25 \mathrm{~F}$ \\
\hline OSNIOSIS INVERSA & 7 & $.1 \mathrm{~F} 2$ & 7 & $.31 \mathrm{F2}$ & 7 & $51 \mathrm{E} 2$ & 7 & $.1 \mathrm{E} 3$ & 7 & $31 \mathrm{E} 3$ & 7 & $51 E 3$ & 7 & $.1 \mathrm{E4}$ \\
\hline E'APORACION & 0 & 0 & 0 & 0 & 0 & 0 & 0 & 0 & 0 & 0 & 0 & 0 & 0 & 0 \\
\hline COL ENZIMIATICA & $45]$ & $.26 \mathrm{E} 1$ & 451 & $.78 \mathrm{Fl}$ & 451 & $.13 \mathrm{E} 2$ & 451 & $.26 \mathrm{E} 2$ & 451 & $.78 \mathrm{E2}$ & 451 & $.13 \mathrm{~F}$ & 451 & $26 \mathrm{GE}$ \\
\hline OSMIOSIS INVERSA & 0 & 0 & 0 & 0 & 0 & 0 & 0 & 0 & 0 & 0 & 0 & 0 & $\underline{0}$ & 0 \\
\hline E'APORACION & 1 & 26 & ] & $.14 \mathrm{EI}$ & 1 & $.13 \mathrm{FI}$ & 1 & $.26 E 1$ & 1 & $.78 \mathrm{EI}$ & 1 & $.13 \mathrm{E} 2$ & 1 & $.48 \mathrm{E} 2$ \\
\hline
\end{tabular}


TABLA A-3.1-13 (CONTINLACNON)

HOJA 2: RESILLTADXS TECNICOS DEI PROCESO MINTIIZANIOO COSTOS

\begin{tabular}{|c|c|c|c|c|c|c|c|c|c|c|c|c|c|c|}
\hline FROCESO N 13 & \multicolumn{2}{|c|}{ ESCALA 1} & \multicolumn{2}{|c|}{ ESCALA 2} & \multicolumn{2}{|c|}{ ESCALA 3} & \multicolumn{4}{|c|}{ ESCALA 4 ESCALA 5} & \multicolumn{2}{|c|}{ ESCALA 6} & \multicolumn{2}{|c|}{ PSCALA 7} \\
\hline OPERACKON & $I^{\prime}$ & $T$ & E & $T$ & $\mathrm{U}$ & $\mathrm{T}$ & I & $\mathrm{I}$ & L & $\mathrm{T}$ & U: & $T$ & $\mathrm{i}$ & $\mathrm{T}$ \\
\hline LITRAFILTRACIOK & 1 & $.11 \mathrm{E}$ & 1 & $34 \mathrm{E3}$ & 1 & $.56 \mathrm{E3}$ & 1 & $.11 \mathrm{~F}_{4}$ & 1 & $34 \mathrm{E} 4$ & 1 & .5654 & 1 & $.11 E 5$ \\
\hline OSMIOSIS INVERSA & $i$ & $.18 E 1$ & 7 & $.55 \mathrm{EI}$ & $\bar{i}$ & $.92 \mathrm{EI}$ & 7 & $.18 \mathrm{E} 2$ & 7 & $.55 \overline{\mathrm{E} 2}$ & 7 & $.92 \mathrm{F2}$ & 7 & $.18 \mathrm{E}$ \\
\hline NAPORACION & 0 & 0 & 0 & 0 & 0 & 0 & $\mathrm{O}$ & 0 & 0 & 0 & 0 & O & 0 & 0 \\
\hline SECADO & 1 & $.17 E 2$ & 1 & $.52 \mathrm{E} 2$ & 1 & $.86 E ?$ & 1 & $.17 E 3$ & 1 & $52 E^{3}$ & 1 & $.86 \mathrm{E3}$ & 1 & $.17 \mathrm{E} 4$ \\
\hline OSMOSIS INVERSA & 7 & $.12 \mathrm{E} 2$ & $\overline{7}$ & 362 & 7 & $61 \mathrm{E}$ & 7 & $.12 \mathrm{E3}$ & 7 & $36 \mathrm{E} 3$ & 7 & $.61 \mathrm{E3}$ & $\overline{1}$ & $.12 \mathrm{E} 4$ \\
\hline E APORACIOX & 1 & $.82 \mathrm{E}-1$ & 0 & 0 & 0 & $y$ & 0 & 0 & 0 & 0 & 0 & 0 & 0 & 0 \\
\hline COL ENZIM & 451 & $31 \mathrm{El}$ & 451 & $.92 \mathrm{~F} 1$ & 451 & .152 & 451 & $31 \mathrm{E}$ & 451 & $92 \mathrm{E}$ & 451 & $.15 E 3$ & 454 & $3 \mathrm{E3}$ \\
\hline OSMOS & 0 & 0 & 0 & 0 & 0 & 0 & 0 & 0 & 0 & 0 & 0 & 0 & 0 & 0 \\
\hline ESAPORACION & 1 & 22 & 1 & .93 & 1 & $.15 \mathrm{E1}$ & 1 & $31 \mathrm{E1}$ & 1 & $.93 \mathrm{E} 1$ & 1 & $.15 \mathrm{E} 2$ & 1 & $31 E 2$ \\
\hline
\end{tabular}

TABIAA-3.1-14 (CONTINI UN)

HOJA 2: RESULTADOS TECNICOS DEI PROCE NITMIZANDO COSTCS

\begin{tabular}{|c|c|c|c|c|c|c|c|c|c|c|c|c|c|c|}
\hline PROCESO N 14 & \multicolumn{2}{|c|}{ ESCALA 1} & \multicolumn{2}{|c|}{ ESCALA 2} & \multicolumn{2}{|c|}{ ESCALA 3} & \multicolumn{2}{|c|}{ ESCALA 4} & \multicolumn{2}{|c|}{ ESCALA 5} & \multicolumn{2}{|c|}{ SCALA 6} & \multicolumn{2}{|c|}{ ESCAlA 7} \\
\hline OPERACION & $\mathrm{U}$ & $T$ & E & $T$ & t1 & $T$ & U & $\mathrm{I}$ & $\mathrm{L}$ & 1 & i & $\mathrm{T}$ & $\mathrm{U}$ & 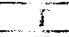 \\
\hline LITRAFILTRACION & 1 & $.14 \mathrm{E} 3$ & 1 & $.41 \mathrm{E}$ & 1 & $.68 \mathrm{E} 3$ & 1 & $.14 E_{-1}$ & 1 & .415 & 1 & $68 \mathrm{E} 4$ & 2 & $.68 \mathrm{E4}$ \\
\hline $\operatorname{OSM}$ & 0 & 0 & 0 & 0 & 0 & 0 & 0 & 0 & 0 & 0 & 0 & 0 & 0 & 0 \\
\hline 105 & 0 & 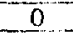 & 0 & 0 & 0 & 0 & 0 & 0 & 0 & 0 & 0 & 0 & 1 & $33 \mathrm{E2}$ \\
\hline SECADO & 1 & 2 & 1 & $51 E 2$ & 1 & $85 \mathrm{E2}$ & 1 & $.17 \mathrm{E} 3$ & 1 & $51{ }^{2}$ & 1 & $.85 E 3$ & 1 & $27 E 3$ \\
\hline OSMOSIS INERSA & 7 & $.13 \mathrm{~F}^{2}$ & 7 & $4 \mathrm{E} 2$ & 7 & $67 \mathrm{T2}$ & $\frac{3}{6}$ & $.13 \mathrm{E} 3$ & 7 & $.4 E^{3}$ & 7 & $.67 \mathrm{E3}$ & 7 & .1354 \\
\hline EVAPORACIOX & 0 & 0 & 0 & 0 & 0 & 0 & 0 & 0 & 0 & 0 & 0 & 0 & 0 & 0 \\
\hline COL ENZMLATICA & 451 & $34 \mathrm{EI}$ & 451 & $.1 \mathrm{E} 2$ & 451 & $.17 \pm 2$ & 451 & $.34 \mathrm{E2}$ & 451 & $1 \mathrm{E} 3$ & 451 & $17 E 3$ & 451 & $34 \mathrm{E} 3$ \\
\hline OSMOSIS INVERSA & 0 & 0 & 0 & 0 & 0 & 0 & 0 & 0 & 0 & 0 & 0 & o & 0 & 0 \\
\hline EVAPORACIOX & 1 & 34 & 1 & $.1 \mathrm{E} 1$ & 1 & $.17 \mathrm{El}$ & 1 & $34 \mathrm{E}$ & 1 & $\{\mathrm{EZ}$ & 1 & $.17 E 2$ & 1 & $34 \mathrm{E} 2$ \\
\hline
\end{tabular}

TABLA A-3.1-15 (CONTINUACION) HOJA 2: RESLITADOS TECNICOS DE PROCESO MEIMIZANDO COSTOS

\begin{tabular}{|c|c|c|c|c|c|c|c|c|c|c|c|c|c|c|}
\hline FROCESO N 15 & \multicolumn{2}{|c|}{ ESCALA 2} & \multicolumn{2}{|c|}{ ESCALA 2} & \multicolumn{2}{|c|}{ ESCALA 3} & \multicolumn{2}{|c|}{ ESCALA 4} & \multicolumn{2}{|c|}{ ESCALA 5} & \multicolumn{2}{|c|}{ ESCALA 6} & \multicolumn{2}{|c|}{ ESCALA 7} \\
\hline OPERACION & U & $\mathrm{T}$ & 0 & $\mathrm{~T}$ & [] & $T$ & $\mathbf{U}$ & $T$ & $i$ & $T$ & $\bar{U}$ & $T$ & $\overline{\mathrm{v}}$ & $\bar{T}$ \\
\hline ULTRAFIL TRACIOA & 2 & $.69 \mathrm{E} 2$ & 1 & $.41 E 3$ & 1 & $69 E 3$ & 1 & $.14 \mathrm{E} 4$ & 1 & .45 & 1 & .6724 & 1 & $.13 E 5$ \\
\hline OSMOSIS INVERSA & 0 & 0 & o & 0 & 0 & 0 & 0 & 0 & 0 & 0 & 0 & o & 0 & 0 \\
\hline E'APORACION & 6 & .15 & 0 & 0 & 1 & .6 & 1 & $.12 \mathrm{EI}$ & 1 & SSE & 1 & $.92 \mathrm{E1}$ & 1 & $.18 E 2$ \\
\hline CRISTAIZZACION & 1 & $.17 E 1$ & 1 & $.11 \mathrm{E2}$ & 1 & $.84 \mathrm{E}_{1}$ & 1 & $.17 \mathrm{E2}$ & 1 & $59 \mathrm{E}$ & 1 & $99 \mathrm{E} 2$ & 1 & $.2 \mathrm{E3}$ \\
\hline CETTRIRUA ACOO & 1 & $.62 \mathrm{~F}-1$ & 1 & $78 \mathrm{E}-1$ & 1 & .19 & 1 & 32 & 1 & 78 & $\frac{1}{1}$ & $11 \mathrm{E}$ & 1 & 19E1 \\
\hline SBCADO & 1 & $38 E 1$ & 3 & $.43 E 2$ & 1 & $.2 \mathrm{E}$ & 1 & $.39 \mathrm{E2}$ & 1 & $.1 E 3$ & 1 & $.17 E 3$ & $i$ & $33 \mathrm{E} 3$ \\
\hline OSMOSIS INIERSA & 7 & $14 \mathrm{E} 2$ & 7 & $A \mathrm{E}^{2}$ & 7 & $.672^{2}$ & 7 & $.14 E 3$ & 7 & $.4 E^{3}$ & 7 & $.67 \mathrm{E} 3$ & & $.13 \mathrm{E} 4$ \\
\hline E'APORACIOX & 0 & 0 & 0 & 0 & 0 & 0 & $\underline{0}$ & $\mathbf{0}$ & 0 & i & 0 & 0 & 0 & 0 \\
\hline COL ENZIMLATICA & 453 & $34 \mathrm{EI}$ & 451 & $\sqrt{E 2}$ & 451 & $.17 \mathrm{E} 2$ & 451 & $.34 \mathrm{E}_{2}$ & 451 & $.1 \mathrm{E3}$ & 451 & $.17 E 3$ & 456 & $33 E 3$ \\
\hline OSMOSIS INVERSA & 0 & 0 & 0 & 0 & $\overline{0}$ & 0 & 0 & 0 & 0 & 0 & 0 & 0 & 0 & 0 \\
\hline FAPORACIOA & 1 & 34 & $\frac{0}{1}$ & $.1 \mathrm{E} 1$ & 1 & $17 E 1$ & 1 & $34 \mathrm{~F} 1$ & 1 &.$m$ & 1 & $.17 E 2$ & $\frac{1}{1}$ & $34 \mathrm{E} 2$ \\
\hline
\end{tabular}


TABLA A-3.1-16 (CONTINU'ACION)

HOMA 2: RESILITADOS TECNTCOS DEL PROCESO MINIMIZZANDO COSTIOS

\begin{tabular}{|c|c|c|c|c|c|c|c|c|c|c|c|c|c|c|}
\hline PROCESO N 16 & \multicolumn{2}{|c|}{ ESCALA 1} & \multicolumn{2}{|c|}{ ESCALA 2} & \multicolumn{2}{|c|}{ ESCALA 3} & \multicolumn{2}{|c|}{$\overline{\text { ESCALA } 4}$} & \multicolumn{2}{|c|}{ ESCALA 5} & \multicolumn{2}{|c|}{ ESCALA 6} & \multicolumn{2}{|c|}{ ESCALA 7} \\
\hline OPERACION & u & $\mathbf{T}$ & $\bar{T}$ & $\overline{\mathrm{T}}$ & $t$ & $T$ & $\mathrm{t}$ & $\bar{T}$ & $\mathrm{U}$ & $T$ & $\bar{t}$ & I & $\underline{v}$ & $\mathrm{~T}$ \\
\hline LLTRAFILTRACION & 1 & $9 \mathrm{E2}$ & 1 & $27 \mathrm{E}^{3}$ & 1 & $45 \mathrm{E}^{3}$ & 1 & $.9 \mathrm{E}^{3}$ & 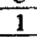 & $.27 E-4$ & 1 & $.45 \mathrm{E} 4$ & 1 & $.9 E-4$ \\
\hline OSMOSIS IN ERSA & 7 & $37 \mathrm{EI}$ & 7 & $.11 \mathrm{E2}:$ & 7 & $.19 \mathrm{E} 2$ & 7 & $37 E 2$ & 7 & $.11 \mathrm{E} 3$ & 7 & $.19 \mathrm{E} 3$ & 7 & $37 \mathrm{TE}$ \\
\hline EVAPORACIO & 0 & $\overline{0}$ & 0 & 0 & 0 & 0 & 0 & 0 & 0 & 0 & 1 & $.16 \mathrm{E} 2$ & $\underline{0}$ & o \\
\hline SECADO & 1 & $.25 \mathrm{E}$ & 1 & $76 E 2$ & 1 & $.13 \mathrm{E} 3$ & 1 & $.25 E^{2}$ & 1 & $.76 \mathrm{E} 3$ & 1 & $.3 \mathrm{E} 3$ & 1 & $25 E 4$ \\
\hline OSAIOSI & 7 & IE2 & 7 & $31 \mathrm{E2}$ & 7 & $.51 \mathrm{E} 2$ & 7 & $.1 \mathrm{E3}$ & 7 & $31 \mathrm{E3}$ & 7 & $.51 \mathrm{E3}$ & 7 & $.1 \mathrm{~F}$ \\
\hline EXAPORACION & 1 & 29 & 1 & .88 & 1 & $.15 \mathrm{E} 1$ & 1 & $.29 \mathrm{EI}$ & 1 & $88 \mathrm{~F} 1$ & 1 & $.15 E 2$ & 1 & $20 \mathrm{E} 2$ \\
\hline NTERCAM IONICO & 1 & $.8 \mathrm{E}-1$ & $=$ & .24 & 1 & .4 & 1 & 8 & 1 & $.24 \mathrm{E} 1$ & 1 & $.4 \mathrm{EI}$ & 1 & $8 \mathrm{EI}$ \\
\hline
\end{tabular}

TABLA A-3.1-17 (CONTINUACION)

HOJA 2: RESULTADOS TECNICOS DEL PROCESO MINTMIZANDO COSTOS

\begin{tabular}{|c|c|c|c|c|c|c|c|c|c|c|c|c|c|c|}
\hline PROCESON 17 & $\operatorname{tsc}$ & ALA 1 & & $\overline{L A} 2$ & & LA 3 & & $\mathrm{LA}$ & $\overline{\text { ESC }}$ & $\overline{L A 5}$ & $\overline{E S C}$ & IA 6 & PSC & $\mathrm{LA}$ \\
\hline OPERACION & C & $\mathrm{T}$ & $\mathbf{C}$ & $T$ & $\mathrm{t}$ & $\bar{T}$ & $\mathrm{U}$ & $\bar{T}$ & $\mathrm{U}$ & $\mathrm{T}$ & $t^{-}$ & $T$ & $\mathrm{~L}$ & $T$ \\
\hline ULTRAFILTRACION & 1 & $.11 \mathrm{E} 3$ & 1 & $.34 \mathrm{E} 3$ & 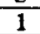 & $.56 \mathrm{E} 3$ & 1 & $.11 \mathrm{E}$ & $\frac{1}{1}$ & $34 \mathrm{E4}$ & 1 & $.56 \mathrm{E}_{4}$ & 1 & $.11 \mathrm{E}^{5}$ \\
\hline OSMOSIS I & 7 & $.18 \mathrm{E}$ & 1 & $.55 \mathrm{E} 1$ & 1 & $.92 \mathrm{E} 1$ & 7 & $.18 \mathrm{E} 2$ & 7 & 5 5E2 & $\overline{7}$ & $.92 \mathrm{E} 2$ & 7 & $.18 \mathrm{E3}$ \\
\hline EVAPORACION & 0 & 0 & 0 & 0 & 0 & 0 & 0 & 0 & 0 & 0 & 0 & 0 & 0 & 0 \\
\hline & 1 & $.17 E 2$ & 1 & $.52 \mathrm{E}^{2}$ & 1 & $.86 E 2$ & 1 & $.17 \mathrm{E} 3$ & 1 & $.52 \mathrm{E}^{3}$ & 1 & $.86 \mathrm{E}^{3}$ & 1 & .1754 \\
\hline OSMOSIS & 7 & $.12 \mathrm{~F} 2$ & 7 & $.36 \mathrm{F2}$ & $\overline{\bar{T}}$ & $.61 \mathrm{E} 2$ & -7 & $.12 \mathrm{E} 3$ & 7 & $36 \mathrm{E3}$ & 5 & $.61 \mathrm{E3}$ & 7 & $.12 \mathrm{E} 4$ \\
\hline EVAPORACION & 1 & 35 & 1 & $.1 \mathrm{EI}$ & 1 & $.17 \mathrm{E}$ & 1 & $35 \mathrm{E} 1$ & 1 & $.1 \mathrm{E2}$ & 1 & $.17 \mathrm{E} 2$ & 1 & $64 E 2$ \\
\hline DTERCAM 1ONICO & 1 & $.95 \mathrm{E}-1$ & 7 & 29 & 1 & .48 & 1 & .95 & 1 & $.29 \mathrm{El}$ & 1 & $.48 \mathrm{E} 1$ & 1 & $.95 \mathrm{E} 1$ \\
\hline
\end{tabular}

TARLA A-3.1-18 (CONTINUACION)

HOJA 2: RESULTADOS TBCNCOS DEL PROCESO MINIMIZANDO COSTOS

\begin{tabular}{|c|c|c|c|c|c|c|c|c|c|c|c|c|c|c|}
\hline PROCESO N 18 & \multicolumn{2}{|c|}{ ESCALA I } & \multicolumn{2}{|c|}{ ESCALA 2} & \multicolumn{2}{|c|}{ ESCALA 3} & \multicolumn{2}{|c|}{ ESCALA 4} & \multicolumn{2}{|c|}{ ESCALA S } & \multicolumn{2}{|c|}{ ESCALA 6} & \multicolumn{2}{|c|}{ ESCALA 7} \\
\hline OPERA & (1) & $\mathbf{T}$ & $\mathbf{U}$ & $\mathbf{T}$ & I & $\mathbf{T}$ & $\mathbf{U}$ & $\mathbf{T}$ & $\mathrm{u}$ & $\mathbf{I}$ & $\mathbf{U}$ & $\mathrm{T}$ & $\mathbf{U}$ & $\mathbf{T}$ \\
\hline ULTRAFII & 1 & $.14 \mathrm{~EB}^{3}$ & 1 & A1E3 & 1 & $.68 \mathrm{E} 3$ & 1 & $.14 \mathrm{E} 4$ & 1 & .4115 & 1 & $.68 \mathrm{E4}$ & 2 & $68 E_{4}$ \\
\hline OSM & 6 & 0 & & 0 & 0 & 0 & 0 & 0 & 0 & 0 & 0 & 0 & 0 & 0 \\
\hline EVAP & 0 & 0 & 0 & 0 & 0 & 0 & 0 & 0 & 0 & $\mathbf{0}$ & 0 & 0 & 1 & $33 \mathrm{E2}$ \\
\hline & 1 & $.17 \mathrm{Z}$ & & $51 \mathrm{E}$ & & $.85 \mathrm{E} 2$ & & $.17 E 3$ & 1 & $51 \mathrm{E3}$ & 1 & $.85 \mathrm{E3}$ & 1 & $27 \mathrm{E} 3$ \\
\hline OSMOSIS INVERSA & 7 & $.13 \mathrm{E2}$ & 7 & $.4 \mathrm{EZ}$ & 7 & $.67 \mathrm{E} 2$ & 7 & $.13 \mathrm{E}^{3}$ & 7 & $.4 E 3$ & 7 & $.67 \mathrm{E}^{3}$ & 7 & $13 \mathrm{~F} 4$ \\
\hline & 1 & 39 & 1 & $.12 \mathrm{El}$ & 2 & $.10 \mathrm{E} 1$ & $=$ & $39 \mathrm{E} 1$ & 1 & $.12 \mathrm{E2}$ & 1 & $.19 E 2$ & 1 & $39 E 2$ \\
\hline DTERCAM IONICO & 1 & .11 & 1 & 32 & 1 & 53 & 1 & $.11 \mathrm{E} 1$ & 1 & $32 \mathrm{EI}$ & 1 & $.53 \mathrm{Fi}$ & 1 & $.11 \mathrm{E} 2$ \\
\hline
\end{tabular}

TABLA A-3.1-19 (CONTINUACION)

HOJA 2: RESI ITADOS TKCNICOS DII PROCESO MINIA IZANDO COSTOS

\begin{tabular}{|c|c|c|c|c|c|c|c|c|c|c|c|c|c|c|}
\hline PROCESO $N^{\circ} 19$ & \multicolumn{2}{|c|}{ FSCALA 1} & \multicolumn{2}{|c|}{ ESCALA 2} & \multicolumn{2}{|c|}{ ESCALA 3} & \multicolumn{2}{|c|}{ ESCAIA 4} & \multicolumn{2}{|c|}{ ESCALA 5} & \multicolumn{2}{|c|}{ ESCAIA 6} & \multicolumn{2}{|c|}{ ESCAIA 7} \\
\hline OPERACION & $\mathrm{I}$ & $T$ & i & $T$ & I & $\mathrm{T}$ & iI & $T$ & U & $\mathrm{I}$ & $\mathbf{E}$ & $\mathrm{T}$ & $\bar{t}$ & $\bar{T}$ \\
\hline DLTRAFILTRACION & 2 & $69 E 2$ & 1 & $.41 \mathrm{E3}$ & 1 & $.69 \mathrm{E} 3$ & 1 & $.14 \mathrm{HA}$ & 1 & $.4 F 4$ & 1 & .6714 & 1 & $13 E 5$ \\
\hline OSMOSIS INUERSA & 0 & 0 & 0 & 0 & 0 & 0 & 0 & 0 & 0 & 0 & 0 & 0 & 0 & 0 \\
\hline E APORACION & 6 & .15 & 0 & 0 & 1 & .6 & 1 & $.12 \mathrm{E} 1$ & $\frac{\pi}{1}$ & $.55 \mathrm{E} 1$ & 1 & $.92 \mathrm{Fl}$ & 1 & $.18 E 2$ \\
\hline CRIST ALIZACION & 1 & $.17 \mathrm{E} 1$ & 1 & $.11 \mathrm{E}^{2}$ & 1 & $.84 \mathrm{E}]$ & 1 & $.17 \mathrm{E}^{2}$ & 1 & .592 .2 & 1 & .9912 & 1 & $.2 \mathrm{~F}^{3}$ \\
\hline CENTRIFLIGACION & 1 & $.62 \mathrm{~F}-1$ & 1 & $.781-1$ & 1 & .19 & 1 & 32 & 1 & .78 & 1 & $.11 \mathrm{EI}$ & 1 & $.19 \mathrm{E}$ \\
\hline SHCADO & 1 & $38 \mathrm{~F} 1$ & 1 & $43 \mathrm{E} 2$ & 1 & $.2 \mathrm{E} 2$ & 1 & $39 \mathrm{~L}$ & 1 & $.1 \mathrm{E3}$ & 1 & .1713 & 1 & $-33 \mathrm{E} 3$ \\
\hline OSMOOSIS INTERSA & 7 & .3452 & 7 & $.4 E^{2}$ & 7 & $.67 \mathrm{E} 2$ & 7 & $.14 E_{3}$ & 7 & $.4 \mathrm{I}^{3}$ & 7 & $.67 \mathrm{E}$ & 7 & $.13 E 4$ \\
\hline E APORACION & 1 & .39 & 1 & $.12 \mathrm{E}]$ & 1 & $.19 \mathrm{~L} 1$ & 1 & 3911 & 1 & $.12 \mathrm{E} 2$ & 1 & $.19[2$ & 1 & $38 \mathrm{E} 2$ \\
\hline INTTRCAM IONICO & 1 & .11 & 1 & 32 & 1 & 53 & 1 & $.11 \mathrm{E} 1$ & 1 & $.32 \mathrm{El}$ & 1 & $.53 \mathrm{~F} 1$ & 1 & $.11 \mathrm{~F} 2$ \\
\hline
\end{tabular}


TABLA A-3.1-20 (CONTINUACION)

HOLA 2: RESIIITAIXS TECNICOS DEL PROCESO AINIMILA NO COSTOS

\begin{tabular}{|c|c|c|c|c|c|c|c|c|c|c|c|c|c|c|}
\hline PROCESO N 20 & \multicolumn{2}{|c|}{ ESCALA 1} & \multicolumn{2}{|c|}{ ESCALA 2} & \multicolumn{2}{|c|}{ ESCALA 3} & \multicolumn{2}{|c|}{ ESCALA 4} & \multicolumn{2}{|c|}{ ESCALA 5} & \multicolumn{2}{|c|}{ ECCALA 6} & \multicolumn{2}{|c|}{ ECALA 7} \\
\hline OPERACION & Li & $T$ & $\mathrm{U}$ & $I$ & $\mathrm{I}$ & $\mathrm{T}$ & $\mathrm{U}$ & $T$ & $\mathrm{U}$ & $T$ & $\mathbf{L}$ & $T$ & C & $\mathrm{T}$ \\
\hline ULTRAFILTRACION & 1 & $.9 \mathrm{E} 2$ & 1 & $.27 \mathrm{E} 3$ & 1 & $.45 E^{3}$ & 1 & $9 \mathrm{E3}$ & 1 & $.27 \mathrm{E} 4$ & 1 & $.45 \mathrm{E} 4$ & 1 & $.9 \mathrm{E} 4$ \\
\hline OSMOSIS DVVERSA & 7 & $37 \mathrm{EI}$ & 7 & $.11 \mathrm{E} 2$ & $\because$ & $.19 E 2$ & 7 & $.37 \mathrm{E} 2$ & 7 & $.11 \mathrm{E}$ & 7 & $.19 \mathrm{E3}$ & 7 & $37 E 3$ \\
\hline EVAPORACIOS & 0 & 0 & 0 & 0 & 0 & 0 & 0 & 0 & 0 & 0 & 1 & $.16 \mathrm{E} 2$ & 0 & 0 \\
\hline SBCADO & 1 & $.25 E 2$ & 1 & $.6 \mathrm{E2}$ & 1 & $13 \mathrm{E} 3$ & 1 & $.25 \mathrm{E3}$ & 1 & $.76 \mathrm{E}$ & 1 & $3 \mathrm{E3}$ & 1 & $25 \mathrm{~F}$ \\
\hline NTERCAM. IONICO & 1 & $.8 \mathrm{E}-1$ & 1 & .24 & 1 & $A$ & 1 & 8 & 1 & $.24 E 1$ & 1 & $.4 \mathrm{E} 1$ & 1 & $.8 \mathrm{E} 1$ \\
\hline COL. ENZIKLATICA & 155 & $.77 \mathrm{E} 1$ & 62 & $.58 E 2$ & 105 & $5-E 2$ & 155 & $.7 \mathrm{E2}$ & 451 & $.79 E 2$ & 451 & $.13 \mathrm{E} 3$ & 451 & $26 \mathrm{E} 3$ \\
\hline OSMOSIS MT ERSA & 7 & $.43 \mathrm{E} 1$ & 5 & $.22 \mathrm{E} 2$ & 4 & $.45 E 2$ & 7 & $.43 \mathrm{E} 2$ & 7 & $13 E 3$ & $\bar{z}$ & $.21 \mathrm{E} 3$ & $\bar{j}$ & $.43 \mathrm{E} 3$ \\
\hline EVAPORACION & 1 & .45 & 7 & .79 & $\overline{7}$ & $.13 \mathrm{E} 1$ & 1 & $.24 \mathrm{E} 1$ & 1 & $.73 \mathrm{E}$ & 1 & $.12 \mathrm{E} 2$ & 1 & $24 \mathrm{E} 2$ \\
\hline
\end{tabular}

TABLA A-3.1-21 (CONTANUACION)

HOLA 2: RESTI ADOS TECNCOS DEL PROCESO MINTIZANTK COSTOS

\begin{tabular}{|c|c|c|c|c|c|c|c|c|c|c|c|c|c|c|}
\hline PROCESO N 21 & \multicolumn{2}{|c|}{ ESCALA 1} & \multicolumn{2}{|c|}{ ESCAIA 2} & \multicolumn{2}{|c|}{ ESCALA 3} & \multicolumn{2}{|c|}{ ESCALA 4} & \multicolumn{2}{|c|}{ ESAAL 5} & \multicolumn{2}{|c|}{ ESCALA 6} & \multicolumn{2}{|c|}{ ESCALA 7} \\
\hline OPERACION & $\bar{U}$ & $T$ & $\mathbf{L}$ & $T$ & $\mathrm{I}$ & $\mathrm{T}$ & $\mathrm{U}$ & $T$ & $\mathrm{U}$ & $\mathrm{T}$ & $\tau$ & $T$ & $\overline{\mathbf{L}}$ & $T$ \\
\hline ULTRAFILTRACION & 1 & $.11 \mathrm{E3}$ & 1 & .341 .3 & 1 & $.56 \mathrm{E} 3$ & 1 & $.11 E 4$ & 1 & $34 E 4$ & 1 & $5 \overline{564}$ & 1 & $.11 \mathrm{ES}$ \\
\hline OSMOSIS INVERSA & 7 & $.8 \mathrm{FI}$ & 7 & $.55 E 1$ & 7 & $.92 \mathrm{E} 1$ & 7 & $.18 \mathrm{E2}$ & 7 & $55 \mathrm{E} 2$ & 7 & $.92 \mathrm{E2}$ & 7 & $.18 \mathrm{E}$ \\
\hline EAPORACION & 0 & 0 & 0 & 0 & 0 & 0 & 0 & 0 & 0 & 0 & 0 & 0 & $\overline{0}$ & 0 \\
\hline SEAADO & 1 & $\mathrm{EZ}$ & 1 & $52 \mathrm{E} 2$ & 1 & $86 \mathrm{E2}$ & 1 & $.17 \mathrm{E} 3$ & 1 & $52 \mathrm{E} 3$ & 1 & $.86 E 3$ & 1 & $.17 \mathrm{E} 4$ \\
\hline NTERCAM 10 NICO & 1 & $95 \mathrm{E}-1$ & 1 & .29 & 1 & .48 & 1 & .95 & 1 & $.29 \mathrm{E1}$ & 1 & $.48 \mathrm{EI}$ & 1 & $.95 \mathrm{E} 1$ \\
\hline COL ENZIMATICA & 149 & $.95 \mathrm{EI}$ & 155 & $.27 \mathrm{E} 2$ & 100 & $71 \mathrm{E2}$ & $\overrightarrow{8 i}$ & $.16 \mathrm{E} 3$ & 113 & $38 \mathrm{E} 3$ & 451 & $.16 \mathrm{E3}$ & 41 & $31 E 3$ \\
\hline OSMOSIS INVERSA & 7 & $51 \mathrm{EI}$ & $\overline{7}$ & $.15 E 2$ & 5 & $.43 \mathrm{E} 2$ & 2 & $31 \mathrm{E} 3$ & 3 & $53 \mathrm{E} 3$ & 7 & $.25 \mathrm{E} 3$ & 7 & 5113 \\
\hline EVAPORACION & 1 & 29 & 1 & .86 & & $16 \mathrm{E} 1$ & 7 & $31 \mathrm{E} 1$ & 7 & $.93 \mathrm{El}$ & 1 & $.14 E 2$ & 1 & 292 \\
\hline
\end{tabular}

TABLA A-3.1-22 (CONTINUACON)

HOIA 2: RESILTADOS TE NICOS DEL PROCESO MINIMIZANDO COSTOS

\begin{tabular}{|c|c|c|c|c|c|c|c|c|c|c|c|c|c|c|}
\hline PROCESO N 22 & \multicolumn{2}{|c|}{ ESCALA 1} & \multicolumn{2}{|c|}{ ESCALA 2} & \multicolumn{2}{|c|}{ ESCALA 3} & \multicolumn{2}{|c|}{ ESCAIA 4} & \multicolumn{2}{|c|}{ ESCALA 5} & \multicolumn{2}{|c|}{ ESCALA 6} & \multicolumn{2}{|c|}{ ESCAIA 7} \\
\hline OPER & $\mathrm{U}$ & $T$ & $\mathrm{c}$ & 1 & $\mathrm{U}$ & $T$ & $\mathrm{U}$ & $\bar{I}$ & $\mathrm{U}$ & $T$ & $\overline{\mathbf{L}}$ & $\mathrm{I}$ & 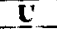 & \\
\hline ULTR & 1 & $14 E 3$ & 1 & $.41 E 3$ & 1 & $68 \mathrm{E} 3$ & 7 & $.14 E^{4}$ & 1 & A1E4 & 1 & $.68 E 4$ & 2 & .6854 \\
\hline OS & $\pi$ & 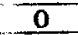 & 0 & 0 & i & 0 & 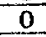 & 0 & $c$ & 0 & 0 & 0 & 0 & 0 \\
\hline & 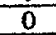 & 3 & 0 & 0 & 5 & $\underline{0}$ & $I$ & 7 & 0 & 0 & 0 & 0 & 1 & $33 E 2$ \\
\hline & 1 & .1772 & 1 & $51 E 2$ & 1 & .8512 & 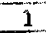 & .17 & 1 & $51 \mathrm{E}$ & 1 & $85 \mathrm{E}^{3}$ & 1 & $27 \mathrm{E3}$ \\
\hline INT & 1 & .11 & 1 & 32 & 1 & 53 & 1 & .1 & 1 & $32 \mathrm{E} 1$ & 1 & S3E1 & 1 & $.11 \mathrm{E2}$ \\
\hline $\mathrm{CO}$ & 148 & $.11 \mathrm{E} 2$ & 92 & $52 \mathrm{E}$ & 93 & $.85 E 2$ & 88 & $.18 \mathrm{E}$ & 91 & $52 \mathrm{E3}$ & 451 & $.17 \mathrm{E} 3$ & 451 & $34 \mathrm{E} 3$ \\
\hline & 7 & $56 \mathrm{E} 1$ & 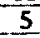 & $.28 \mathrm{E} 2$ & 5 & $.48 E 2$ & 7 & 3 & 7 & & 7 & $.28 \mathrm{E} 3$ & 7 & $56 E 3$ \\
\hline 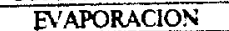 & 1 & 32 & & $.1 \mathrm{E} 1$ & & $.17 E 1$ & 7 & $35 \mathrm{E} 1$ & 6 & $11 E 2$ & 1 & $.16 E 2$ & 1 & $32 \mathrm{E}$ \\
\hline
\end{tabular}

TABLA A-3.1-23 (CONTINUACION)

HOIA 2: RPSTT ADOS TECNTCOS DEI PROCESO MINTMUZAVT DO COSTOS

\begin{tabular}{|c|c|c|c|c|c|c|c|c|c|c|c|c|c|c|}
\hline \multirow{2}{*}{$\begin{array}{l}\text { PROCESON } \\
\text { OPERACION }\end{array}$} & \multicolumn{2}{|c|}{ ESCALA 1} & \multicolumn{2}{|c|}{ ESCALA 2} & \multicolumn{2}{|c|}{ ESCALA 3} & \multicolumn{2}{|c|}{ ESCALA 4} & \multicolumn{2}{|c|}{ ESCALA 5} & \multicolumn{2}{|c|}{ ESCALA 6} & \multicolumn{2}{|c|}{ ESALA 7} \\
\hline & i & $T$ & $\overline{\mathrm{I}}$ & $\bar{T}$ & $\mathrm{~L}$ & $\mathrm{~T}$ & U & $\mathbf{T}$ & 0 & $\mathrm{~T}$ & 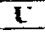 & 4 & $\mathrm{E}$ & $\bar{T}$ \\
\hline ULTRAFILTRACION & 2 & .6012 & 1 & $.41 \mathrm{E}$ & 1 & .6953 & 1 & $.14 \mathrm{H4}$ & 1 & .454 & 1 & .6754 & 1 & $.13 \mathrm{ES}$ \\
\hline OSMOOSIS INTERSA & 0 & 0 & 0 & 0 & 0 & 0 & 0 & 0 & 0 & 0 & 0 & 0 & o & 0 \\
\hline EVAPORACION & 6 & .15 & 0 & 0 & 1 & 6 & 1 & $.12 \mathrm{El}$ & 1 & $.55 E 1$ & 1 & $.92 \mathrm{E} 1$ & 1 & $.18 E 2$ \\
\hline CRISTALIZACION & 1 & $.17 \mathrm{HI}$ & 1 & $.11 \mathrm{~F}^{2}$ & 1. & $.84 \mathrm{E} 1$ & 1 & $.17 \mathrm{E} 2$ & 1 & $.50 \mathrm{E} 2$ & 1 & $.99 E 2$ & 1 & $.2 \mathrm{E} 3$ \\
\hline CENTRIFUGACION & 1 & $.62 \mathrm{E}-1$ & 1 & $.781-1$ & 1 & .19 & 1 & .32 & 1 & .8 & 1 & $.11 \mathrm{FI}$ & 1 & $.19 E 1$ \\
\hline SECADO & 1 & $38 \mathrm{Fl}$ & 1 & $.43 E 2$ & 1 & $.2 \mathrm{E} 2$ & 1 & $3 \overline{9 E 2}$ & 1 & $.1 \mathrm{E} 3$ & 1 & $.17 \mathrm{E}_{3}$ & 1 & $.33 E^{3}$ \\
\hline INTERCAM IONICO & 1 & .11 & 1 & 32 & 1 & .53 & 1 & $.11 \mathrm{EI}$ & 1 & $32 \mathrm{El}$ & 1 & $.53 \mathrm{El}$ & 1 & $.11 \mathrm{E} 2$ \\
\hline COL ENZIMIATICA & 142 & $.11 \mathrm{E}$ & 108 & $.44:$ & 110 & $.56 \mathrm{E} 2$ & 68 & $.23 \mathrm{E} 3$ & 71 & $.67 \mathrm{E} 3$ & 92 &. $\mathrm{BGE3}$ & 92 & $.17 \mathrm{TA}$ \\
\hline OSMOSIS INIERSA & 7 & $.56 E 3$ & 5 & .287 & 7 & $.28 \mathrm{E} 2$ & 2 & $.35 \mathrm{E} 3$ & 7 & $.17 E^{3}$ & 4 & $.69 \mathrm{E} 3$ & 6 & $.72 \mathrm{E3}$ \\
\hline EVAPORACION & 1 & 32 & 7 &.$\overline{\mathrm{F}} 1$ & 1 & .1601 & 7 & $35 \mathrm{E1}$ & 7 & $.1 E 2$ & 6 & $.18 \mathrm{E}$ & 6 & $36 \mathrm{~F}_{2}$ \\
\hline
\end{tabular}


TABIA A-3.1-24 (CONTINUACION,

HOJA 2: RESI LTAIXOS TEC VKOOS DEL PROCESO MINTVIZANDO COSTOS

\begin{tabular}{|c|c|c|c|c|c|c|c|c|c|c|c|c|c|c|}
\hline PROCESO N 24 & \multicolumn{2}{|c|}{ ESCALA 1} & \multicolumn{2}{|c|}{ ESCALA 2} & \multicolumn{2}{|c|}{ ESCALA 3} & \multicolumn{2}{|c|}{ ESCALA 4} & \multicolumn{2}{|c|}{ ESCALA 5} & \multicolumn{2}{|c|}{ ESCALA 6} & \multicolumn{2}{|c|}{ SCALA 7} \\
\hline OPERACION & L & $\mathbf{I}$ & I & $T$ & 1 & $T$ & $\mathrm{U}$ & $\mathbf{I}$ & E & $\mathbf{T}$ & $\mathbf{E}$ & $\mathbf{T}$ & L & $T$ \\
\hline UITRAFILTRACIOS & 1 & $.9 \mathrm{E} 2$ & 1 & $.27 \mathrm{~F}_{3}$ & 1 & $.45 E^{3}$ & 1 & $.9 \mathrm{E} 3$ & 1 & $27 E^{4}$ & 1 & $.45 \mathrm{E} 4$ & 1 & .954 \\
\hline OSMOSIS INTERSA & 7 & $.37 \mathrm{E1}$ & 7 & $.11 \mathrm{E} 2$ & 7 & $.19 \mathrm{E} 2$ & 7 & $37 E 2$ & 7 & $.11 \mathrm{E} 3$ & 7 & $.19 \mathrm{E} 3$ & 7 & $37 \mathrm{E} 3$ \\
\hline ENAPORACION & 0 & 0 & 0 & 0 & 0 & 0 & 0 & 0 & 0 & 0 & 0 & $.16 \mathrm{E} 2$ & 0 & 0 \\
\hline SBCADO & 1 & $.25 E 2$ & 1 & $.76 \mathrm{E2}$ & 1 & $.13 \mathrm{E}_{3}$ & 1 & $.25 E^{3}$ & 1 & $.76 \overline{E 3}$ & 1 & $3 \mathrm{E} 3$ & 1 & $.25 \mathrm{KH}$ \\
\hline OSMIOSIS IVIERSA & 7 & $.1 \mathrm{E} 2$ & 7 & $.31 E 2$ & 7 & $51 E 2$ & 7 & $.1 \mathrm{E} 3$ & 7 & $31 \mathrm{E} 3$ & 7 & $51 \mathrm{E3}$ & 7 & $.1 \mathrm{E} 4$ \\
\hline E APOR $\triangle C I O N$ & 1 & 27 & 1 & 82 & 1 & $.14 \mathrm{E} 1$ & 1 & $.27 \mathrm{El}$ & 1 & $.82 \mathrm{El}$ & 1 & $.14 \mathrm{E} 2$ & 1 & $.27 \mathrm{E2}$ \\
\hline
\end{tabular}

TABLA A-3.1-25 (CONTINUACION)

HOJA 2: RESLLTADOS TECNICOS DEL PROCESO MDTMIZANDO COSTOS

\begin{tabular}{|c|c|c|c|c|c|c|c|c|c|c|c|c|c|c|}
\hline PROCESO $\mathbb{N}^{*} 25$ & \multicolumn{2}{|c|}{ ESCALA 1} & \multicolumn{2}{|c|}{ ESCALA 2} & \multicolumn{2}{|c|}{ ESCALA 3} & \multicolumn{2}{|c|}{ ESCALA 4} & \multicolumn{2}{|c|}{ ESCALA 5} & \multicolumn{2}{|c|}{ ECCALA 6} & \multicolumn{2}{|c|}{ FSCALA 7} \\
\hline OPERACION & 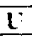 & $\mathrm{T}$ & $i$ & $\mathrm{I}$ & $\mathrm{I}$ & $I$ & $\mathrm{U}$ & $\mathbf{T}$ & $\mathrm{E}$ & $\mathbf{T}$ & $\mathbf{i}$ & $T$ & $\mathrm{I}$ & $\mathrm{T}$ \\
\hline LLTRAFILTRACION & 1 & $.11 \mathrm{E} 3$ & 1 & $.34 \mathrm{E}^{3}$ & 1 & $.56 \mathrm{E} 3$ & 1 & $.11 \mathrm{E} 4$ & 1 & $34 E 4$ & 1 & $.56 E 4$ & 1 & $.11 \mathrm{E} 5$ \\
\hline OSMOSIS INIERSA & 7 & $.18 \mathrm{E} 1$ & 7 & $.55 \mathrm{E} 1$ & 7 & $.92 \mathrm{E} 1$ & 7 & $.18 \mathrm{E} 2$ & 7 & $55 \mathrm{E2}$ & 7 & $.9 \overline{2 E 2}$ & 7 & $.18 \mathrm{E} 3$ \\
\hline DAPORACION & 0 & 0 & 0 & 0 & 0 & 0 & 0 & 0 & 0 & 0 & 0 & 0 & 0 & 0 \\
\hline SBCADO & 1 & $.17 \mathrm{E} 2$ & 1 & $.52 \mathrm{E}$ & 1 & $.86 E 2$ & 1 & $.17 \mathrm{E} 3$ & 1 & $.52 \mathrm{E} 3$ & 1 & $.86 \mathrm{E} 3$ & 1 & $.17 \mathrm{E} 4$ \\
\hline OSMOSIS MNERSA & $\bar{i}$ & $.12 \mathrm{E2}$ & 7 & $36 \mathrm{E} 2$ & 7 & $61 \mathrm{E2}$ & 7 & $.12 \mathrm{E3}$ & 7 & $.36 \mathrm{E} 3$ & 7 & .6113 & 7 & $.12 \mathrm{E} 4$ \\
\hline E'APORACION & 1 & 33 & 1 & $18 \mathrm{EI}$ & 1 & $.16 \mathrm{E} 1$ & 1 & $33 \mathrm{EI}$ & 1 & $.98 \mathrm{E} 1$ & 1 & $.16 \mathrm{E} 2$ & 1 & $33 \mathrm{E2}$ \\
\hline
\end{tabular}

TABLA A-3.1-26 (CONTTNUACION)

HOJA 2: RESLITADOS TECNICOS DEL PROCESO MINTIZANDO COSTOS

\begin{tabular}{|c|c|c|c|c|c|c|c|c|c|c|c|c|c|c|}
\hline PROCESO N 26 & \multicolumn{2}{|c|}{ ESCALA 1} & \multicolumn{2}{|c|}{$\overline{\mathrm{ESCALA}} 2$} & \multicolumn{2}{|c|}{ ESCALA 3} & \multicolumn{2}{|c|}{ ESCAIA 4} & \multicolumn{2}{|c|}{ ESCALA 5} & \multicolumn{2}{|c|}{ ESCAIA 6} & \multicolumn{2}{|c|}{ ESCALA 7} \\
\hline OPERACION & $\mathbf{E}$ & $\mathrm{T}$ & $\mathbf{U}$ & $\mathbf{T}$ & $\mathrm{U}$ & $T$ & U & $\mathbf{T}$ & $\mathbf{U}$ & $T$ & $\mathbf{U}$ & $T$ & $\mathrm{U}$ & $T$ \\
\hline ULTRAFILTRACION & 1 & $.14 \mathrm{E} 3$ & 1 & $.41 E 3$ & 1 & $.68 \mathrm{E} 3$ & 1 & $.14 \mathrm{E} 4$ & 1 & $.41 \mathrm{E} 4$ & 1 & $.68 \mathrm{E} 4$ & 2 & $.68 \mathrm{E} 4$ \\
\hline OSMOSLS INTERSA & $\mathbf{0}$ & 0 & 0 & 0 & 0 & 0 & 0 & o & $\mathbf{0}$ & 0 & o & 0 & 0 & 0 \\
\hline EVAPORACION & $\mathbf{0}$ & 0 & 0 & 0 & 0 & 0 & 0 & O & $\mathbf{0}$ & o & 0 & 0 & 1 & $33 E_{2}$ \\
\hline SBCADO & 1 & $.17 \mathrm{E} 2$ & 1 & $51 \mathrm{E2}$ & 1 & $.85 \mathrm{E} 2$ & 1 & $.17 \mathrm{E3}$ & 1 & $51 \mathrm{E}^{3}$ & 1 & $.85 \mathrm{E} 3$ & 1 & $27 \mathrm{E} 3$ \\
\hline OSMOSIS LNE & 7 & $.13 E 2$ & 7 & $.4 \mathrm{E}^{2}$ & 7 & $.67 \mathrm{E} 2$ & 7 & $.13 E 3$ & 7 & $.4 \mathrm{E} 3$ & 7 & $.67 \mathrm{E} 3$ & 7 & $.13 \mathrm{E}$ \\
\hline EVAPORACION & 1 & 36 & 1 & $.2 \mathrm{El}$ & 1 & $.18 \mathrm{E} 1$ & 1 & $36 \mathrm{El}$ & 1 & $.11 \mathrm{E} 2$ & 1 & $.18 \mathrm{E} 2$ & 1 & $.67 \mathrm{E2}$ \\
\hline
\end{tabular}

TABLA A-3.1-27 (CONTINUACION)

HOJA 2: RESLLTADOS TECNICOS DEL PROCESO MINTUIIZANDO COSTOS

\begin{tabular}{|c|c|c|c|c|c|c|c|c|c|c|c|c|c|c|}
\hline \multirow{2}{*}{$\begin{array}{l}\text { PROCESO N } 27 \\
\text { OPERACION }\end{array}$} & \multicolumn{2}{|c|}{ ESCALA 1} & \multicolumn{2}{|c|}{ ESCALA 2} & \multicolumn{2}{|c|}{ ESC $\overline{A L A ~} 3$} & \multicolumn{2}{|c|}{ ESCALA 4} & \multicolumn{2}{|c|}{ ESCALA 5} & \multicolumn{2}{|c|}{ ESCALA 6} & \multicolumn{2}{|c|}{ ESCALA 7} \\
\hline & $1:$ & $\mathrm{T}$ & 1 & $T$ & I & $T$ & II & $T$ & I & $\mathrm{T}$ & E. & $T$ & $\mathrm{I}^{\circ}$ & $T$ \\
\hline GITRAFIITRACION & 2 & $.69 \mathrm{H2}$ & 1 & $.41 \mathrm{E}^{3}$ & ] & $.69 \overline{\mathrm{E3}}$ & 1 & $.1+\mathrm{Ft}$ & 1 & $.4 \mathrm{EH}$ & 1 & $.67 \overline{F 4}$ & 1 & $.13 \mathrm{~F} 5$ \\
\hline OSMOSIS INTERSA & 0 & 0 & 0 & 0 & 0 & 0 & 0 & 0 & $\overline{0}$ & $\overline{0}$ & 0 & 0 & 0 & 0 \\
\hline EVAPORACION & 6 & .15 & 0 & 0 & 1 & .6 & 1 & $.12 \mathrm{El}$ & 1 & $.55 \mathrm{El}$ & 1 & $.92 \mathrm{E} 1$ & 1 & $.18 \mathrm{E} 2$ \\
\hline CRISTALYKACION & 1 & $.17 \mathrm{EI}$ & 1 & $.11 E 2$ & 1 & .8451 & 1 & $.37 E 2$ & 1 & $59 \mathrm{E} 2$ & $i$ & .9912 & 1 & $2 \mathrm{E3}$ \\
\hline CENTR & 1 & $.62 \mathrm{~F}-1$ & 1 & $.78 \mathrm{~K}-1$ & 1 & .19 & 1 & 32 & , & .78 & $-\frac{1}{1}$ & $.11 \mathrm{Fl}$ & $\frac{2}{1}$ & $.19 \mathrm{El}$ \\
\hline $\mathrm{CA}$ & 1 & & 1 & $.43 \mathrm{E}^{2}$ & 1 & $.2 \mathrm{E2}$ & 1 & .3912 & i & F3 & 1 & E 3 & 1 & $33 \mathrm{E}$ \\
\hline OSMOSIS INTERS & 7 & $.14 \mathrm{E} 2$ & $i$ & $.4 \mathrm{E}$ & 7 & .6712 & 7 & .1413 & 2 & $.4 \mathrm{E}^{3}$ & 7 & $.67 \mathrm{E} 3$ & 7 & $.13 \mathrm{H}$ \\
\hline FNAPORACION & 1 & 36 & 1 & .111 & 1 & $.18 \mathrm{II}$ & 1 & 3651 & 1 & $.11 \mathrm{E} 2$ & 1 & $.18 \mathrm{~F} 2$ & 1 & $36 \mathrm{~F} 2$ \\
\hline
\end{tabular}


TABLA A-3.1-28 (CONTINLACION)

HOJA 2: RESLITADOS TBCNTCOS DE PROCESO MDNIMIZANDO COSTOS

\begin{tabular}{|c|c|c|c|c|c|c|c|c|c|c|c|c|c|c|}
\hline \multirow{2}{*}{$\begin{array}{l}\text { PROCESON } 28 \\
\text { OPERACION }\end{array}$} & \multicolumn{2}{|c|}{ ESCALA 1} & \multicolumn{2}{|c|}{ ESCALA 2} & \multicolumn{2}{|c|}{ ESALA 3} & \multicolumn{2}{|c|}{ ESCALA 4} & \multicolumn{2}{|c|}{ ESCALA 5} & \multicolumn{4}{|c|}{ ESCALA 6 ESCALA 7} \\
\hline & $\bar{i}$ & $T$ & I & $\mathrm{T}$ & ? & $T$ & [I & $T$ & $\mathbf{U}$ & $\mathrm{T}$ & $\mathbf{L}$ & $T$ & $\mathrm{E}$ & $T$ \\
\hline LITRAFILTRACION & 1 & $.9 E 2$ & 1 & $2 \pi \mathrm{E}$ & 1 & $.45 E 3$ & 1 & $.9 E 3$ & 1 & $27 \mathrm{E}$ & 1 & $.45 E 4$ & 1 & $.9 \mathrm{E} 4$ \\
\hline OSNIOSIS INT'ERSA & 7 & $37 \mathrm{El}$ & 7 & $.11 \mathrm{E} 2$ & 7 & $.19 E 2$ & 7 & $37 \mathrm{E2}$ & 7 & $.11 \mathrm{E}$ & 7 & $.19 E 3$ & 7 & $37 \mathrm{E} 3$ \\
\hline FAP & 0 & 0 & 10 & & 0 & -1 & 0 & 0 & 0 & 0 & 1 & $.16 E 2$ & 0 & 0 \\
\hline & 1 & $.25 \mathrm{E} 2$ & 1 & $.76 E^{2}$ & 1 & $E$ & $\frac{0}{1}$ & $.25 \mathrm{E} 3$ & 0 & $.76 \mathrm{E} 3$ & 1 & $3 E 3$ & 1 & $.25 E 4$ \\
\hline OS! & 7 & $.1 \mathrm{E} 2$ & $\because$ & $31 E 2$ & 7 & $51 \mathrm{E}$ & 7 & $.1 \mathrm{E3}$ & 7 & $31 \mathrm{E} 3$ & 7 & $51 \mathrm{E}$ & 7 & .1054 \\
\hline $\mathrm{BT}$ & 1 & $.82 \mathrm{E}-1$ & & 25 & 1 & .41 & 1 & .82 & & $25 \mathrm{E} 1$ & 1 & $\mathrm{E} 1$ & 1 & $.82 \mathrm{E} 1$ \\
\hline 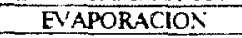 & 1 & 22 & 0 & 0 & 1 & $.11 \mathrm{FI}$ & 1 & $23 \mathrm{E} 1$ & 1 & $65 \mathrm{E} 1$ & 1 & $11 E 2$ & 1 & $22 \mathrm{E2}$ \\
\hline CRISTA & 1 & $.44 \mathrm{E}$ & 1 & $2 \mathrm{E} 2$ & 1 & 2212 & 1 & $.46 \mathrm{E} 2$ & 1 & $.13 \mathrm{E} 3$ & 1 & $22 \mathrm{E} 3$ & 1 & $.44 E 3$ \\
\hline CENTRI & 1 & .11 & 1 & 2 & 1 & 37 & 1 & .62 & 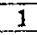 & $13 \mathrm{EI}$ & 1 & $.19 \mathrm{E} 1$ & 1 & $31 \mathrm{E} 1$ \\
\hline SBCADO & 1 & $.23 \%$ & 1 & $.13 \mathrm{E} 3$ & 1 & $.11 E 3$ & 1 & $.22 \mathrm{E3}$ & 1 & $.69 \mathrm{E}^{3}$ & 1 & $11 E 4$ & 1 & $23 \mathrm{E} 4$ \\
\hline
\end{tabular}

TABLA A-3.1-29 (CONTINUACl HOJA 2. RESUTTADCS TECNICOS DEL PROCESO MI IIZANDO COSTOS

\begin{tabular}{|c|c|c|c|c|c|c|c|c|c|c|c|c|c|c|}
\hline PROCESO N" 29 & \multicolumn{2}{|c|}{ ESCALA : } & \multicolumn{2}{|c|}{ ESCAIA 2} & \multicolumn{2}{|c|}{ ESCALA 3} & \multicolumn{2}{|c|}{ ESCALA 4} & \multicolumn{2}{|c|}{ ESCALA 5} & \multicolumn{2}{|c|}{ ESCALA 6} & \multicolumn{2}{|c|}{ ESCALA 7} \\
\hline OPERAC & 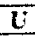 & I & i & $T$ & $\mathrm{v}$ & $I$ & $\underline{\mathcal{U}}$ & $T$ & $\mathbf{U}$ & $\mathrm{T}$ & $\bar{U}$ & I & $\mathbf{U}$ & $\mathbf{T}$ \\
\hline CLTRAFILTRACION & 1 & $.11 \mathrm{E3}$ & 1 & $34 E 3$ & 1 & $56 E 3$ & 1 & $.11 \mathrm{E4}$ & 1 & $.34 E 4$ & 1 & 5654 & 1 & $.11 \mathrm{ES}$ \\
\hline OSM & 7 & $.18 \mathrm{EE}$ & 7 & 55E1 & 5 & $.92 \mathrm{E1}$ & 7 & $.18 \mathrm{E} 2$ & 7 & $55 \mathrm{E} 2$ & 7 & $.92 \mp 2$ & 7 & $.18 \mathrm{E} 3$ \\
\hline ENP & $\overline{0}$ & 0 & 0 & 0 & 0 & 0 & 0 & 0 & 0 & 0 & 0 & 0 & 0 & 0 \\
\hline & 7 & $.17 \mathrm{E}_{2}$ & $=$ & $52 \mathrm{E} 2$ & 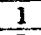 & $.86 E 2$ & 1 & $.17 E 3$ & 1 & $.52 \mathrm{E} 3$ & 9 & $.86 E 3$ & 1 & .1754 \\
\hline OSNOOSIS IMUERSA & 7 & $.12 E 2$ & 7 & 3622 & 7 & $.61 \mathrm{E2}$ & 7 & $.12 \mathrm{E3}$ & $\overline{7}$ & $.36 E^{3}$ & 7 & $.61 \mathrm{E3}$ & 7 & $.12 \mathrm{E} 4$ \\
\hline DTER & 1 & $.97 \mathrm{E}-1$ & 1 & 29 & 1 & .49 & 1 & .97 & 1 & $.29 \mathrm{E} 1$ & 8 & $.49 \mathrm{E} 1$ & 1 & $.97 \mathrm{EI}$ \\
\hline EA & 1 & 26 & 1 & .77 & 1 & $.13 E$ & 1 & $26 E 1$ & 1 & $.77 \mathrm{E} 1$ & 1 & $.13 E 2$ & 1 & $.26 \mathrm{E} 2$ \\
\hline CRIS & 1 & 52EI & 1 & .1652 & 1 & 2652 & & $2 \mathrm{E} 2$ & 1 & $.16 \mathrm{E}^{3}$ & 1 & 2653 & 1 & $.52 \mathrm{E3}$ \\
\hline CEVTRI & 1 & .13 & 1 & 29 & 1 & $A 1$ & 1 & 68 & 1 & $.15 E 1$ & 1 & $.22 \mathrm{FI}$ & 1 & 3651 \\
\hline SBCADO & 1 & $.27 \mathrm{E} 2$ & 1 & B1E2 & 1 & $.14 E^{2}$ & 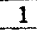 & $27 \mathrm{E} 3$ & 1 & $.81 \mathrm{E} 3$ & 1 & $.14 E-4$ & 1 & 27E-4 \\
\hline
\end{tabular}




\begin{tabular}{|c|c|c|c|c|c|c|c|c|c|c|c|c|c|c|}
\hline$F \bar{E}$ & I & tIS $\mathrm{I}^{\circ}$ & I & $876^{\circ}$ & I & $E \exists \varepsilon$ & I & E I & $I$ & $236^{\circ}$ & $I$ & TЈE & I & 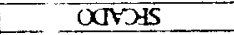 \\
\hline $178 \varepsilon$ & I & IIEC & $I$ & $1391^{\circ}$ & $I$ & $+L$ & $I$ & 15 & I & $\sqrt{\varepsilon}$ & I & $+\bar{L}$ & I & YOIOY IHIYLUJ \\
\hline E785 & $T$ & $\varepsilon 76$ & $I$ & 9า1 & I & 7985 & I & $210 \bar{c}^{\circ}$ & $I$ & $\mathrm{ZJ} \angle \mathrm{I}^{\circ}$ & 1 & 1385 & I & ¿OIDVZIVISIYO \\
\hline$\overline{Z E}$ & $\mathrm{I}$ & $27 t \mathrm{I}^{\circ}$ & {[} & 1758 & I & 755 & I & I.IFI & I & 58 & $\bar{I}$ & $6 \tau$ & I & SOIDVYOdVAG \\
\hline ट्ञाँ & $\bar{I}$ & $17+5$ & I & $I \exists Z E$ & $\mathrm{I}$ & IIII & $\mathrm{I}$ & +5 & I & $2 \xi$ & I & $\mathrm{II}^{\circ}$ & I & OJINOI IVVJYALVI \\
\hline $\operatorname{HE} I^{\circ}$ & 2 & $\mathcal{E} ! 9$ & 2 & $E \exists 5^{\circ}$ & 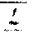 & $E]+I^{\circ}$ & 1 & 210 & $L$ & $235^{\circ}$ & $\div$ & $\operatorname{Tat} \mathrm{I}^{\circ}$ & $\therefore$ & BSUINUISISOWSO \\
\hline छદE & $\bar{I}$ & $E I\left\lfloor I^{-}\right.$ & $I$ & $\varepsilon t^{\circ}$ & $i$ & $736 \varepsilon$ & $\mathrm{I}$ & $\tau i \bar{z}$ & $\mathrm{I}$ & ZAEt & 1 & $118 \varepsilon$ & I & तणिS \\
\hline $1361^{\circ}$ & I & IIII & I & $8 !^{\circ}$ & $\bar{I}$ & $\overline{\boldsymbol{E}}$ & I & $6 \mathrm{l}$ & $\mathrm{I}$ & $1-781$ & I & $I-329^{\circ}$ & I & $\triangle O 1,0.1$ ITLAO \\
\hline$\varepsilon \exists Z^{\circ}$ & $I$ & $2366^{\circ}$ & $\mathrm{I}$ & 0365 & I & 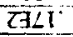 & $\mathrm{I}$ & $13+8$ & $I$ & $21 I^{\circ}$ & $I$ & {$\left[\exists \leq I^{\circ}\right.$} & 1 & VOIJVZTIV ISIAD \\
\hline $278 \mathrm{I}^{\circ}$ & I & $1326^{\circ}$ & $\mathrm{I}$ & $13 S S$ & $I$ & $192 \mathrm{I}^{\circ}$ & I & 9 & $I$ & 0 & 0 & $\mathrm{SL}^{\circ}$ & 9 & VOIJYYOdVA3 \\
\hline 0 & 0 & 0 & 0 & 0 & 0 & 0 & 0 & 0 & 0 & 0 & 0 & 0 & 0 & VSY L LI SISOWSO \\
\hline SAE I & $\mathrm{t}$ & 1719 & $\mathrm{I}$ & $t+5 t^{\circ}$ & I & $5 \pm I^{\circ}$ & I & $\$ 169^{\circ}$ & I & EIt & I & $2369^{\circ}$ & 2 & XOI J⿹LIIFY IA \\
\hline$I$ & $\underline{n}$ & $I$ & $\mathrm{~A}$ & $I$ & I & I & $\Omega$ & I & $\Omega$ & $I$ & .7 & $I$ & .1 & NOIJWYAdO \\
\hline \multicolumn{2}{|c|}{$\angle$ VTVOSA } & \multicolumn{2}{|c|}{$9 \forall$ TVOSA } & \multicolumn{2}{|c|}{ S VTVOSA } & \multicolumn{2}{|c|}{ t VIVDSA } & \multicolumn{2}{|c|}{$\varepsilon \forall T \forall D S A$} & \multicolumn{2}{|c|}{2 VTVSA } & \multicolumn{2}{|c|}{ I VTVOSA } & I $\varepsilon$ av OSATOXd \\
\hline
\end{tabular}

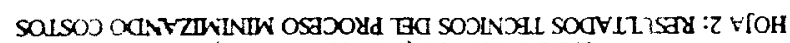

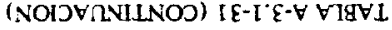

$\vec{s}$

\begin{tabular}{|c|c|c|c|c|c|c|c|c|c|c|c|c|c|c|}
\hline NE & I & HSI & I & $896^{\circ}$ & I & EقE & I & ESSI & I & $236^{\circ}$ & I & स्रE & I & OUF'as \\
\hline $138 \varepsilon$ & I & IJEC & I & $199 \mathrm{I}^{\circ}$ & I & $\varepsilon L^{-}$ & I & $s b^{+}$ & I & IE & I & $t \mathrm{I}^{\circ}$ & $t$ & 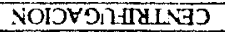 \\
\hline$\varepsilon] 8 S^{\circ}$ & T & $E 76 T$ & i & $\dot{\varepsilon} \equiv$ & I & $738 \mathrm{~S}^{\circ}$ & I & $76 \bar{Z}^{\circ}$ & I & $23 \angle I^{\circ}$ & I & {$[385$} & I & NOIJVZTVLSIYJ \\
\hline चद & I & $\mathrm{CAt} \mathrm{I}^{\circ}$ & I & {$[798$} & I & $1162^{\circ}$ & I & $13 \overline{2}^{\circ}$ & I & 98 & I & $6 t$ & i & NOIJV8ONVA \\
\hline $\operatorname{cat} \mathrm{I}^{\circ}$ & 1 & IJPS & I & IЭZE & I & IJII & I & $t S$ & $I$ & $2 \varepsilon$ & I & II & I & OOINOI IVEJYAIN \\
\hline tIEI & 2 & $E \pm 19$ & 2 & $\varepsilon \exists \nabla^{-}$ & $L$ & $\varepsilon \exists \varepsilon I^{\circ}$ & 6 & $23 \angle 9$ & 1 & $2 \exists t^{\circ}$ & 2 & दहां & 1 & FSUALI SISOINSO \\
\hline$\xi \exists L Z^{\circ}$ & $\bar{I}$ & 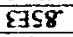 & I & EITS & I & $E \exists \angle I^{\circ}$ & I & $2 \exists S 8^{\circ}$ & I & 핀 & I & 근. & I & OCIVJAS \\
\hline$\overline{Z I E E}$ & $I$ & 0 & 0 & 0 & 0 & 0 & 0 & 0 & 0 & 0 & 0 & 0 & 0 & NOIOFYOAVA \\
\hline 0 & 0 & 0 & 0 & 0 & 0 & 0 & 0 & 0 & 0 & 0 & 0 & 0 & 0 & FSdANI SISONSO \\
\hline$\$ 789^{\circ}$ & I & 5789 & I & NIt & I & $\operatorname{tit} \mathrm{I}^{\circ}$ & $\mathrm{I}$ & $8189^{\circ}$ & I & EีIt & $I$ & $\varepsilon \exists+I^{\circ}$ & I & VOI Jvy IIHVYL In \\
\hline L & $\mathrm{n}$ & $I$ & 7 & $\mathrm{I}$ & $\mathrm{n}$ & I & $\Omega$ & $\underline{I}$ & 1 & 1 & .1 & $I$ &. $\bar{x}$ & जOID F्यJdO \\
\hline \multicolumn{2}{|c|}{$\angle \forall T O S A$} & \multicolumn{2}{|c|}{9 VTVOSA } & \multicolumn{2}{|c|}{ S VTYSSA } & \multicolumn{2}{|c|}{ - VTVSA } & \multicolumn{2}{|c|}{$\varepsilon$ VTVOSI } & \multicolumn{2}{|c|}{$\tau$ VTYXSA } & \multicolumn{2}{|c|}{ I VTVOSA } & OE aV OSAXOYd \\
\hline
\end{tabular}

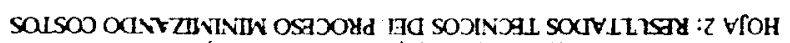
(NOIDVINIJNOJ) OE-I'E- $\forall$ IGVI 

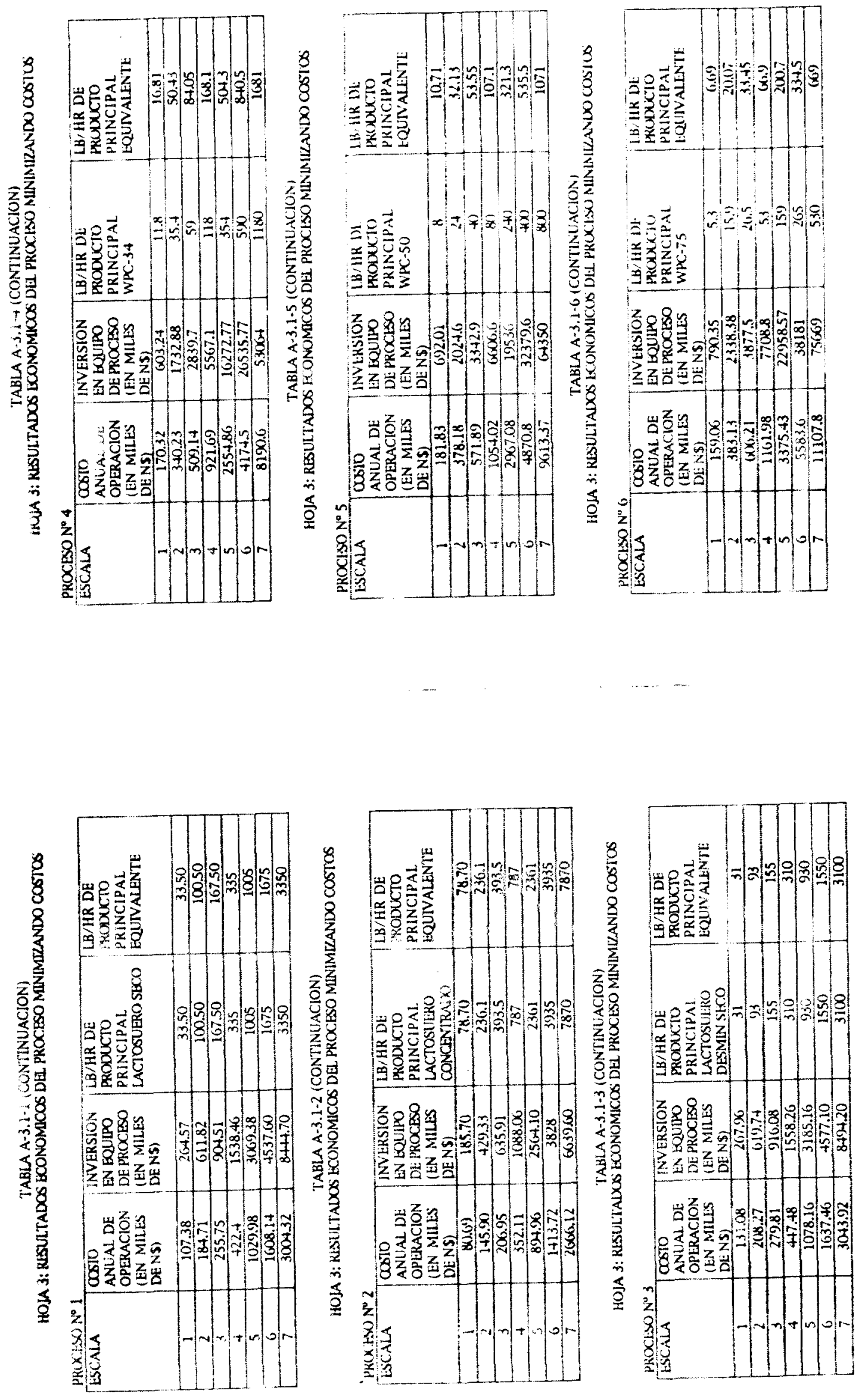


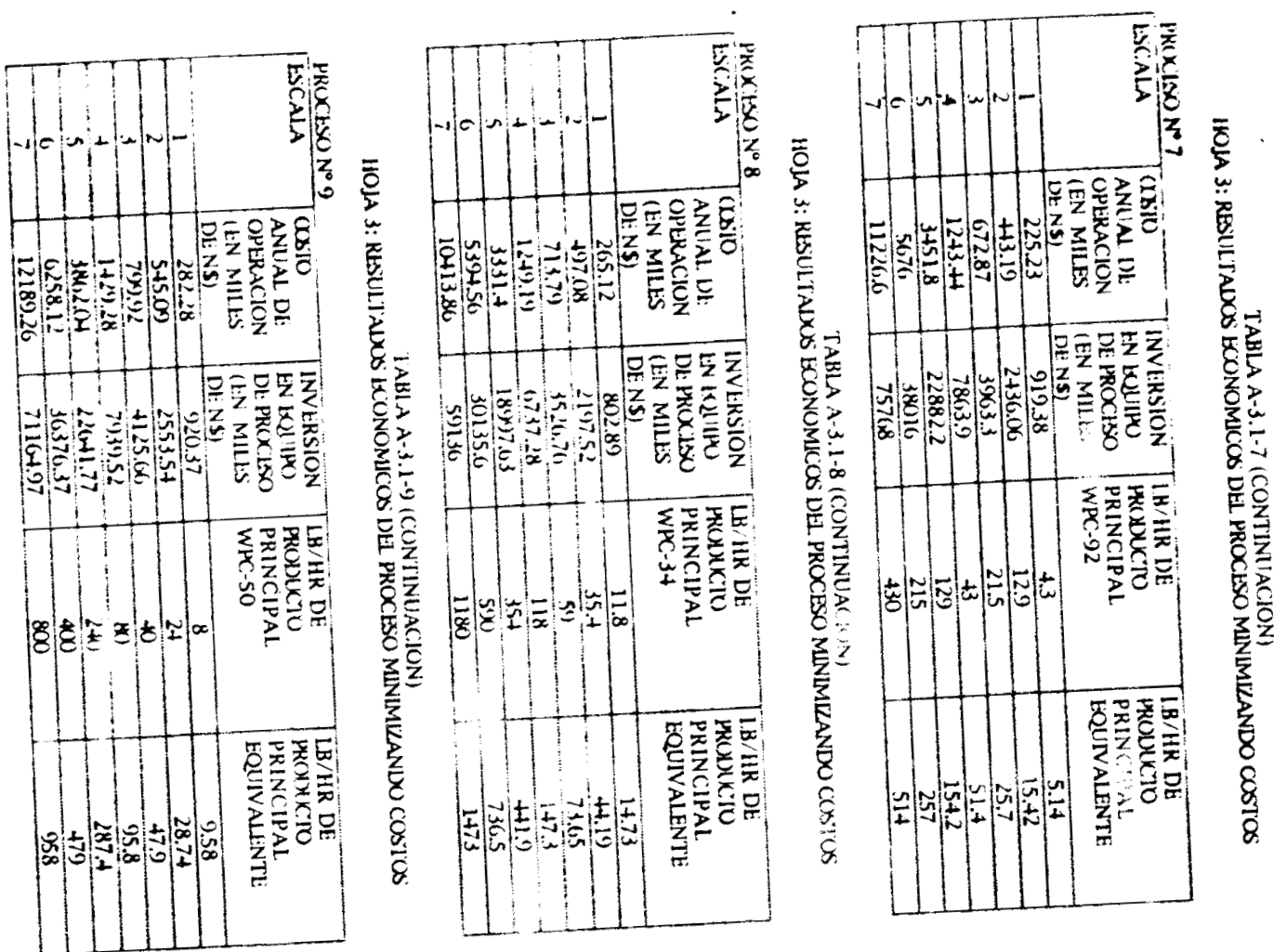

E
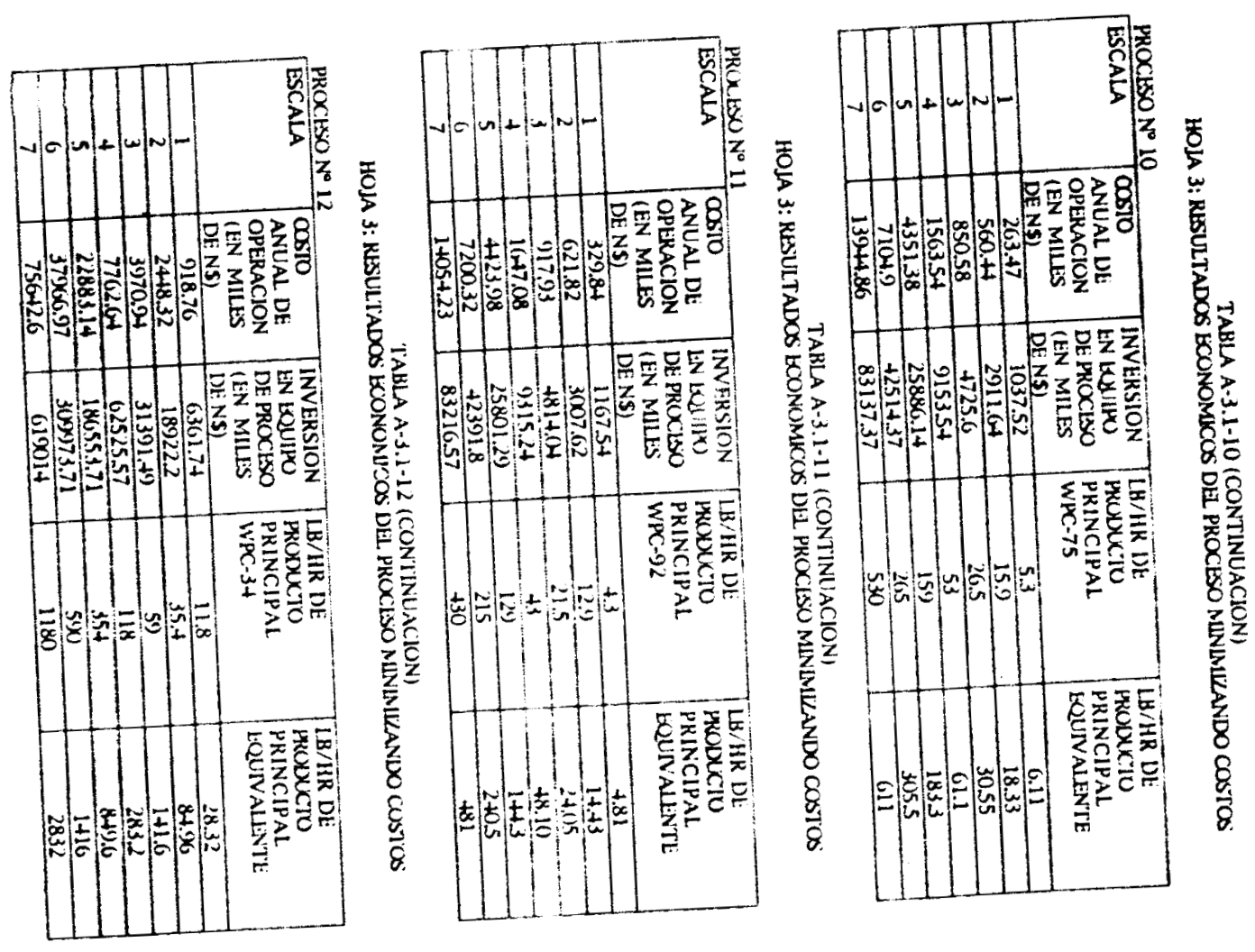

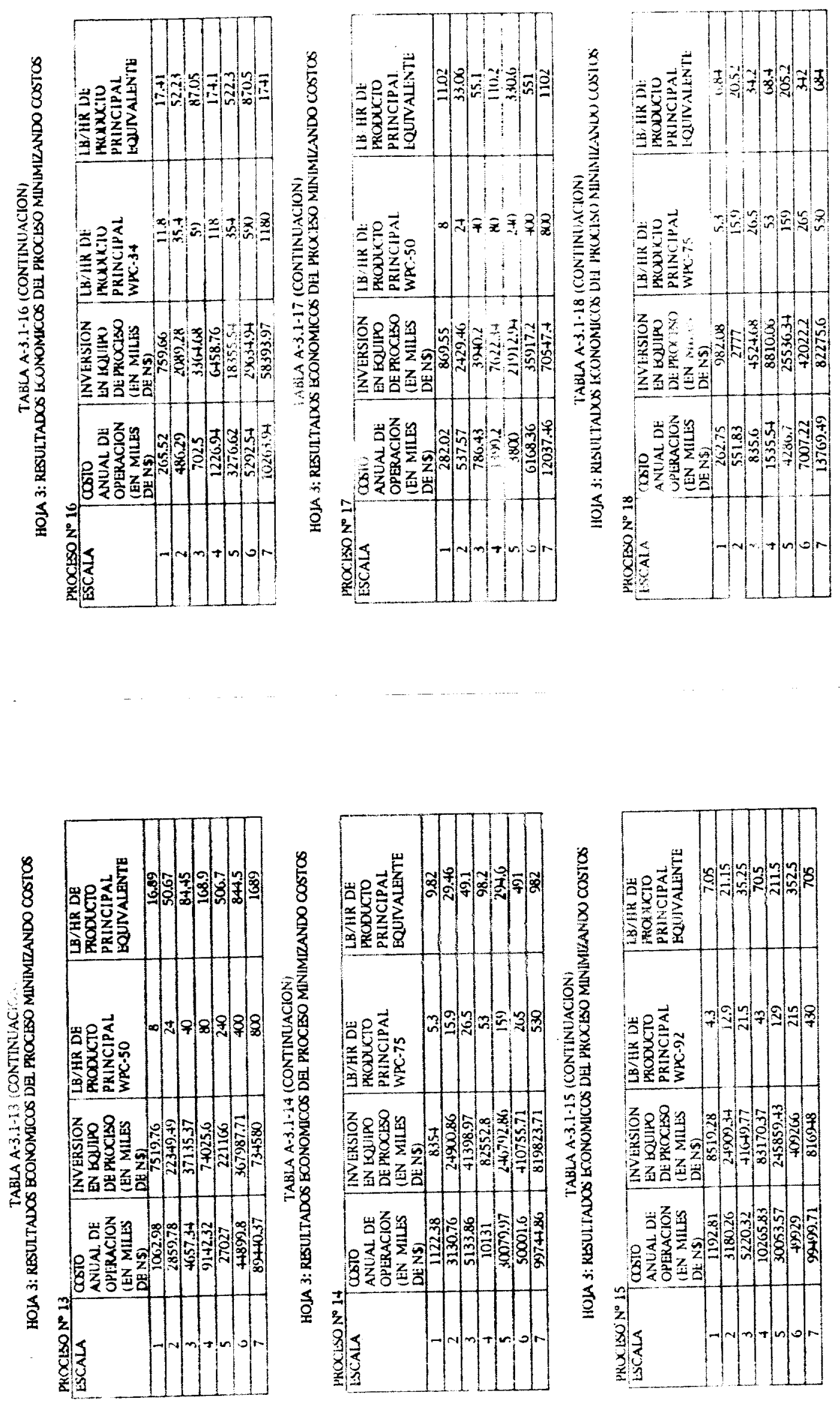

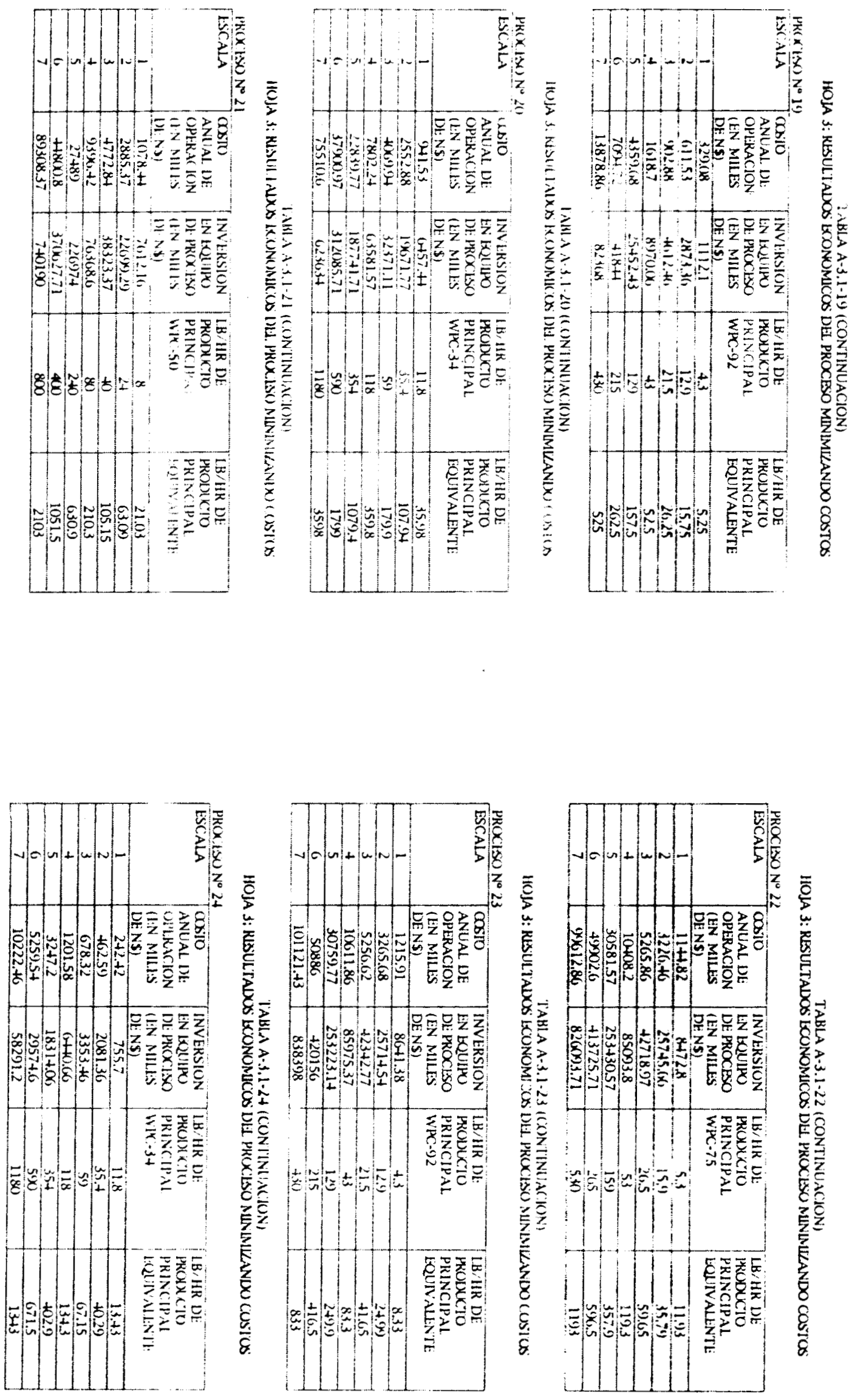

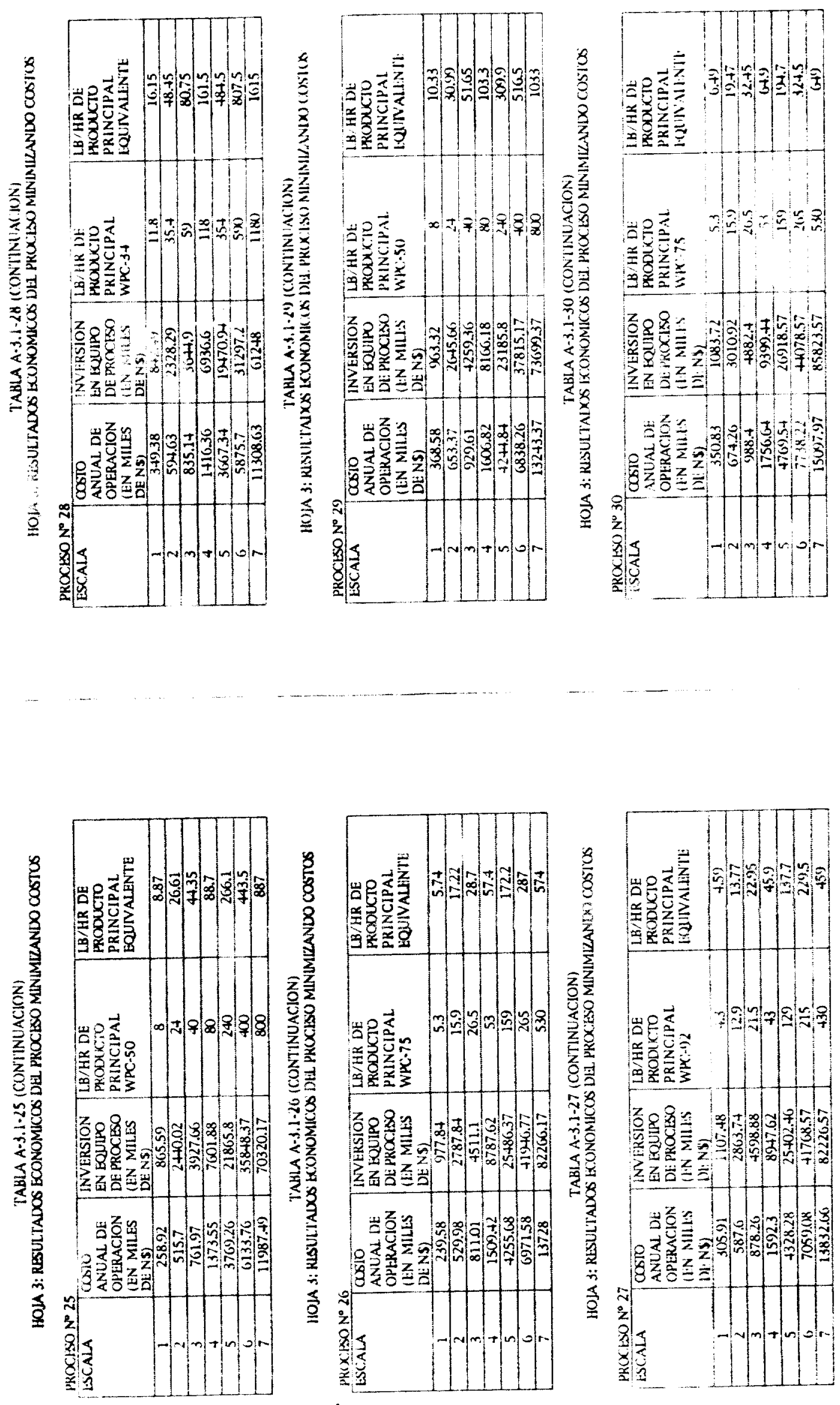


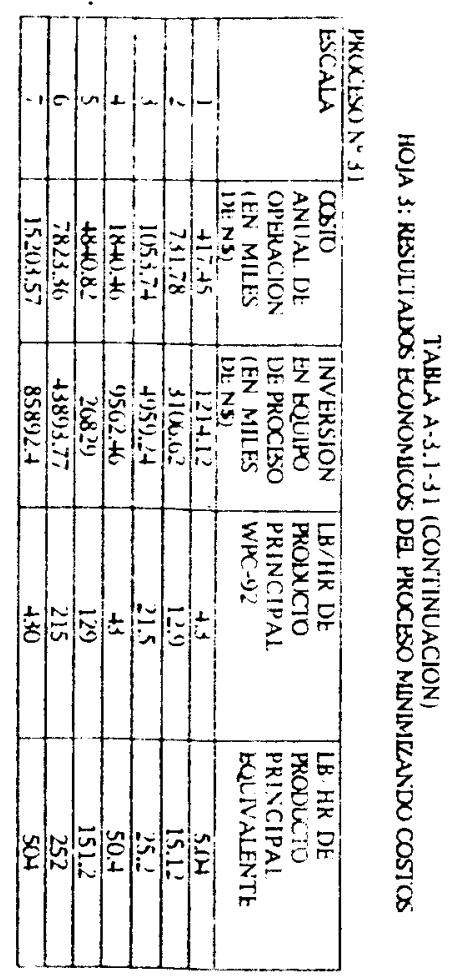

$\vec{s}$ 


\section{APENDICE C}

\section{LISTADO DEL SIMULADOR EMPLEADO EN EL CAPITUL 5}

Este simulador calcula la rentabilidad del proceso quesc o reconvertido sugún se describe en el Capítulo, 5, respecto del radicional en términos del paráme:ro DROI, y la in:ersión necesaria para la recinversion en miles de nuevos pesos de 1993 para tres es alas de proceso. Está escrito en 'unguaje FORTRAN y consta de un programa principal y una subrutina.

El programa principal permite elegir de entre un menú, el tipo de queso que se quiere considerar y las condiciones económicas del escenario que se desea estudiar. Las pérdidas de grasa y caseína son las mismas para ambos procesos y las condiciones límite de concentración por ultrafiltración y adición de caseína están incluidas para cada tipo de queso. La subrutina resuelve los balances de masa para los procesos según las fuguras 5-1 y 5-2 del Capítulo 5. 


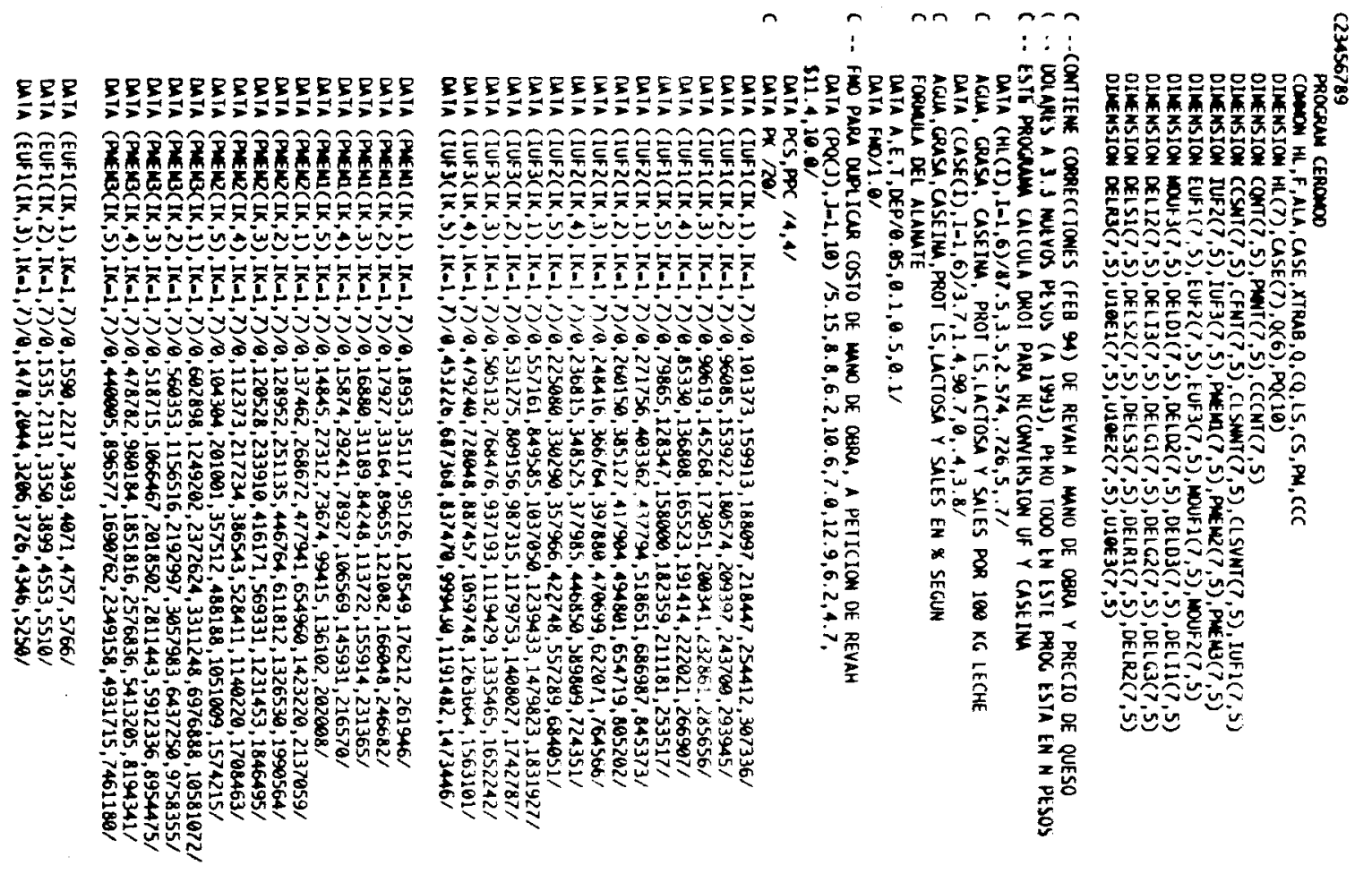

$\overline{5}$

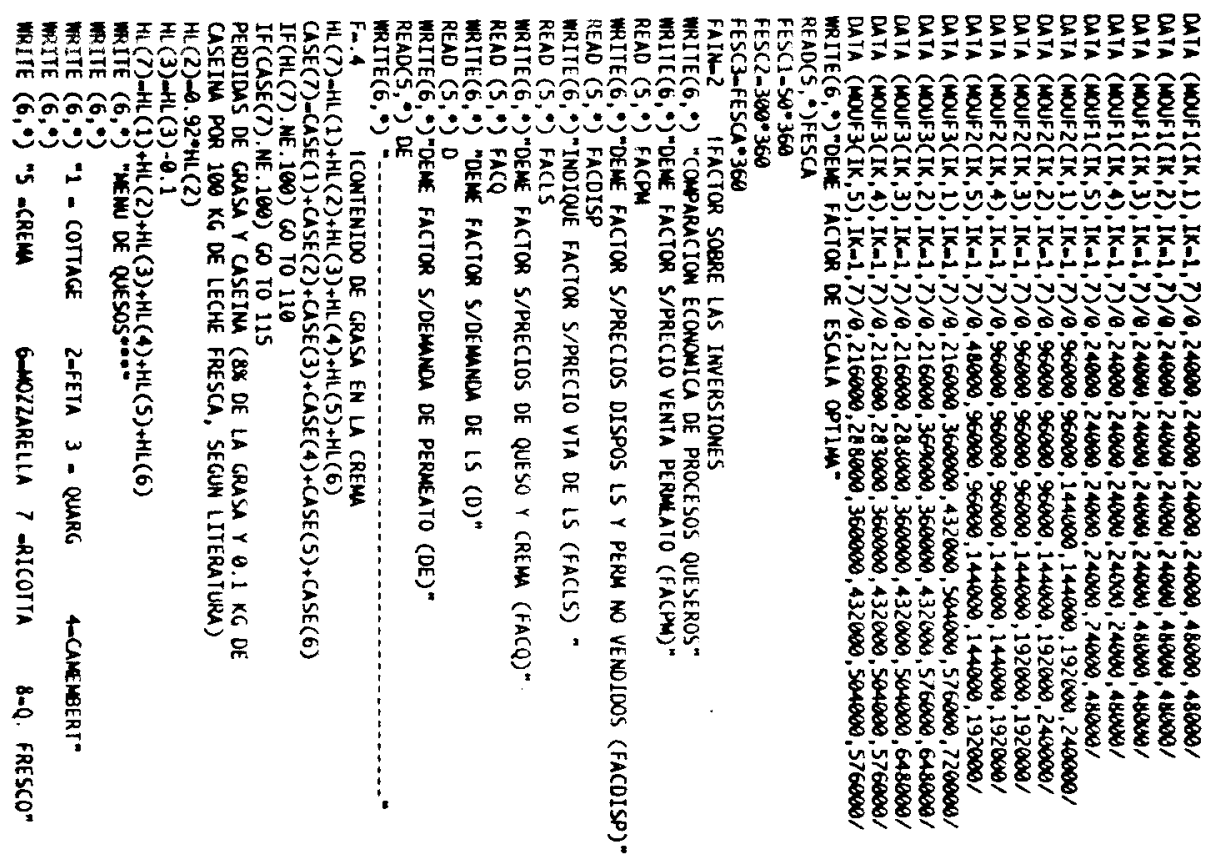

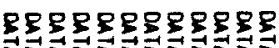

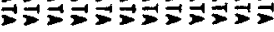

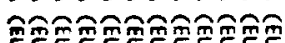

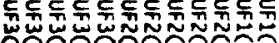

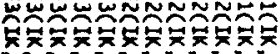
is

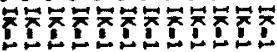

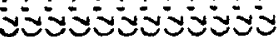
- adadadada 象政

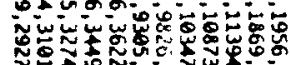
ชำ

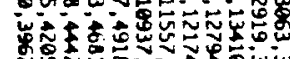

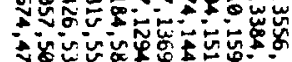

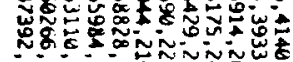
ove Nuñ

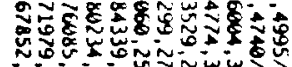

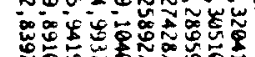
8888 \% min 

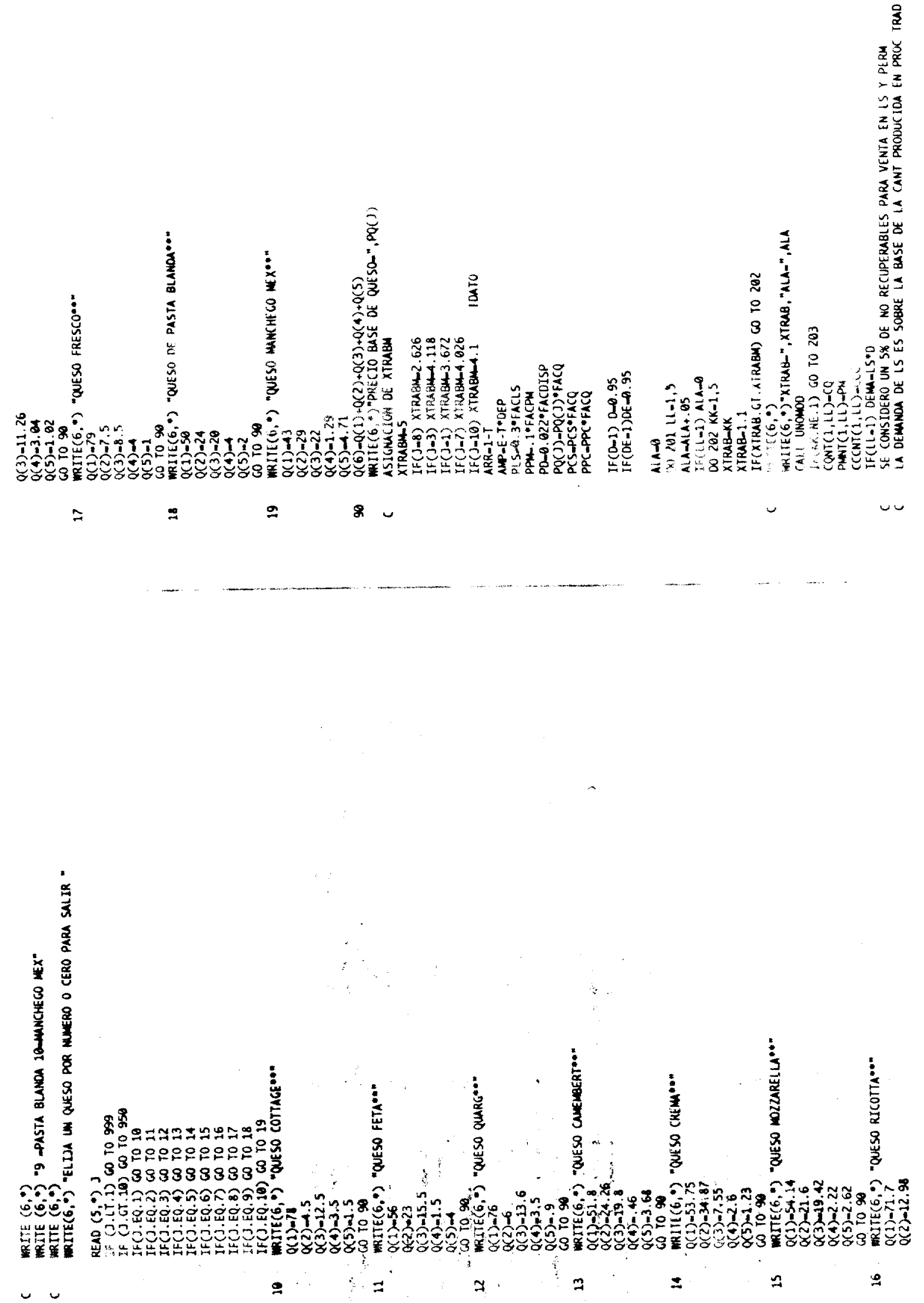


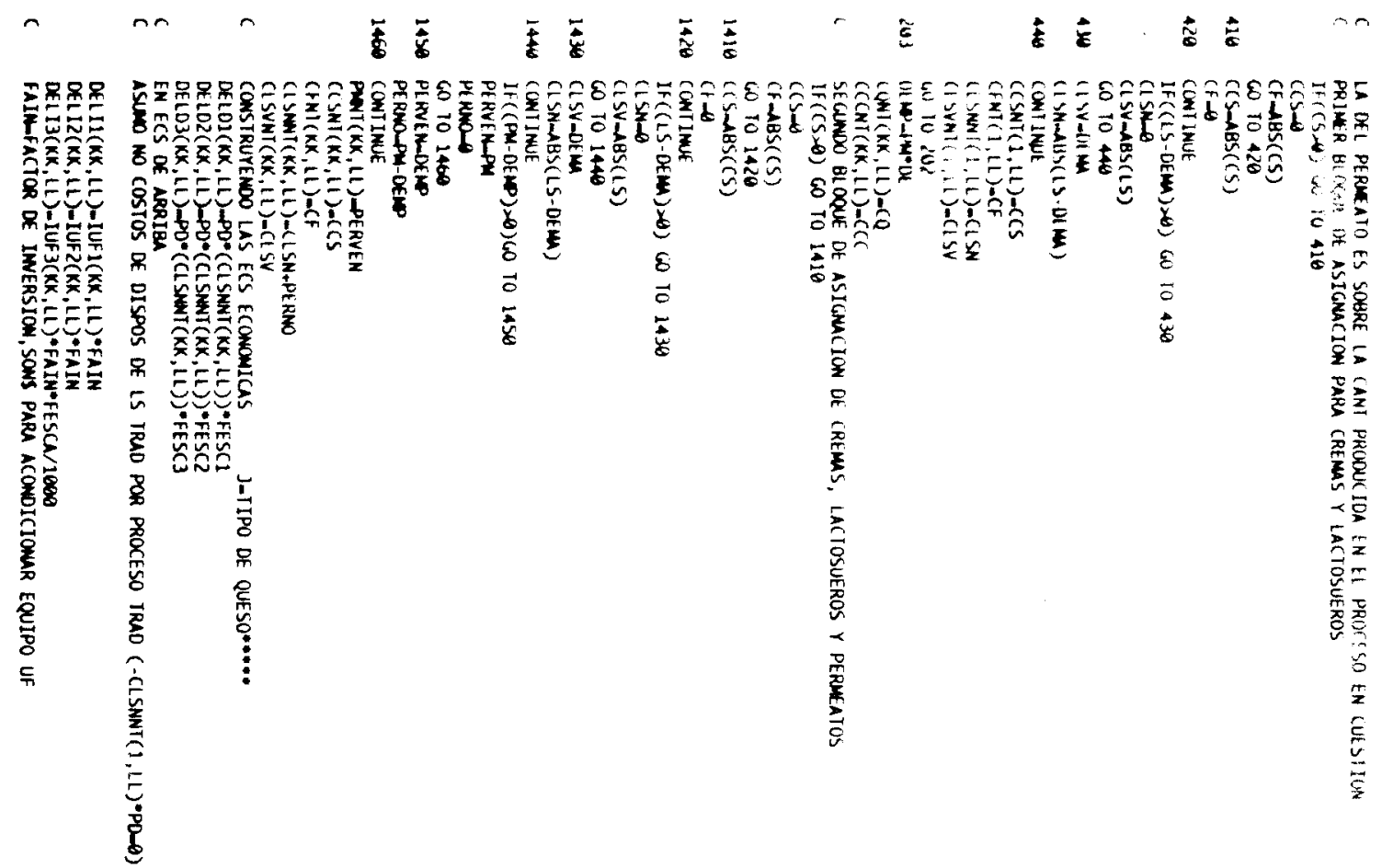

$\vec{n}$

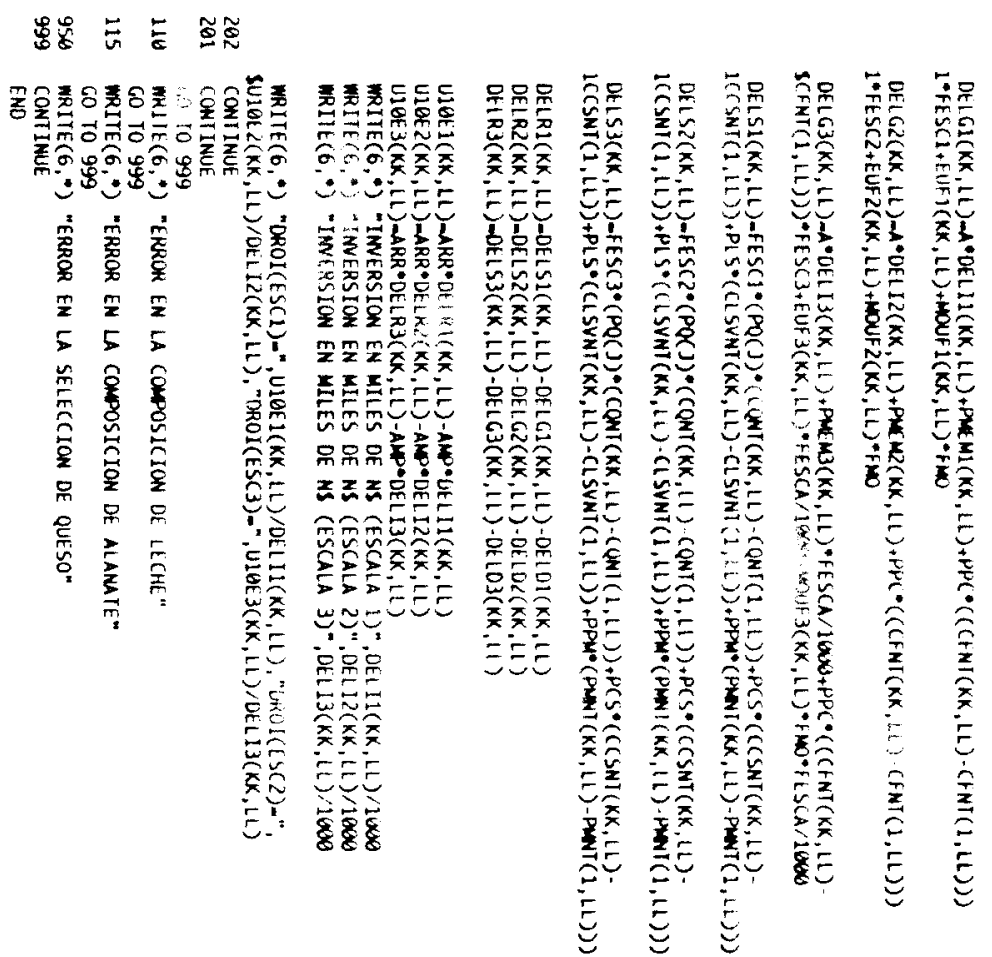




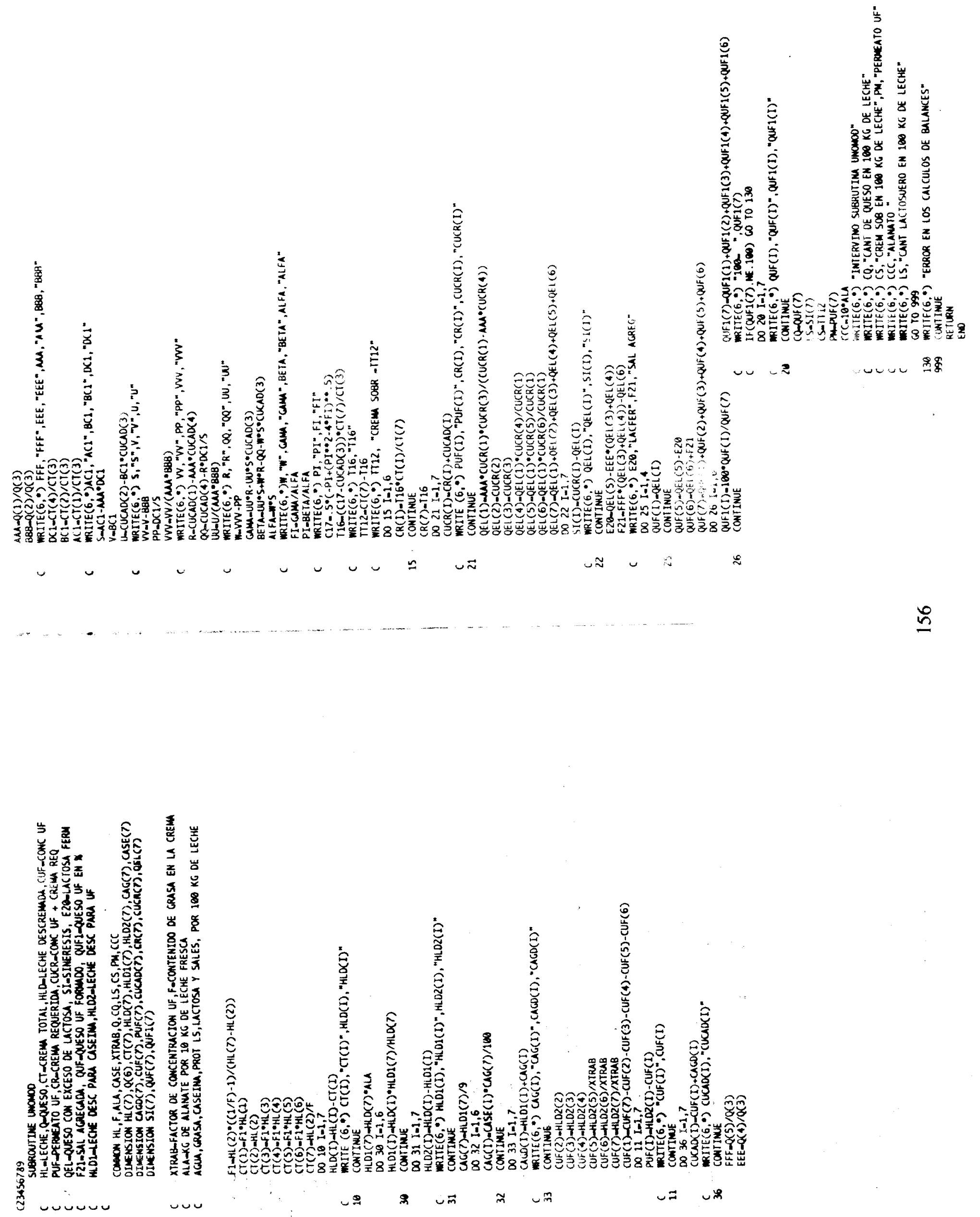




\section{APENDICE D}

\section{ESTRUCTURA DE LA LECHE Y DESCKIPCION DEL PROCESO QUESERO TRADICIONAL}

Estructura de la leche.

La leche puede considerarse como una superposición sucesiva de solutos en agua. Estos, que son de muy distinto tamaño y caracteristicas, están presentes en cantidades muy variables también, formando según el caso, suspensión o emusión con el resto de la mezcla. La tabla A-4.1-1 presenta los principales solutos en orden de tamaño (con las ambigüedades que el concepto de tamaño pudiera tener, debido a que no se trata de objetos esféricos). Algunos solutos se asocian a otros por medio de ligaduras (como las proteínas con algunas sales).

Leyendo la tabla A-4.1-1 en orden descendente, se puede visualizar el orden de la superposición mencionada. Existen además otros microcomponentes, como vitaminas, enzimas. pigmentos, gases disueltos, etcétera. También pueden existir virus llamados fagos, que pueden actuar sobre las bacterias presentes y al replicarse están presentes en la leche $y$ el lactosuero.

TABLA A-4.1-1

COMPONENTES DE LA LECHE CLASIFICADOS POR TAMAÑO

\begin{tabular}{|c|c|c|c|}
\hline $\begin{array}{c}\text { Tipo de } \\
\text { dispersión }\end{array}$ & Tamaño & Componente & $\begin{array}{c}\text { Medio de } \\
\text { separación } \\
\text { usando } \\
\text { membranas }\end{array}$ \\
\hline $\begin{array}{c}\text { Solvente } \\
\text { Solución }\end{array}$ & $<1 \mathrm{~nm}$ & Agua & - \\
\hline $\begin{array}{c}\text { Solución coloidal } \\
\text { Suspensión } \\
\text { coloidal }\end{array}$ & $0-1 \mathrm{~nm}$ & Lactosa, sales en solución & O.I. \\
\hline Suspensión & $1-10 \mathrm{~nm}$ & $\begin{array}{c}\text { Albúminas, globulinas, } \\
\text { caseína soluble, fosfato } \\
\text { coloidal }\end{array}$ & U.F. \\
\hline Emulsión & $10-200 \mathrm{~nm}$ & $\begin{array}{c}\text { Micelas de caseína (30-300 } \\
\text { nm), citrato de calcio }\end{array}$ & U.F. \\
\hline Emulsión & $1-10 \mathrm{n}$ & $\begin{array}{c}\text { Bacterias (cocos), células } \\
\text { somáticas }\end{array}$ & M.F. \\
\hline
\end{tabular}

Nota: $\mathrm{nm}=$ nanómetros, $\mathrm{u}=$ micrómetros, $\mathrm{O} . \mathrm{I} .=$ Osmosis Inversa, U.F.= Ultrafiltración, M.F. = Microfiltración 
La leche puede cambiar su composición original por los más diversos mecanismos; desde la simple separación de fases por reposo, donde la crema se concentra en la fase más ligera, hasta por reacciones enzimáticas sobre la grasa (lipólisis) o las proteinas (proteólisis). También la historia térmica (cambios de temperatura sufridos anteriormente). cinemática (estados de agitación u homogeneización ocurridos antes) y los cambios en el pH por acción microbiana $\mathrm{o}$ adición de agentes externos, modifican su composición y estructura irreversiblemente, lo que hace que la leche sea un producto altamente perecedero (12). (285).

Formación del queso

El proceso de formacion de queso es en su conjunto tan complicado que sigue siendo un arte. No obstante, se pueden distinguir en el dos clases de transformaciones: Las que implican separaciones de grandes cantidades de masa desde la materia prima (macrotransformaciones) y las que no implican grandes cambios en el peso de la materia en transformación, pero que sin embargo son tan importantes o más que las de la primera clase (microtransformaciones). tas macro? microtransformaciones se llevan a cabo de manera superpuesta, aunque en las etaj as de coagulación y sinéresis predominan las macro $y$ en la maduración predominan las micro; efe tuadas éstas por microorganismos especificos, a diferencia de las primeras, que se producen por operaciones fisicas deliberadas o por cambios de fase de algunos componentrs. De las macrotransformaciones depende principalmente la cantidad de suero y queso producidos, en tanto que las microtransformiciones son responsables de la calidad del producto, medida a través de sus propiedades sensoriales (aroma, sabor, textura, etcétera).

Existe conexión entre las macro y las microtransformaciones, de modo que los cambios efectuados en las primeras tienen efecto sobre las seguncias. La especificidad requerida en estas transf rmaciones dá por resultado la xistencia de una gran diversidad de tipos de queso. algunos de los cuales están perfectamente caracterizados a nivel mundial, tanto en su composición como en sus propiedades físicas, sensoriales, etcétera.

Descripción del proceso quesero tradicional.

El proceso de producción de queso se basa en la desestabilización de la caseína micelar por la actividad proteolítica del cuajo $\mathrm{y} / \mathrm{o}$ del medio ácido producido por las bacterias lacticas iniciadoras. Para hacer queso, se usan conjunta o individualmente un cuajo (que contiene un tipo de enzima llamado renina, la cual rompe la estructura de la k-caseina en un punto preciso, y luego otros más con el tiempol y bacterias capares de transformar la lactosa en ácido láctico, modificando el $\mathrm{pH}$. La ruptura de la $\mathrm{k}$-caseína origina su precipitación formando un gel o coígulo atie será la base del producto final. En la fig A4.1-1 se presenta la secuencia del proceso tradicional de producción de queso (184), (103), (265). 


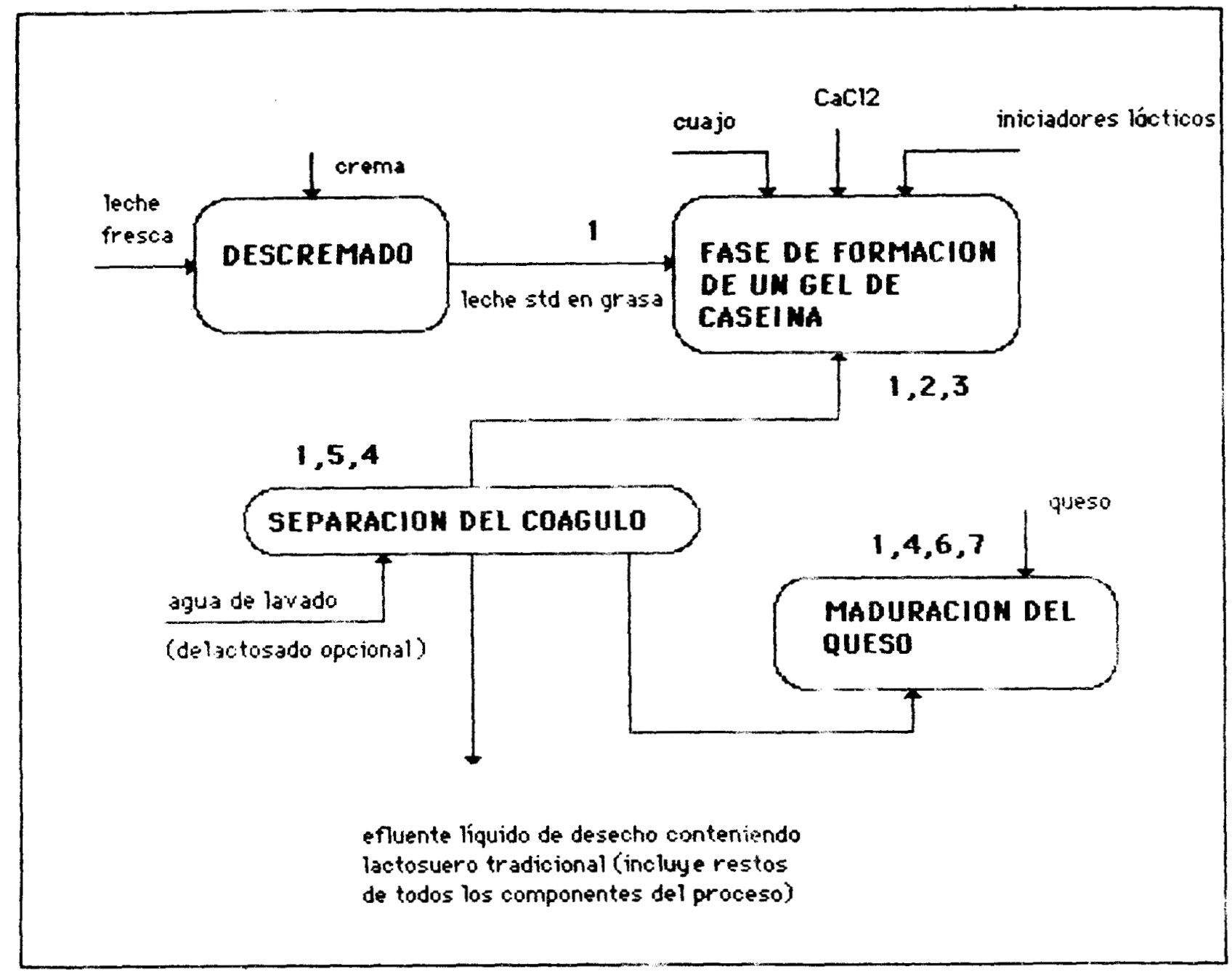

FIGURA A-4.1-1

ESQUEMATIZACION DEL PROCESO QUESERO TRADICIONAL

Nota: los números que aparecen en la figura A-4.1-1 representan la presencia de alguno de los siguientes procesos de transformacion:

$1=$ Actividad fermentativa de los iniciadores lácticos sobre la lactosa, produciendo ácido lactico y logrando un $\mathrm{pH}$ ácido.

$2=$ Actividad proteolítica específica (coagulante) de las enzimas contenidas en el cuajo. 3 =Desplazamiento del equilibrio de la caseína hacia su forma no soluble por adición de $\mathrm{CaCl} 2$ a fin de que precipite por completo en el coágulo.

4=Continúa actividad proteolítica de las enzimas del cuajo y de enzimas producidas por los iniciadores lácticos.

$5=$ Endurecimiento del coágulo y expulsión de lactosuero de su interior (sinéresis). $6=$ Actividad fermentativa de diversos organismos, inoculados o favorecidos por condiciones de humedad, salinidad, temperatura, aireación, composición del medio, etc. $7=$ Actividad proteolítica y lipolítica de enzimas diversas.

Siguiendo a Maubois y Mocquot (228), se puede conceptualizar al coágulo formado como 
una estructura tridimensional parecida a una esponja, formada de caseina y grasa, donde se encuentra embebido un líquido en determinada proporción. Este líquido es agua y los componentes solubles en ella, es decir, proteínas de lactosuero, lactosa y sales. Durante la sinéresis una gran parte del líquido se retira del coágulo, y el remanente se queda alojado en la estructura de esponja de manera estable. Las condiciones de estabilidad son muy variadas y dependen de múltiples factores de proceso, lo que da origen a la gran variedad de quesos, cada uno con una composicion particular.

Además de su composición especifica, cada queso es el producto de una complicada y a veces muy larga secuencia de microtransformaciones efectuadas por una flora que también es caracteristica del mismo. las cuales van delineando durante la maduracion el sabor, aroma y textura del producto final.

Como puede verse, el queso es un producto formado aprovechando todas las calacteristicas de la leche, del cuajo y de las dis intas ba erias y enzimas que paricipan en su descomposición y reformación estructurai. De ant que "efecto de cada participante en la transformación, sea aprovechado por los demás pariici antes en las etapas subsecuentes.

El descubrimiento del efecto del cuajo (o más bien de las enzimas conteridas en el) sobre la leche mucho antes de que existiera la mas : lemental comprensión del fenomeno proteolitico involucrado, fue una muy afortun da casualidad. Si se piensa un poco sobre ello, puede calificarse de extraordinaria la accion tan especifica, extensa y rápida de las enzimas presentes en el cuajo sobre la casenna, enmedio de un sin numero de otros componentes presentes, incluyendo proteinas, ninguno de los cuales interfiere con la acción enzimatica. La rapidez y facilidad con que se resliza sta transformación permitio que miles de años antes le que se conocieran los reactures enzimáticos existiera el queso. Otro tanto se puede decir de los procesos de maduracion. donde la intuicion aventajo durante muchos siglos al conocimiento de las fermentaciones involucradas.

De todo lo anterior se desprende que hacer queso aun hoy día es mas un arte que una ciencia. 


\section{APENDICE E}

\section{ASIGNACION DE ALGUNOS COSTOS RELACIONADOS CON LA OPERACION DE ULTRAFILTRACION}

Esta asigna ión está basada en información técnica de fabricantes de equipo de ultrafiltración (15) y en un estudio económico realizado en la Universidad de WisconsinMadison sobre equipo de ultrafiltración aplicado a leche (314) al que se hará referencia en lo sucesivo como el caso Slack.

En el presente estudio se consideraron, al igual que en el caso Slack, membranas fabricadas por ABCOR, con clave HFM-100-SO, cuyo peso molecular de corte es de $8000-$ 10000. Las membranas son de tipo espiral enrollada ("spiral wound") y constan de dos hojas planas de membrana separadas por un material poroso de soporte; el conjunto va sellado por tres lados y el cuarto va sellado separadamente a un tubo perforado de recolección. El conjunto de partes va enrollado al tubo de recolección, formando un elemento compacto que se denominará módulo UF. Cada módulo contiene 45 pies cuadrados de membrana y 7.28 litros de volumen de retención. La presión máxima permisible durante la operación es de 100 psig; el flujo máximo con membrana limpia es de $182 \mathrm{l} / \mathrm{min}$ y la temperatura máxima permisible de operación es de $54 \mathrm{C}$.

De acuerdo a fabricantes, el flujo promedio de permeato en un módulo de ultrafiltración varía en la proporción mostrada en la tabla A-4.2-1 para la membrana utilizada.

TABLA A-4.2-1

TASA DE REDUCCION DEL FLUJO DE PERMEATO PARA LA MEMBRANA SELECCIONADA

\begin{tabular}{|c|c|}
\hline (F ACTOR DE CONCENTR ACIOH UF) & FLUJO DE PERMEATO \\
\hline $\mathbf{2}$ & $100 \%$ \\
2 & 85.28 \\
4 & 77.92 \\
5 & 69.12 \\
6 & 50 \\
7 & 49.6 \\
\hline
\end{tabular}

El caso considerado en esta tesis utiliza las mismas membranas del caso Slack, los mismos periodos de limpieza y la misma capacidad por módulo, por lo que, tomando como base los datos de la tabla A-4.2-1y el flujo de permeato de Slack para $X=2(93.75 \mathrm{~kg} / \mathrm{hr})$, se proyectan los siguientes flujos de permeato (tabla $\mathrm{A}-4.2-2$ ). 
TABLA A .2-2

YALORES PROMEDIO DEL FLUJO DE PERMEATO DURANTE EL CICLO

\begin{tabular}{|c|c|}
\hline $\begin{array}{c}\text { (FACTOR DE CONCENTRACION UF) } \\
X\end{array}$ & $\begin{array}{c}\text { FUJO PROMEDIO DE } \\
\text { PERMEATO POR MODULO } \\
\text { (ko/hr) }\end{array}$ \\
\hline 2 & 93.75 \\
3 & 79.95 \\
4 & 73.05 \\
5 & 64.8 \\
6 & 56.25 \\
7 & 16.5 \\
\hline
\end{tabular}

La cantidad de ieche a procesar es como se indica en la Tabla A-4.2-3

TABLA $\therefore$. $4.2-3$

CANTIDAD DE LECHE A PROCESAR

\begin{tabular}{|c|c|}
\hline Escala 1 & $5000 \mathrm{~kg} / \mathrm{dia}$ \\
\hline Escala 2 & $30000 \mathrm{~kg} / \mathrm{dia}$ \\
\hline Escala 3 & $100000 \mathrm{~kg} / \mathrm{dia}$ \\
\hline
\end{tabular}

La ultrafiltración no es un proceso continuo, sino que se compone de ciclos cortos, compuestos por una etapa de operación y otra de limpieza. La duración de cada etapa depende de las condiciones de trabajo y del sistema en separación.

De la información de fabricantes y tomando en cuenta las condiciones utilizadas por Slack, se fijó la estructura de los ciclos de ultrafiltración como se indica en la tabla A-4.2-4. Estas condiciones permiten garantizar que durante la operación se mantengan los flujos promedio requeridos de permeato (tabla A-4.2-2).

TABLA A-4.2-4

ESTRUCTURA DE CICLOS DE OPERACION UF

\begin{tabular}{|c|c|c|c|}
\hline $\begin{array}{c}\text { X (FACTOR DE } \\
\text { CONCENTRACION UF) }\end{array}$ & $\begin{array}{c}\text { HRS DE LA ETAPA } \\
\text { DE OPERACION }\end{array}$ & $\begin{array}{c}\text { HRS DE IA ETAPA } \\
\text { DE LIMPIEZA }\end{array}$ & $\begin{array}{c}\text { HRS TOTALES DEL } \\
\text { CIILO }\end{array}$ \\
\hline 2 & 4 & 2 & 6 \\
\hline 3 & 4 & 2 & 6 \\
\hline 4 & 3 & 2 & 5 \\
\hline 5 & 3 & 2 & 5 \\
\hline
\end{tabular}

la ultrafiltracion considerada será para la leche previamente descremada. Cuando se considera la adición de cascína, una parte de la leche descremada se une con la caseína para formar una mezcla al $10 \%$ de ésta y solo el resto de la leche se ultrafiltra.

Por las razones anteriores, la cantidad de leche a tratar por ultrafiltración es menor a la cantidad de leche total considerada, y para una crema con $40 \%$ de grasa y diferentes cantidades de caseina agregada, las cifras son como se indica en la tabla 1-4.2-5. 
TABLA $A-4.2-5$

KG DE LECHE DESCREMADA A PROCESAR POR ULTRAFILTRACION ( $C C=$ KG DE CASENNA POR $100 \mathrm{KG}$ DE LECHE)

\begin{tabular}{|c|c|c|c|c|c|}
\hline & $O C=0$ & $\alpha=05$ & $\alpha=1$ & $C=15$ & $\alpha=2$ \\
\hline ESCALA 1 & 4578 & 4350 & 4120 & 3892 & 3663 \\
\hline ESCALA 2 & 27471 & 26097 & 24724 & 23350 & 2197 \\
\hline ESCALA 3 & 91570 & 86991 & 82413 & 77834 & 73256 \\
\hline
\end{tabular}

Con los datos anteriores, se prepararon las tablas $A-4.2-6, A-4.2-7$ y $A-4.2-8$, en cantidad de permeato por día se calculó por la echación (A-4.21) (en la página 46 aparecen las ecuaciones empleadas), el numero de modulos Slack se obtuvo por la ecuación (A-4.2-2); las horas de operación por día se establecieron arbitrariamente y con ellas y la tabla $A-4.2-4$. se determinaron las horas de limpieza $y$ horas totales por día, asi como el uúmero de ciclos y de turnos de operador.

Con la información del número de módulos Slack necesarios y una correlación (ecuaciones $\mathrm{A}-4.2-3$ y $\mathrm{A}-4.2-4$ ) obtenida del estudio económico de Slack, se determinó la inversión (en dólares de 1980) necesaria en equipos de ultrafiltración.

Con los datos de la tabla A-4.2-9 y los números de módulos y ciclos, se obtuvieron los costos anuales de membranas en dólares de 1980.

Despues de cada ciclo, el equipo de ultrafiltración pasa por un proceso de limpieza que utiliza agua tibia a presión, hidróxido de sodio, ácido fosfórico y cloro, a fin de desincrustar e higienizar las membranas y demás partes del equipo LF en contacto con la leche. La estimación de costos de los productos químicos empleados se basó en los datos de Slack, quien consideró $\$ 3050$ dólares de 1980 para conjuntos pequeños (de hasta 10 modulos) y $\$ 9200$ para conjuntos mayores (de hasta 20 módulos), todo ello por ciclo y por año.

Para convertir estos datos a una línea continua de $\$$ quím vs $\mathrm{N}^{\circ}$ de módulos, se propuso la ecuación (A-4.2-5), la cual se usó en junto con el número de módulos de las tablas A-4.2-6, A-4.2-7 y A-4.2-8 para obtener el costo anual de químicos.

Para determinar la cantidad de caballos de potencia (HP) necesarios en cada caso, se correlacionaron en el trabajo de Slack los HP vs $N^{\circ}$ de módulos, encontrando que los datos se ajustan aproximadamente a la ec $(A-4.2-6)$, con la que se estimaron los $H P$ en las tablas A-4.2-6 a la A-4.2-8.

El consumo anual de energía eléctrica de los equipos se calculó siguiendo a Slack, mediante la ec (A-4.2-7). Y el costo de esta energía en pesos nuevos de 1993, se determinó mediante la tarifa de N\$O.138 por Kilowatt-hora, proporcionada por la Comisión Federal de Electricidad (19).

Para estimar costos de mano de obra se supuso que un operador atendiendo 15 módulos en un turno gana $N \$ 24,000$ anuales (a precios de 1993). Con esta base y el número de módulos y turnos, se obtuvo el costo anual de mano de obra.

Para estimar los gastos derivados del tratamiento de aguas provenientes del lavado del equipo UF, se cargó un $5 \%$ de sobreprecio a las membranas y productos químicos involucrados.

Enseguida se trasladaron las cantidades en dólares de 1980 a pesos nuevos de 1993 , utilizando los factores de conversión dados por las ecs (A-4.2-8, A-4.2-9 y A-4.2-10). 
FORMULAS EMPLEADAS

$\mathrm{Kg}$ dia de permeato $=\mathrm{Kg}$ dia de leche ${ }^{\star}(\mathrm{X}-1) / \mathrm{X}$

$-(-\cdot)-(A+2-1)$

$N^{\circ}$ mod Slack $=A \cdot\left(B^{\star} \mathrm{C}\right)$

$(A+.2-2)$

donde $A=k g$ dia de permeato segun ec $(A+.2-1)$

$B=$ Flujo de permeato por módulo, en $\mathrm{kg}$ hr segun tabla $1+.2-$ ?

$C=$ Horas de operacion LF por dia

Il $F=3.29 \times M-1.15$ (baja escald. para $\mathrm{M}<9$ módulos $S 1$ ack

$(-2-3)$

IL $F=2.38^{*} \mathrm{M}+7.139$ (alta scala. para $\because>9$ modulos lack)

1+.2-+1

Il F esta dado en miles de dolares de 1980.

Squim $=N^{\circ}$ de $C i c l o s *\left(150^{*} N^{\circ} \bmod -15.5 * x^{\circ} \bmod * x^{\circ} \mathrm{m}\right) \mathrm{d}$ $+4.2-5$

en dolares de 1980.

$\mathrm{N}^{\circ} \mathrm{HP}=0.603 * \mathrm{~N}^{\circ}$ mo Slack +1.58

$(+2-6)$

kw-hr anuales $=365.125 * \mathrm{~N}^{\circ} \mathrm{HF} *($ Hrs rotales dia $)$ $(-2 \cdot-(-2-7)$

Para proyectar la inversion de la planta LF a valor presente, se uso el indice Velson y la conversión de dolares a posos nuevos, por la cual se tiene vue:

I(de 1993 en pesos nuevos de 1993) I(de 1980 en dolares $)=$

$=3.3^{\star} 1336 \cdot 822.8=5.3583$

$--(A 4.2-8)$

del mismo modo, para membranas:

I(de 1993 en pesos nuevos de 1993), l(de 1980 en dólares)=

$=3.3 * 533: 325.2=5.408$;

$\cdots(A+.2-9)$

y para químicos:

I(de 1993 en pesos nuevos de 1993) I(de 1980 en dólares)= $=3.3 * 226 / 229.2=3.2539$

$-(A+2-10)$ 


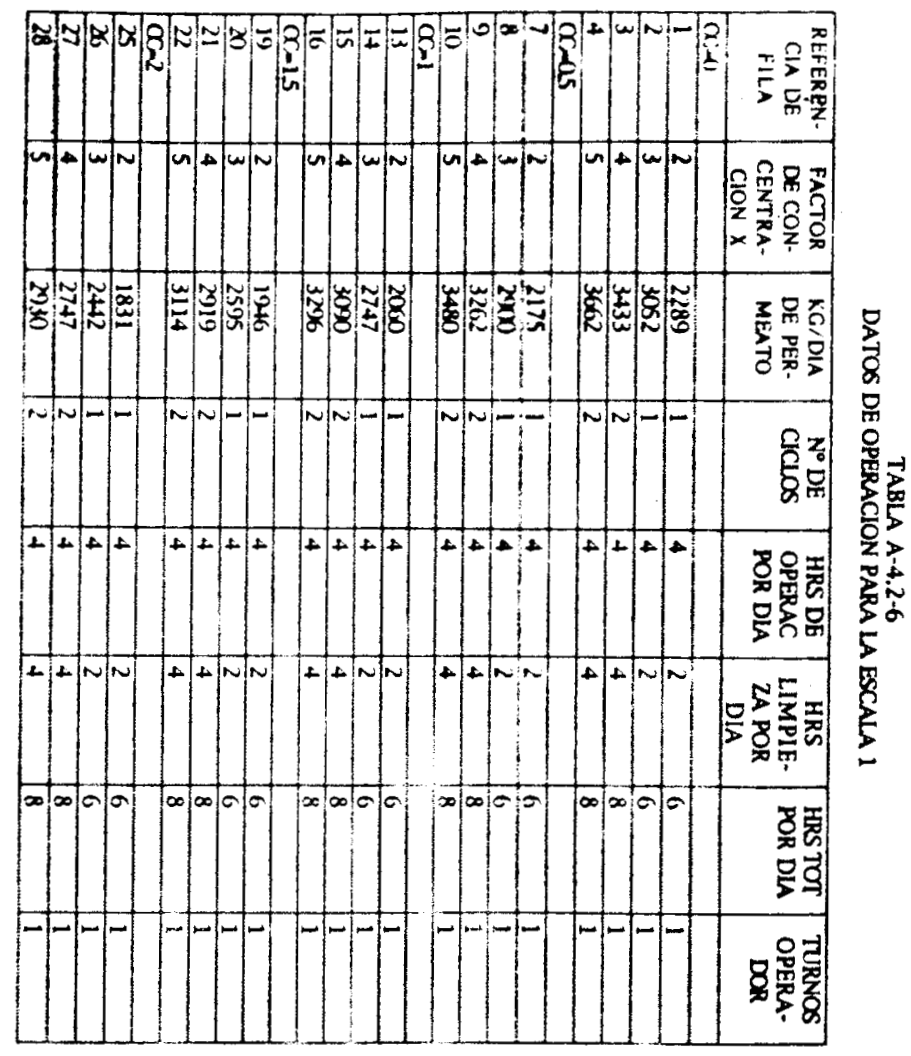

$\bar{g}$

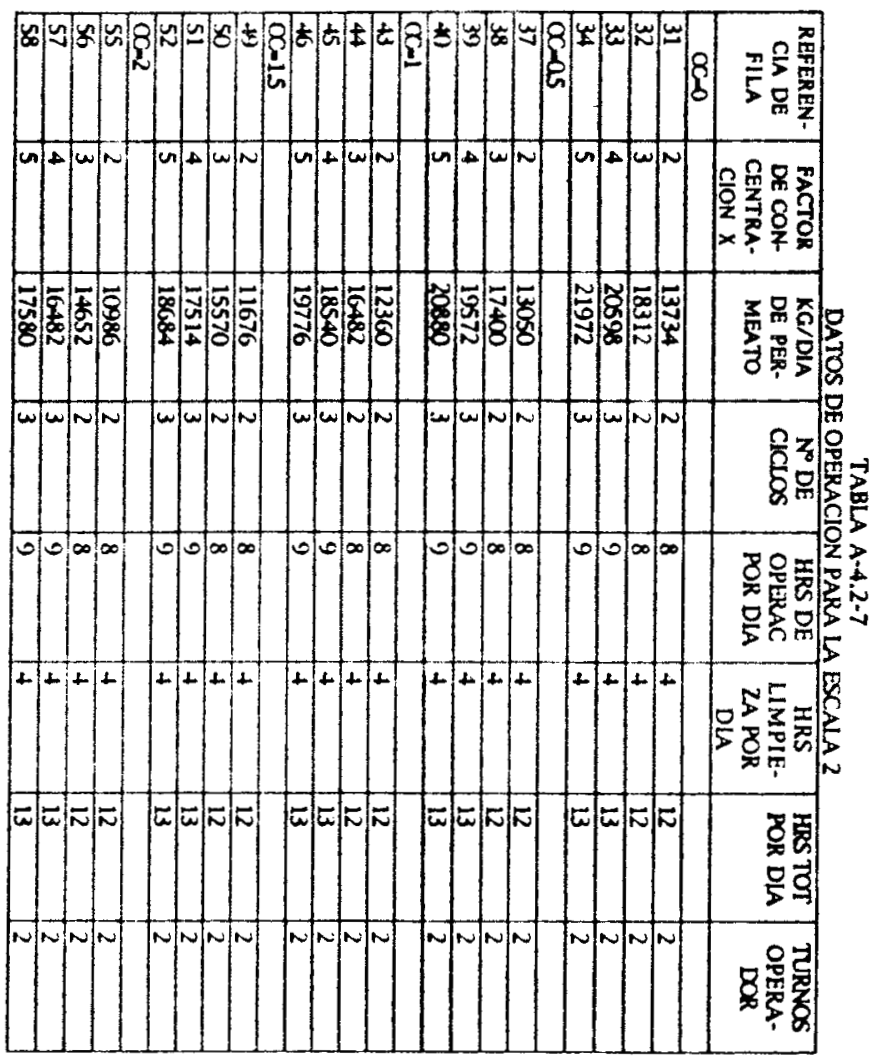



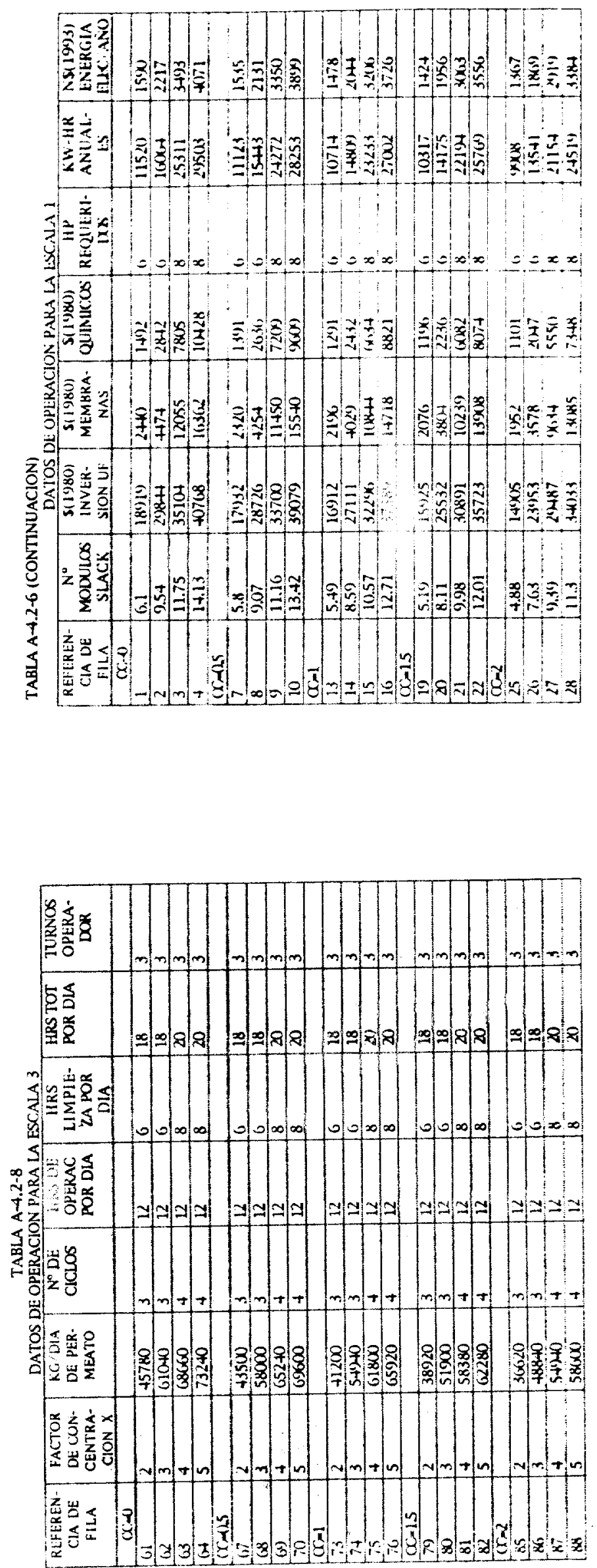

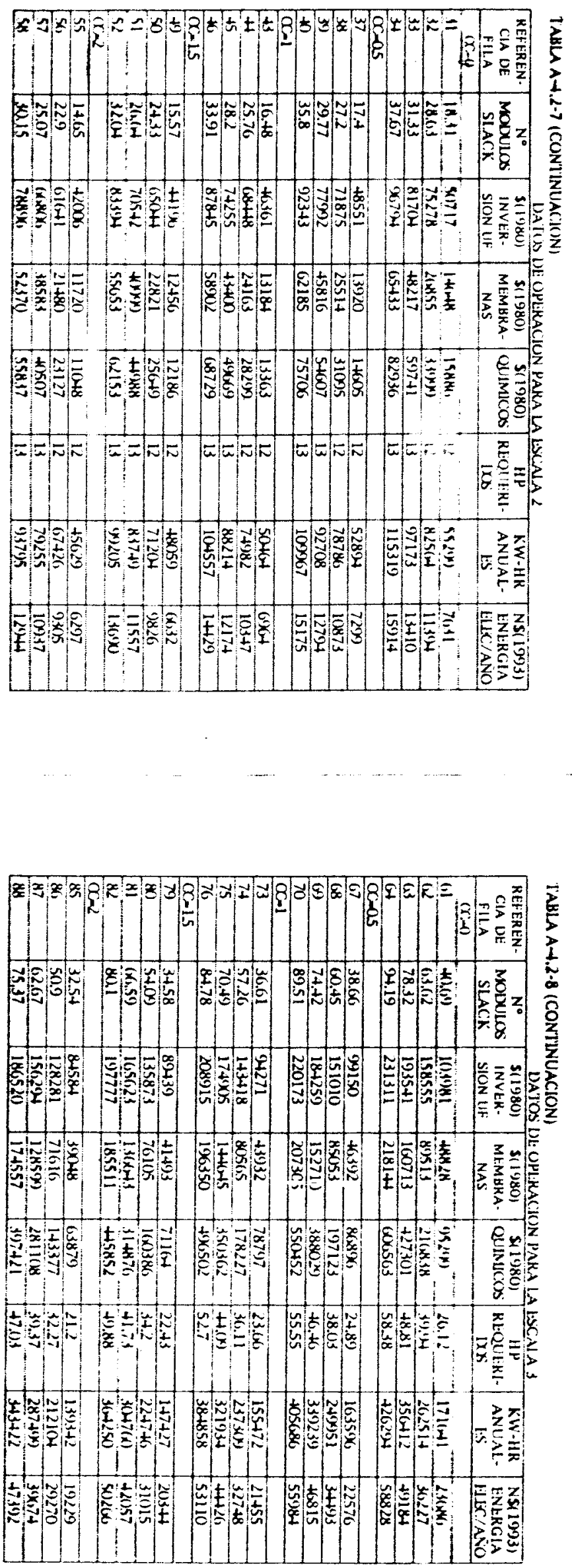

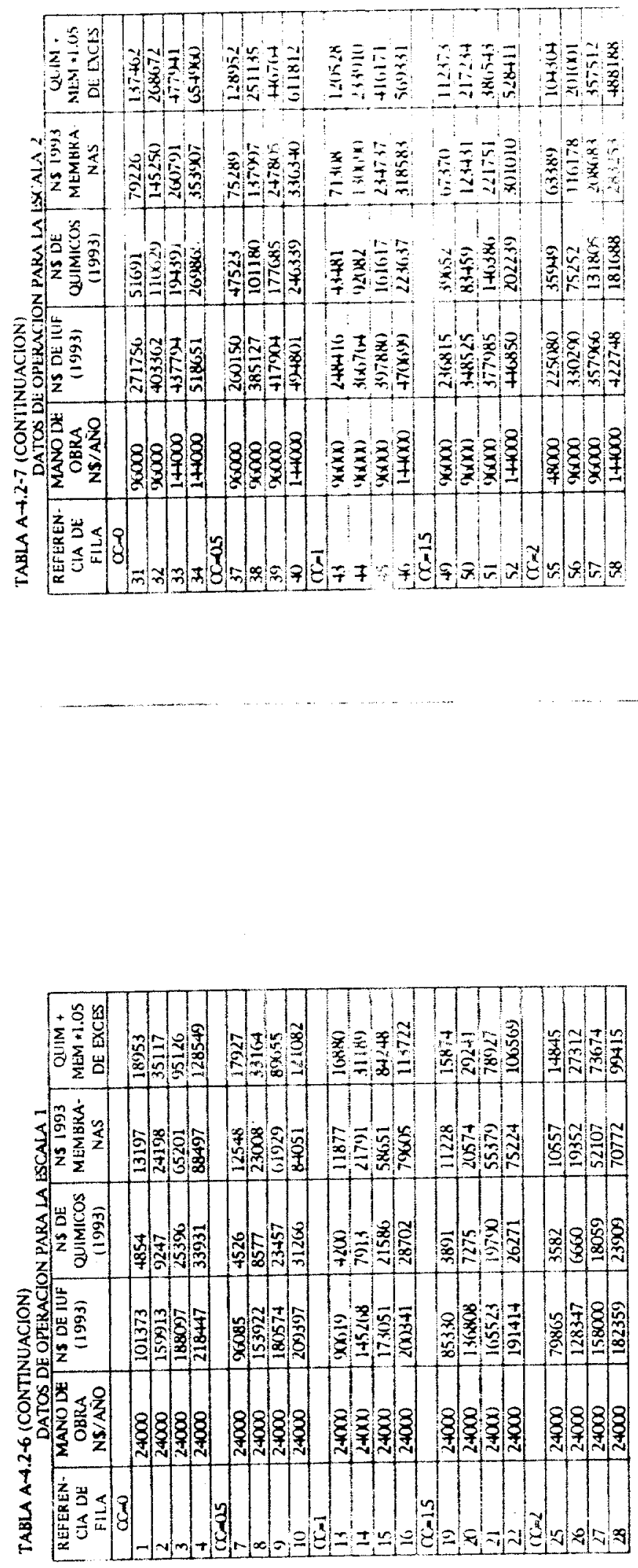

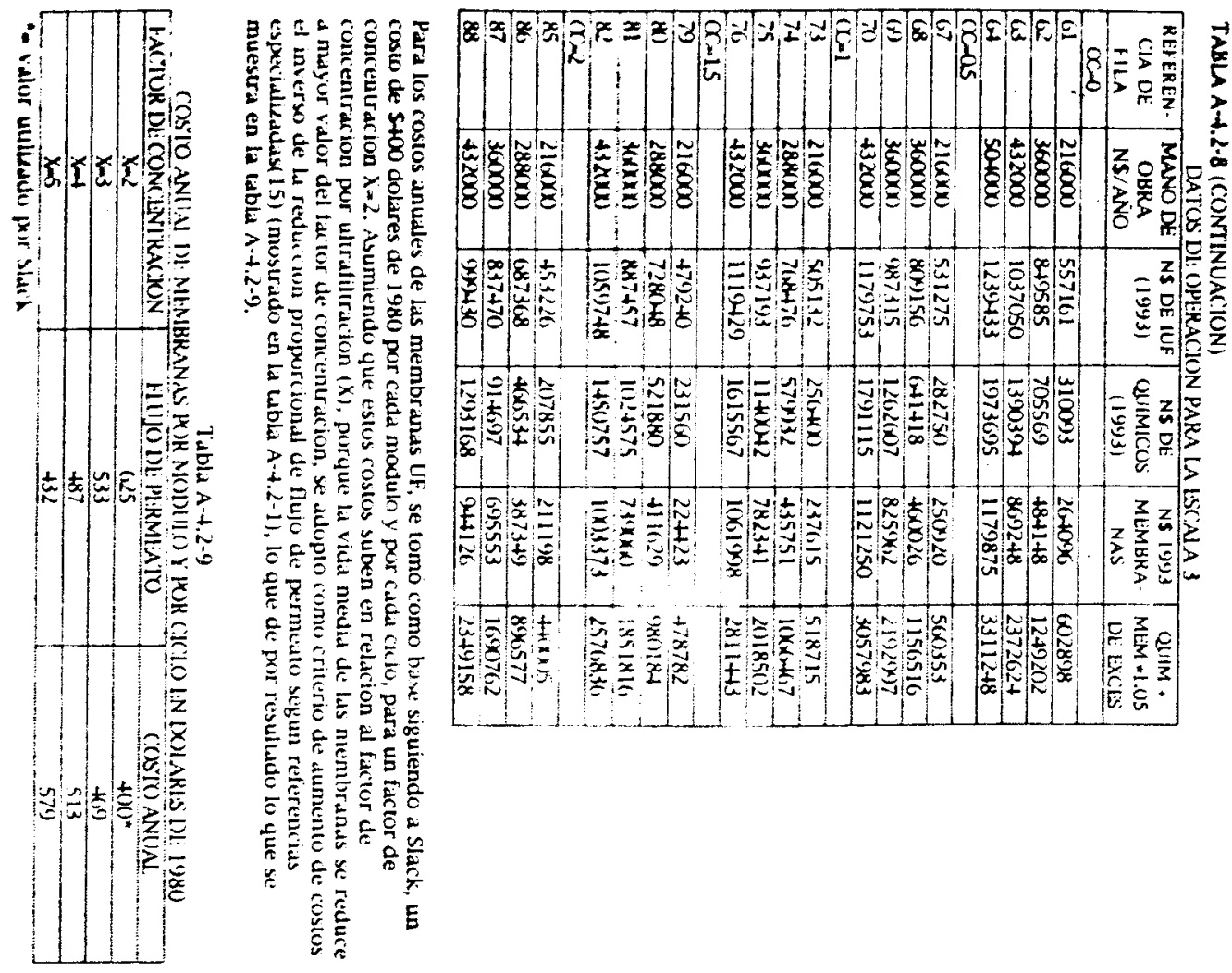

$\overline{8}$

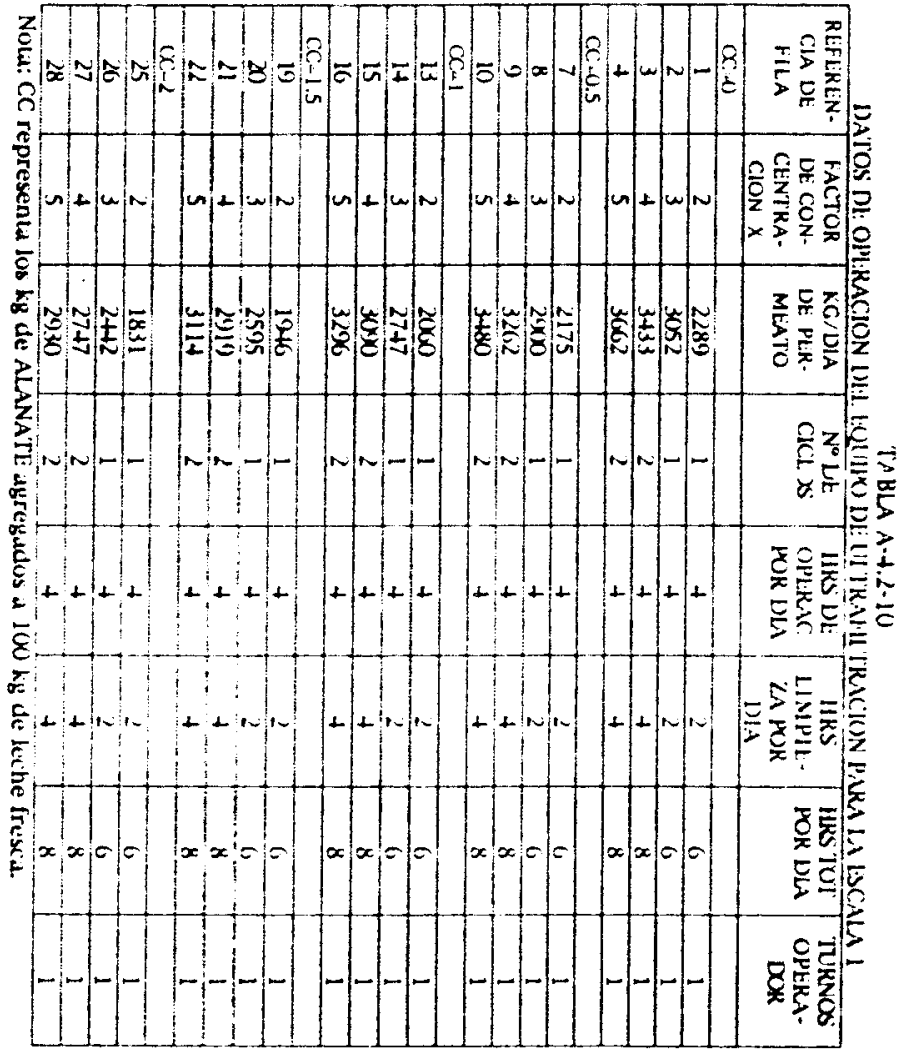



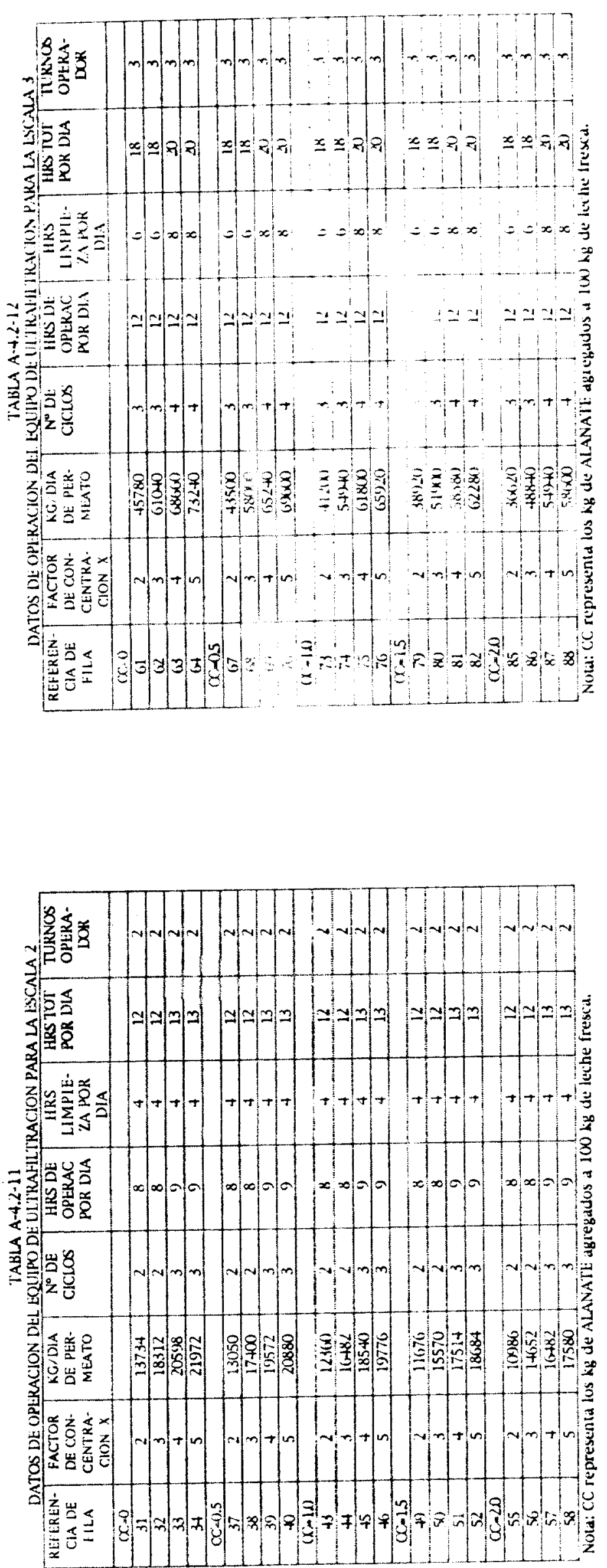

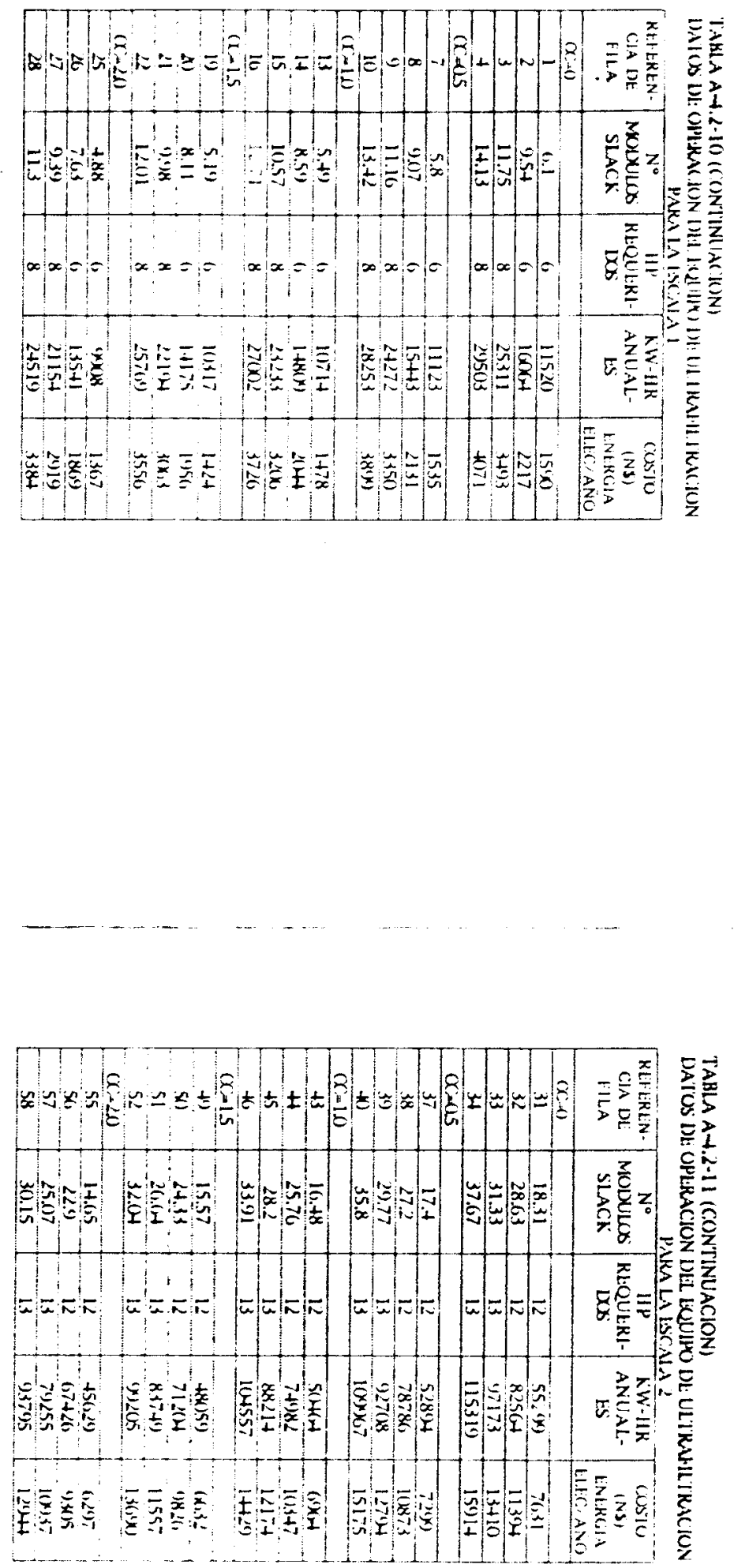


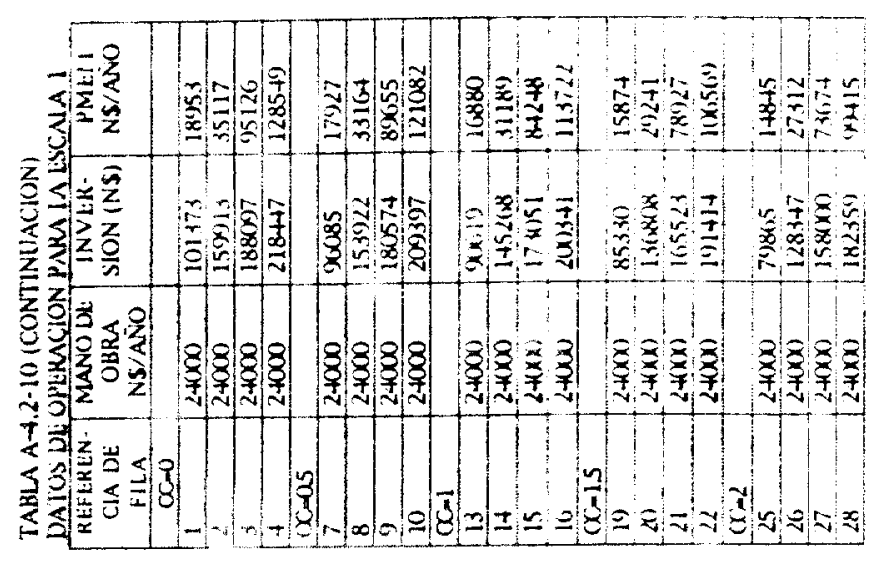

N

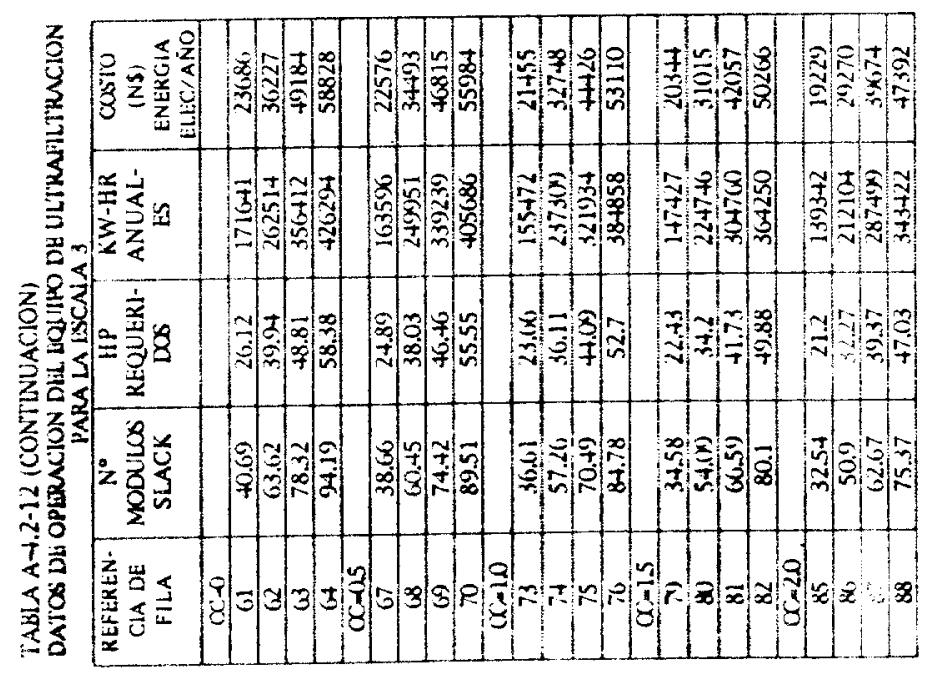



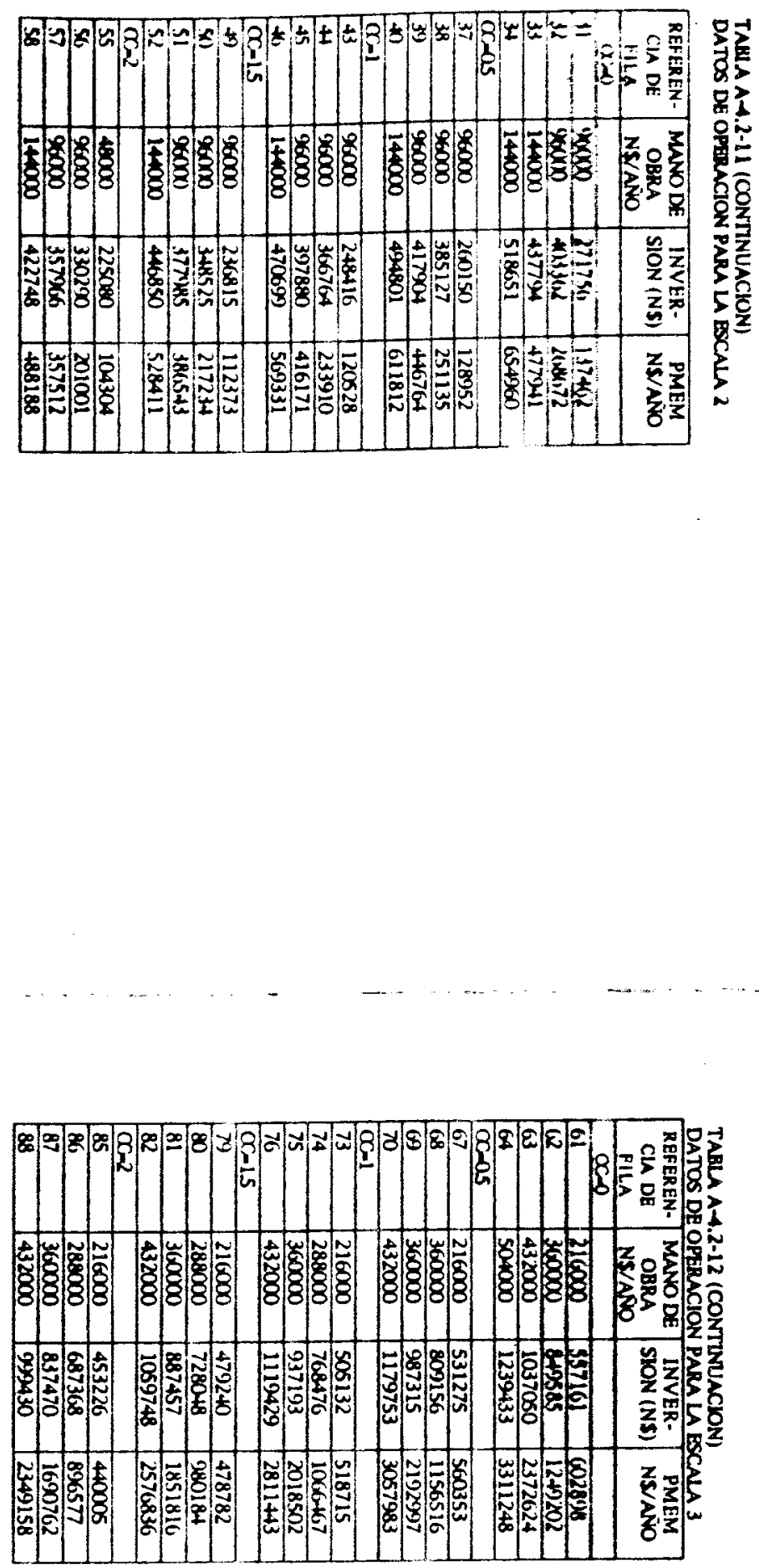

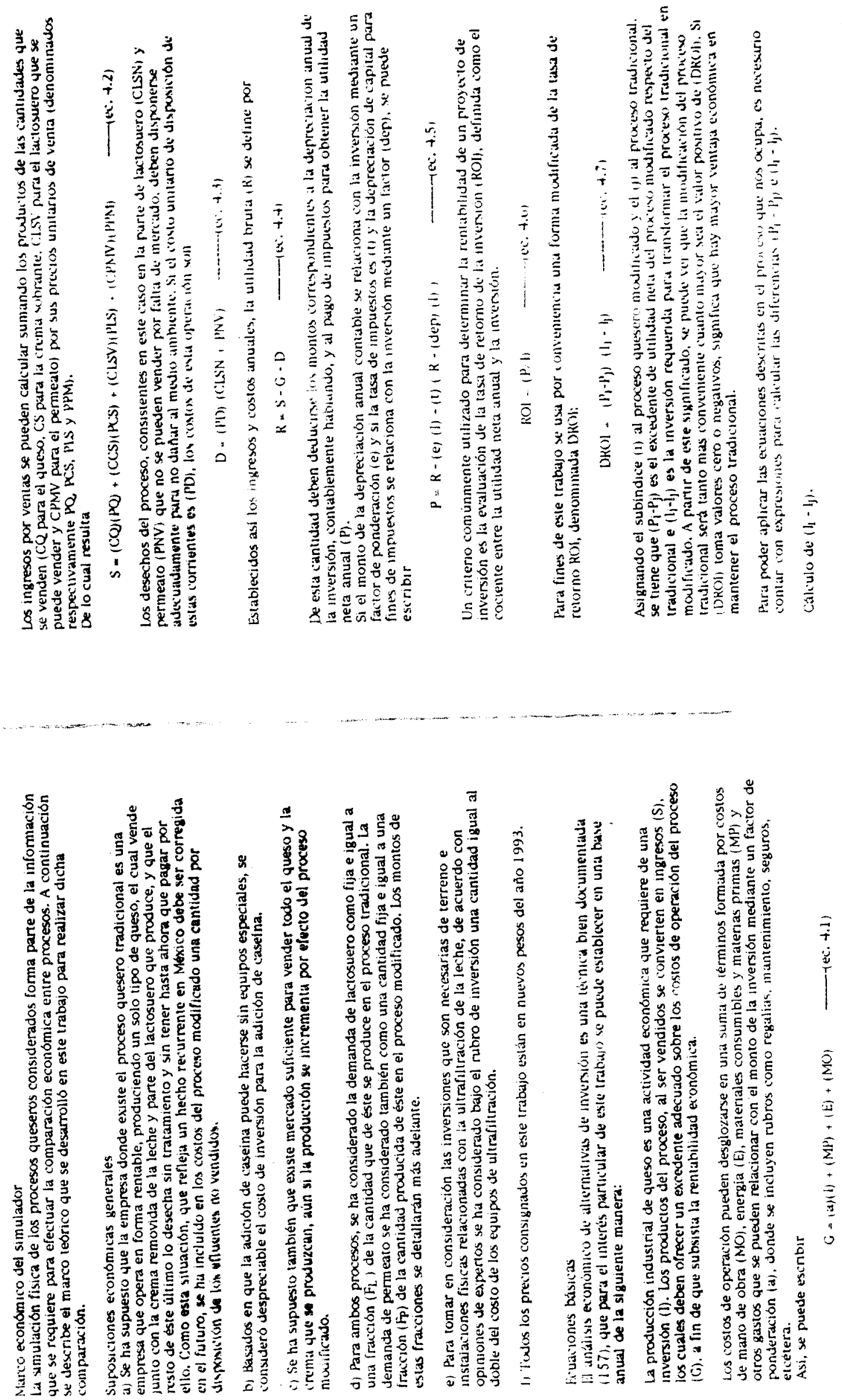


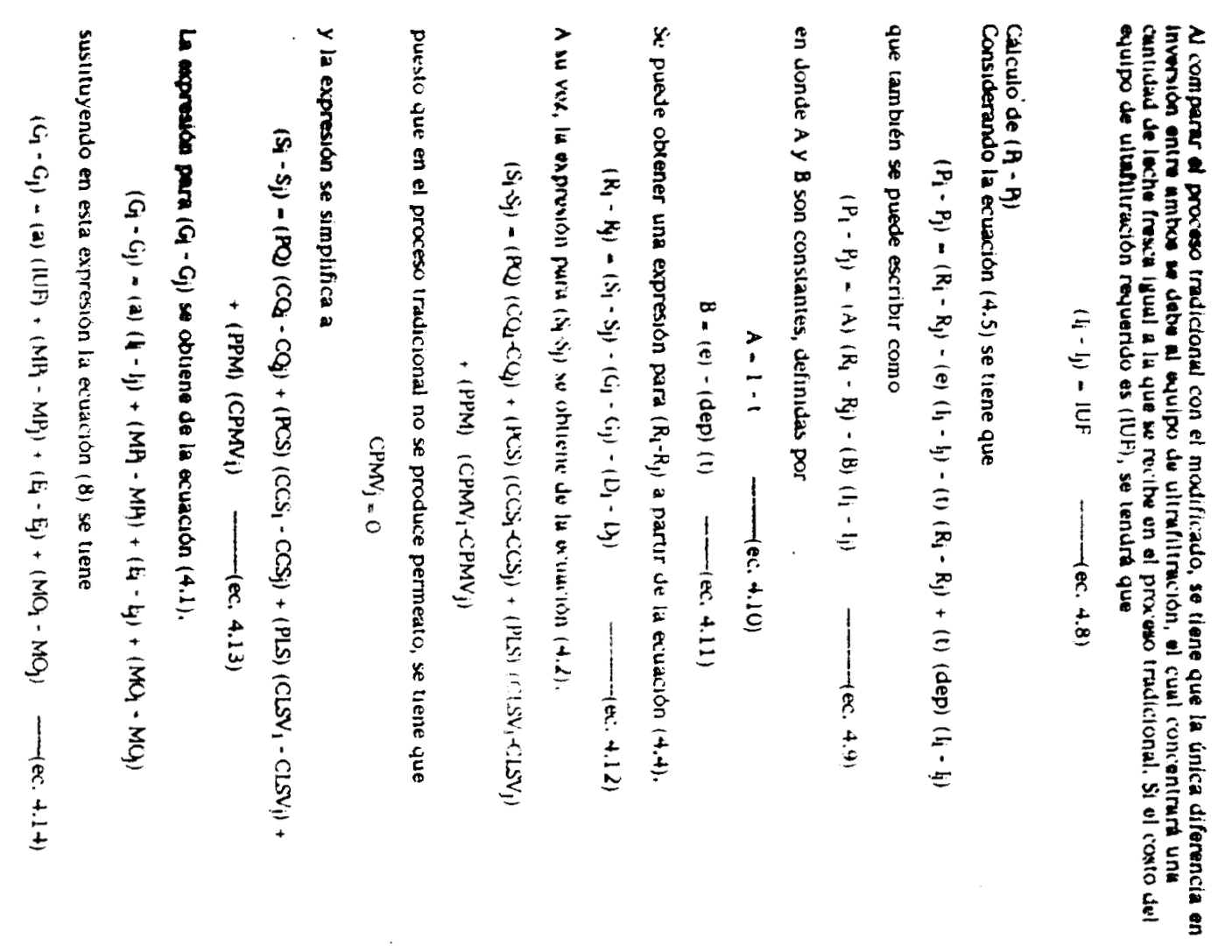

$\vec{s}$

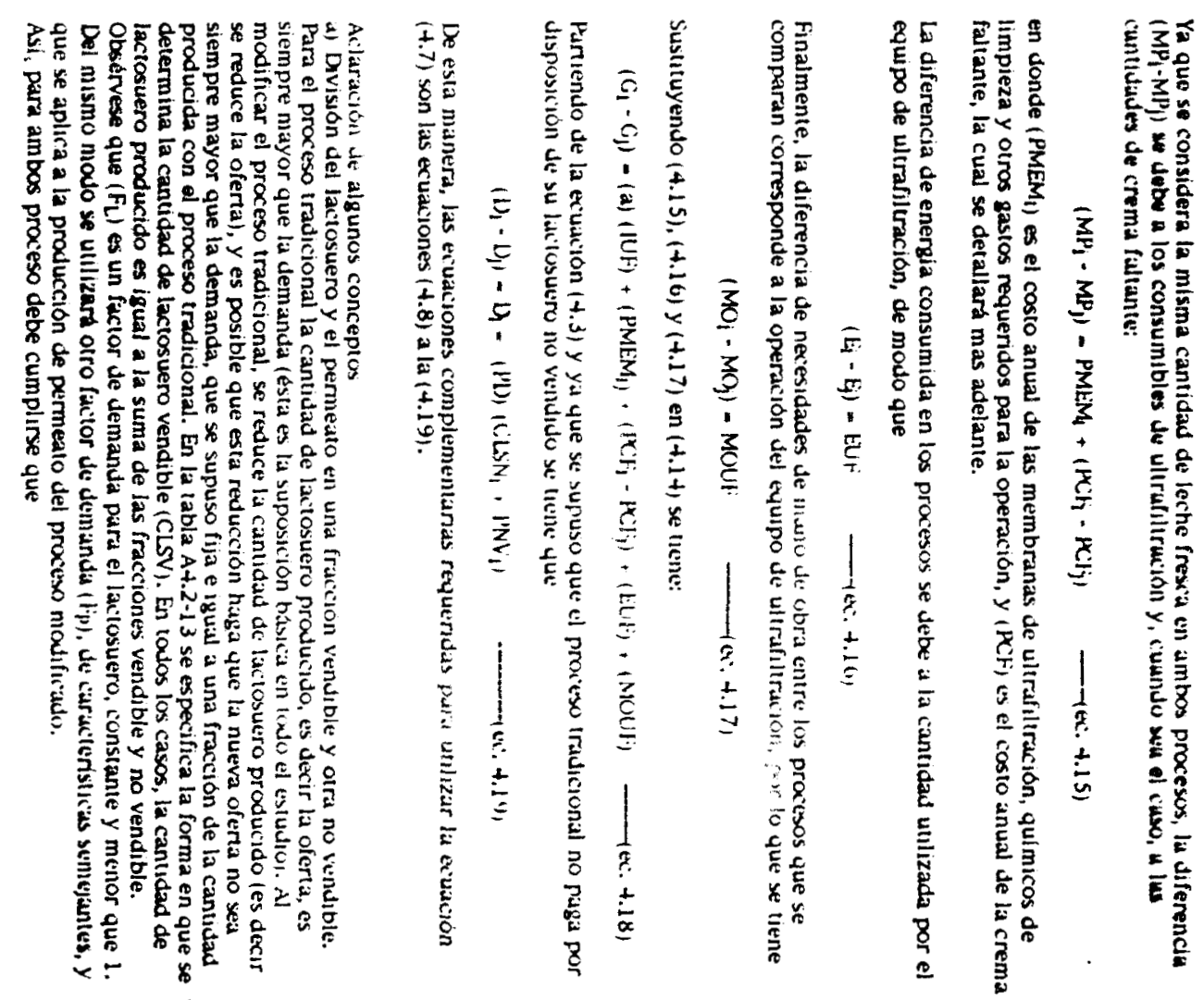


$\cong$

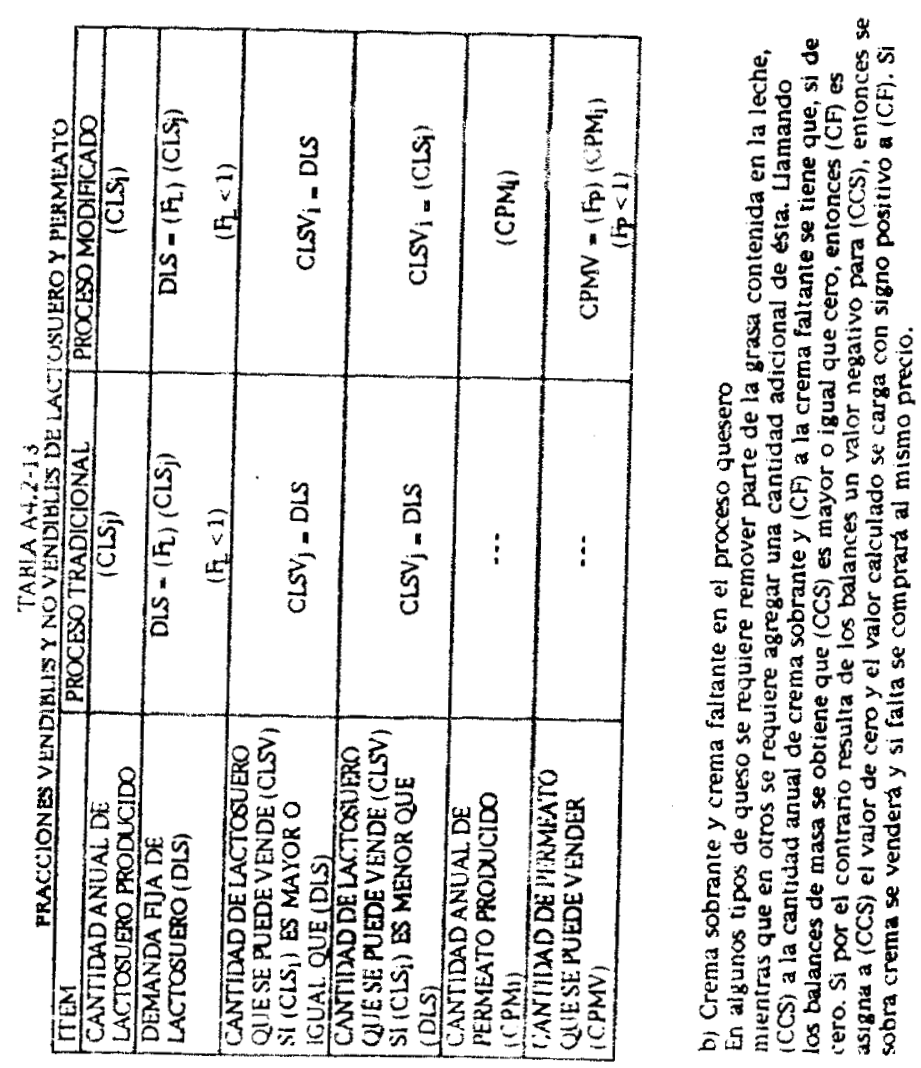




\section{APENDICE F}

\section{RESULTADOS DE LAS CORRIDAS DEL SIMULADOR DI L APENDICE C}

En este apéndice se presentan los valores del parámetro indicador de rentabilidad DROI obtenidos de las corridas de simulación realizadas en el Capítulo 5. La información se presenta en tablas para los distintos escenarios (llamados aquí casos) considerados en la tabla 5-8 del Capítulo 5.

En todas las tablas de este apéndice se presenta en la segunda columna el caso sin adición de caseína y en las siguientes columnas, las distintas cantidades de casc ina agregada hasta el máximo permisible.

Los resultados incluyen las tres escalas de proceso estudiadas y valores de concentración de leche por ultrafiltración (representados por la letra "X"), a partir de 2 y aumentando en 1 hasta su límite máximo permisible según la tabla 5-2 del Capítulo 5.

La relación entre los indicadores económicos ROI y DROI, definidos en la página 173 es tal que para un proceso que se modifica DROI tiene que ser mayor que ROI, c omo se demuestra a continuación.

Sea un proceso iradicional 1 , con $\mathrm{ROI}_{1}=\mathrm{P}_{1} / \mathrm{I}_{1}$

y su proceso modificado 2 , con $\mathrm{ROl}_{2}=\mathrm{P}_{2} / \mathrm{l}_{2}$

De las ecuaciones (1) y (2) se puede obtener

$$
\mathrm{I}_{2}-\mathrm{I}_{1}=\left(\mathrm{P}_{2} / \mathrm{ROI}_{2}\right)-\left(\mathrm{P}_{1} / \mathrm{ROI}_{1}\right)
$$

Por definición, la DROI de la reconversión del proceso es: 
DROI $=\left(\mathrm{P}_{2}-\mathrm{P}_{1}\right) /\left(\mathrm{I}_{2}-\mathrm{I}_{1}\right)$

No tiene objeto invertir dinero en la reconversión si no se va a obtener mayor beneficio. Por lo anterior, el proceso modificado 2 debe tener unmás alto ROI que el proceso tradicionall:

$\mathrm{ROI}_{2}=(\mathrm{K}) \mathrm{ROI}_{1}$; donde $\mathrm{K}>1$

Sustituvendo (5) en (3) se puede escribir:

$I_{2}-I_{1}=\left(\left(P_{2} / K\right)-P_{1}\right) / R O I_{1}$

Sustituyendo ( 6 ) en (4) resulta:

$\mathrm{DROI}=\left(\mathrm{P}_{2}-\mathrm{P}_{1}\right)\left(\mathrm{ROI}_{1}\right) /\left(\mathrm{P}_{2} / \mathrm{K}-\mathrm{P}_{1}\right)$

Como $\mathrm{K}>1$, la cantidad $\left(\mathrm{P}_{2}-\mathrm{P}_{1} /\left(\mathrm{P}_{2} / \mathrm{K}-\mathrm{P}_{1}\right)\right.$ támbién es mayor que 1 , y se puede denominar por $\mathrm{K}_{2}$ Asi, se puede escribir

$\mathrm{DROI}=\mathrm{K}_{2}\left(\mathrm{ROI}_{1}\right) ;$ donde $\mathrm{K}_{2}>1$

Con lo que se demuestra que la DROI del proceso modificado tiene que ser mayor que la ROI del proceso tradicional, o proceso 1 . 

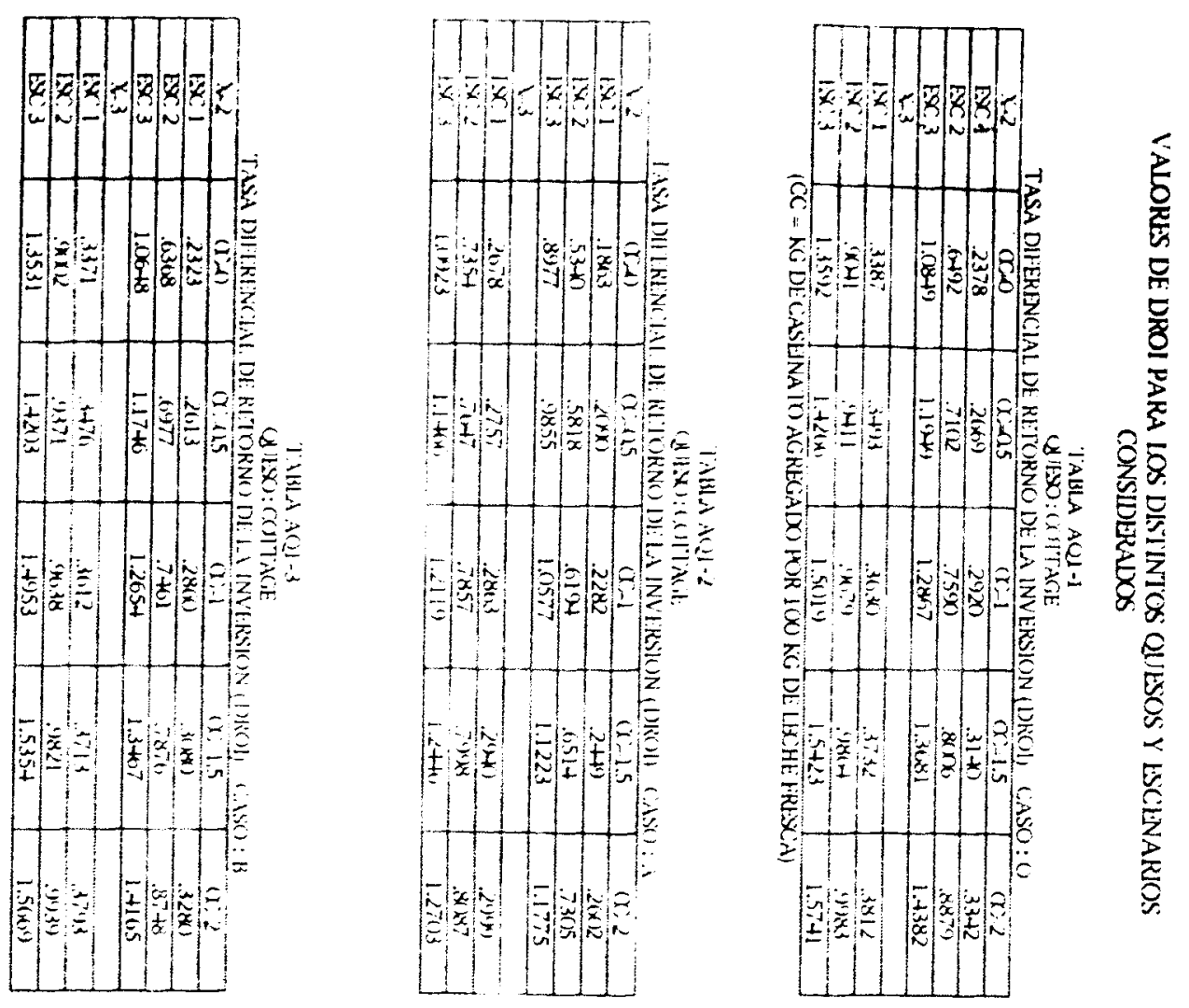

\section{$\bar{\sigma}$}
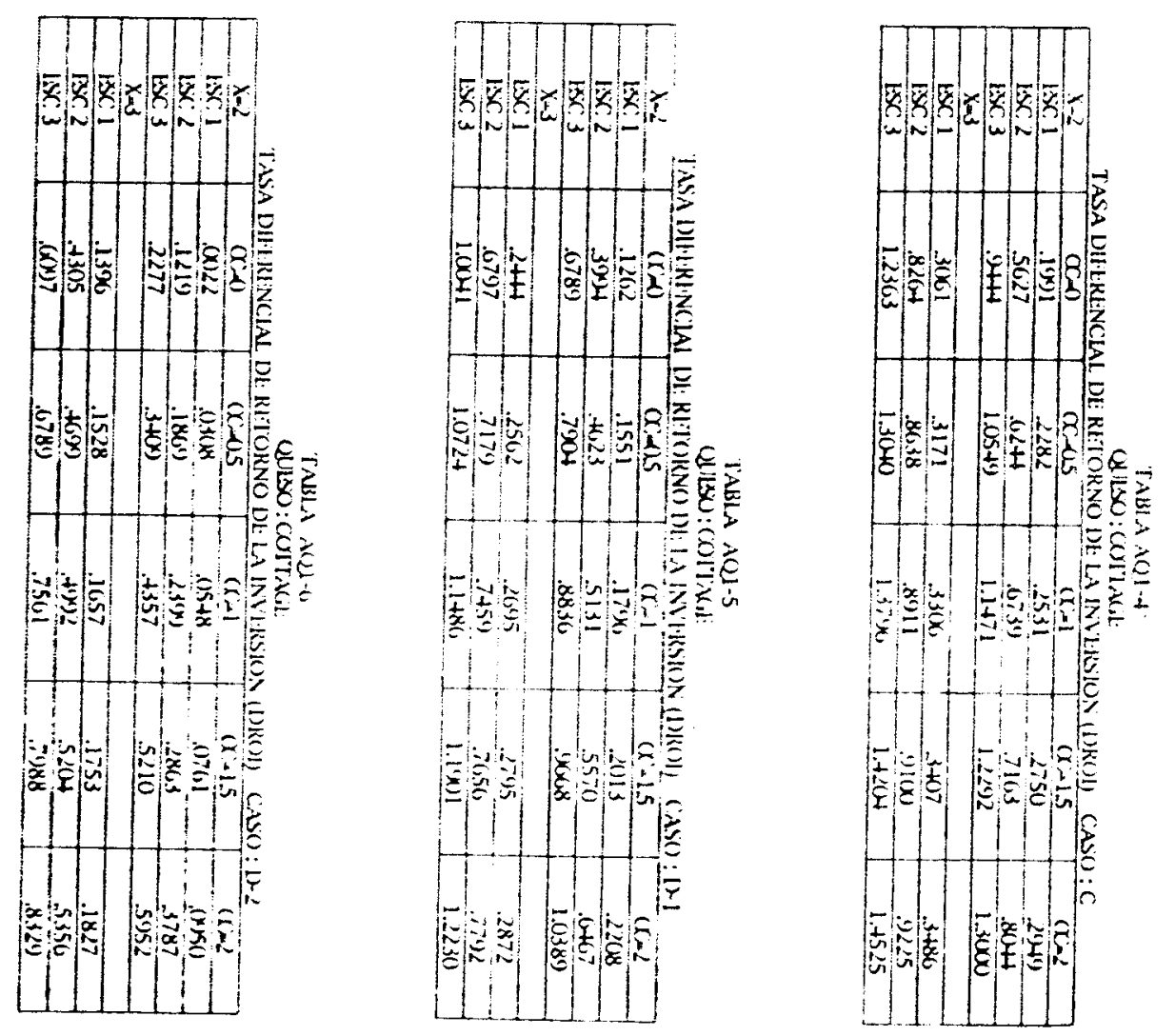

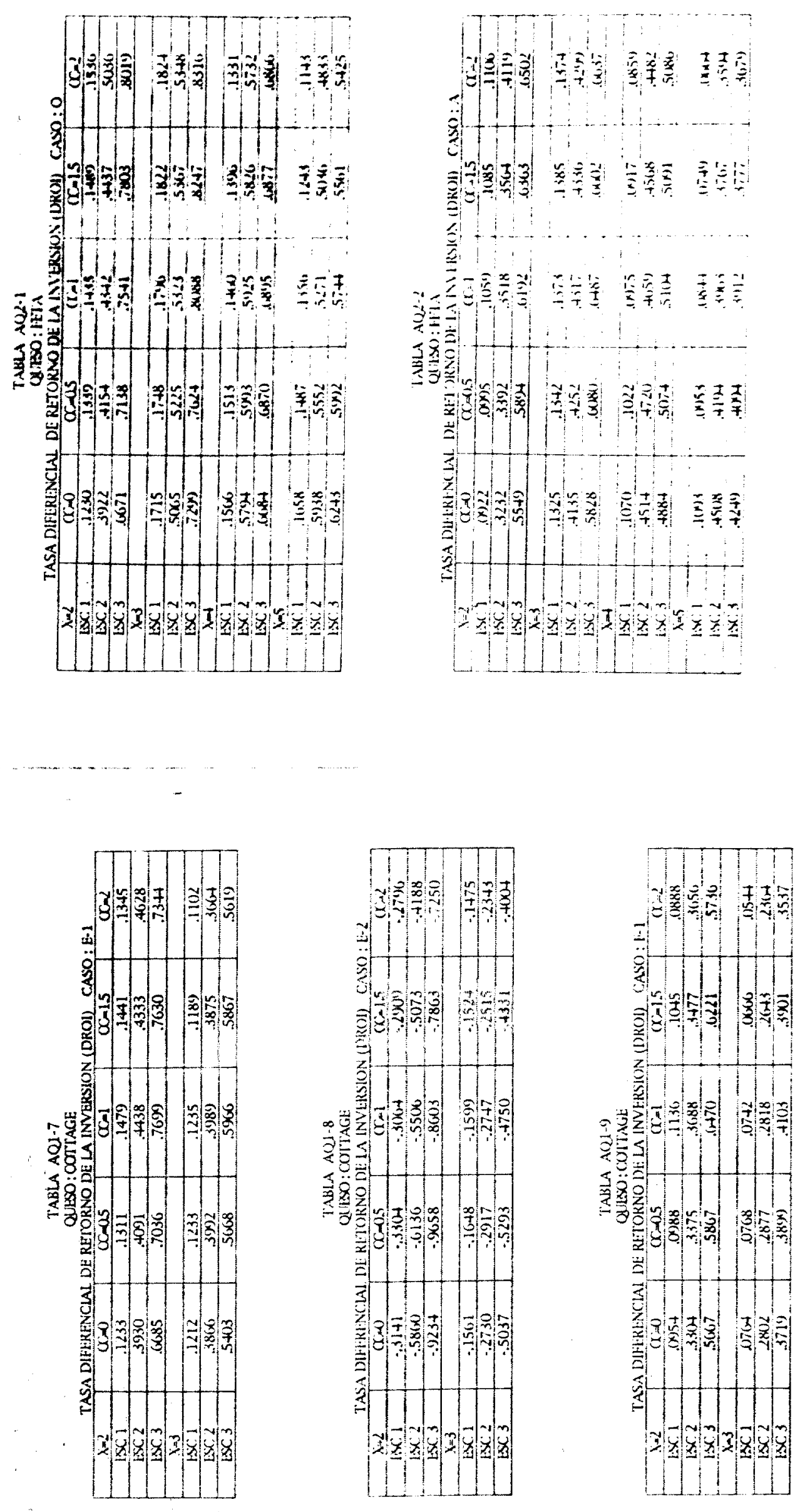
$\sqrt{1}+$

$\bar{x} \bar{x}-\bar{x} \bar{x}-\bar{x} x y \bar{x}$

$H+1+1+1+1+1+1$

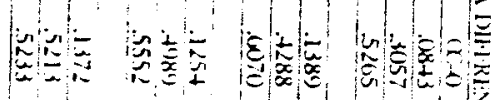

W

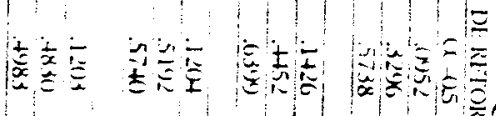

ㄴ.

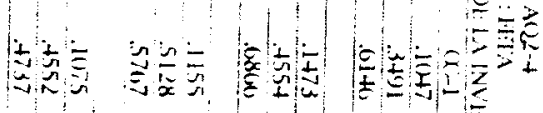

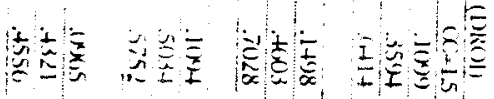

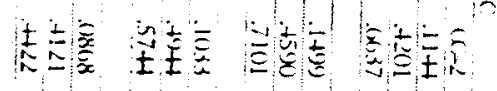

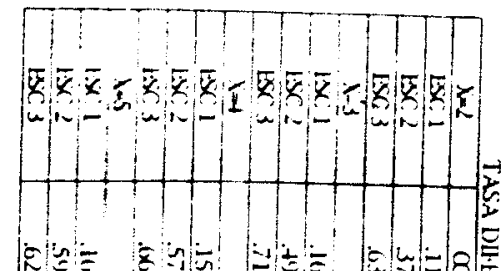

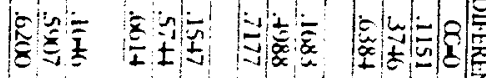

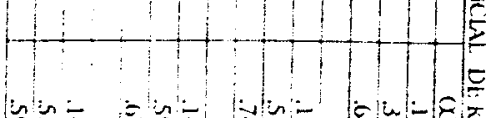

船

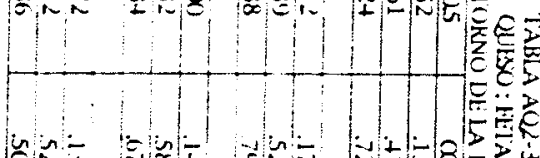

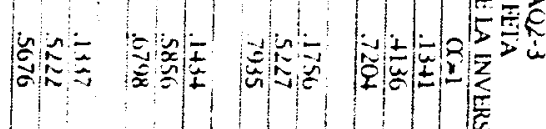

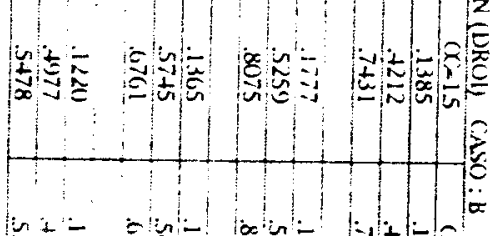

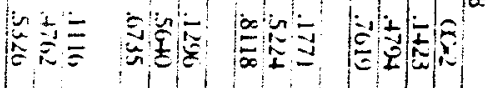

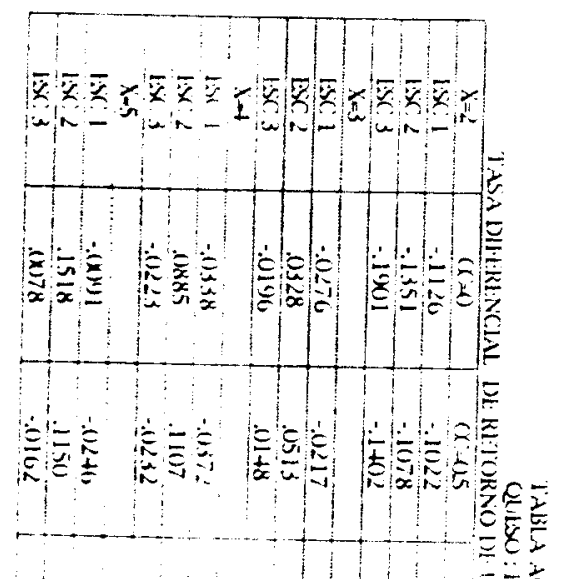

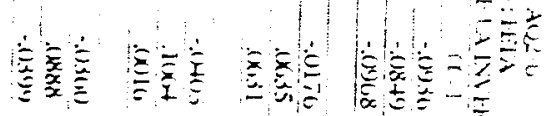

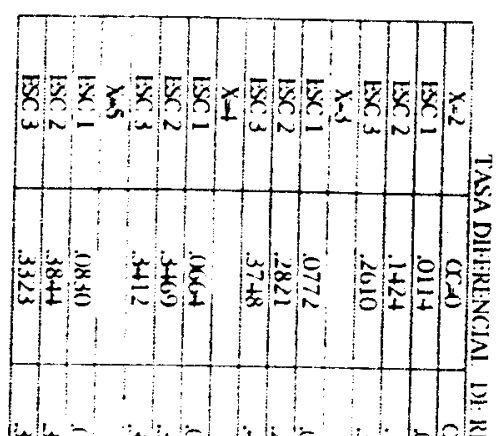

触

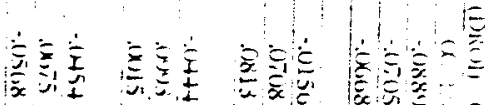

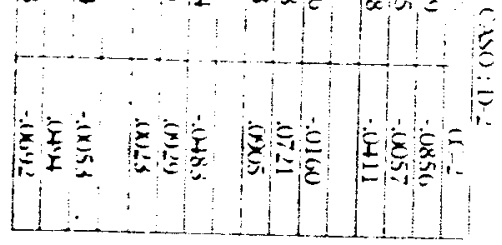

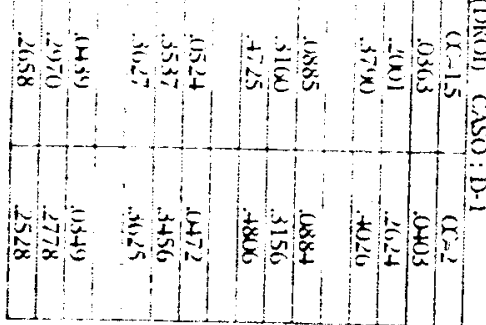



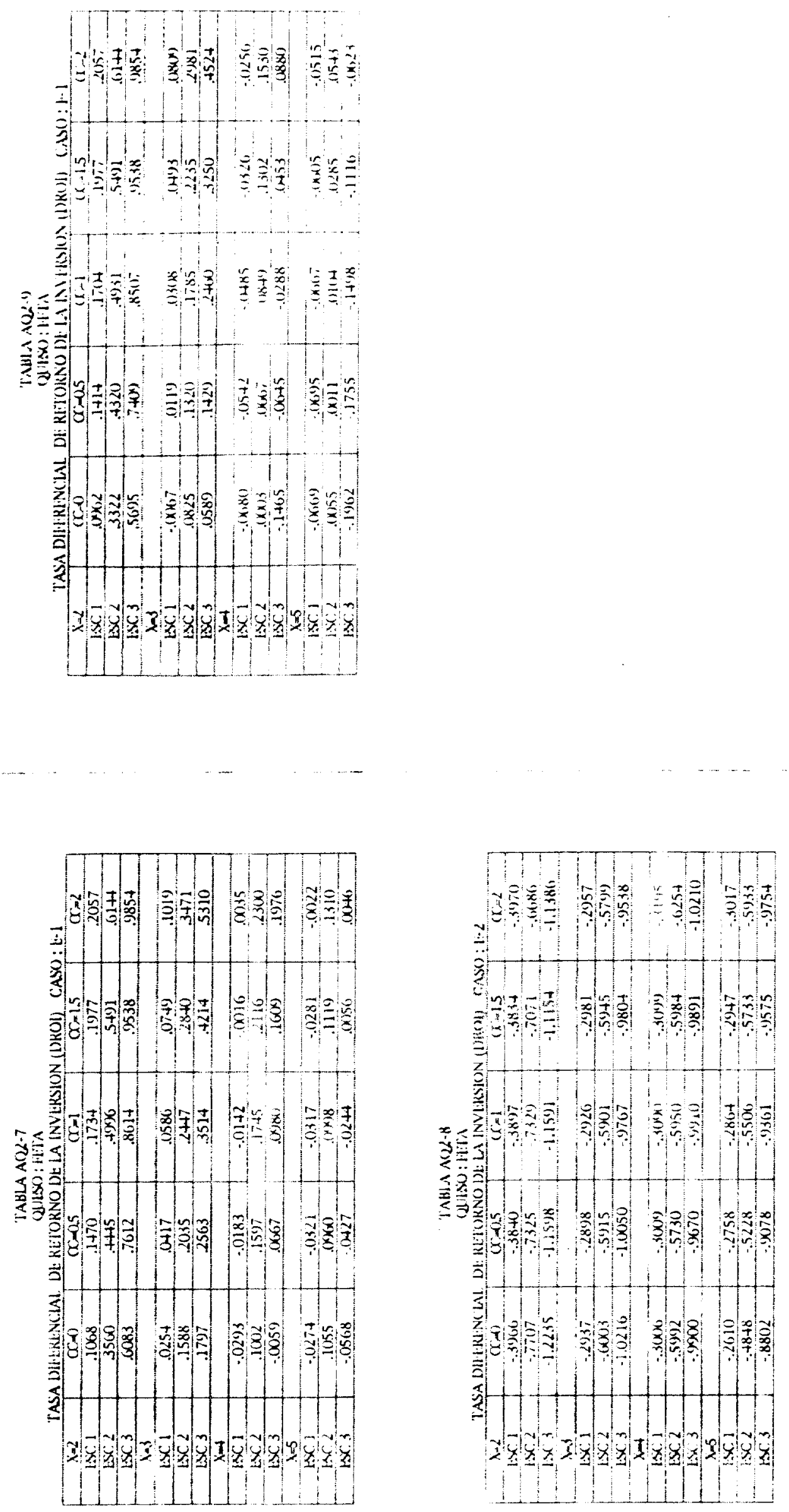


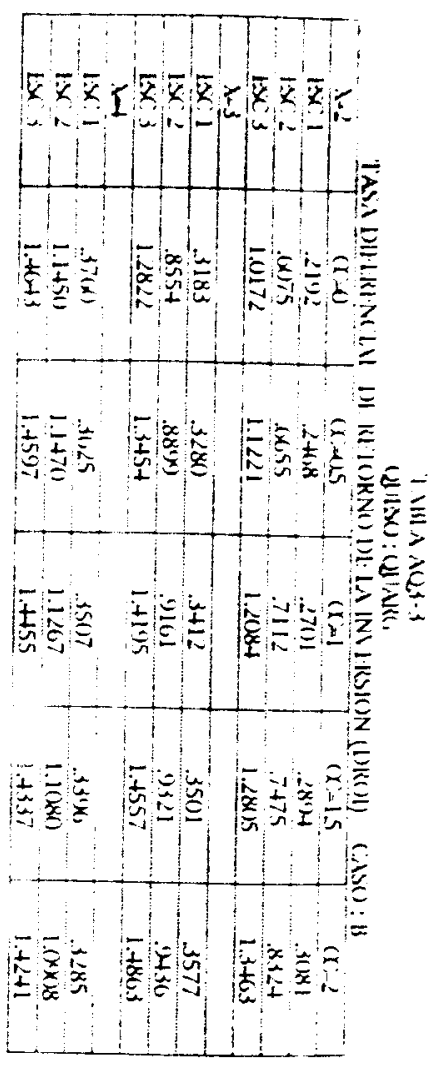

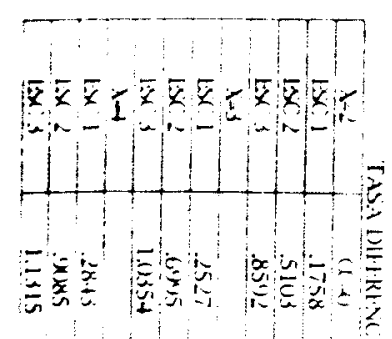

$\frac{1+1}{1+1}$

Coy

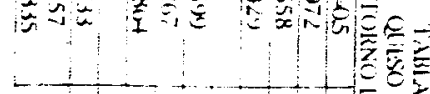

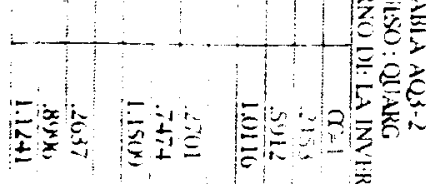

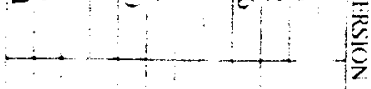

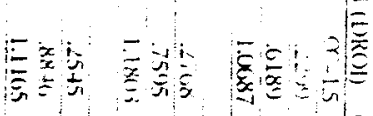

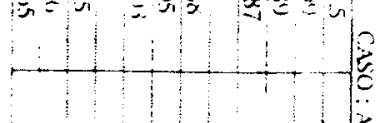

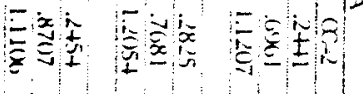

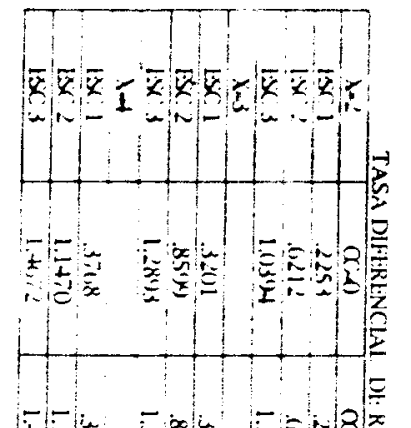

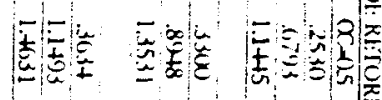

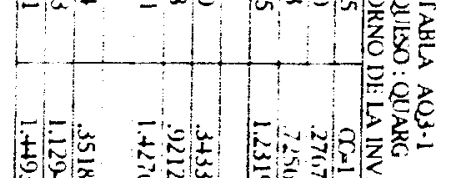

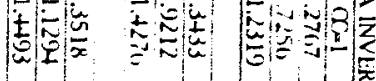

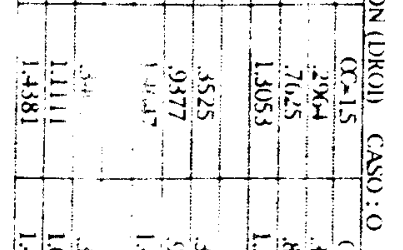

his

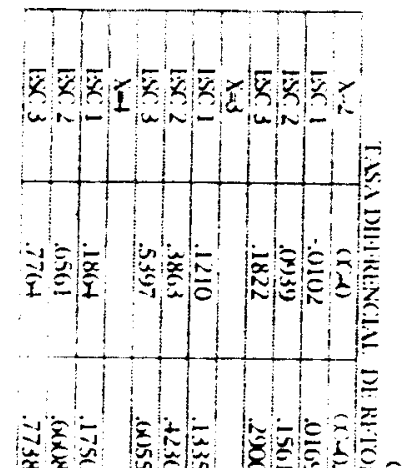

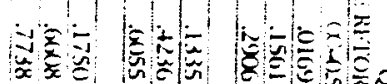

全

$1 \frac{E}{E}$

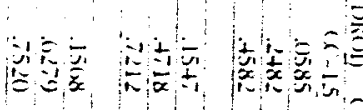

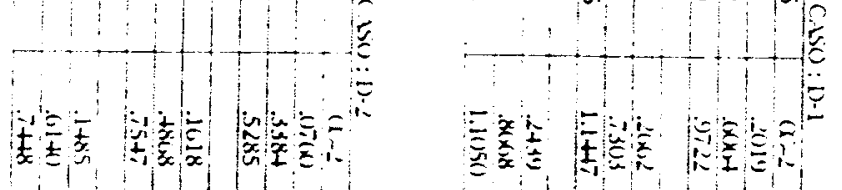

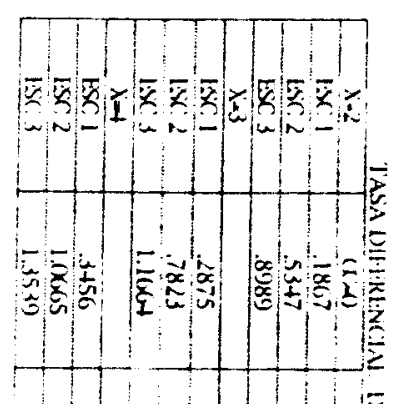

$-20 x=\frac{1}{x}$

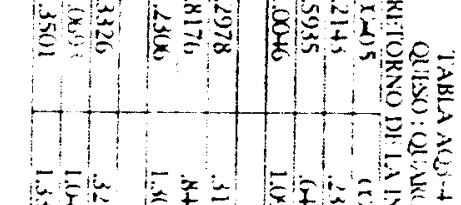

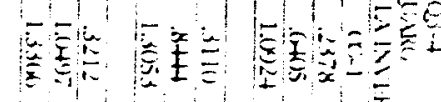

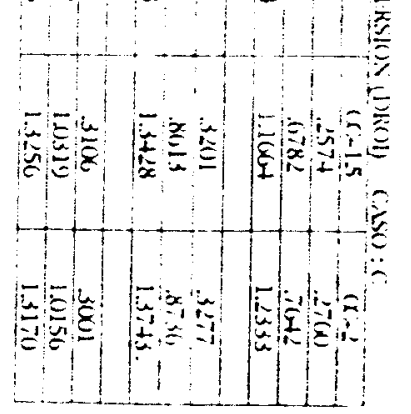



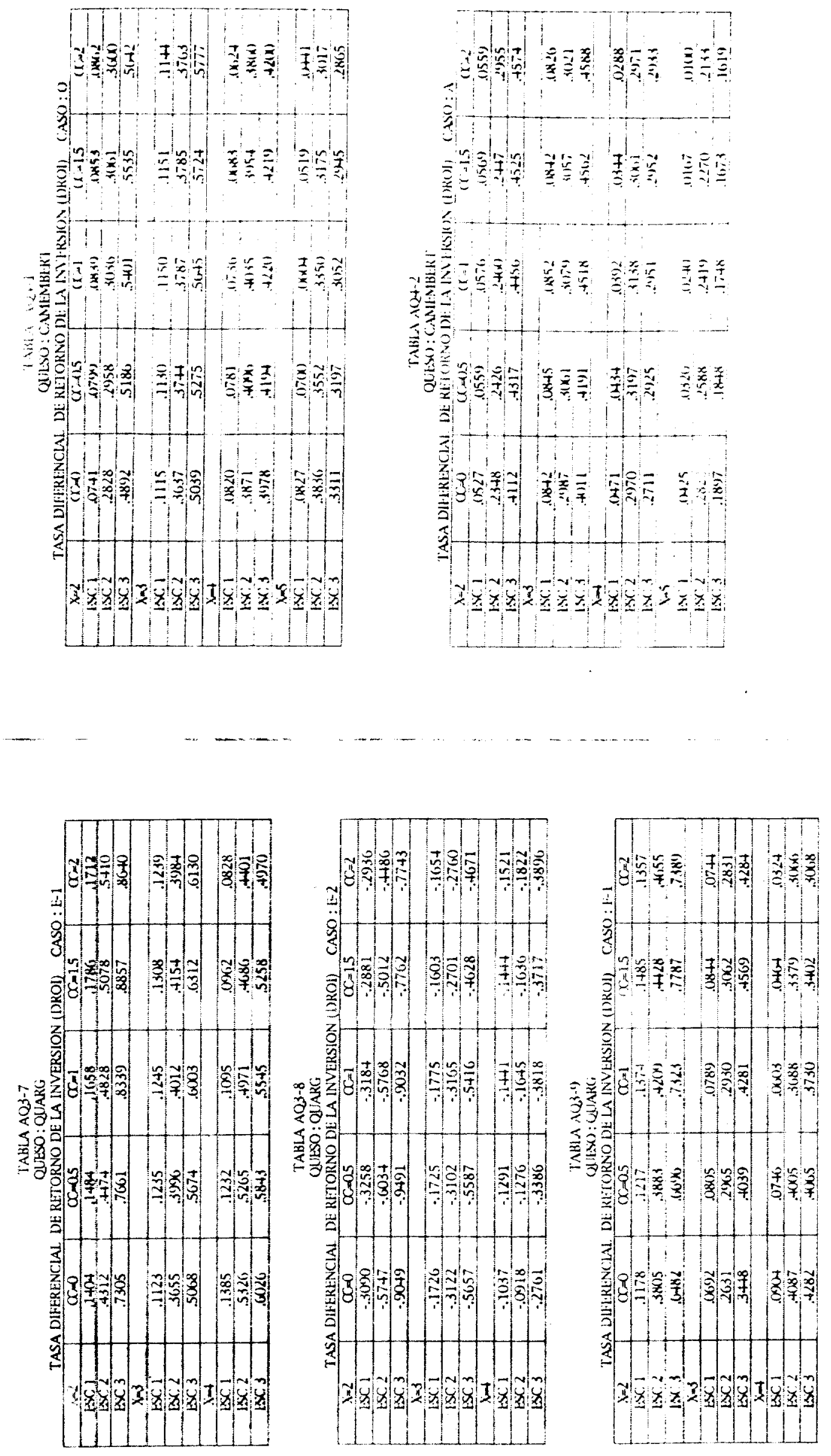

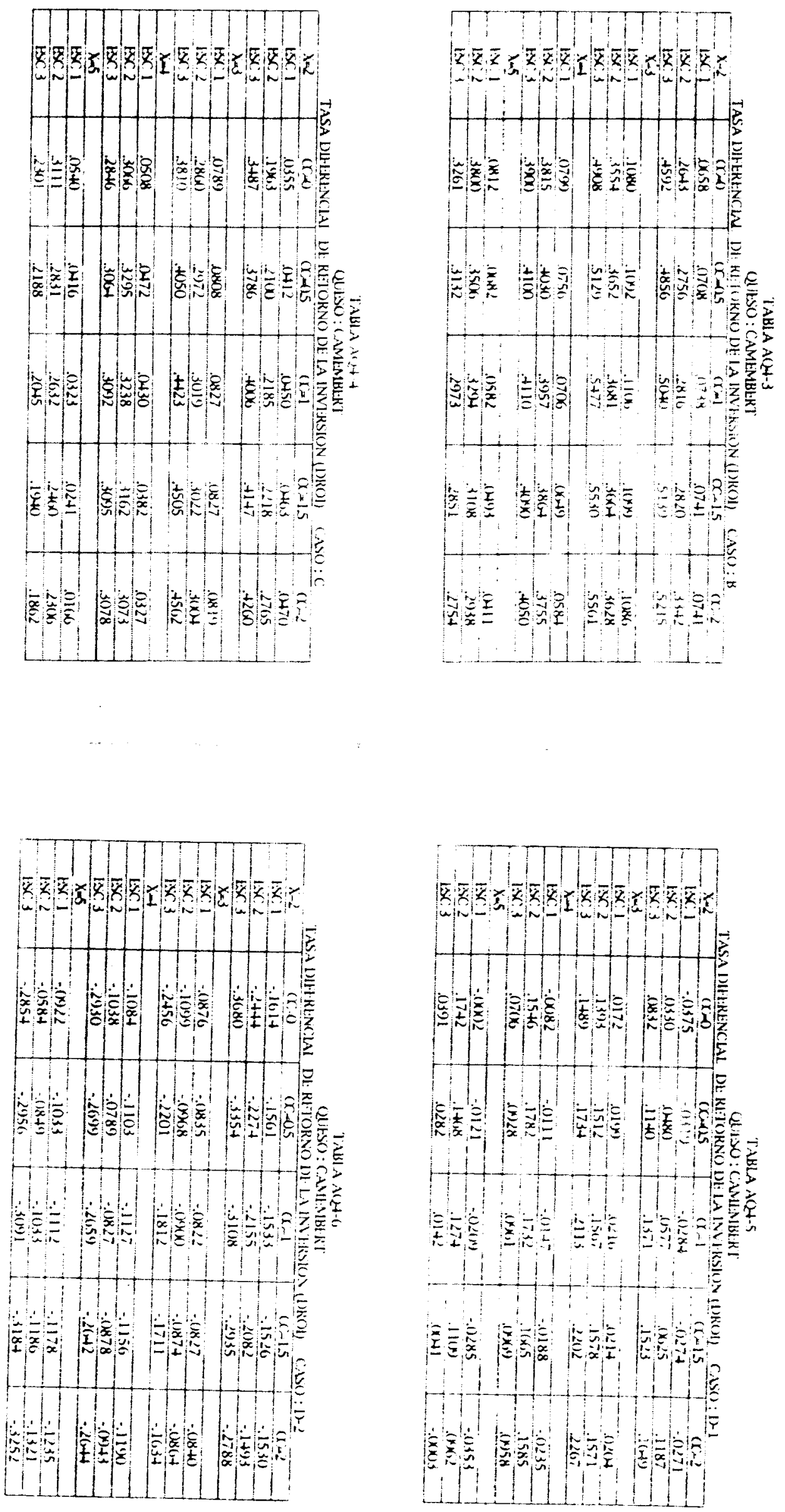

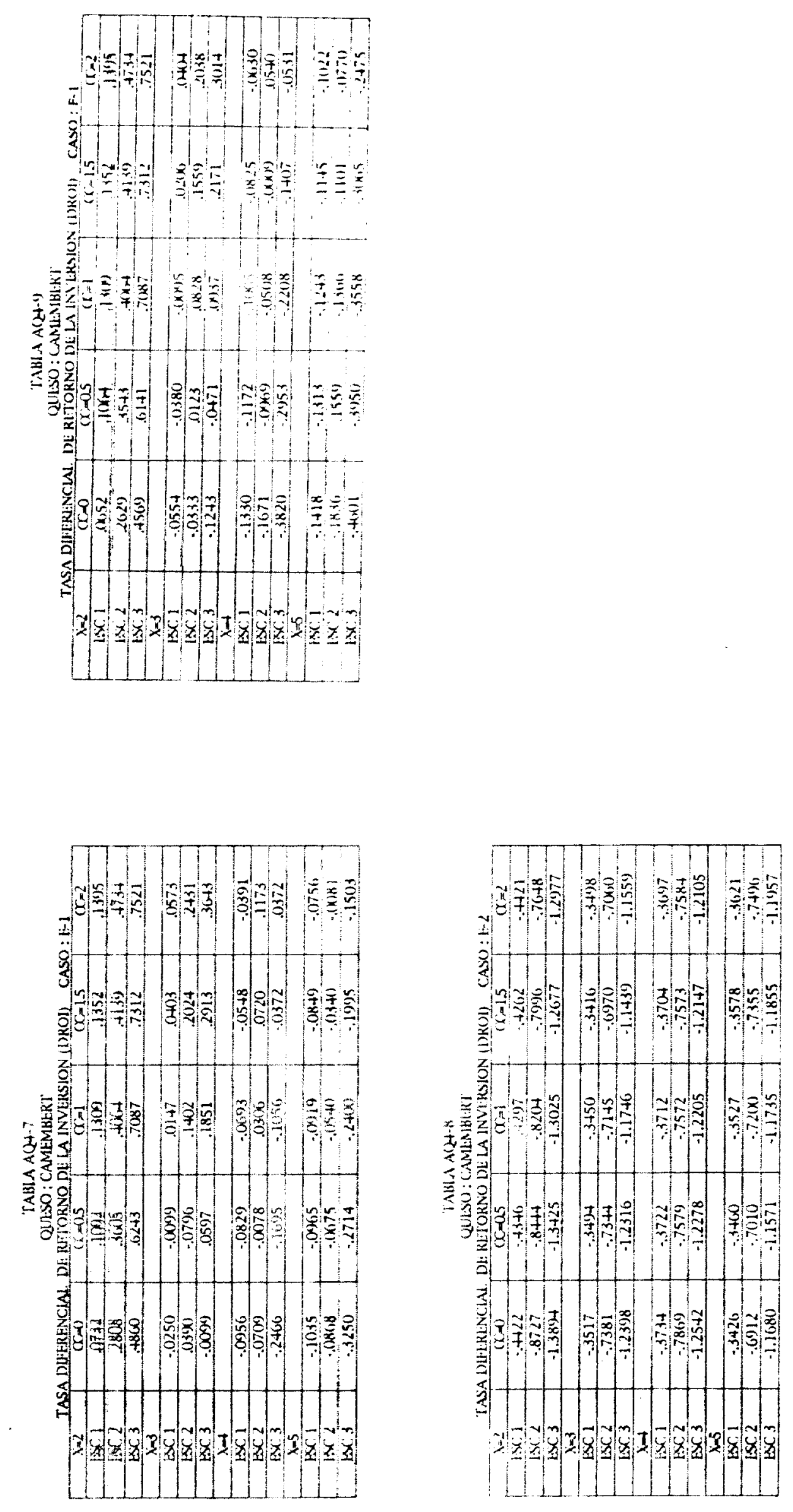

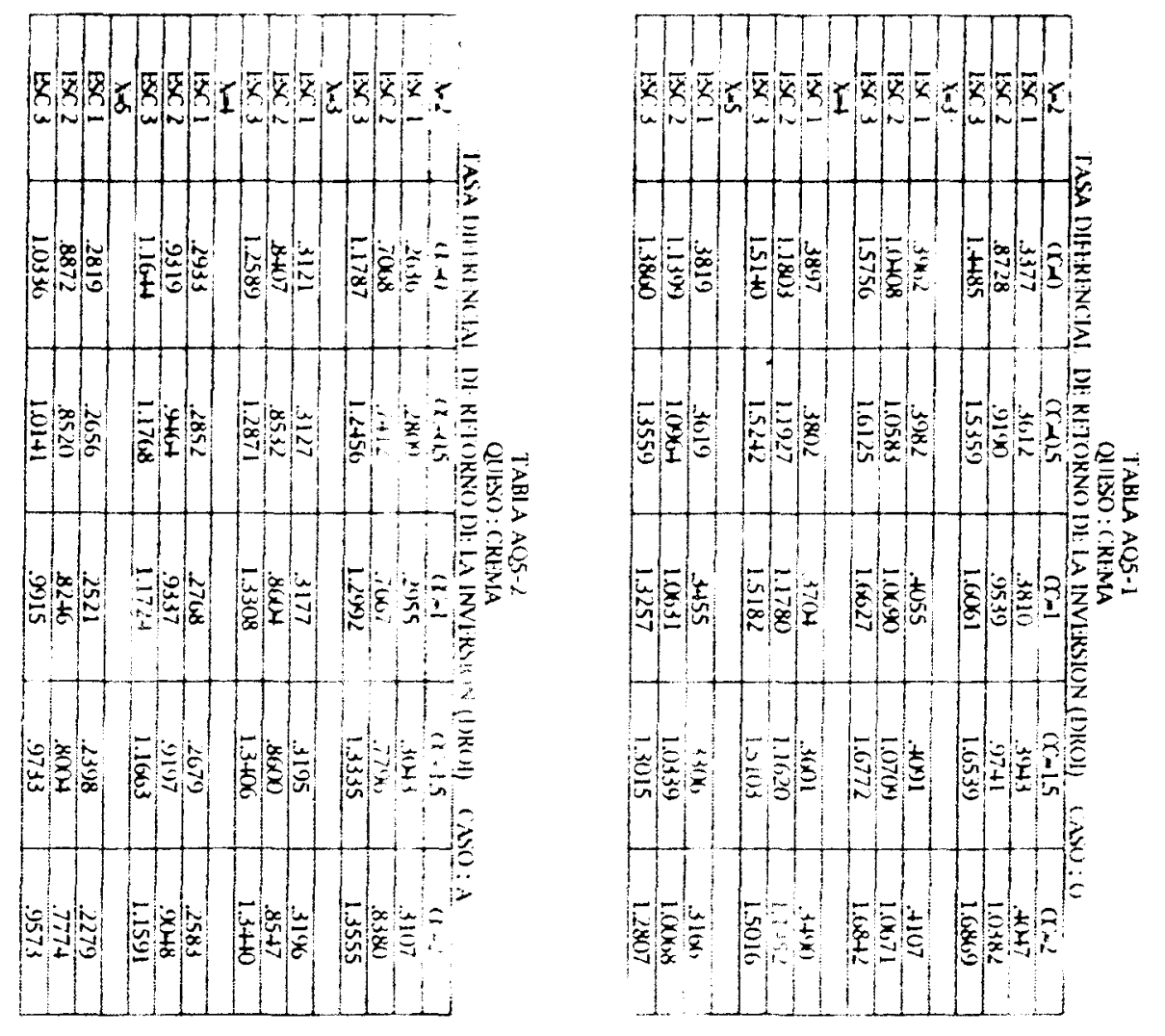

$\vec{\Phi}$
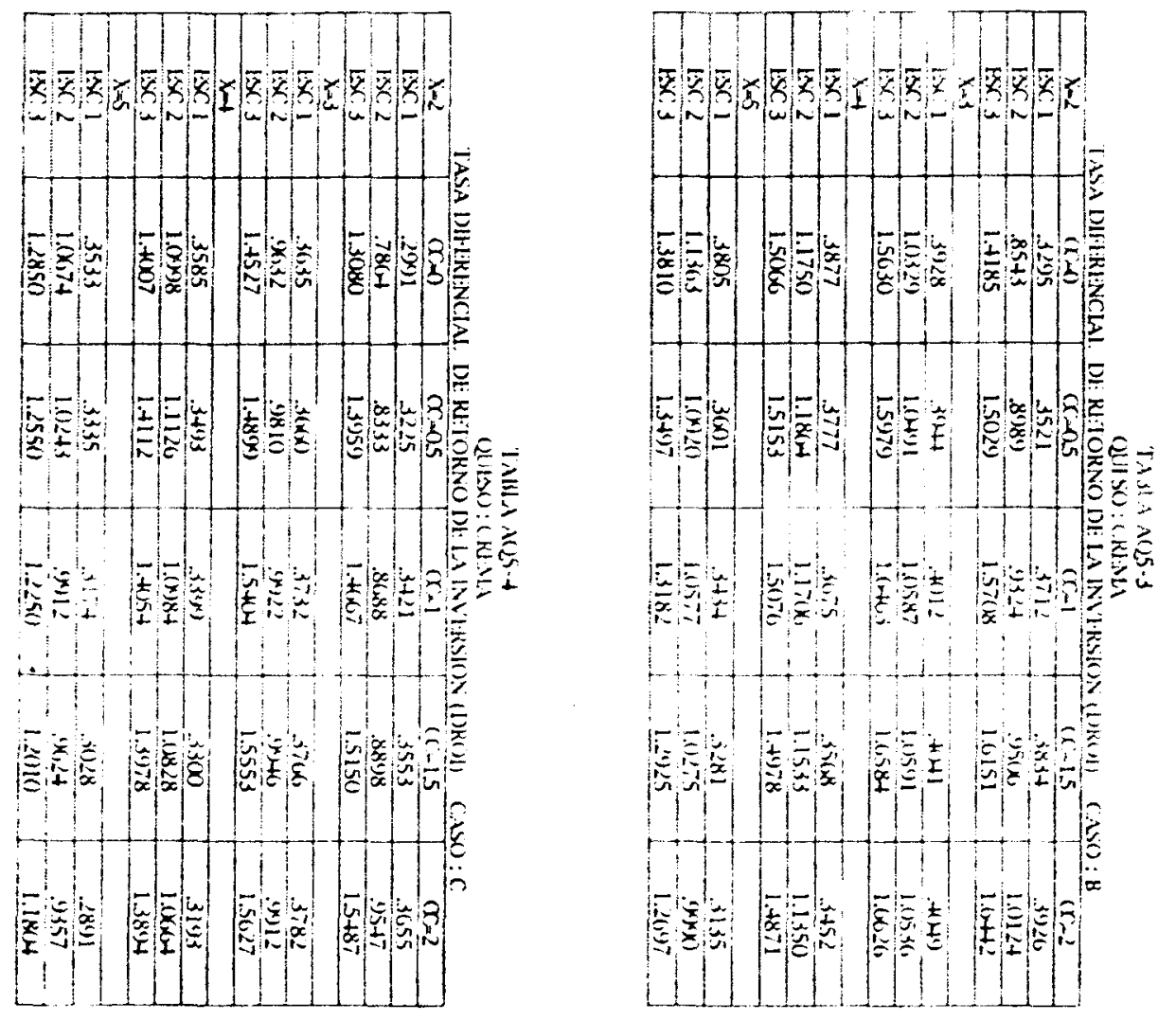

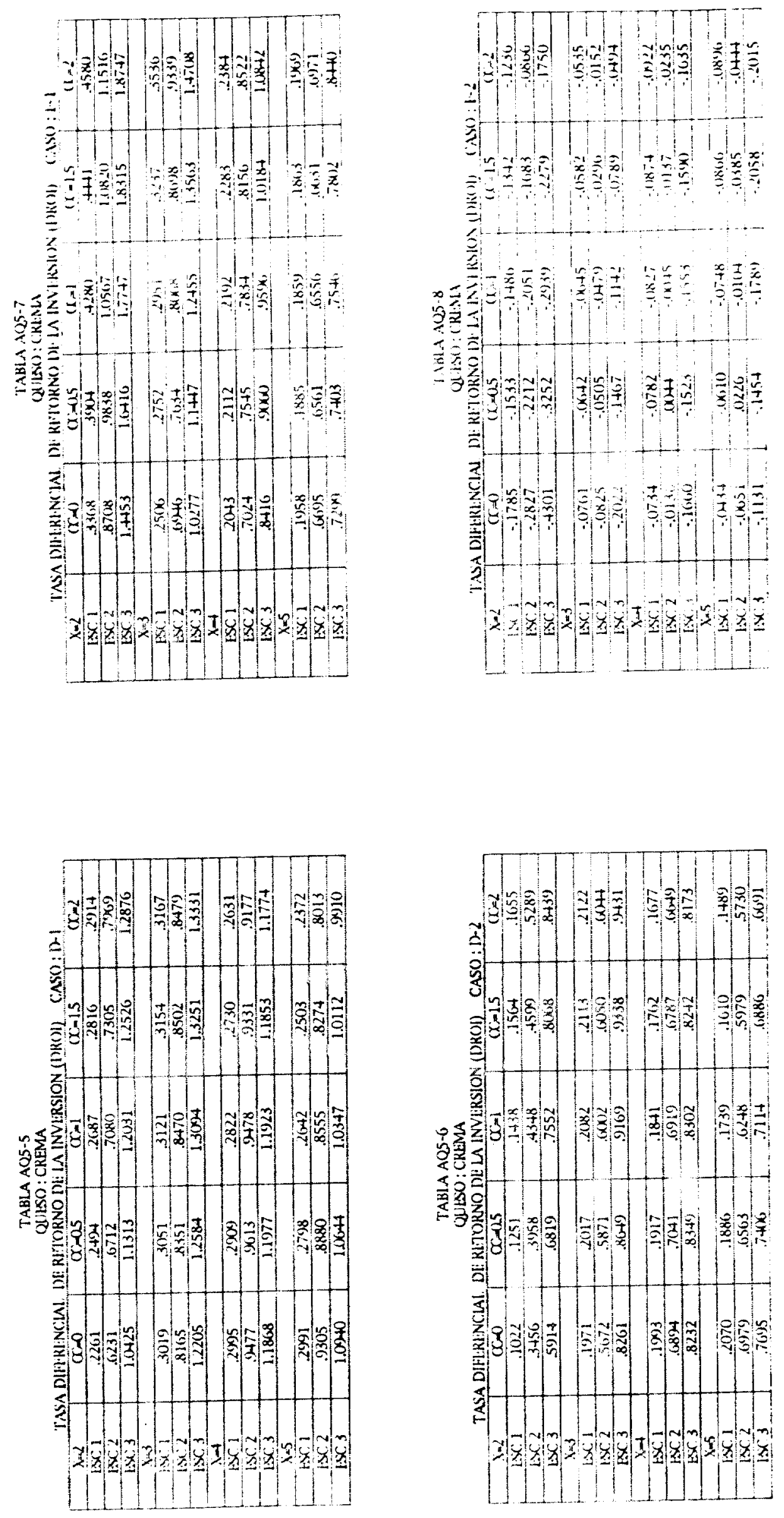

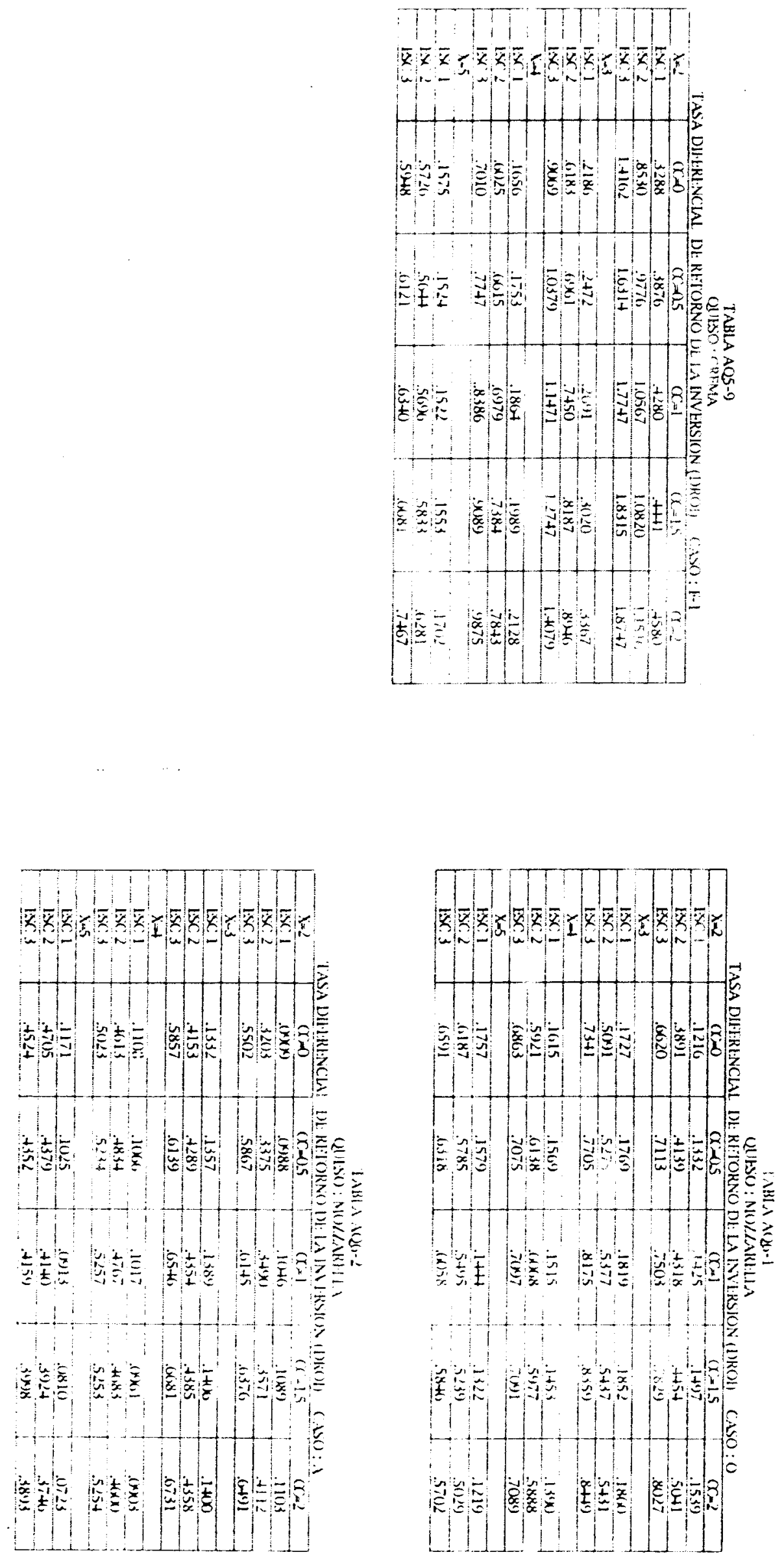

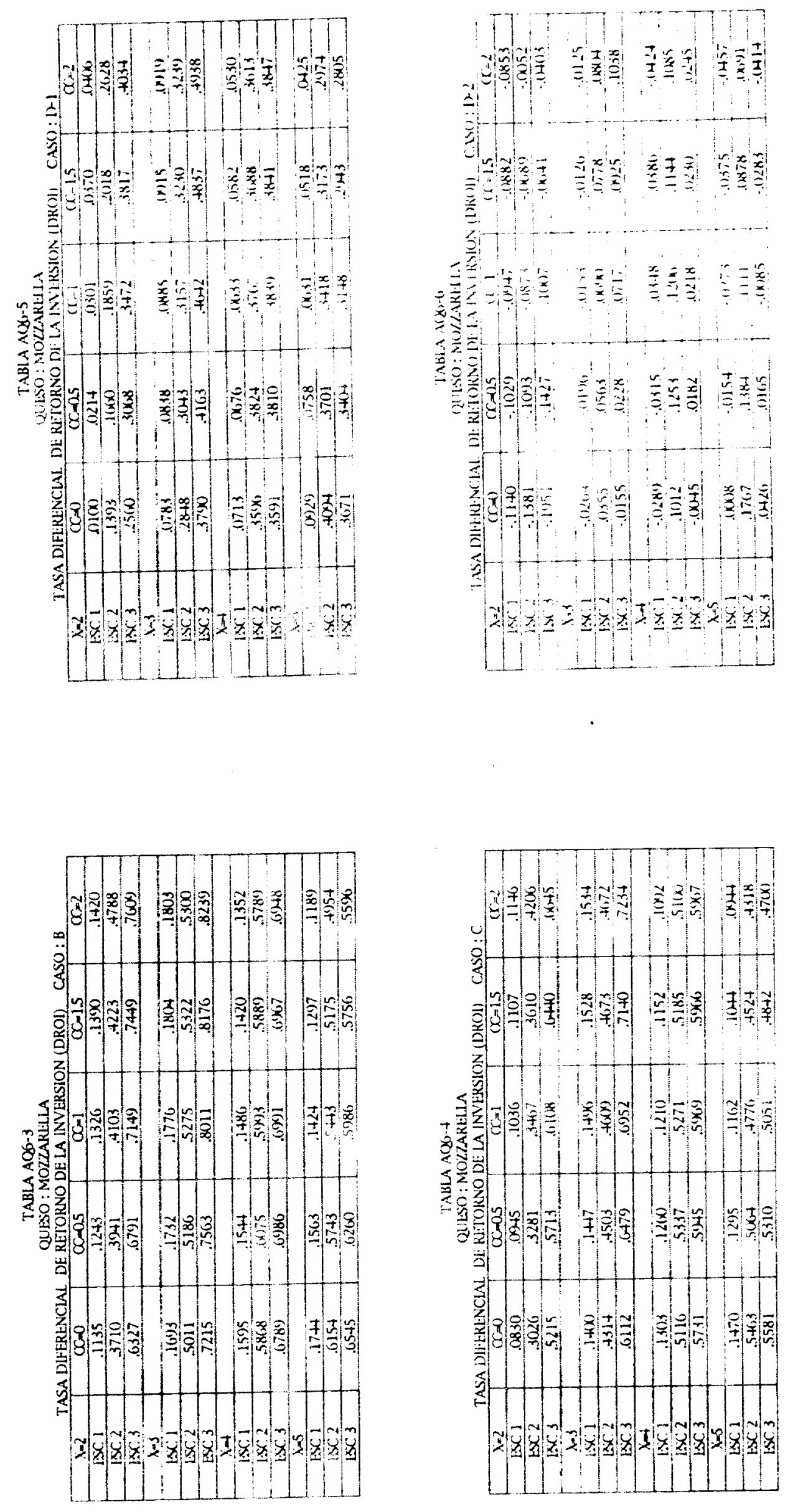

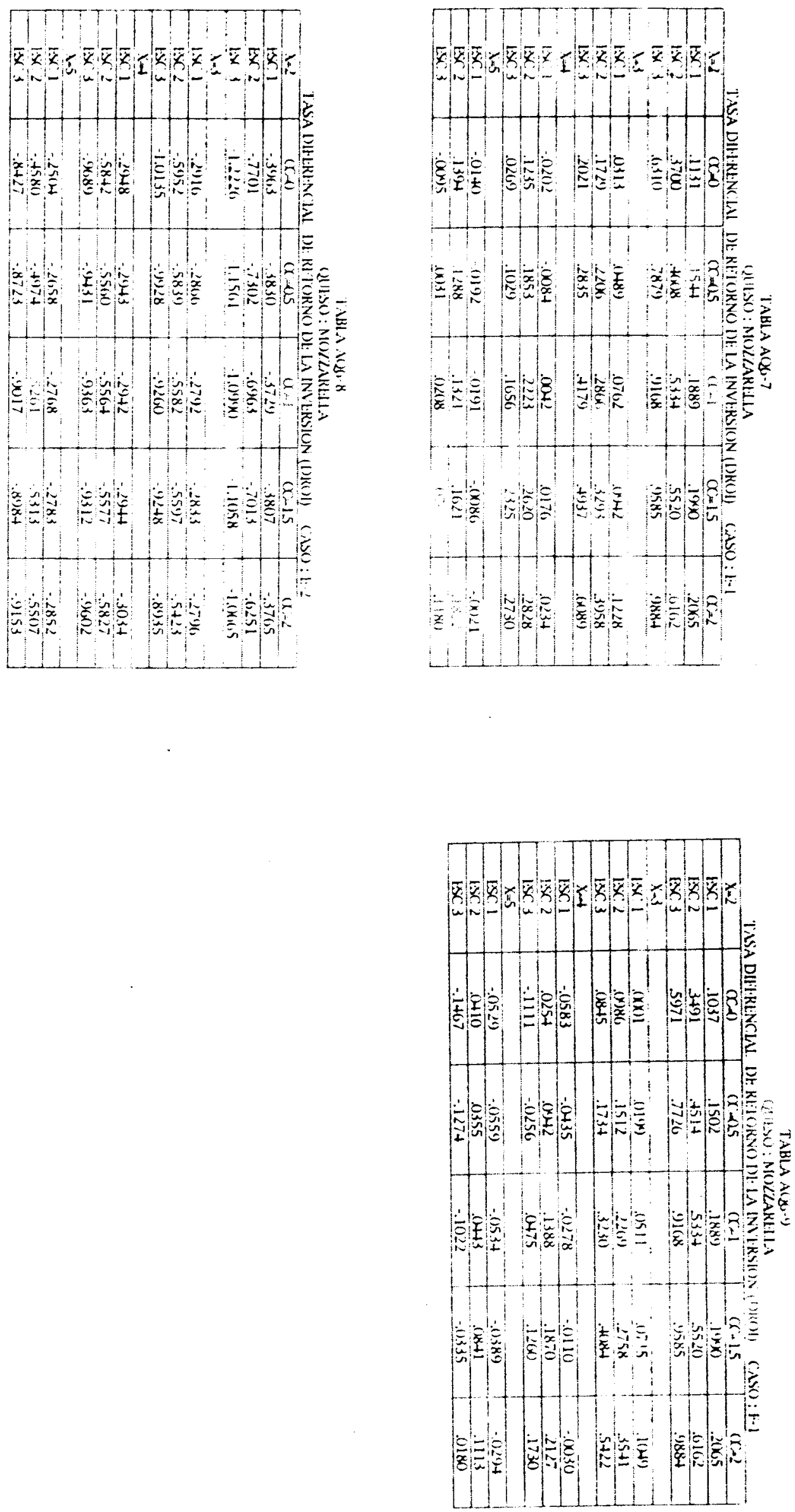

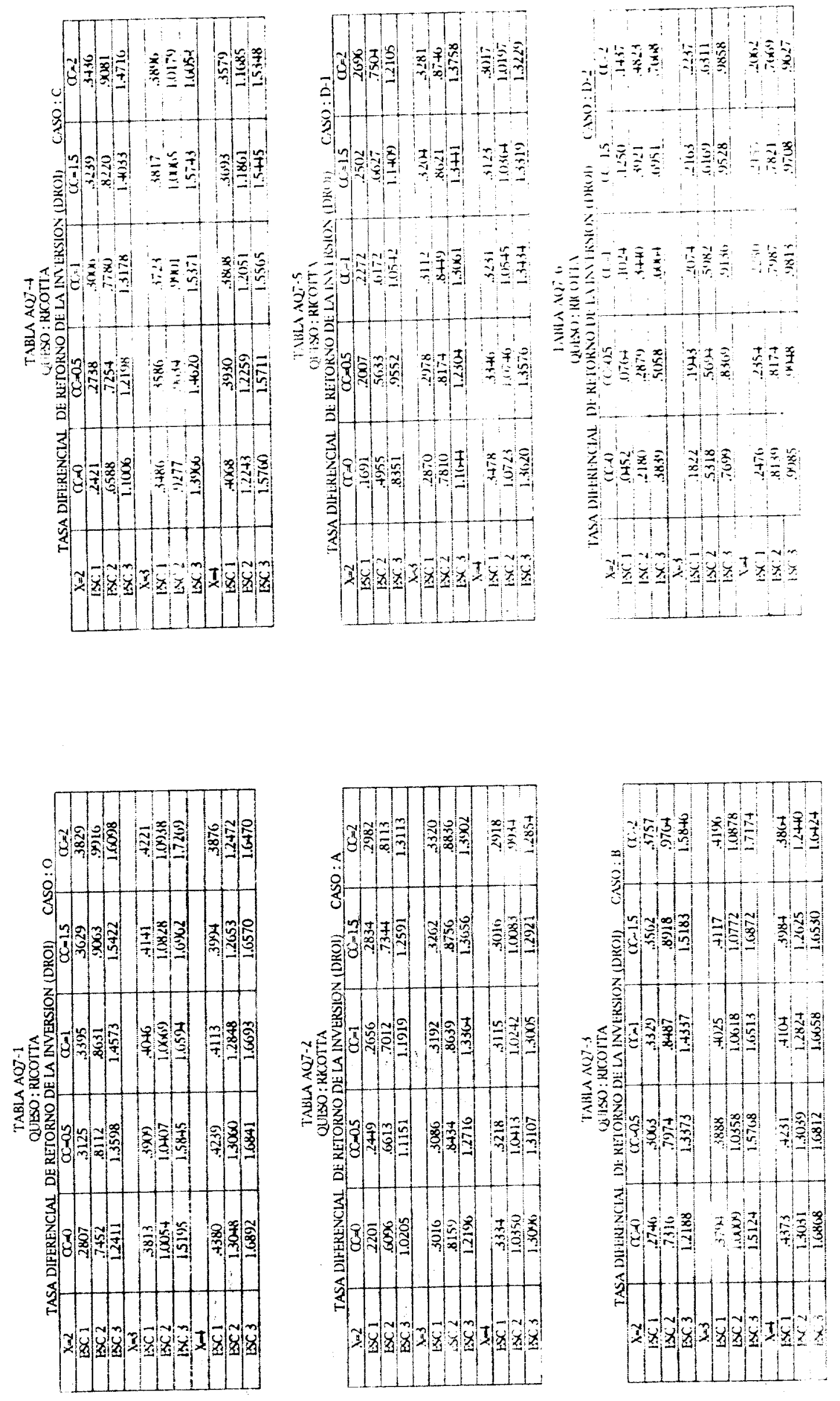


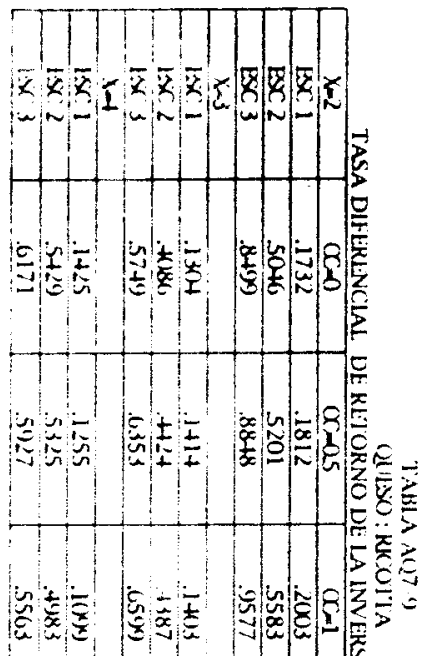

$\rightarrow \frac{1}{0}+1+10$

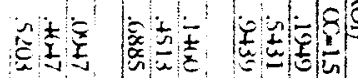

HAHH㞔

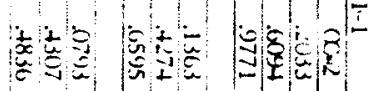

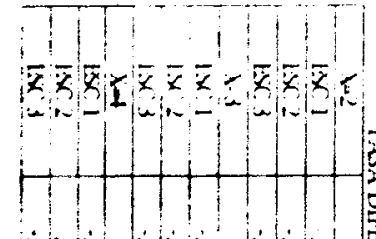

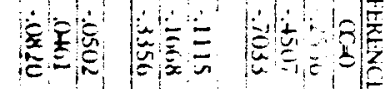

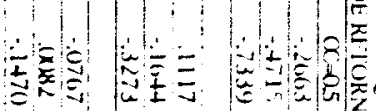

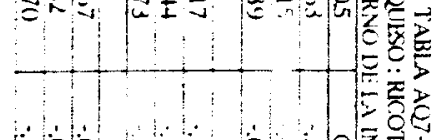

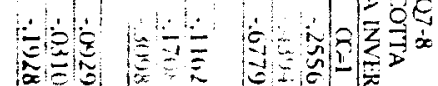

(

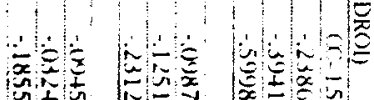

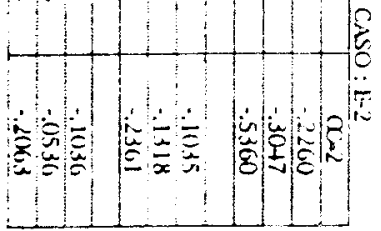

$\bar{x} \bar{x}-\bar{x} \bar{x}-\bar{x} \bar{x}$

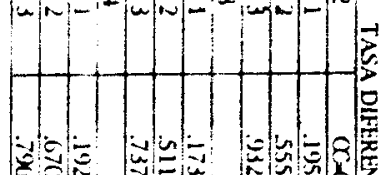

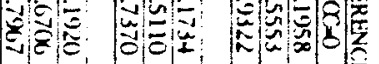

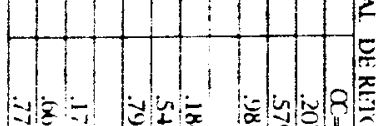

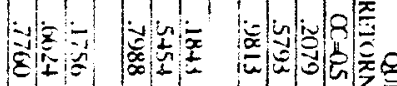

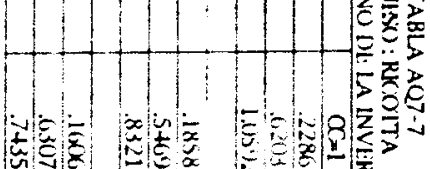

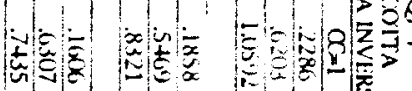

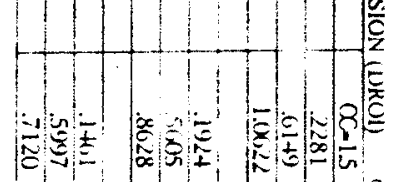

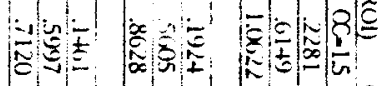

[द

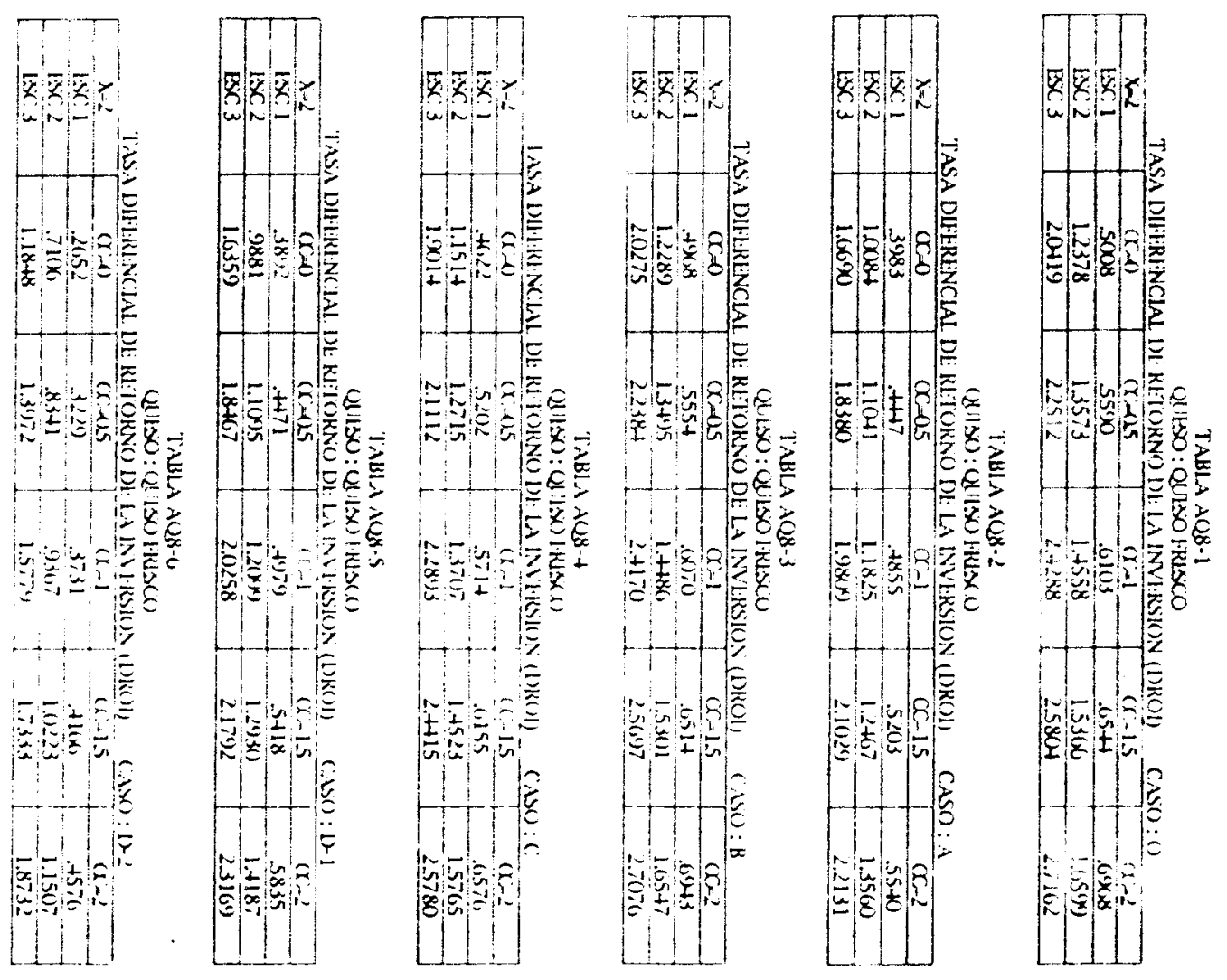



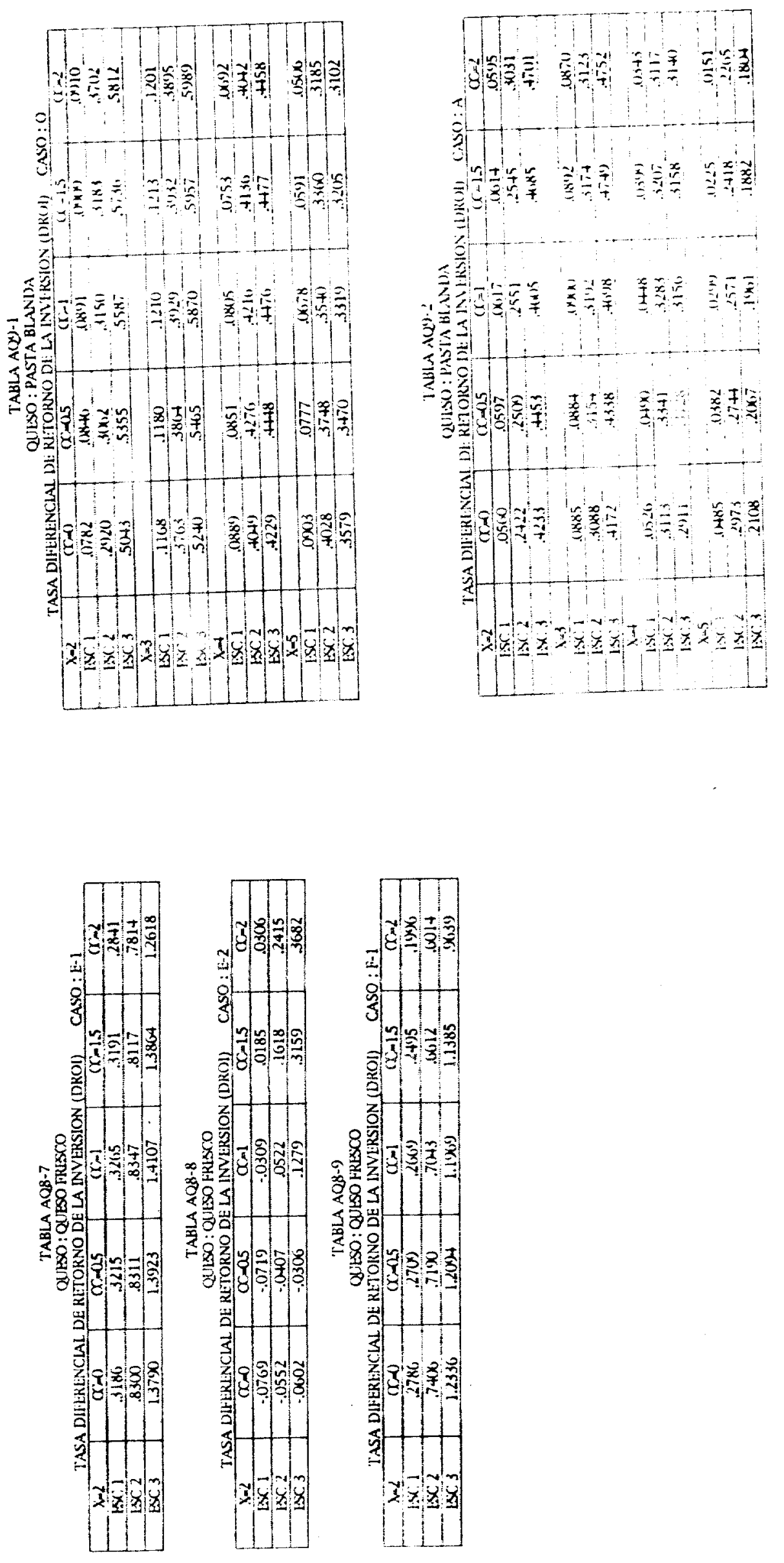


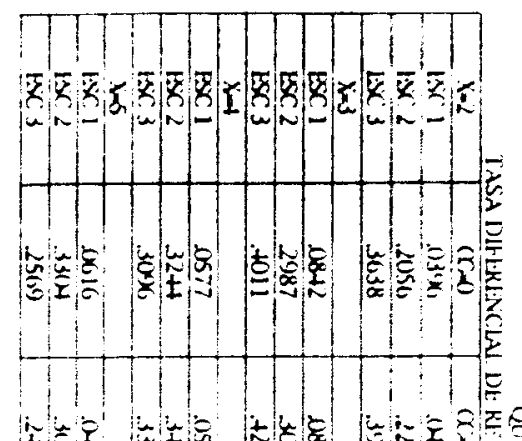

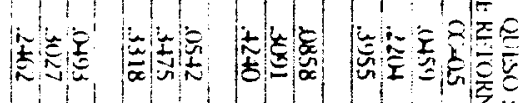

4014 H

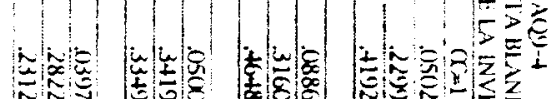

110

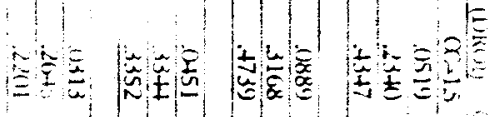

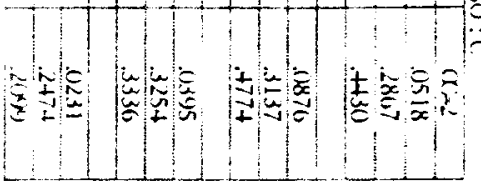

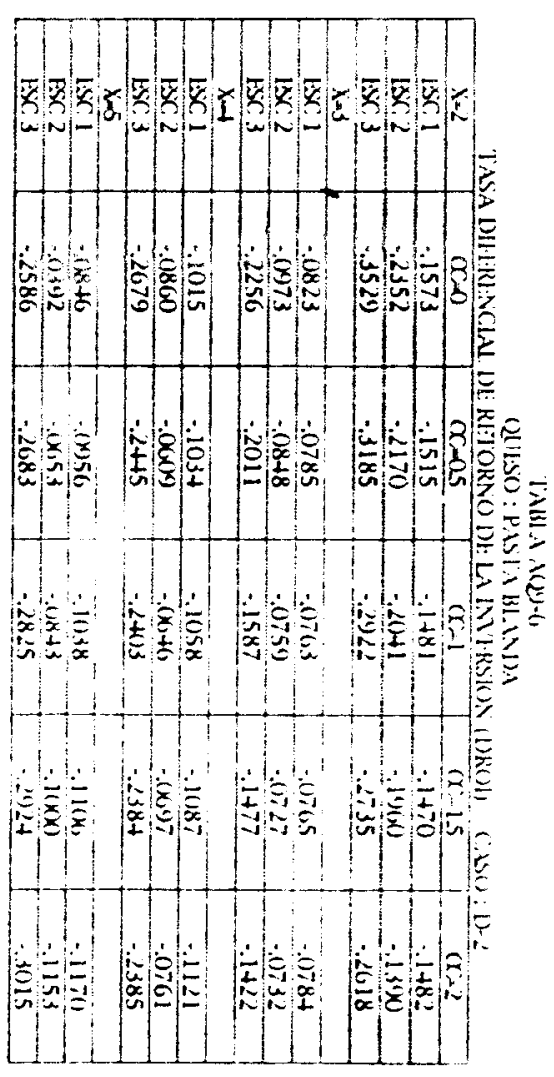

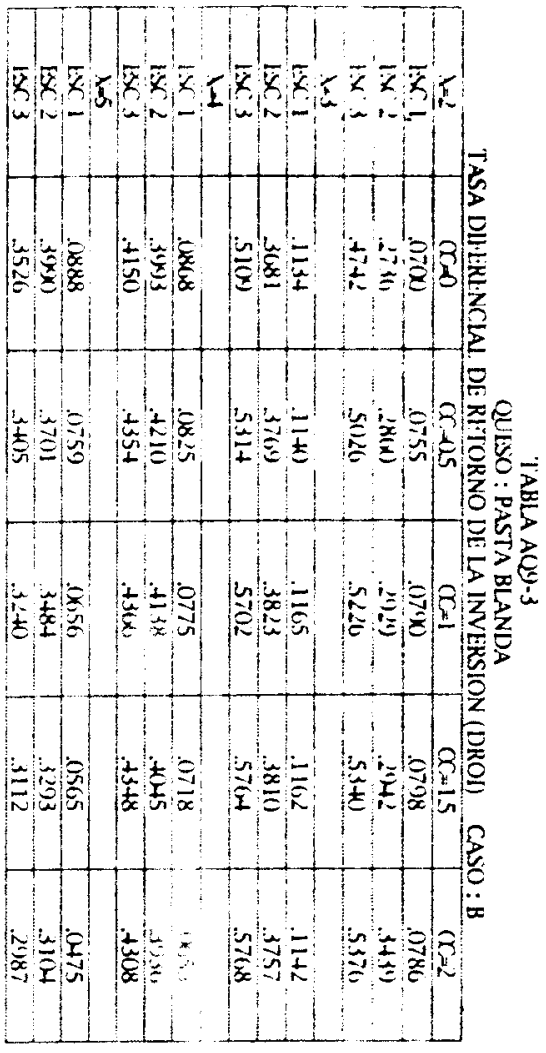

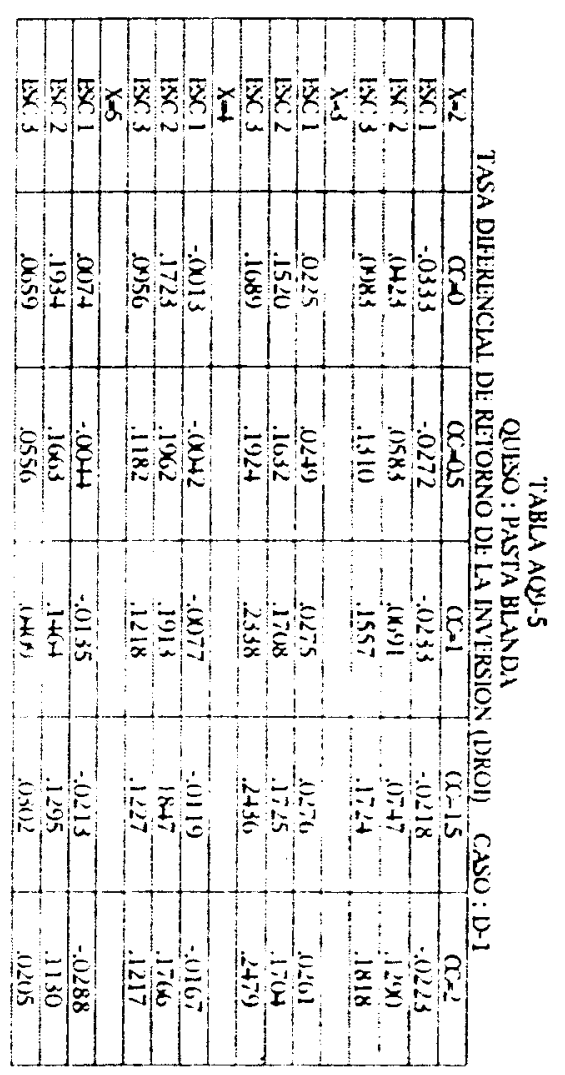



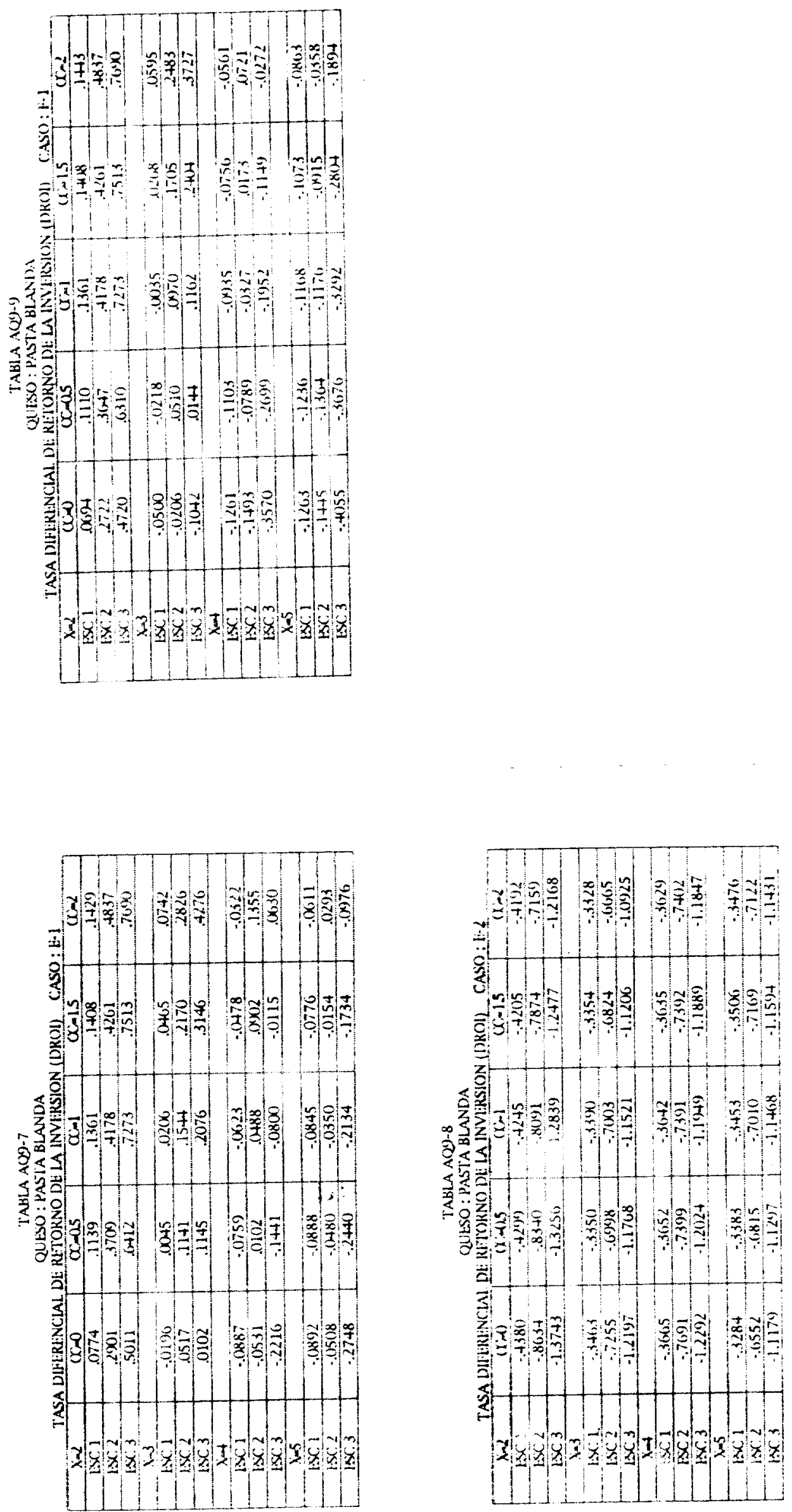